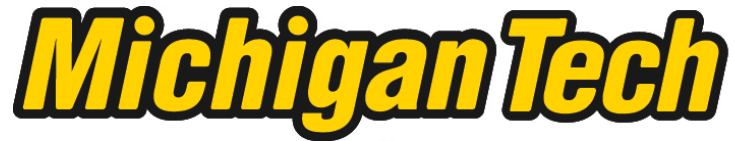 \\ Michigan Technological University Create the Future Digital Commons @ Michigan Tech
}

2013

\section{A HYDRO-CLIMATIC MODELING FRAMEWORK FOR ADAPTIVE WATER RESOURCES MANAGEMENT IN THE GREAT LAKES BASIN}

Rabi Gyawali

Michigan Technological University

Follow this and additional works at: https://digitalcommons.mtu.edu/etds

Part of the Environmental Engineering Commons

Copyright 2013 Rabi Gyawali

\section{Recommended Citation}

Gyawali, Rabi, "A HYDRO-CLIMATIC MODELING FRAMEWORK FOR ADAPTIVE WATER RESOURCES

MANAGEMENT IN THE GREAT LAKES BASIN", Dissertation, Michigan Technological University, 2013.

https://doi.org/10.37099/mtu.dc.etds/454

Follow this and additional works at: https://digitalcommons.mtu.edu/etds

Part of the Environmental Engineering Commons 
A HYDRO-CLIMATIC MODELING FRAMEWORK FOR ADAPTIVE WATER RESOURCES MANAGEMENT IN THE GREAT LAKES BASIN

\author{
By \\ Rabi Gyawali
}

\begin{abstract}
A DISSERTATION
Submitted in partial fulfillment of the requirements for the degree of DOCTOR OF PHILOSOPHY

In Environmental Engineering
\end{abstract}

MICHIGAN TECHNOLOGICAL UNIVERSITY

2013 
This dissertation has been approved in partial fulfillment of the requirements for the Degree of DOCTOR OF PHILOSOPHY in Environmental Engineering.

Department of Civil and Environmental Engineering

Dissertation Co-Advisor: $\quad$ Dr. David W. Watkins

Dissertation Co-Advisor: $\quad$ Dr. Veronica W. Griffis

Committee Member: Dr. Alex S. Mayer

Committee Member: $\quad$ Dr. Brent M. Lofgren

Department Chair: $\quad$ Dr. David Hand 


\section{Table of Contents}

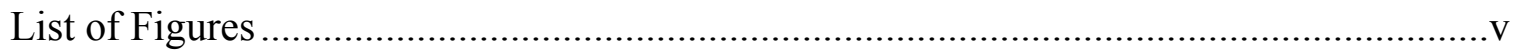

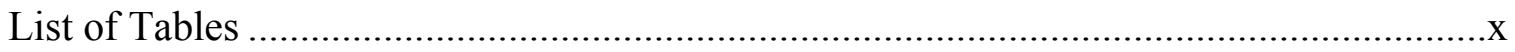

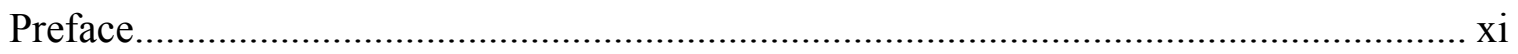

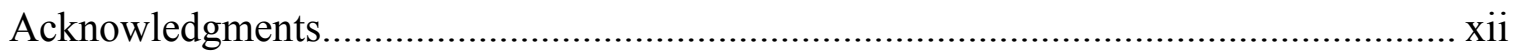

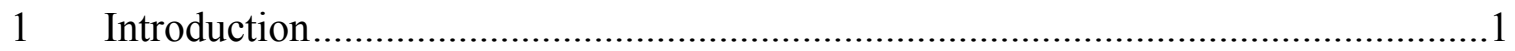

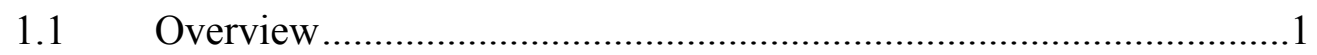

1.1.1 Assessment of climate models .......................................................

1.1.2 Assessment of hydrologic models .................................................5

1.2 Research objectives and organization of chapters .........................

2 Continuous Hydrologic Modeling of Snow-Affected Watersheds in the Great Lakes Basin using HEC-HMS ................................................................................

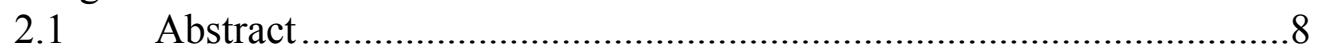

2.2 Introduction....................................................................... 9

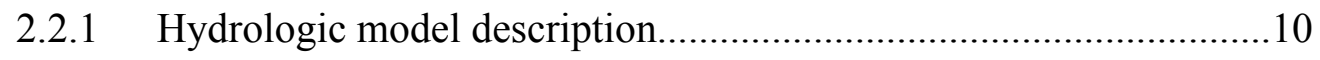

2.2.2 Snowmelt model ................................................................ 12

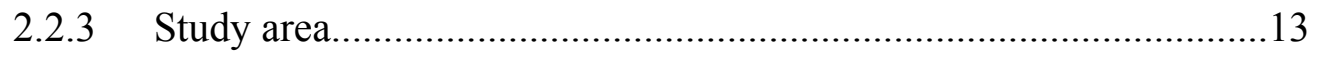

2.3 Modeling procedure and parameter estimation.............................15

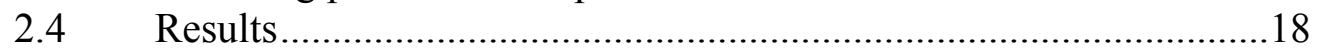

2.4.1 Snow model calibration ....................................................... 18

2.4.2 Streamflow calibration and validation .........................................22

2.4.3 Comparison with LBRM............................................................24

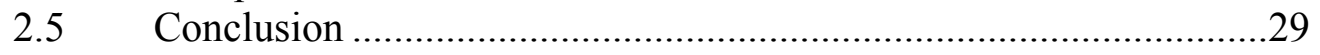

3 Regional Regression Models for Hydro-Climate Change Impact Assessment ........31

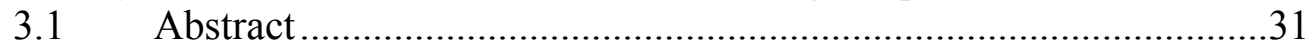

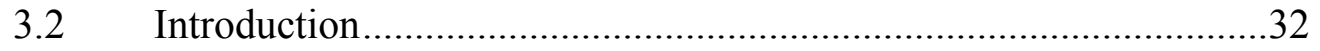

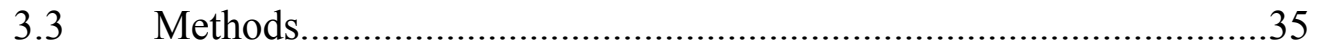

3.3.1 GCM derived climate simulations and bias correction.....................35

3.3.2 Physically based hydrologic models.............................................37

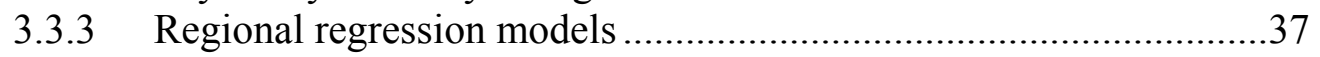

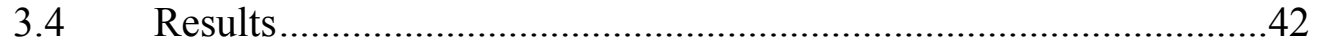

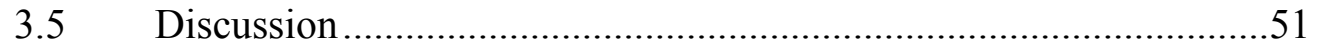

3.6 Conclusions .......................................................................53

$4 \quad$ Energy Budget Considerations for Hydro-climatic Impact Assessment ..................55

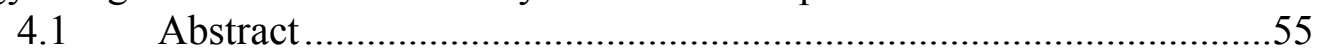

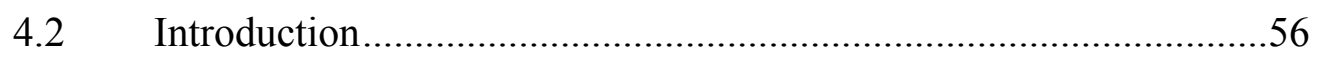

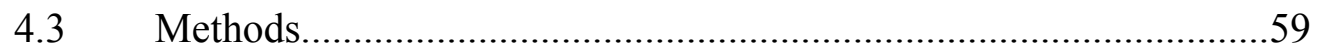




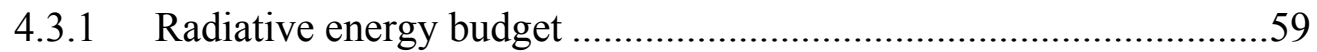

4.3.2 Climate scenario selection .............................................................60

4.3.3 LBRM simulation using temperature and energy adjustment

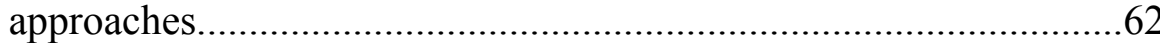

$4.4 \quad$ Results...................................................................................65

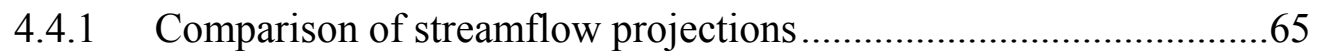

4.4.2 Snow water equivalent (SWE) projections ....................................... 88

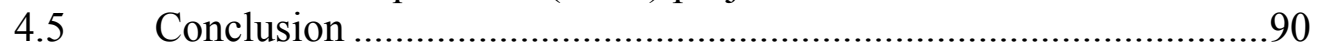

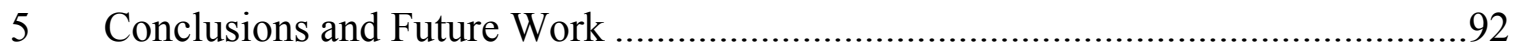

5.1 Major findings and contribution ...................................................92

5.1.1 Development of continuous hydrologic modeling of snow affected watersheds in the Great Lakes basin using HEC-HMS ....................92

5.1.2 Development of regional regression models for hydro-climate change impact assessment................................................................93

5.1.3 Significance of energy budget considerations for assessment of climate change impacts on water resources......................................93

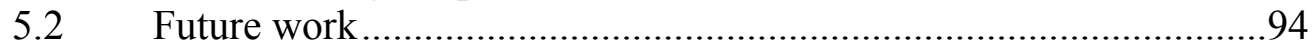

5.2.1 Adaptive decision modeling using hydro-climate projections..........94

5.2.2 Adaptive management applications ....................................................98

5.2.3 Snowmelt modeling opportunities in the Great Lakes basin ..........100

5.2.4 Sensitivity of hydrologic processes to climate change in temperate

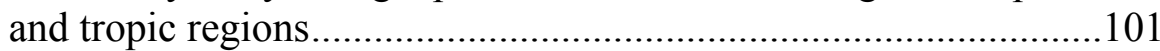

5.2.5 Integrated uncertainty assessment of hydro-climate change impact

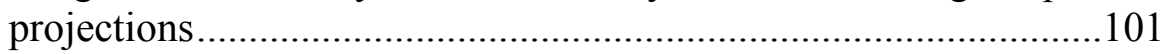

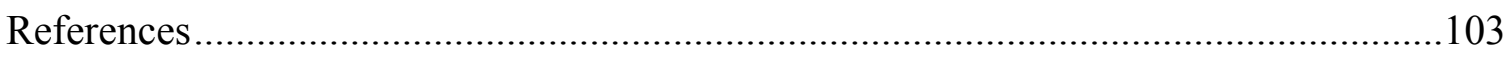

Appendix A: Copyright permissions .....................................................................115

Appendix B: Regression iterations and diagnostics (Chapter 3) .....................................117

Appendix C: Supplementary tables (Chapter 4) ……………………............................125 


\section{List of Figures}

Figure 2-1 The U.S. side of the Great Lakes watersheds, showing St. Louis,

Kalamazoo, and Maumee River watersheds.

Figure 2-2 (a) Schematic of soil moisture accounting algorithm in HEC-HMS, and (b) schematic of snowmelt algorithm (USACE 2010).

Figure 2-3 Conceptual model of (a) Maumee, (b) Kalamazoo, and (c) St. Louis in HMS, showing junctions, reaches, flow direction, and subbasins.

Figure 2-4 Calibrated snow water equivalent models of (a) Kalamazoo, (b) Maumee, and (c) St. Louis watersheds.

Figure 2-5 Simulated and observed hydrographs of Maumee watershed at (a) an interior watershed-Augalize, and (b) the outlet-Lower Maumee.

Figure 2-6 Hydrographs at junction 1: (a) observed, HEC-HMS; (b) observed, areascaled LBRM hydrographs at the outlet of Kalamazoo Riverwatershed; (c) observed, HEC-HMS; (d) observed, LBRM hydrographs.

Figure 2-7 Timing and magnitude of snowmelt, derived from NOHRSC SWE and HMS simulated SWE: (a) Kalamazoo, (b) Maumee...........................................24

Figure 3-1 A schematic of the hydro-climatic modeling framework, including physically based and regression based hydrologic modeling approaches (Adapted from Bae et al., 2011).

Figure 3-2 GCM projected precipitation changes showing observed 1/8th degree resolution precipitation (1980-1999), CMIP3 ensemble means (19801999, 2046-2065, 2081-2100), and standard deviations about 53 climate scenarios: before correction for residual BCCA bias, a); after residual bias correction applying the change factor method, b).

Figure 3-3 Reference streamflow gauges in the Western Great Lakes States used to develop the regional regression models and watershed boundaries of regulated and undisturbed basins where hydrologic and regression models are applied.

Figure 3-4 Logarithm of streamflow time series and flow duration curve, (FDC) of the USGS site 04105000 showing flow quantiles used in regression modeling (drainage area $18,821 \mathrm{~km}^{2}$ ). 
Figure 3-5 Cross validated regression models and average correlations $\left(R^{2}\right)$ over six folds of selected stream flow quantiles $\left(Q_{\min }, Q_{50}\right.$ and $\left.Q_{\max }\right)$.

Figure 3-6 Relation of low streamflow quantiles to precipitation (a); high streamflow quantiles to precipitation (b); low stream flow quantiles to temperature (c); and high stream flow quantiles to temperature $(\mathrm{d})$.................................45

Figure 3-7 CDFs of observed historic, LBRM, HMS and regression flows, at the outlet of Kalamzoo watershed, a); at the interior subbasin of Kalamazoo watershed, b); at the outlet of Maumee watershed, c); and the interior subbasin of Maumee watershed, d)

Figure 3-8 Selected wet-warm average (s30), dry-cool average (s52), dry-warm average (s18) and wet-cool average (s51) climate scenarios of Maumee river watershed from 53 BCCA CMIP3 projections, based on percent change in precipitation and absolute change in temperature (in degree Celsius) between the historic and the near future period 2046-2065.

Figure 3-9 CDFs of observed historic and future LBRM, HMS and regression flows, driven by GCM scenarios at the outlet of Kalamazoo (a), Maumee (b) and interior St. Louis (c) watersheds.

Figure 4-1 Selected watersheds in the Great Lakes basin.

Figure 4-2 Future climate scenarios in the Great Lakes basin represented by percent change in precipitation and absolute change (degree Celsius) in temperature between the historic and the near future period 2046-2065 from 53 BCCA CMIP3 projections; selected climate scenarios representative of characteristic future climates are highlighted.

Figure 4-3 Relationship between parameters $\mathrm{T}_{\mathrm{b}}$ and A for 14 Great Lakes watersheds ...63

Figure 4-4 Comparison of temperature adjust (TA) and energy adjust (EA) method estimated PET of the baseline (1980-1999) and the ensemble mean of the future periods (2046-2065) and (2081-2100) for Maumee River watershed65

Figure 4-5 Annual average percent changes in runoff, precipitation and PET of the selected watersheds between the baseline period (1980-1999) and the ensemble mean of the near-future period (2046-2065) 
Figure 4-6 Annual average percent changes in runoff, precipitation and PET of the selected watersheds between the baseline (1980-1999) and the ensemble mean of far-future period (2081-2100)

Figure 4-7 Relationship of percent change in runoff and the difference in percent change in precipitation and evapotranspiration between the periods (1980$1999)$ and (2046-2065)

Figure 4-8 Relationship of interflow and deep percolation coefficients to percolation coefficient, indicating base flow regime in LBRM

Figure 4-9 River networks, flow directions and the most downstream USGS streamflow locations for Saginaw, a); Fox, b); Black, c) and Cattaraugus, d) watersheds

Figure 4-10 Energy adjust (EA) projections of Au Sable River watershed as simulated by LBRM. Standard deviations are shown about ensemble means of near future (2046-2065) and far future (2081-2100) periods.

Figure 4-11 Characterization of the humidity regime of the selected watersheds in the Great Lakes basin based on the ratio of ET to precipitation as a function of ratio of PET to precipitation. Values are based on LBRM simulations, calibrated to observations (1961-1999).

Figure 4-12 Maumee watershed inputs to the Large Basin Runoff Model (LBRM). Shown are bias-corrected monthly precipitation, a); maximum temperature, b); temperature adjust PET, c); and energy adjust PET, d); projections. Standard deviations are shown about ensemble means of near future (2046-2065) and far future (2081-2100) periods.

Figure 4-13 Temperature adjust, a); and Energy adjust, b); evapotranspiration (ET) projections for Maumee River watershed as simulated by Large Basin Runoff Model (LBRM). Standard deviations are shown about ensemble means of near future (2046-2065) and far future (2081-2100) periods

Figure 4-14 Temperature adjust, a); and Energy adjust, b); runoff hydrographs for Maumee River watershed as simulated by Large Basin Runoff Model (LBRM). Standard deviations are shown about ensemble means of near future (2046-2065) and far future (2081-2100) periods.

Figure 4-15 Cumulative distribution functions (CDFs) of Large Basin Runoff Model (LBRM) simulated runoff based on Temperature Adjust (TA), a); and Energy Adjust (EA), b) methods for Maumee River watershed. Shown are the base period (1980-1999) and two future periods (2046-2065) and (2081-2100) from selected climate scenarios. 
Figure 4-16 St. Louis watershed inputs to the Large Basin Runoff Model (LBRM). Shown are bias-corrected monthly projections of precipitation, a); maximum temperature, b); temperature adjust PET, c); and energy adjust PET, d). Standard deviations are shown about ensemble means of near future (2046-2065) and far future (2081-2100) periods.

Figure 4-17 Temperature adjust, a); and Energy adjust, b); evapotranspiration (ET) projections for St. Louis River watershed as simulated by Large Basin Runoff Model (LBRM). Standard deviations are shown about ensemble means of near future (2046-2065) and far future (2081-2100) periods.

Figure 4-18 Temperature adjust, a); and Energy adjust, b); runoff hydrographs for St. Louis River watershed as simulated by Large Basin Runoff Model (LBRM). Standard deviations are shown about ensemble means of near future (2046-2065) and far future (2081-2100) periods.

Figure 4-19 Cumulative distribution functions (CDFs) of Large Basin Runoff Model (LBRM) simulated runoff based on Temperature Adjust (TA), a); and Energy Adjust (EA), b) methods for St. Louis River watershed. Shown are the base period (1980-1999) and two future periods (2046-2065) and (2081-2100) from selected climate scenarios.

Figure 4-20 Fox River watershed inputs to the Large Basin Runoff Model (LBRM). Shown are bias-corrected monthly precipitation, a); maximum temperature, b); temperature adjust PET, c); and energy adjust PET, d); projections. Standard deviations are shown about ensemble means of near future (2046-2065) and far future (2081-2100) periods.

Figure 4-21 Temperature adjust, a); and Energy adjust, b); evapotranspiration (ET) projections for Fox River watershed as simulated by Large Basin Runoff Model (LBRM). Standard deviations are shown about ensemble means of near future (2046-2065) and far future (2081-2100) periods.

Figure 4-22 Temperature adjust, a); and Energy adjust, b); runoff hydrographs for Fox River watershed as simulated by Large Basin Runoff Model (LBRM). Standard deviations are shown about ensemble means of near future (2046-2065) and far future (2081-2100) periods.

Figure 4-23 Cumulative distribution functions (CDFs) of Large Basin Runoff Model (LBRM) simulated runoff based on Temperature Adjust (TA), a); and Energy Adjust (EA), b) methods for Fox River watershed. Shown are the base period (1980-1999) and two future periods (2046-2065) and (20812100) from selected climate scenarios. 
Figure 4-24 Snow water equivalent (SWE) projections of Maumee River watershed as simulated by Large Basin Runoff Model (LBRM). Standard deviations are shown about ensemble means of near future (2046-2065) and far future (2081-2100) periods

Figure 4-25 Snow water equivalent (SWE) projections for St. Louis River watershed as simulated by Large Basin Runoff Model (LBRM). Standard deviations are shown about ensemble means of near future (2046-2065) and far future (2081-2100) periods

Figure 4-26 Snow water equivalent (SWE) projections for Fox River watershed as simulated by Large Basin Runoff Model (LBRM). Standard deviations are shown about ensemble means of near future (2046-2065) and far future (2081-2100) periods

Figure 5-1 Scenario tree corresponding to CMIP3 projections of 21 st century temperature in the Kalamazoo River watershed. Nodes in the tree represent decision stages, and branches represent uncertain states of nature that will become known after each decision stage. .95

Figure 5-2 HUC-12 ratios of flow depletions to maximum allowable flow depletions for July $Q_{10}$ (low) flows and upper-limit consumptive use coefficients (Mayer et al. 2012) 


\section{List of Tables}

Table 1-1 Overview of the Statistical Downscaling Methods ${ }^{1}$ (adapted from Schmidli et al. (2007) and Haylock et al. (2006).......................................................... 3

Table 1-2 Major characteristics of the applied models for future projection. ...................6

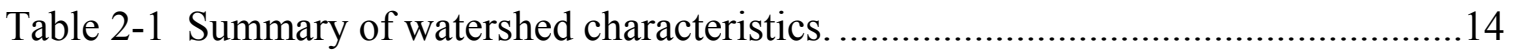

Table 2-2 Hydrometeorological data time series. ........................................................ 15

Table 2-3 Estimated soil moisture accounting parameter inputs and sources. ................16

Table 2-4 Calibrated soil moisture accounting parameters across the study area. ..........16

Table 2-5 Soil texture properties of subbasin 2, Kalamazoo River watershed.................17

Table 2-6 Calibrated snowmelt model parameter estimates. ......................................21

Table 2-7 Comparison of average annual runoff and contribution of snowmelt to

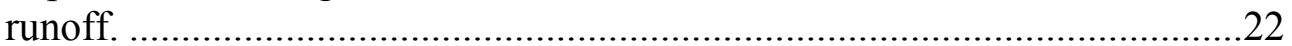

Table 2-8 Objective functions used to compare area scaled LBRM and HMS models. ..26

Table 2-9 Goodness of fit indices comparing area scaled LBRM and HMS model hydrographs during the calibration period- 2004-2006 ............................22

Table 3-1 Range of historic climate variables upon which the regression models are based and the future climate variables for the watersheds considered.

Table 3-2 Summary statistics of significant physical variables in the regional regression model and flow quantiles.

Table 3-3 Goodness of fit metrics of OLS and WLS regressions, and significant variables and associated coefficient values of WLS models. Metrics are calculated based on the natural logarithms of stream flows.

Table 4-1 Selected GCMs runs, corresponding grid size, emission scenario and representative future climate used as inputs to LBRM.

Table 4-2 Significant physical variables of the regional regression model (Gyawali et. al., 2013) based on GAGES II dataset (Falcone et al., 2012).

Table 4-3 The range of projected changes in runoff in the study watersheds across nine climate change scenarios 


\section{Preface}

This dissertation is the compilation of publications either in print or in preparation. Chapters 2-4 are co-authored, and the author's contribution to each of these chapters is described below.

Chapter 2 is published in Gyawali, R., and Watkins, D.W. (2013). "Continuous Hydrologic Modeling of Snow-Affected Watersheds in the Great Lakes Basin Using HEC-HMS." Journal of Hydrologic Engineering 18(1), 29-39. This chapter was primarily authored by the dissertation author. The dissertation author carried out the analyses and wrote the manuscript. Both authors were involved in the design of the research from its inception. The co-author, Dr. David W. Watkins, provided research direction, reviews and edited the paper. With permission from ASCE the paper is presented as a chapter is this dissertation (see Appendix A for permissions).

Chapter 3 is being planned for submission as Gyawali, R., Griffis, V.W., Watkins, D.W. and Fennessey, N. (2013). "Regional Regression Models for Hydro-Climate Change Impact Assessment." Hydrological Processes. This chapter was primarily authored by the dissertation author. The dissertation author carried out the analyses and wrote the chapter. All authors were involved in the design of the research from its inception. The co-authors, Drs. Veronica W. Griffis and David W. Watkins, provided research direction, reviews and edited the paper.

Chapter 4 is being planned for submission as Gyawali, R., Watkins, D.W., Griffis, V.W., Lofgren, B.M. (2013). "Energy Budget Considerations for Hydro-climate Impact Assessment." Journal of Great Lakes Research. This chapter was primarily authored by the dissertation author. All authors were involved in the design of the research from its inception. The dissertation author carried out the analyses and wrote the chapter. The coauthors, Drs. David W. Watkins, Veronica W. Griffis and Brent M. Lofgren, provided research direction, reviews and edited the paper.

Sections 5.2.1 and 5.2.2 of Chapter 5 were primarily authored by the dissertation author and Dr. David W. Watkins. Figure 5 -2 in this dissertation was published in Mayer A., Watkins, D.W., Mirchi, A., Gyawali, R., Watson, K.A. (2012), "Determination of Water Stress Indices as a Function of Ecological Flows." Proceedings, World Environment and Water Resources Congress, Albuquerque, NM, May 20-24, 2012, ASCE (2012). With permission from ASCE the figure is reused in this dissertation (see Appendix A for permissions). 


\section{Acknowledgments}

I would like to thank my co-advisors Drs. David Watkins and Veronica Griffis for their continued guidance and inspiration throughout the course of my doctoral education. I feel fortunate to have been advised by brilliant scientists and dedicated Professors. I look forward to any opportunity to continue to working with them again. I owe my sincere gratitude to Dr. Alex Mayer for providing me an opportunity to pursue doctoral research at Michigan Tech and leading an intellectually stimulating collaborative research group. I wish to thank Dr. Brent Lofgren for mentoring and providing me with a research opportunity at Great Lakes Environmental Research Laboratory (GLERL), National Oceanic and Atmospheric Administration (NOAA).

My gratitude also extends to Professor Brian Barkdoll for mentoring my teaching and providing constant motivation; Professors Noel Urban, Robert Froese, Veronica Griffis for teaching courses I could build on towards my doctoral research; all my committee members including Dr. David Watkins, Dr. Veronica Griffis, Dr. Alex Mayer and Dr. Brent Lofgren for reviewing my dissertation, providing constructive criticisms, critical reasoning and comments that helped develop a broader perspective to this dissertation. I am thankful to Dr. Neil Fennessey for his vision and help in the regression modeling effort. I am also grateful to all my other teachers and friends who in their varied and unique ways shaped the foundation I had to pursue my efforts.

This pursuit would have been impossible without the unconditional love, support, encouragement and the endless patience of my wife, Dr. Preetiza Dixit Gyawali, who put her own medical career in the back burner to put up with me and filled up for me to give as much love, our children Sourya and Reva deserve. My parents, siblings Shashi, Smriti, Biraj and my in-laws have been a tremendous source of support, inspiration and strength throughout.

Finally, I sincerely acknowledge the funding sources that contributed towards my doctoral education: the Civil and Environmental Engineering Department at Michigan Technological University, the U.S. National Science Foundation by the Grant Number CMMI-0725636, the Cooperative Institute for Limnology and Ecosystem Research's Great Lakes Summer Fellowship Program, School of Natural Resources and Environment, University of Michigan. 


\section{Abstract}

This dissertation addresses water resources decision making in the Great Lakes Basin by developing a multi-model framework for climate change impact assessment, including integrated climate and hydrologic modeling. Physically based watershed models, using soil moisture accounting and temperature index (degree-day) snowmelt algorithms, are developed, calibrated and validated to simulate baseflow, snowmelt, and surface runoff under historic conditions. Comparison with an existing model of the Great Lakes basin, the NOAA Large Basin Runoff Model (LBRM), showed improvements resulting from the increased spatial resolution and use of a more process-based snow algorithm in the Hydrologic Engineering Center's Hydrologic Modeling System (HECHMS). As an alternative to the physically based hydrologic models, and particularly appealing for ungauged basins or locations where record lengths are short, regional regression models are developed to directly predict selected streamflow quantiles, using physical basin characteristics as well as meteorological variables output by general circulation models (GCMs). Hydrologic responses are evaluated based on different combinations of hydro-climatic modeling approaches, when driven using GCM outputs. The model results, presented in a probabilistic context of multi-model predictions, provide insights to potential model weaknesses, including comparatively low runoff predictions from hydrologic models using temperature proxy potential evapotranspiration (PET) approaches and limited accuracy of regional regression models for small, groundwater-dominated watersheds. Additional insights are gained by replacing the temperature-proxy PET method with an approach that maintains a consistent energy budget between the climate and hydrologic models.

Hydrologic projections for the Great Lakes watersheds under future climates are evaluated using the model with a consistent energy budget, and differences in responses are explained by differences in watershed characteristics, aridity index, and the future climate projections. It is proposed that these hydrologic projections inform adaptive water resources decision making through a multi-stage decision model, and applications to water withdrawal permitting and BMP implementation are described. The framework developed herein demonstrates an integrated analysis of climate change impact assessment and will potentially be useful for researchers, water managers, and regulators as an aid to decision making and policy implementation. 


\section{Introduction}

\subsection{Overview}

This dissertation seeks to advance hydro-climatic impact assessment in the Great Lakes region by (1) developing new physically based watershed models to simulate snowmelt, base-flow and surface runoff under existing and changed land use and climate scenarios; (2) developing a novel regression-based watershed modeling approach to evaluate how hydrological responses may vary in the future; (3) evaluating hydrologic projections from different energy budget considerations; and (4) providing a multi-model impact projection framework that better represents uncertainties and supports adaptive decision making in the Great Lakes basin.

The multi-model framework comprises of bias-corrected and downscaled Coupled Model Inter-comparison Project (CMIP3) climate projections as inputs to the NOAA Large Basin Runoff Model (LBRM), the US Army Corps Hydrologic Modeling System (HEC-HMS) model, and Ordinary Least Squares (OLS) and Weighted Least Squares (WLS) regional regression models. These models vary in parameterizations, calibration/validation periods, spatial and temporal resolutions, and physically based processes, including snowmelt and evapotranspiration (ET) estimation methods. In order to use the models for climate change impact studies, model performances are evaluated in a probabilistic context of multi-model projections. Specifically, it is demonstrated how projections of hydrological responses may vary based on different combinations of hydro-climatic downscaling and watershed modeling approaches and how these variations may affect adaptation planning and management.

\subsubsection{Assessment of climate models}

Atmospheric-oceanic general circulation models (AOGCMs) are the most advanced and complex climate models which are commonly used for climate projections based on anthropogenic forcing (IPCC 2007). However, it is acknowledged that AOGCMs are limited in their ability to provide accurate meteorological variables, such as precipitation and temperature, at relevant spatial and temporal resolutions, thus affecting accurate climate change impact assessment (e.g., Xu et al. 1999, Prudhomme et al. 2002, Sharma et al. 2011). Dynamic and statistical downscaling of AOGCMs outputs can provide finer spatial resolution information relevant for climate change impact assessment (Wilby and Fowler 2010), but the capability of downscaling to provide detailed accurate predictions is debatable. Some studies have used the term "prediction" in reference to downscaled future climate change impacts (e.g. Hurrell et al. 2009, 
Shapiro et al. 2010), while others note serious reservations about the ability of downscaling methods to provide accurate predictions (Kerr 2011, Brown 2010, Pielke and Wilby 2012).

There has already been an increasing interest to study and describe the implications of various statistical and dynamical approaches to downscale climate model outputs at different temporal and spatial scales (e.g., Antic et.al 2004, Hanssen-Bauer et al. 2005, Haylock et al. 2006, Meier et al. 2006, Wilby and Fowler 2010). There is, however, no clear consensus on the selection of one method over another, and numerous statistical methods have appeared in the literature. For example, among statistical downscaling methods studied, a canonical correlation analysis (CCA) approach captured phenological variances better than multiple linear regression (MLR) in central Europe (Matulla et al. 2003). In another study, bias-corrected spatial disaggreagation (BCSD) better reproduced main features of observed hydrometereology than the linear interpolation (LI) method (Wood et al. 2004).

This study uses the projections based on bias corrected constructed analogs (BCCA) downscaling method archived in CMIP 3 database. Residual biases are further corrected using the change factor method. An overview of additional statistical downscaling methods is summarized in Table 1-1. 
Table 1-1 Overview of the Statistical Downscaling Methods ${ }^{1}$ (adapted from Schmidli et al. (2007) and Haylock et al. (2006).

\begin{tabular}{|c|c|c|c|c|c|}
\hline & $\begin{array}{l}\text { Statistical } \\
\text { methods }\end{array}$ & $\mathbf{P}$ & Predictor(s) & Description & Reference(s) \\
\hline 1 & $\begin{array}{l}\text { Canonical } \\
\text { correlation } \\
\text { analysis (CCA) }\end{array}$ & $\mathrm{S}$ & $\begin{array}{l}\text { PCs of SLP, } \\
\text { RH, SH, T }\end{array}$ & Multisite method. & $\begin{array}{l}\text { Haylock and } \\
\text { Goodess } \\
(2004)\end{array}$ \\
\hline 2 & $\begin{array}{l}\text { Local Intensity } \\
\text { Scaling (LOCI) }\end{array}$ & $\mathrm{D}$ & $\begin{array}{l}\text { GCM } \\
\text { precipitation }\end{array}$ & $\begin{array}{l}\text { Location scaling of GCM } \\
\text { precipitation with bias and } \\
\text { frequency correction. } \\
\text { Single site method. }\end{array}$ & $\begin{array}{l}\text { Schmidli et } \\
\text { al. }(2006)\end{array}$ \\
\hline 3 & $\begin{array}{l}\text { Multiple-linear } \\
\text { regression (MLR) }\end{array}$ & $\mathrm{S}$ & $\begin{array}{l}\text { ZX, RHX, TX, } \\
\text { DIVX and } \\
\text { VORX; with } \\
\text { X=500,700,850; } \\
\text { MF700, CPs }\end{array}$ & $\begin{array}{l}\text { Predictor values are } \\
\text { averaged over nearest grid } \\
\text { points. Single site method. }\end{array}$ & $\begin{array}{l}\text { Schmidi et al. } \\
\text { (2007) }\end{array}$ \\
\hline 4 & $\begin{array}{l}\text { Multiple-auto } \\
\text { regressive models } \\
\text { (MAR) }\end{array}$ & $\mathrm{D}$ & CPs, MF700 & $\begin{array}{l}\text { Multivariate auto- } \\
\text { regressive models. Multiple } \\
\text { site method. }\end{array}$ & $\begin{array}{l}\text { Stehlik and } \\
\text { Bardossy } \\
(2002) \text {. }\end{array}$ \\
\hline 5 & $\begin{array}{l}\text { Conditional } \\
\text { weather } \\
\text { generator(CWG) }\end{array}$ & $\mathrm{D}$ & CI based on SLP & $\begin{array}{l}\text { Conditional on quantiles of } \\
\text { a CI (transitional } \\
\text { probabilities, scale and } \\
\text { location parameter. Single } \\
\text { site method }\end{array}$ & $\begin{array}{l}\text { Wilks and } \\
\text { Wilby } \\
\text { (1999). }\end{array}$ \\
\hline 6 & $\begin{array}{l}\text { Two step analog } \\
\text { method (ANA) }\end{array}$ & d & $\begin{array}{l}\text { VG1000, } \\
\text { VG500 }\end{array}$ & $\begin{array}{l}\text { 1) Determine } 30 \text { most } \\
\text { similar days and 2) } \\
\text { determine pdf of daily } \\
\text { precipitation from all days } \\
\text { in the season. Multisite } \\
\text { method. }\end{array}$ & $\begin{array}{l}\text { Zorita and } \\
\text { Storch (1999) }\end{array}$ \\
\hline
\end{tabular}

${ }^{1} \mathrm{P}$, predictand; d, daily; s, seasonal; $\mathrm{CP}$, circulation pattern; CI, circulation index; PC, principal component; SLP, sea level pressure; RH, relative humidity; $\mathrm{SH}$, specific humidity; T, temperature; Z, geopotential height; DIV, divergence; VOR, vorticity; MF700, moisture flux at $700 \mathrm{hPa}$; VG, geostrophic velocity at various $\mathrm{hPa}$.

Dynamic downscaling methods are based on regional climate models (RCMs) and have finer grid resolution of surface features than GCMs (Castro et al., 2005), while the statistical downscaling methods are based on regression relationships of large scale atmospheric variables and local meteorology (Wibly and Fowler, 2010). Both approaches are found to improve climate projection skill at the watershed scale, but statistical methods are less expensive and less computationally intensive and therefore more widely used. 
It is also not clear if further (statistical) downscaling of regional climate model (RCM) data would be beneficial for hydrological impact studies. Sharma et.al (2011) showed experimental results, demonstrating that downscaled RCM outputs from the Canadian Regional Climate Model (CRCM 4.2) matched the observed data much better than the raw CRCM4.2 outputs; but these results would be expected as downscaling RCM outputs provided another level of fitting. The comparison of modeled runoff using rainfall from different downscaling methods for historical and future climate showed that downscaling models offered potential improvements by capturing a fuller range of daily rainfall characteristics (Chiew et al. 2010). Sharma et al. (2010) compared the raw RCM and downscaled RCM using metrics like root mean squared error (RMSE), mean absolute error (MAE), mean relative error (RE) and Nash and Sutcliffe (1970), and showed downscaled RCM outputs improved hydrological model performance.

Comparisons of downscaling methods and guidelines for use of climate scenarios are provided in Wilby et al. (1998) and Wilby et al. (2004). Statistical downscaling methods, though simple and computationally less intensive than dynamic downscaling methods, are criticized for stationarity assumptions - a premise that the relationship which exists between the variables in the observed hydrological time series will stay the same in the future (Milly et.al. 2008). Despite this criticism, its simplicity and operational value for managing water systems is well acknowledged (Milly et al. 2002, Lins et al., 1999). Furthermore, dynamical downscaling methods may also be implicitly affected by the stationarity assumption through the calibration process.

Uncertainties are associated with every anticipated change in climate and depend on a range of factors, including emission scenarios, GCM/RCM configurations, GCM/RCM downscaling methods, boundary conditions, variability in models and nature, complexities in terrain, and other factors (Jones et al. 2000, Anderson et al.2003, Déqué et al. 2007, Bae et al. 2011). Thus, caution is required while interpreting the downscaled climate model results. To account for model uncertainty, it is recommended that a suite of models be used to represent climate change scenarios at the local scale, rather than rely on a single model or scenario (Haylock et al. 2006). In the past, climate change impact assessments have typically used a scenario-based approach (Carter et al. 2001, Means et al. 2001). Impact assessment using an ensemble of climate model outputs, as done in this study, is a developing field in terms of approaches for making decisions based on probabilistic impact information (New et al. 2007).

Accounting for the complexity in quantifying the certainty required in climate change projections to justify investment in adaptation measures (Dessai and Humle 2007), this study contributes towards improving regional water availability projections by using a multi-model hydro-climatic framework with appropriately coupled climate and hydrologic models. 


\subsubsection{Assessment of hydrologic models}

Hydrologic models can be broadly classified as two types: (a) Empirical/statistical models, which are based on mathematical and statistical concepts to link a certain model input to the model output, for example rainfall to runoff, using techniques like regression, transfer functions, neural networks and system identification, and (b) Physically based models, which explicitly represent physical processes including base flow, evapotranspiration, surface runoff, and channel routing. These models are typically deterministic and may be based on single events or continuous simulation. A more comprehensive assessment of hydrologic models is provided in Chapter 3.

The two physically based hydrologic models applied in this research are the NOAA Large Basin Runoff Model (Croley 2002) and the Hydrologic Engineering Center-Hydrologic Modeling System (HEC-HMS) (USACE 2010). The major characteristics of these hydrological models are listed in Table 1-2. In addition, a regional regression approach was applied, whereby selected streamflow quantiles are related to watershed and climate characteristics. 
Table 1-2 Major characteristics of the applied models for future projection.

\begin{tabular}{|c|c|c|c|}
\hline & HEC-HMS & LBRM & Regression \\
\hline Model Type & $\begin{array}{l}\text { Deterministic, distributed, } \\
\text { lumped; Physically based }\end{array}$ & $\begin{array}{l}\text { Deterministic, } \\
\text { lumped generally at } \\
\text { HUC-8 scale }\end{array}$ & $\begin{array}{l}\text { Stochastic, significant } \\
\text { meteorological } \\
\text { /physical variables } \\
\text { included }\end{array}$ \\
\hline Time step & Hourly, daily, monthly & Daily & $\begin{array}{l}\text { Daily*,Monthly, } \\
\text { annual }\end{array}$ \\
\hline $\begin{array}{l}\text { Input } \\
\text { variables }\end{array}$ & $\begin{array}{l}\text { Precip., Temp., Elevation, } \\
\text { land use, canopy cover, } \\
\text { PET. }\end{array}$ & $\begin{array}{l}\text { Precip., Temp., } \\
\text { Solar insolation }\end{array}$ & $\begin{array}{l}\text { Meteorological and } \\
\text { physical variables }\end{array}$ \\
\hline $\begin{array}{l}\text { Output } \\
\text { variables }\end{array}$ & $\begin{array}{l}\text { Streamflow, soil moisture, } \\
\text { ET, SWE, baseflow }\end{array}$ & $\begin{array}{l}\text { Streamflow, SWE, } \\
\text { soil moisture }\end{array}$ & $\begin{array}{l}\text { Selected streamflow } \\
\text { quantiles }\end{array}$ \\
\hline Loss method & $\begin{array}{l}\text { SCS, Green and Ampt, } \\
\text { SMA, Initial and constant, } \\
\text { Deficit and constant }\end{array}$ & $\begin{array}{l}\text { Soil moisture } \\
\text { accounting (SMA) }\end{array}$ & Not applicable \\
\hline $\begin{array}{l}\text { Vertical snow } \\
\text { band }\end{array}$ & $\begin{array}{l}\text { Present, specified using } \\
\text { elevation and a lapse rate } \\
\text { temperature }\end{array}$ & Absent & Absent \\
\hline Simulation & $\begin{array}{l}\text { Both event-based and } \\
\text { continuous }\end{array}$ & Continuous & $\begin{array}{l}\text { Flow quantiles using } \\
\text { regression equations }\end{array}$ \\
\hline Routing & $\begin{array}{l}\text { Simple Lag, Modified } \\
\text { puls, Muskingum etc. }\end{array}$ & No flow routing & No flow routing \\
\hline ET calculation & $\begin{array}{l}\text { Applicable for long term } \\
\text { simulation; Based on user } \\
\text { input avg. monthly PET or } \\
\text { Priestley Taylor method }\end{array}$ & $\begin{array}{l}\text { Based on empirical } \\
\text { PET, computed } \\
\text { using air } \\
\text { temperature as a } \\
\text { proxy }\end{array}$ & $\begin{array}{l}\text { Applicable if the } \\
\text { variable is significant }\end{array}$ \\
\hline Snow model & $\begin{array}{l}\text { Multilayer, degree day- } \\
\text { temperature index method }\end{array}$ & $\begin{array}{l}\text { Temperature index } \\
\text { method }\end{array}$ & Not applicable \\
\hline $\begin{array}{l}\text { Set-up } \\
\text { calibration }\end{array}$ & $\begin{array}{l}\text { Flexible, } 3 \text { years for the } \\
\text { models used herein. }\end{array}$ & $\begin{array}{l}\text { Flexible, } 30 \text { years } \\
\text { for models herein }\end{array}$ & $\begin{array}{l}\text { Historical data used to } \\
\text { estimate coefficients. }\end{array}$ \\
\hline Parameters & $\begin{array}{l}\text { Multiple parameters }(10- \\
14) \text {, depends on choice of } \\
\text { loss, baseflow \& routing } \\
\text { methods }\end{array}$ & 9 parameters & $\begin{array}{l}\text { Typically } 3-8 \\
\text { parameters are } \\
\text { estimated }\end{array}$ \\
\hline References & $\begin{array}{l}\text { (Gyawali \& Watkins 2013, } \\
\text { Fleming \& Neary 2004) }\end{array}$ & $\begin{array}{l}\text { (Croley 2002, He } \\
\text { and Croley 2007) }\end{array}$ & ( Kroll et al. 2004) \\
\hline
\end{tabular}

*Archfield et. al (2010) use regional regression models to generate daily time series of streamflow 


\subsection{Research objectives and organization of chapters}

The objective of the proposed research is to develop a framework for hydroclimatic analysis of water resource systems in the Great Lakes basin, potentially useful for researchers, water managers, regulators and practitioners as an aid to decision making and policy implementation. In this effort, a comprehensive framework for climate change impact projection is developed by appropriately coupling climate and hydrologic models. This objective is met by the completion of the following tasks:

Task 1: Develop and evaluate physically based hydrologic models. This task is achieved by developing, calibrating and verifying hydrologic models in Great Lakes watersheds using HEC-HMS. The model perfomances are compared and evaluated with another existing hydrologic model of the Great Lakes - LBRM. Chapter 2 presents the results of this analysis, as published in the Journal of Hydrologic Engineering (Gyawali and Watkins 2013).

Task 2: Develop regional regression models to complement hydrologic models for hydroclimate change impact assessment. This is accomplished by developing OLS and WLS regression models for the western Great Lakes States to directly simulate future flow quantiles from the downscaled climate model outputs used in CMIP 3 models. Chapter 3 presents these regression models as part of an ensemble approach to predict hydroclimate change impacts in the Great Lakes watersheds, and it is planned for submission to Hydrological Processes.

Task 3: Re-evaluate the hydrologic models (in Task 2) with a consistent energy budget maintained between climate and hydrologic models. This is accomplished by comparing runoff projections based on "temperature adjusted" (TA) and "energy adjusted" (EA) potential evapotranspiration (PET) input in hydrologic models. For the TA methods, PET is adjusted by the change factor of temperature, as in Task 2. For the EA method, PET is adjusted using the ratio of future radiative fluxes to historical values from GCMs, instead of temperature changes. The results of this analysis are presented in Chapter 4, with submission planned to the Journal of Great Lakes Research.

Task 4: Present potential model applications in the context of adaptive decision making in the Great Lakes region. Two potenetial applications are proposed in the future work section of Chapter 5: 1) Water withdrawal permitting in the Kalamazoo River basin in Michigan, and 2) Best management practices (BMP) implementation in the Kalamazoo River basin under future climate scenarios. An expected outcome of this study is recommendations for water withdrawal permitting and BMP implementation policy in the Great Lakes region. Chapter 5 also presents the conclusion, future work and recommendations based on the research presented in the preceeding chapters. 


\section{Continuous Hydrologic Modeling of Snow-Affected Watersheds in the Great Lakes Basin using HEC-HMS ${ }^{1}$}

\subsection{Abstract}

Climate and land use change studies require watershed models with physicallybased parameters rather than empirical models which are simply calibrated to reproduce historical streamflows. With this in mind, soil moisture accounting and the temperature index (degree-day) snowmelt models embodied in the Hydrologic Engineering Center's Hydrologic Modeling System (HEC-HMS) are applied to three Great Lakes watersheds Kalamazoo, Maumee and St. Louis - with different climatic and land use characteristics. Watershed and sub-watershed models are calibrated and validated on a daily time step using gauge precipitation measurements, observed snow water equivalent data, and physically based parameters estimated using geospatial databases. Results are compared to area-scaled outputs from the NOAA Large Basin Runoff Model (LBRM) for historical conditions. The results show modest improvements resulting from the increased spatial resolution of the HEC-HMS models, as well as the benefits of the more process-based snow algorithm in HEC-HMS, particularly for the snow-dominated St. Louis watershed. However, both LBRM and HEC-HMS models had difficulty reproducing peaks in late winter and early spring runoff, and discrepancies could not be attributed to any systematic errors in the snowmelt models.

\footnotetext{
${ }^{1}$ The material contained in Chapter 2 was published in Journal of Hydrologic Engineering
} 


\subsection{Introduction}

The Laurentian Great Lakes and their connecting channels form the largest fresh surface water system on earth, comprising $95 \%$ of freshwater in North America and $18 \%$ of the world's available freshwater. The system provides drinking water to 40 million U.S. and Canadian citizens and supports a range of services including hydroelectric and thermal-power generation, navigation, and fishing and other recreational activities. It has been estimated that streams contribute 46 percent of the water that goes into the Great Lakes, while direct precipitation on to the lakes makes up about 53 percent. The remaining 1 percent of water comes to the Great Lakes by diverting water from outside of the basin (Hodgkins et al. 2007). Although variable from year to year, runoff due to snowmelt is a significant component of the net basin supply to the Great Lakes.

This study is a part of a larger effort that aims to contribute to the broader issue of global water resources sustainability by analyzing the use, efficiency and governance of water in the Great Lakes basin. It is expected that millions more will be subjected to increased water stress and floods with increasing population and changing climate/land use patterns throughout the world in the coming decades. Hence, effective management of water resources is an increasingly important issue (Vörösmarty et al. 2010). In order to address long term water resources planning and management, as well as short term water availability during low flow periods, physically based water balance models are developed. These models should incorporate most, if not all, hydrologic processes, with the ability to predict watershed responses to drivers like land use and climate change.

Advances in remote surveillance techniques and the availability of geo-spatial databases have enabled estimation of a range of hydro-climatic variables and a better description of hydrological regimes, reducing uncertainty in predictions at a range of scales (e.g., Ogden et al. 2001, Hoblit et al. 2002, Emerson et al. 2005). This paper discusses a continuous hydrologic modeling approach, including a soil moisture accounting algorithm along with a snow accumulation and melt algorithm, which utilizes these advances in data availability. The model, the HEC Hydrologic Modeling System (USACE 2010), is applied to three Great Lakes watersheds - Kalamazoo, Maumee and St. Louis, shown in Figure 2-1. Model development, parameterization, calibration and validation are described, and model results are compared to results from the Large Basin Runoff Model (LBRM), developed by the NOAA Great Lakes Environmental Research Laboratory (Croley 2002). 


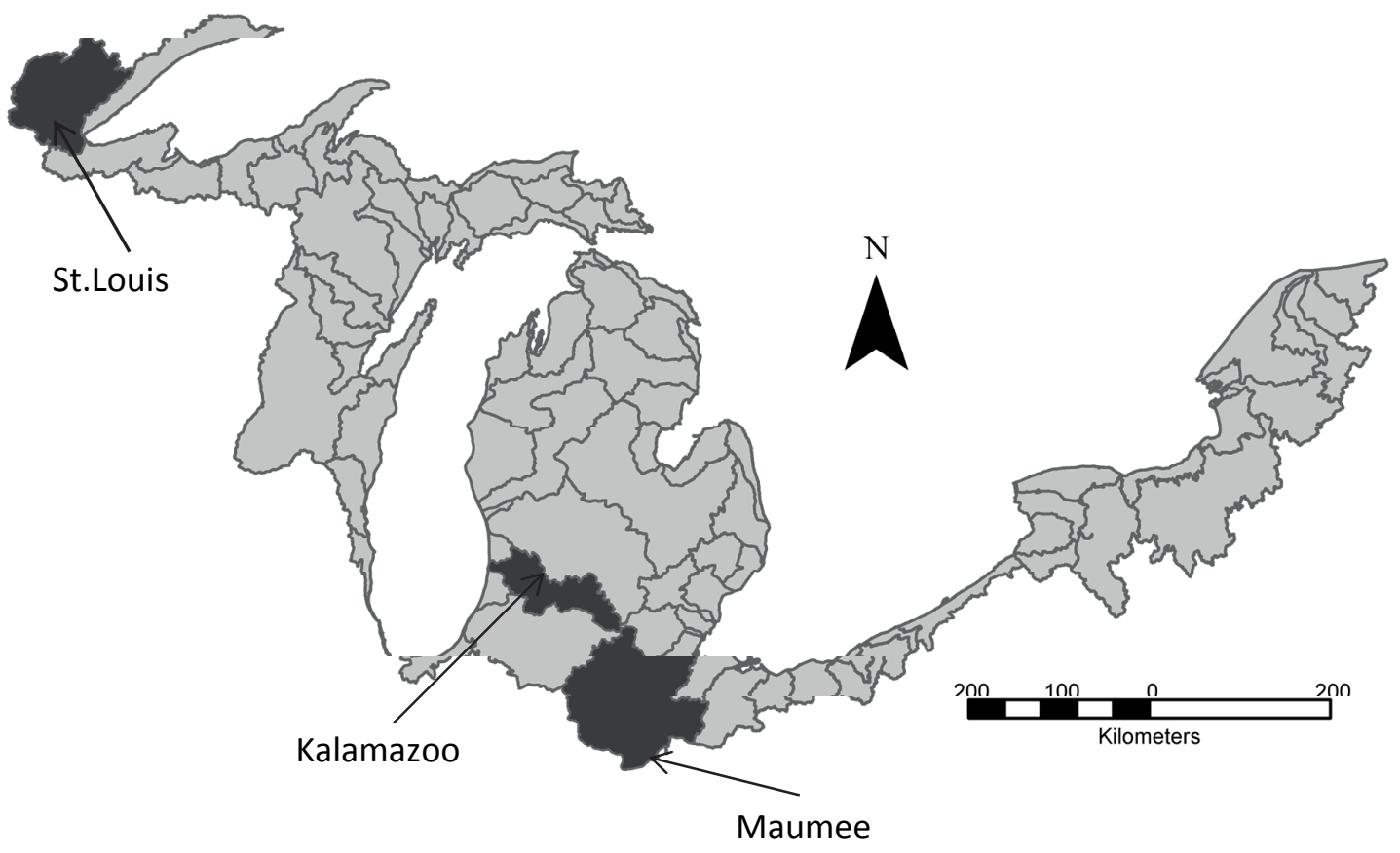

Figure 2-1 The U.S. side of the Great Lakes watersheds, showing St. Louis, Kalamazoo, and Maumee River watersheds.

\subsubsection{Hydrologic model description}

The $\mathrm{H}$ ydrologic Engineering Center- $\mathrm{H}$ ydrologic Modeling System (H HEQAS) is designed for both continuous and event-based hydrologic modeling and provides the user with several different options for modeling various components of the hydrologic cycle. Event-based modeling uses a smaller simulation time window that begins just before a storm and ends a short time after the storm stops. This may be several hours to several days, depending on watershed size. Continuous modeling has a much larger time window, including dry and wet periods, typically ranging from months to several years. The major difference is that evapotranspiration and groundwater seepage can typically be ignored for event-based modeling, but not in continuous modeling because these are critical processes of soil drying (Scharffenberg 2008). Two of the loss methods in H MS that include a representation of evapotranspiration are the D eficiConstant method and Soil Moisture Accounting (SMA). In this study, SMA is used as the loss rate method associated with each sub-basin. The SMA loss method simulates the movement of water over time through the various storage components that represent the physical aspects of the watershed (Figure 2-2). Inputs to the SMA algorithm are precipitation, temperature, 
and potential evapotranspiration, and the outputs are precipitation excess (surface runoff), groundwater flow, and deep percolation. Excess precipitation is transformed to a direct runoff hydrograph externally from the SMA loss method. The resulting direct runoff and groundwater hydrographs are then combined. Deep percolation is considered water removed from the system.

In this study, results from HEC-HMS are compared to results from LBRM, a watershed runoff model developed by the NOAA Great Lakes Environmental Research Lab (GLERL). LBRM is a lumped-parameter model of basin outflow consisting of a cascade of moisture storages, or "tanks," each modeled as a linear reservoir. The model simulates surface water outflows at the mouth of each watershed as well as average subsurface moisture storages over the watershed. Inputs to the model are minimum and maximum temperature and precipitation at a daily time step; the model outputs runoff, snow accumulation, snowmelt, and storages at different zones integrated over the basin (Croley 2002). Similar to HEC-HMS, LBRM includes components for representing precipitation, evaporation, and snowmelt, and for computing runoff, base-flow, and moisture storages in different surface and sub-surface layers. In LBRM evapotanspiration is modeled in all three sub-surface zones (USMZ, LSMZ and groundwater zone), while in HEC-HMS it is modeled only in the surface and the soil zones, in addition to the canopy storage zone. LBRM and HEC-HMS both use SMA methods, but they account for soil moisture in different ways - LBRM considers two soil layers, while HEC-HMS considers a single soil layer that is divided into a gravity drainage zone and a tension storage zone. 


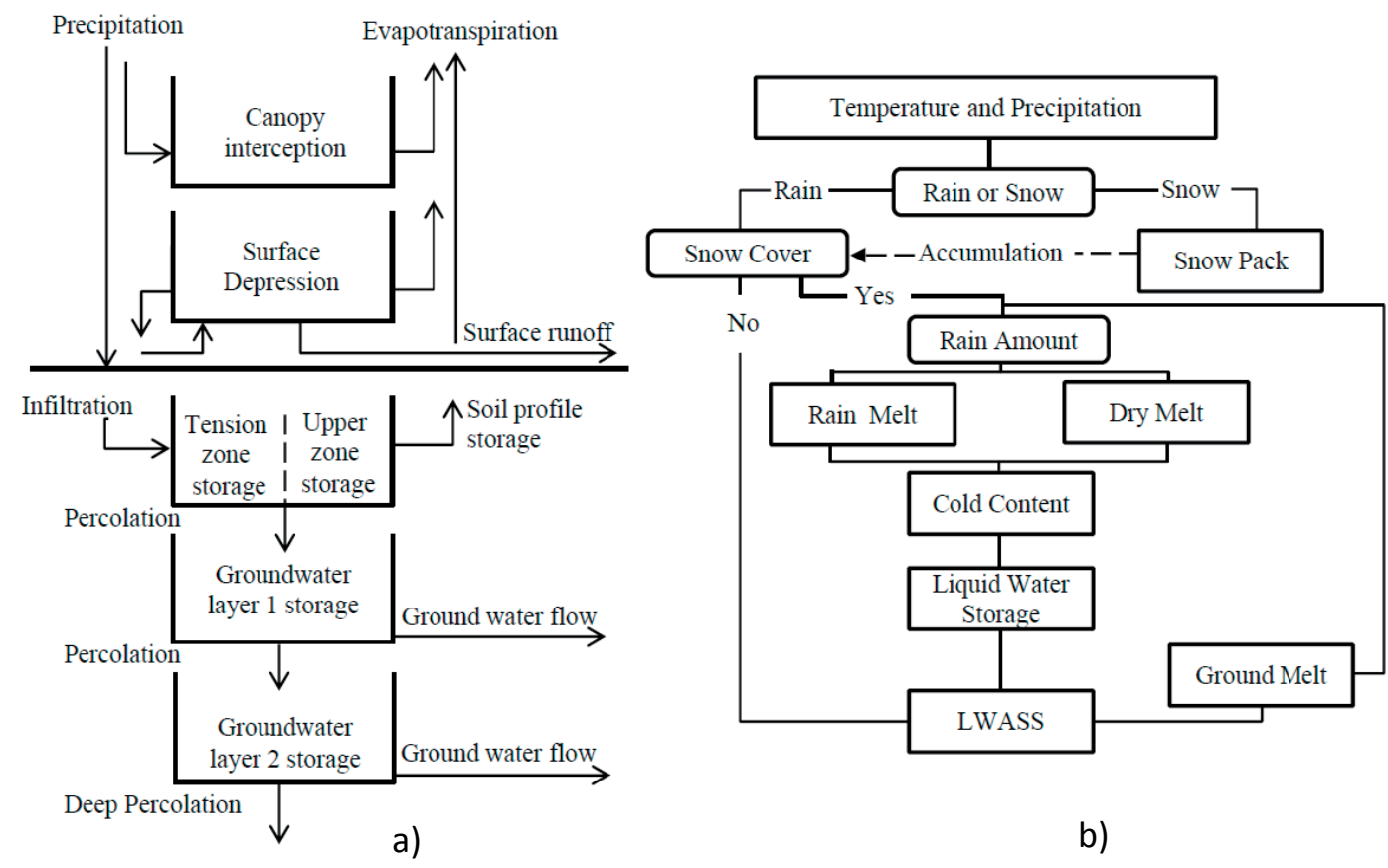

Figure 2-2 (a) Schematic of soil moisture accounting algorithm in $\mathrm{H}$ ECH MS, and (b) schematic of snowmelt algorithm (USACE 2010

\subsubsection{Sn o wmel t mo del}

Snowmelt modeling allows estimation of the volume of snow water equivalent (SWE) and the timing and magnitude of snowmelt which impacts soil moisture, runoff, and streamflow. $\mathrm{H}$ EC-H MS has two snowmelt modeling options, the temperature index method and the gridded temperature index method. The former, used in this study (Figure 2-2), is generally applied to lumped watershed models, while the latter is applied to distributed models (USACE 2010). With only air temperature and precipitation as inputs, the temperature index method is computationally simpler than other numerical snow models which use complete energy budget estimates (Melloh 1999). The temperature index method describes the melting rate either as a function of an antecedent temperature index (ATI) or a predetermined function of the time of year. A single snow layer is assumed, with user-defined cold content, liquid water content and ground meltrate. The cold content is defined as the heat required to raise the temperature of the snowpack to 0 ${ }^{\circ}$ Celsius. The cold content parameters, ATI cold function and ATI cold coefficient function, are incorporated to account for the ability of a cold snowpack to freeze the liquid water entering the pack from rainfall. $\mathrm{H}$ eavy rains trigger a separate melt procss defined by the wet meltrate. The snowmelt that occurs from beneath the snowpack is defined as the ground melt. For relatively shallow seasonal snow cover ( $\mathrm{SWE}<12$ 
inches), this is set to zero (Daly n.d.). A simple 'bucket' concept provides the mechanism to retain liquid water in the snowpack against drainage processes until the water reaches a user-defined threshold. The output of the method is the liquid available at the soil surface (LWASS), which is added to the input precipitation hyetograph of the sub-basin runoff model (USACE 2010).

For watershed modeling applications, calibration of the temperature index snowmelt method is recommended (Daly 1999). In a recent application of the temperature index snowmelt method in HEC-HMS and LBRM to the Upper Euphrates River basin in Turkey (Yilmaz et al. 2011), the performance of the streamflow models was assessed, but calibration of the snowmelt models was not discussed, probably due to SWE data limitations. The snow models in this study are calibrated against basin-wide (HUC8 and HUC12) average SWE data obtained from NOAA National Operational Hydrologic Remote Sensing Center (NOHRSC).

Previous snow hydrology studies (e.g., Doesken and Judson 1997, Kopp et al. 1996, Helfrich et al. 2007) provide guidelines for both in-situ and remote sensing snow measurement, despite inherent limitations of accurate SWE measurements. For this study, daily time series of SWE are obtained from the National Snow and Ice Data Center (NSIDC), which archives NOHRSC's snow data products. The snow data sets are based on outputs from the SNOw Data Assimilation System (SNODAS), a modeling and data assimilation system developed by the NOHRSC that provides estimates of snow cover and associated variables to support hydrologic modeling and analysis (NOHRSC 2004). SNODAS is an integrated system which uses a range of models and processes for data assimilation. This includes downscaling outputs from Numerical Weather Prediction models, assimilating airborne satellite observations, and ground truth snow measurements. The gridded data sets for the continental United States at 1-km spatial resolution and 24-hour temporal resolution are available from NSIDC (NOHRSC 2004).

\subsubsection{Study area}

Three snow-affected watersheds in the Great Lakes watershed -Kalamazoo, Maumee and St. Louis-are modeled in this study (Figure 2-1). The Kalamazoo watershed is located in southwest Michigan and drains $5273 \mathrm{~km}^{2}\left(2036 \mathrm{mi}^{2}\right)$. The watershed is 261 $\mathrm{km}$ long and 18 to $47 \mathrm{~km}$ in width and drains to Lake Michigan. The watershed is modeled as six sub-basins, each draining to a USGS streamflow gage at its outlet. Agriculture (50\%) and irrigation are the major land and water use categories, respectively. The Maumee River watershed drains $17,115 \mathrm{~km}^{2}\left(6608 \mathrm{mi}^{2}\right) \mathrm{mi}^{2}$ to Lake Erie, including area in the states of Ohio $\left(12,593 \mathrm{~km}^{2}\right)$, Indiana $\left(3,323 \mathrm{~km}^{2}\right)$ and Michigan $\left(1,199 \mathrm{~km}^{2}\right)$. This is the largest of the watersheds being studied and comprises seven HUC 8 basins. Removal of forest for agricultural activities in the Maumee River watershed has been so extensive that only $3-5 \%$ of the watershed is wooded, mostly 
along the river corridor. The major land use category is agriculture (78\%). The St. Louis River watershed drains $9,412 \mathrm{~km}^{2}\left(3634 \mathrm{mi}^{2}\right)$ to Lake Superior, including area in the states of Minnesota $\left(8,731 \mathrm{~km}^{2}\right)$ and Wisconsin $\left(681 \mathrm{~km}^{2}\right)$. The watershed is characterized as having a diverse morphology, ranging from steep headwater streams to a freshwater estuary as it empties into Lake Superior. A significant land use category in the watershed is wetlands (24\%). Although a significant proportion of the watershed is gaged, only two of the three available USGS gages are used for watershed modeling. The USGS streamflow measurements at Scanlon, MN, are adjusted to account for reservoir regulation upstream. The USGS streamflow measurements at Nemadji, WI, although relatively unimpaired, are affected by ice jams, which may hinder accurate flow estimation during the snow season due to undocumented increases in river stage.

Each watershed has unique geologic and hydro-climatic characteristics with unique watershed responses. For example, the Kalamazoo River has delayed and sustained responses to rainfall while the Maumee River has a flashy response. This difference is mainly attributed to groundwater storages in the watersheds, with dominant ground water storage causing delayed hydrologic response in the Kalamazoo basin, while reduced ground water storage results in more rapid response in the Maumee basin (Croley, 2006). The St. Louis River watershed is distinguished from both the Kalamazoo and Maumee basins by the occurrence of sustained snowpack through the winter season. A summary of land use, basin characteristics and climatology is provided in Table 2-1.

Table 2-1 Summary of watershed characteristics.

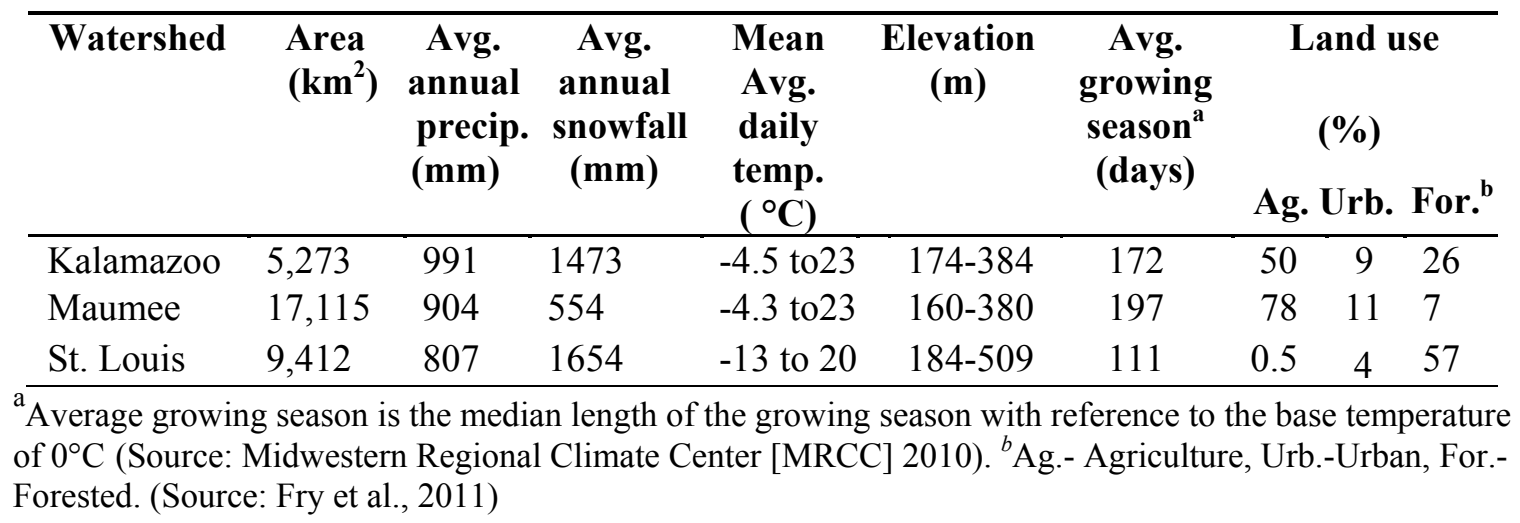




\subsection{Modeling procedure and parameter estimation}

The watersheds are disaggregated into a number of sub-basins, with each sub-basin having a USGS stream gauge at its outlet, as shown in Figure 2-3. Meteorological data inputs, required for each sub-basin, are summarized in Table 2-2. Theissen polygons are used to compute areal average precipitation based on available gage measurements.

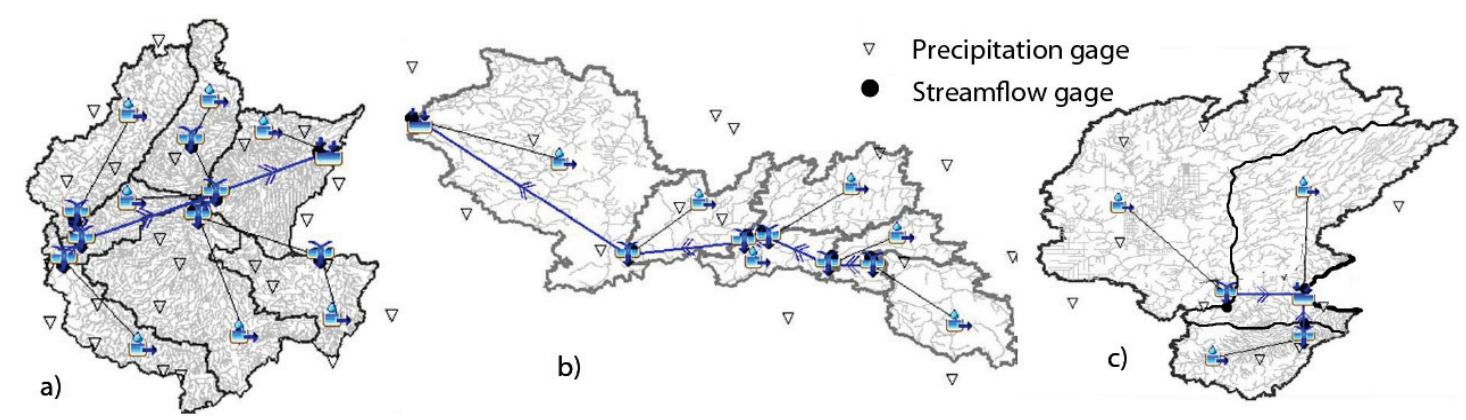

Figure 2-3 Conceptual model of (a) Maumee, (b) Kalamazoo, and (c) St. Louis in H MS, showing junctions, reaches, flow direction, and subbasins.

Table 2-2 H ydrometeorological dattime series.

\begin{tabular}{lll}
\hline Variables & \multicolumn{2}{c}{ Data bases } \\
\hline $\mathrm{D}$ aily precipitation & National Climatic D ata Center, NO AA \\
$\mathrm{D}$ aily air temperature & National Climatic D ata Center, NO AA \\
$\mathrm{D}$ aily flows & USGS D ischarge database \\
$\mathrm{D}$ aily snow water & NO SH RC, NO AA database & \\
equivalent (SWE) & & \\
\hline
\end{tabular}

P arameter estimation of SMA in H MS is discussed in Fleming and Neary (2004). Unlike the seasonal parameterization approach used in that study, a single parameter estimate is used for different variables throughout the calibration and validation periods in this study, spanning 2004-2009. Table 2-3 and Table 2-4 provide the list of required SMA parameter inputs, data sources, and ranges of values assumed in this study. The parameter variables are defined in USACE (2010). 
Table 2-3 Estimated soil moisture accounting parameter inputs and sources.

\begin{tabular}{lll}
\hline Parameters & Source & Range \\
\hline Canopy storage $(\mathrm{mm})$ & HMS help file $^{\mathrm{a}}$ & $1.1-5.3$ \\
Surface storage $(\mathrm{mm})$ & HMS help file $^{\mathrm{a}, \mathrm{b}}$ & $20-70$ \\
Max infiltration $(\mathrm{mm} / \mathrm{hr})$ & USDA STATSGO $^{\mathrm{c}, \mathrm{e}}$ & $5-45$ \\
Impervious\% & GIS data $^{\mathrm{d}}$ & $3-10$ \\
Soil storage $(\mathrm{mm})$ & STATSGO $^{\mathrm{c}, \mathrm{e}}$ & $20-80$ \\
Tension storage $(\mathrm{mm})$ & HMS help file $^{\mathrm{a}}$ & $10.2-40.6$ \\
Soil percolation $(\mathrm{mm} / \mathrm{hr})$ & (WMS, 1999) $^{\text {(W) }}$ & $57.1-137$ \\
\hline
\end{tabular}

${ }^{\mathrm{a} U . S . ~ A r m y ~ C o r p s ~ o f ~ E n g i n e e r s ~(U S A C E, ~ 2010) ~}$

${ }^{\mathrm{b}}$ Fleming and Neary (2004)

${ }^{c}$ USDA

${ }^{\mathrm{d}}$ Fry et al. (2011)

${ }^{\mathrm{e}}$ Saxton et al. (1986)

Table 2-4 Calibrated soil moisture accounting parameters across the study area.

\begin{tabular}{ll}
\hline Parameters & Range \\
\hline Lag Time (min) & $5500-9500$ \\
GW 1 coefficient (h) & $100-800$ \\
GW 1 Storage (mm) & $40-155$ \\
GW 1 Percolation $(\mathrm{mm} / \mathrm{h})$ & $0.01-0.1$ \\
GW 1 Storage Coefficient $(\mathrm{h})$ & $500-2500$ \\
\hline
\end{tabular}

GIS and STATSGO data bases have been increasingly used for parameter estimation in hydrologic studies (e.g. Senrath et al. 2000, Xu et al. 2001, Fortin et al. 2001, Garbrecht et al. 2001), as was done in this study. Only the texture properties of the first STATSGO layer are considered for computational efficiency. The soil texture properties ( $\%$ clay, $\%$ silt and $\%$ sand) of each sub-basin are obtained by using a weighted average method; a weight is assigned to each soil class - defined by a distinct percent of sand, silt and clay - based on the area it intercepts on the sub-basins. The soil texture hydraulic properties calculator (Saxton et al. 1986) is used to calculate the Field Capacity (FC) and Permanent Wilting Point (PWP) of the sub-basin of interest. FC is the upper limit of relative volume of water stored in the soil, while PWP is the lower limit. The difference between the two limits is available water (AW), reported in $\mathrm{cm}^{3}$ of water per $\mathrm{cm}^{3}$ of soil (Saxton et al. 1986). Table 2-5 shows an example of computing the soil storage in one of Kalamazoo watershed sub-basins. The soil storage volume is calculated for a depth of $60.96 \mathrm{~cm}$ ( $2 \mathrm{ft}$ soil), which is about the maximum root depth of most 
vegetation except trees. In estimating impervious surface area, only half of the estimated developed land area is assumed to be impervious, accounting the disconnected impervious area as described in (Han and Burian 2009). Lakes and reservoirs are not modeled explicitly; in order to account for this additional storage in some lake-dominated sub basins, surface storage values up to $90 \mathrm{~mm}$ are adopted.

Table 2-5 Soil texture properties of subbasin 2, Kalamazoo River watershed.

\begin{tabular}{lcclclc}
\hline MUID & \% Sand & \% Clay & $\begin{array}{l}\text { Field capacity } \\
\text { (FC) }\end{array}$ & $\begin{array}{l}\text { Permanent } \\
\text { wilting point } \\
\text { (PWP) }\end{array}$ & $\begin{array}{l}\text { Available } \\
\text { water } \\
\text { (AW) }\end{array}$ & Weight \\
\hline MI045 & 54 & 13 & 0.22 & 0.1 & 0.12 & 0.20 \\
MI034 & 58 & 13 & 0.22 & 0.1 & 0.11 & 0.55 \\
MI022 & 0 & 0 & 0 & 0 & 0 & 0.04 \\
MI043 & 56 & 12 & 0.22 & 0.1 & 2.03 & 0.21 \\
\hline
\end{tabular}

Note: Soil storage $(\mathrm{mm})=$ Average available water $\times$ Soil depth $(609.6 \mathrm{~mm})$ or $(2 \mathrm{ft})$

$=(0.2 \times 0.12+0.55 \times 0.11+0.04 \times 0+0.21 \times 2.03) \times 25.4 \times 24$

$=66.87 \mathrm{~mm}$.

Potential evapotranspiration (PET) is the measure of the ability of the atmosphere to remove water from the surface through the process of evaporation and transpiration, assuming unlimited water availability. However, water availability on the surface is limited in reality, and evapotranspiration (ET) requires energy for the evaporation process. Approximately $80 \%$ of this energy comes from the sun and the rest from wind and the gradient of vapor pressure. Wind enables water to be removed from the surface by the process of eddy diffusion, and ET is also dependent on the gradient of vapor pressure between the ground surface and the layer of atmosphere receiving the evaporated water (Pidwirny 2006).

Although the surface energy budget is critical to estimating evapotranspiration (see Lofgren et al. 2011), ET has been estimated for watersheds in various ways (e.g. Sellers et al. 1996, Xu and Singh 2001, Monteith 1981). HEC-HMS requires either specifying monthly average PET values or parameters for the Priestly-Taylor method to model ET. The Priestley-Taylor method, although capable of capturing temporal variability, requires solar radiation, crop coefficient, and dryness coefficient inputs to represent climatic and soil water conditions during the simulation. The monthly average PET method is selected for this study due to data limitations, with PET estimated using the Hamon method as follows (Hamon 1963), shown in equations 2-1 and 2-2: 


$$
\begin{gathered}
\text { PET }=29.8 D \frac{e_{a}^{*}\left(T_{a}\right)}{T_{a}+273.2} \\
e_{a}^{*}\left(T_{a}\right)=\left(2.7489 * 10^{8}\right) * \exp \left(\frac{-4286}{\left(T_{a}+242.79\right)}\right)
\end{gathered}
$$

This method is only a function of daylight hours $(D)$, air temperature $\left(T_{a}\right)$ in degree Celsius and saturated vapor pressure $\left(e_{a}\right)$, which itself is a function of air temperature, and thus does not account for wind or the vapor pressure gradient. The daily PET values are computed using Equations 2-1 and 2-2, and values are summed over each month to obtain average monthly PET values for input to HEC-HMS. Although ET is not modeled in HEC-HMS in any time step when precipitation occurs, the water available for ET remains available in the next time step, so this would compensate to some extent over a longer period. A comparison of monthly ET computed by HEC-HMS and LBRM showed that values are reasonably close (within 10-20\%) for each month of the year. For more details, see Gyawali (2010).

In reality, ET from the canopy, soil, and the surface (i.e., ponded water) occurs simultaneously. However, ET calculation is not coupled between these layers in HECHMS. Instead, HEC-HMS assumes ET occurs from the following components in the order: canopy, surface, and soil. In addition to the SMA parameters and meteorological inputs, the initial canopy, soil and ground water storage levels (0-100\%) are defined for each sub-basin to account for initial conditions. Optionally the model may be allowed to run for a spin-up time period so that seasonal cycles are established.

\subsection{Results}

\subsubsection{Snow model calibration}

The watersheds considered in this study have varying climatology, land use and seasonal snow cover (Table 2-1, Figure 2-4). The Kalamazoo and Maumee watersheds have less snow cover and ephemeral snow content, resulting in flashy snow hydrographs compared to the more sustained snow cover in the St. Louis watershed. Snow models for each watershed are calibrated for the period 2004-2009 using a manual calibration approach to obtain a best fit with the SNODAS SWE product. The final calibrated snow model parameters values are shown in Table 2-6. Other parameter estimates are assigned similar values across all three watersheds. For details of parameter definitions and typical values, see USACE (2010). The temperature index method is governed by the concept that the precipitation falls as rain under warm air temperatures and as snow or ice under cold temperatures, with solid precipitation accumulating in the snow pack. A temperature 
threshold, denoted by PX, distinguishes snowfall from rainfall. Similarly, base temperature distinguishes melt from non-melt periods. The PX temperature and base temperature are set to $1{ }^{\circ} \mathrm{C}$ and $0{ }^{\circ} \mathrm{C}$, respectively. 

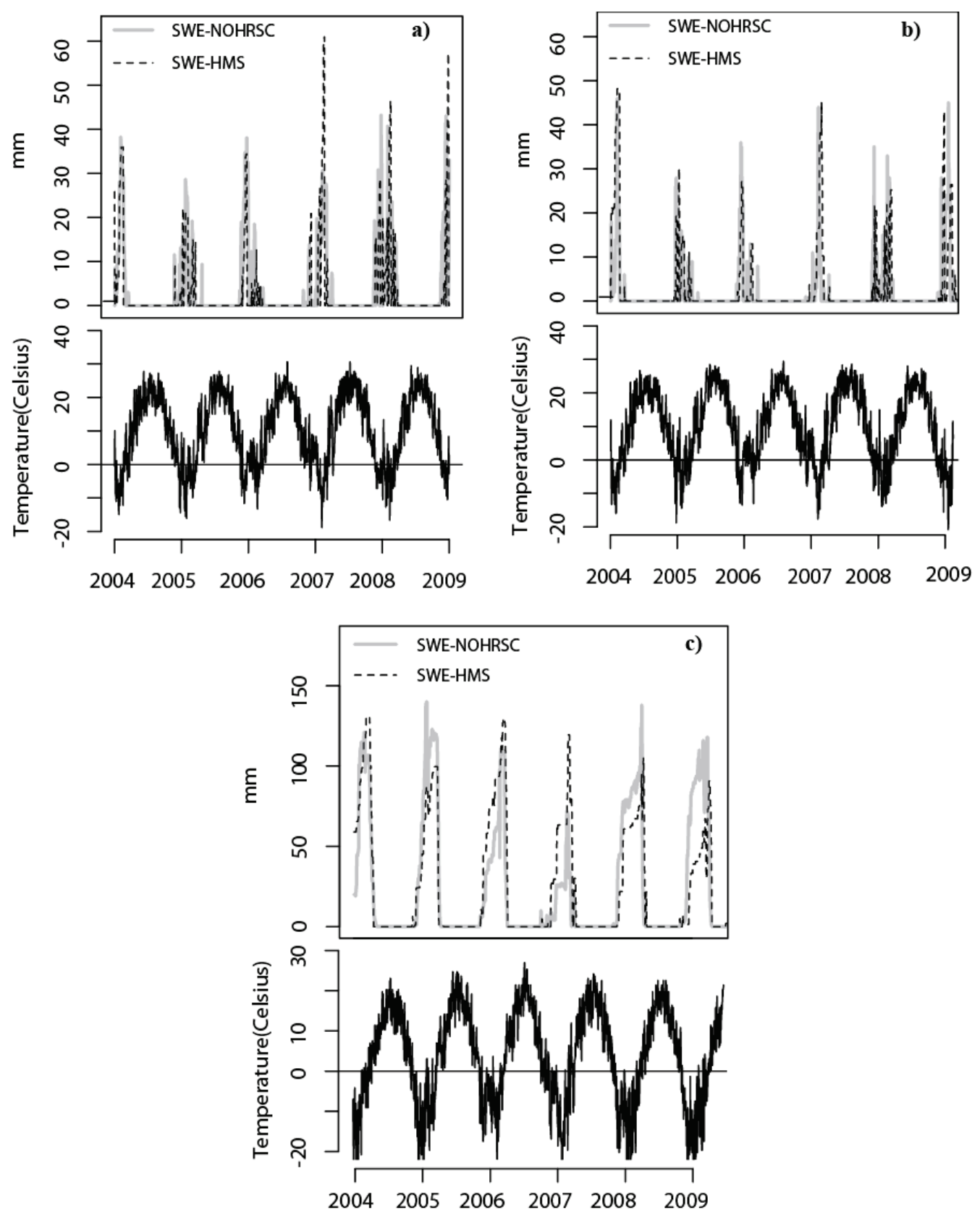

Figure 2-4 Calibrated snow water equivalent models of (a) Kalamazoo, (b) Maumee, and (c) St. Louis watersheds. 
The meltfactor may be constant or vary with time. Thin ephemeral snow cover has a constant melt factor, while more sustained cover has a variable melt factor.

Accordingly, a constant melt factor is used for the Kalamazoo and Maumee watersheds, while a variable melt factor is used for the St. Louis watershed. A variable melt factor recognizes that as snowpack matures, heat transfer rates change. This seasonal variation of the melt rate is indexed by the Antecedent Temperature Index function (ATIMR). ATIMR values are calibrated in this study to obtain a best fit to the SNOWDAS SWE product. The calibrated values in Table $2-6$, although variable across watersheds, are within the recommended range of 1.8 - $3.7 \mathrm{~mm} / \mathrm{C}$-day (USACE, 2010). As expected, the calibrated ATIMR of the warmer watershed, Maumee, was found to be higher than that of Kalamazoo. Similarly, the ATI cold function, an index to the snow temperature near the surface, is calculated assuming approximation to transient heat flow equations. Typical ATI cold function values associated with ATIMR $(0.45-1.125 \mathrm{~mm}$ per degree Cday or 0.01-0.025 inches per degree F day), given in USACE (2010), are also used.

Table 2-6 Calibrated snowmelt model parameter estimates.

\begin{tabular}{llccccc}
\hline Watershed & $\begin{array}{c}\text { Interior } \\
\text { basin }\end{array}$ & $\begin{array}{c}\text { Wet melt } \\
\text { rate } \\
(\mathbf{m m} / \mathbf{C}- \\
\text { day) }\end{array}$ & $\begin{array}{c}\text { Rain } \\
\text { rate limit } \\
(\mathbf{m m} / \mathbf{d a y})\end{array}$ & $\begin{array}{c}\text { ATI melt } \\
\text { rate } \\
(\mathbf{m m} / \mathbf{C}- \\
\text { day) }\end{array}$ & $\begin{array}{c}\text { ATI cold } \\
\text { rate } \\
\text { coefficient }\end{array}$ & $\begin{array}{l}\text { Water } \\
\text { capacity } \\
\mathbf{( \% )}\end{array}$ \\
\hline Kalamazoo & Subbasin3 & 4.2 & 0.5 & 2.4 & 0.4 & 5 \\
Maumee & Augalize & 4.2 & 0.4 & 3.8 & 0.4 & 3 \\
St. Louis & Nemadji & 3.9 & 0.6 & $0.2-3$ & 0.5 & 5 \\
\hline
\end{tabular}

Due to space limitations, only snow model results (daily SWE) for an interior subbasin of each watershed are shown in Figure 2-4. Although the temperature index method does not explicitly account for processes like wind, net radiation, layers of snowpack, or sublimation from and condensation onto the snow pack, the calibrated models provide a reasonable representation of snow processes, both ephemeral and sustained, in each of the study watersheds. Snowmelt may be calculated as the difference in SWE between two consecutive days, $\operatorname{SWE}(\mathrm{t})$ - SWE(t-1), with a positive value indicating snowfall and a negative value indicating melt. The contribution of average annual NOHRSC snowmelt to runoff varied from $33.3 \%$ to $72.7 \%$, compared to similar estimates from HEC-HMS ranging from $24.5 \%$ to $65.8 \%$, as shown in Table $2-7$. Snowmelt computed by LBRM is also shown for comparison. 
Table 2-7 Comparison of average annual runoff and contribution of snowmelt to runoff.

\begin{tabular}{cccccc}
\hline Watershed & $\begin{array}{c}\text { Avg. } \\
\text { annual } \\
\text { Precip. } \\
\text { (mm) }\end{array}$ & $\begin{array}{c}\text { Avg. } \\
\text { annual } \\
\text { Runoff } \\
(\mathbf{m m})\end{array}$ & $\begin{array}{c}\text { Avg. } \\
\text { annual } \\
\text { HMS } \\
\text { snowmelt } \\
\text { (mm) }\end{array}$ & $\begin{array}{c}\text { Avg. annual } \\
\text { LBRM } \\
\text { snowmelt } \\
(\mathbf{m m})\end{array}$ & $\begin{array}{c}\text { Avg. annual } \\
\text { NOHRSC } \\
\text { snowmelt } \\
\text { (mm) }\end{array}$ \\
\hline Kalamazoo & 991 & 321 & $132(41.1 \%)$ & $159(49.5 \%)$ & $134(41.7 \%)$ \\
Maumee & 904 & 327 & $80(24.5 \%)$ & $88(26.9 \%)$ & $109(33.3 \%)$ \\
St. Louis & 807 & 249 & $164(65.8 \%)$ & $108(43.3 \%)$ & $181(72.7 \%)$ \\
\hline
\end{tabular}

Note: Snowmelt is listed with the percentage immediately following in parentheses.

\subsubsection{Streamflow calibration and validation}

The sub-basin streamflow models are calibrated for the period 2007-2009, validated for the period 2004-2006, and finally recalibrated, adjusting for the initial conditions at the beginning of 2004 (Figure 2-5). The validation approach taken for this study was simply to extend the time window of the calibration period back in time, without adjusting model parameters, to see how closely the model matches the observed data. D ue to the potential for ovefitting a model to observed data, validation results provide a better estimate of model predictive ability. Since the model was validated back in time, the initial conditions at the beginning of the simulation ( $\mathrm{J}$ anuary 1,2004$)$ had to be corrected, and some parameters were adjusted to better estimate low flows during the initial period of model run. These adjustments are apparent in the recalibrated model results.
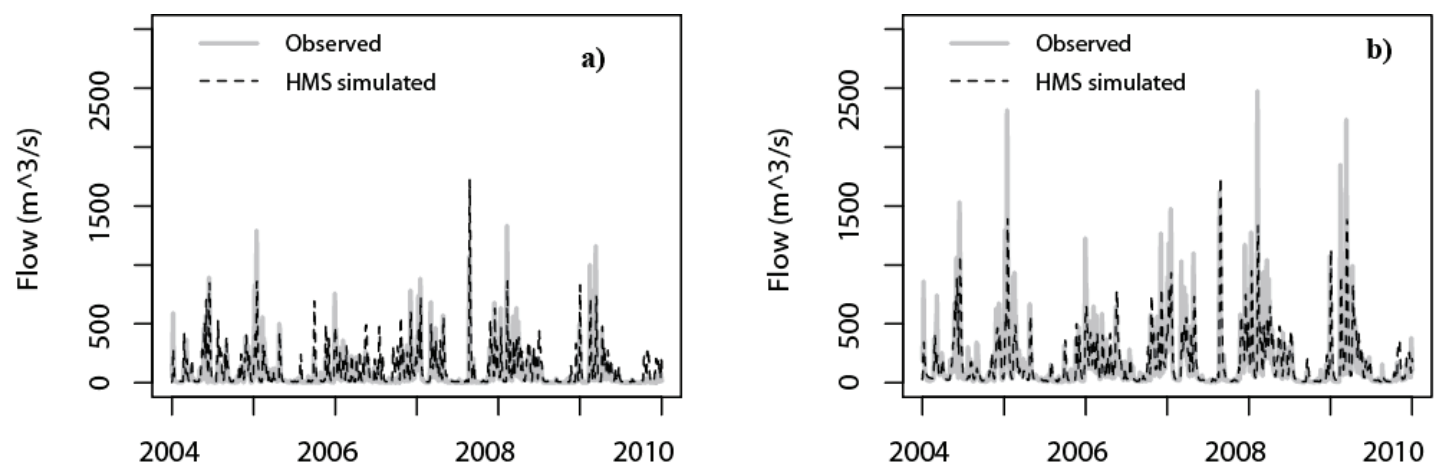

Figure 2-5 Simulated and observed hydrographs of Maumee watershed at (a) an interior watershed- Augalize, and (b) the outletEower Maumee. 
A manual calibration approach was deemed to yield better fitting hydrographs than the automatic optimization methods (Nelder-Mead simplex method and the univariate gradient search) provided in $\mathrm{H}$ ECH MS. The optimization methods minimized the defined objective function, e.g. sum of squared errors, but at times over-fit or underfit the low and high flows. D ue to space limitations, only two sets of calibrated and validated hydrographs of the Maumee and Kalamazoo River watershed are shown, including those for one interior basin and the outlet (Figure 2-5 and Figure 2-6). For additional calibrated hydrographs, see Gyawali (2010).
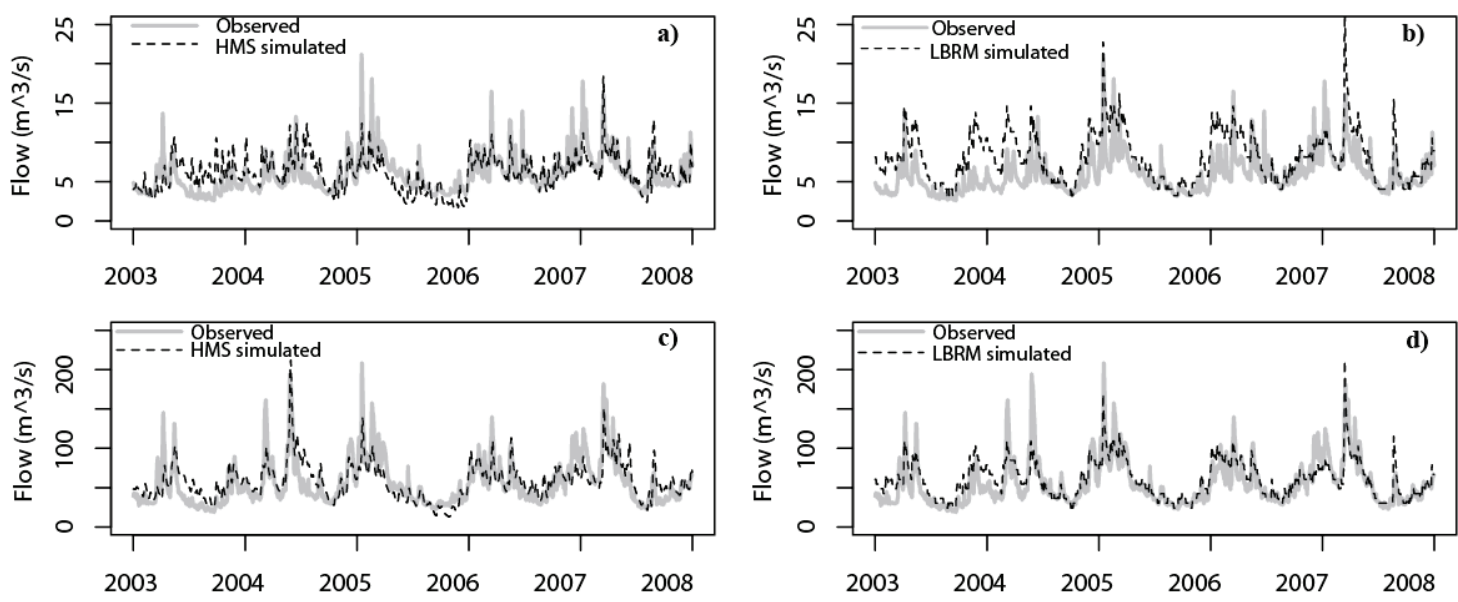

Figure 2-6 H ydrographs at junction 1: (a) observed, H EC-H MS; (b) observed,saakad LB RM hydrographs at the outlet of Kalamazoo Riverwatershed; (c) observed, H ECH MS; (d) observed, LB RM hydrographs.

It can be seen from the hydrograph comparisons that the low flows are relatively well captured by H EC-H MS, but winter and early spring peak flows tend to be underestimated. To investigate the cause of this discrepancy, snowmelt hydrographs from $\mathrm{H}$ EC-H MS and the NO H RSC SWE product (Figure 2-4) are compared in Figure 2-7. As expected, the Kalamazoo and Maumee watersheds, which have ephemeral snow cover, had most peak melt events occur in late $\mathrm{D}$ ecember and early $\mathbf{J}$ anuary, while peak melt events in the St. Louis watershed (not shown) tended to occur in late March and early April. Although these results were consistent between the NO H RSC SWE product and $\mathrm{H}$ EC-H MS, a higher frequency of snowmelt events was indicated by the NO $\mathrm{H}$ RSC product. In other words, $\mathrm{H}$ EC-H MS produced fewer days with snowmelt, but the melt events tended to be larger in magnitude than events estimated directly from the NO $\mathrm{H}$ RSC product. This may be the result of failing to account for diurnal variability in temperature in the $\mathrm{H}$ EC-H MS model, but it does not help tquain the discrepancies in winter and early spring streamflows. 

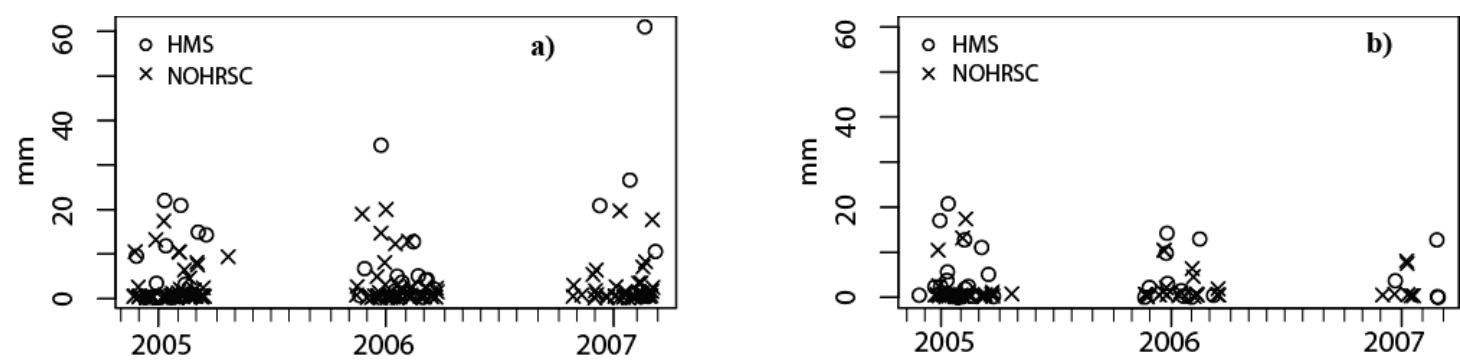

Figure 2-7 Timing and magnitude of snowmelt, derived from NO $\mathrm{H}$ RSC SWE and $\mathrm{H}$ MS simulated SWE: (a) Kalamazoo, (b) Maumee.

O verall, based on SWE hydrographsF(igure 2-4), snowmelt hydrographs (Figure 2-7), and estimates of annual snowmelt (Table 2-7), these results indicate that a good representation of seasonal SWE accumulation and depletion may not necessarily result in good estimates of snowmelt on a daily basis. $\mathrm{H}$ owever, no bias in the timing of $\mathrm{H}$ EC$\mathrm{H}$ MS snowmelt was detected, and thus the discreppcies in late winter and early spring peak flows cannot be attributed to systematic errors in the snowmelt model. Apart from the limitations in the calibration procedure, input data uncertainties in the streamflow model, and limited representation of the energy budget, some differences between the observed and simulated peaks may be caused by undocumented increases in river stage due to ice effects, although further investigation would be needed to attribute discrepancies to this phenomenon.

\subsubsection{Comparison with LBRM}

LB RM and $\mathrm{H} \quad \mathrm{EC}$-MS models are compared in order to assess watershed model performances and limitations for climate change impact studies. LB RM is an established hydrologic model for the Great Lakes region, which has been used for a number of applications (e.g., Chao 1999, Lofgren et al. 2002, Croley et al. 2005, Watk ns et al. 2007, H e et.al. 2007, Angel and Kund 2010). Relevant to this study, LB RM has been applied to all 121 Great Lakes watersheds, including the Kalamazoo, Maumee and St. Louis River watersheds studied herein. It has been calibrated and validated for a period of more than 30 years, using an automated calibration procedure (univariate gradient search) to minimize RMSE at the mouth of each watershed (Croley, 2002). In contrast, the HEC$\mathrm{H}$ MS models developed in this study are calibrated manually using only three years of data. In addition to being calibrated over different time periods, the models are developed at different spatial resolutions. For comparisons, the simulated $H$ ECH MS andB RM flows are evaluated for a common validation period (2004 to 2006), and comparisons are made at the mouth of the watershed and also at the sub-basin outlets, with the LB RM flows within the watershed estimated using a simple drainage area ratio approach. 
The model comparison for the Kalamazoo River watershed at both an interior sub-basin outlet and at the watershed mouth is shown in Figure 2-6. It is evident from the hydrographs that the HEC-HMS model does a comparatively good job of simulating streamflow at a finer spatial scale. Several goodness-of-fit indices, described in the Table 2-8, are computed for the HEC-HMS and area-scaled LBRM simulated hydrographs at each gauge location within the watersheds. 
Table 2-8 Objective functions used to compare area scaled LBRM and HMS models.

\section{Objective functions $\quad$ Equations $^{\mathrm{a}}$}

1 Sum of absolute errors

(Stephenson,1979)

2 Sum of squared residuals (Diskin and Simon, 1977)

$$
\mathrm{Z}=\sum_{i=1}^{N Q}\left|q_{o}(i)-q_{s}(i)\right|
$$

$$
\mathrm{Z}=\sum_{i=1}^{N Q}\left[q_{o}(i)-q_{s}(i)\right]^{2}
$$

3 Percent error in peak

$$
Z=\{100 / N Q\} \sum_{i=1}^{N Q}\left|\frac{q_{o}(\text { Peak })-q_{s}(\text { Peak })}{q_{o}(\text { Peak })}\right|
$$

4 Peak-weighted root mean square error objective function (USACE, 1998)

$$
\mathrm{Z}=\left\{\frac{1}{\mathrm{NQ}}\left[\sum_{i=1}^{N Q}\left[q_{o}(i)-q_{s}(i)\right]^{2}\left(\frac{q_{o}(i)+q_{o}(\text { mean })}{2 q_{o}(\text { mean })}\right)\right]\right\}^{\frac{1}{2}}
$$

5 Nash-Sutcliffe model efficiency coefficient (Nash and Sutcliffe, 1970)

$$
\mathrm{Z}=1-\frac{\sum_{i=1}^{N Q}\left[q_{o}(i)-q_{s}(i)\right]^{2}}{\sum_{i=1}^{N Q}\left[q_{o}(i)-q_{o}(\text { mean })\right]^{2}}
$$

${ }^{\mathrm{a}} Z=$ objective function; $N Q=$ number of computed hydrograph ordinates (1096 days); $q_{\mathrm{o}}(t)=$ observed flows; $q_{\mathrm{s}}(t)=$ calculated flows, computed with a selected set of model parameters; $q_{\mathrm{o}}($ peak $)=$ observed peak; $q_{\mathrm{o}}($ mean $)=$ mean of observed flows; and $q_{\mathrm{s}}$ $($ peak $)=$ calculated peak. All flows have the unit of cubic meters per second $(\mathrm{cms})$

The results are summarized in Table 2-9 for the validation period. Note that smaller index values indicate a better match between simulated and observed flows, except for the Nash-Sutcliffe coefficient which is maximized to achieve the best fit. 

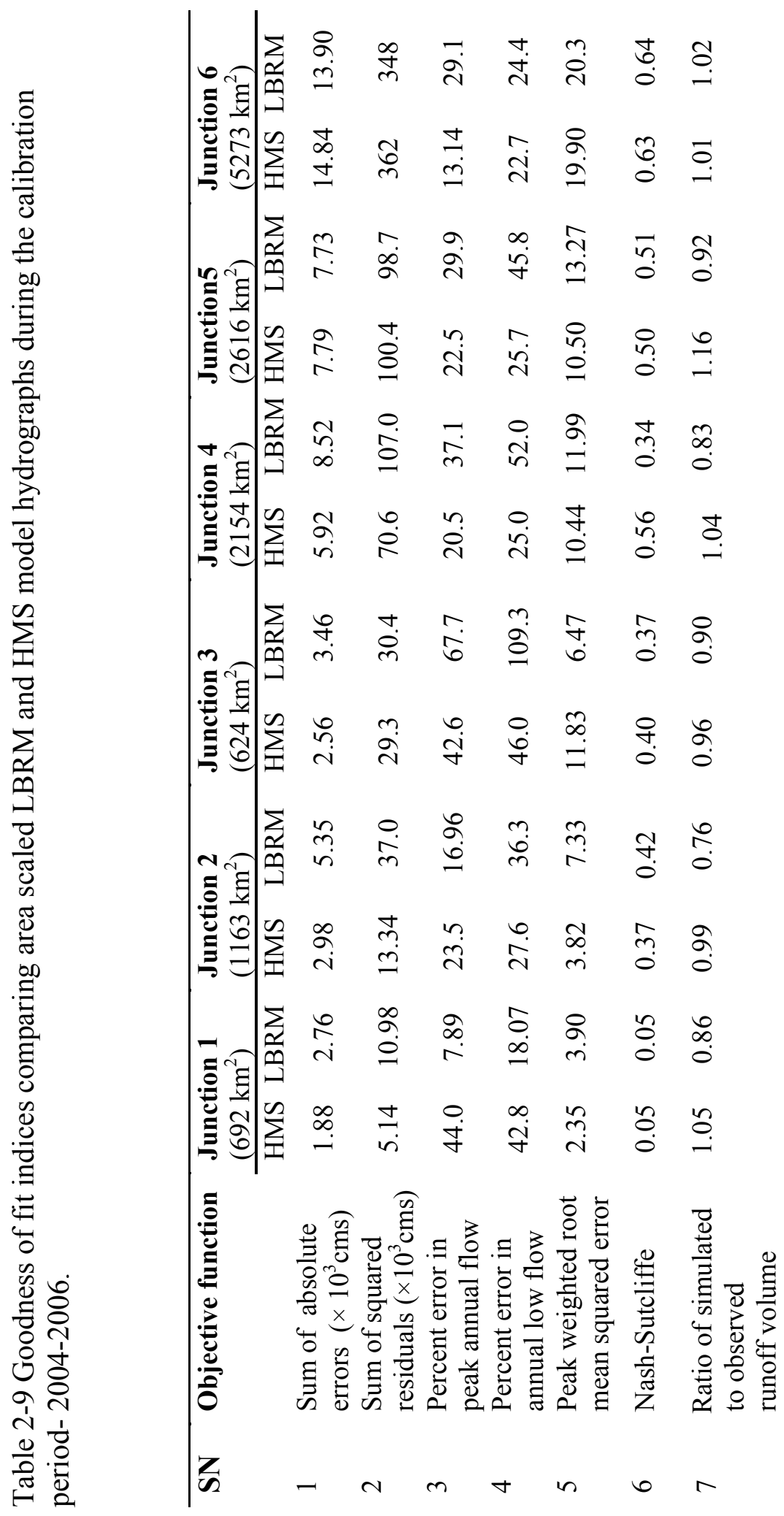
It is found that the HEC-HMS model generally provided better results than LBRM according to these indices, with some exceptions. For example, the sum of absolute errors in HMS results is less than that of the LBRM results for all of the upstream sub-basins. However, the sum of absolute errors is slightly greater in HECHMS results at the two downstream sub-basins. For most sub-basins, the peakweighted root mean square error is found to be lower in the HEC-HMS results than in the LBRM results. Although the HEC-HMS and LBRM model Nash-Sutcliffe coefficients are similar, with HEC-HMS performing better than LBRM in most instances, the values from both models indicate a great deal of model uncertainty. The Nash-Sutcliffe coefficient at Junction 1 in the validation period is the lowest observed, just 0.05 for both LBRM and HMS models. This indicates that, for practical purposes, the observed mean is as accurate a predictor as the model in both cases. In general, the Nash-Sutcliffe coefficient improves as the basin area increases, which may indicate that a daily time step is not appropriate for the smaller sub-basins. A finer time-step may be needed to adequately model rainfall-runoff. However, estimates of basin lag time obtained from calibration ranged from about 4 days for the smaller subbasins to 6 days for the larger sub-basins. Thus, the poor performance in smaller subbasins may also partly be due to the relative sparsity of precipitation gages. According to Schaake (1981), the recommended number of precipitation gages $(\mathrm{N})$ for estimating mean areal precipitation is given by $\mathrm{N}=0.6(\mathrm{~A})^{\wedge} 0.3$, where $\mathrm{A}$ is area in square kilometers. Accordingly, 8 precipitation gages are recommended for the $5,273 \mathrm{~km}^{2}$ Kalamazoo River watershed, but 4 gages are recommended for a sub-basin just 1/10 this size.

Both HEC-HMS and LBRM models reasonably estimate runoff volumes, as shown in the last row of Table 2-9, with HEC-HMS showing some modest improvements over LBRM. This indicates both models are applicable to climate change studies showing runoff volume responses to changing climate.

Additionally, both models simulate seasonal snow processes reasonably well for the Kalamazoo and Maumee watersheds (Table 2-7). However, HEC-HMS more accurately simulates snowmelt in the St. Louis watershed. Although both models use a temperature index snow algorithm, HEC-HMS allows calibration to the SNODAS SWE product and accounts for melt rates, cold content and antecedent conditions, making it more appropriate for watersheds with sustained snow cover. Further motivation for using HEC-HMS models for planning studies is that it allows a more spatially detailed watershed analysis, with provision for changing land use characteristics and predicting streamflow at additional gauging locations, while the lumped-parameter LBRM has been calibrated to predict streamflow only at the mouth of each watershed. The Kalamazoo River basin is predominantly an agricultural watershed, and average land use characteristics at the HUC-12 scale do not vary much throughout the (HUC-8) watershed. As a result, the area-scaled LBRM model also captures the low flows reasonably well, but in general not quite as well as does the 
HEC-HMS model. Area-scaled outputs may not predict flows as well for urban areas, or watersheds with more varying land use and soil type characteristics. The judgment to choose the correct model scale depends largely upon the physical characteristics of the watershed and the purpose of the model application.

\subsection{Conclusion}

The focus of this study was hydrologic model development, calibration and validation of continuous HEC-HMS models, including soil moisture accounting and snow model algorithms, for three Great Lakes watersheds with varying climatic and land use characteristics. Since calibrating a hydrologic model is recognized as a complicated process and a potentially onerous task (Wagener et al. 2001, Beven and Freer 2001, Duan et al. 1992, Kuczera and Parent 1998, Montanari and Brath 2004), and because the HEC-HMS models are intended for use in climate and land use change studies, an attempt was made to estimate parameters based on physical watershed characteristics to the extent possible. Comparison with an established hydrological model, the NOAA Large Basin Runoff Model (LBRM), demonstrates that in addition to some modest improvements from increased spatial resolution, HECHMS allows some flexibility to change physically based parameters and model climate change scenarios with a more process-based snow algorithm. It is also demonstrated using several goodness-of-fit indices that it may be insufficient to conclude model superiority based only on a few commonly used indices such as NashSutcliffe or Root Mean Square Error. The correct choice of model largely depends on its application. For example, a model with low percent error in peak discharges may be preferred for floodplain management and flood control design purposes, but model selection based on other objective functions would likely be appropriate for streamflow depletion or drought studies.

Comparison of simulated and observed daily SWE and streamflow hydrographs indicates that both HEC-HMS and LBRM models can be used to make water availability predictions at seasonal and annual time scales. Both models simulate seasonal snow processes reasonably well for the Kalamazoo and Maumee River watersheds, but HEC-HMS more accurately simulates snowmelt in snowdominated St. Louis watershed due to its ability to account for varying melt rates, cold content and antecedent conditions. However, both models showed poorer performance for smaller drainage areas, and also missed a number of peak discharges in late winter and early spring. Since estimates of basin lag time ranged from about 4 to 6 days, a daily time step should be appropriate for most runoff events, and the poor performance in smaller sub-basins may be primarily due to the relative sparsity of precipitation gages (Schaake 1981). A shorter time step would capture diurnal variability in temperature and its effects on snowmelt, but based on the daily SNODAS SWE product used for calibration of the snow model, the discrepancies in peak discharges could not be attributed to systematic errors in snowmelt modeling. 
Additional challenges that need to be addressed in hydrologic modeling studies include estimating ET, sublimation and condensation to snowpack; quantifying the effects of slope, aspect and forest cover on snowmelt; and modeling energy transfer from rain on snow. These estimates are particularly important in snow-dominated areas. This study uses the Hamon (1963) method to compute potential ET as a function of temperature, daylight hours, and saturated vapor pressure, but the need for an improved method for ET estimation is recognized. In reality, ET is also a function of canopy cover and vegetation, which are seasonally varying. Although data intensive, the Priestly-Taylor method incorporates seasonally varying canopy and vegetation cover to account for the growing season, which could improve simulation model results. Other parameter inputs (e.g., infiltration capacity, surface storage) are considered constant throughout the simulation period but, in fact, may fluctuate on a daily or seasonal basis. To address this issue, Fleming and Neary (2004) developed seasonal models.

This study also contributes to literature describing SMA and the application of an extended temperature-index snowmelt algorithm using HEC-HMS. Improved remote surveillance techniques, specifically the availability of NORHSC's estimated daily snow cover data and SNODAS SWE product, enabled calibration of the snowmelt model, providing better a description of the hydrological regime. Explicit representation of snow processes is important for many water resources studies, especially for climate change studies in Great Lakes watersheds.

Finally, the calibrated HEC-HMS model is capable of making predictions only at the selected stream gauge locations, unless a simple area-scaling approach is applied to estimate flows at ungaged locations. Regional statistical approaches, e.g., regional regression based on watershed and hydro-climatic characteristics (e.g., Vogel et al. 1992), can potentially be useful to estimate flow statistics at ungaged locations. Such statistical models may potentially be an alternative, or complement, to process-based hydrologic models for policy analysis for climate and land use change impact mitigation. 


\section{Regional Regression Models for Hydro-Climate Change Impact Assessment ${ }^{2}$}

\subsection{Abstract}

Hydro-climatic impacts in water resources systems are typically assessed by forcing a hydrologic model with outputs from general circulation models (GCMs) or regional climate models (RCMs). Challenges of this approach include maintaining a consistent energy budget between climate and hydrologic models and also properly calibrating and verifying the hydrologic models. Subjective choices of loss, flow routing, snowmelt and evapotranspiration (ET) computation methods also remarkably increase watershed modeling uncertainty and thus complicate impact assessment. An alternative approach, particularly appealing for ungauged basins or locations where record lengths are short, is to directly predict selected streamflow quantiles from regional regression models that include physical basin characteristics as well as meteorological variables output by climate models (Fennessey, 2011). In this study, regional regression models are developed for the western Great Lakes states using ordinary least squares (OLS) and weighted least squares (WLS) techniques applied to selected Great Lakes watersheds. Model inputs include readily available downscaled GCM outputs from the Coupled Model Inter-comparison Project phase 3 (CMIP3). The model results, presented in a probabilistic context of multi-model predictions, provide insights to potential model weaknesses, including comparatively low runoff predictions from hydrologic models using temperature proxy potential evapotranspiration (PET) approaches.

Keywords: Climate change, Great Lakes basin, Regional regression models, Hydrologic models, Hydro-climatic framework, Temperature proxy PET

\footnotetext{
2 The material contained in Chapter 3 is being submitted to Hydrological Processes
} 


\subsection{Introduction}

Given the growing consensus that climate change is already occurring, water managers, consultants, researchers and government agencies are increasingly using climate model outputs for research, decision support and impact assessments (Mote et al., 2011). A typical approach to project climate change impact on water resources systems is to downscale a number of GCM or RCM outputs as inputs (forcings) to a hydrologic model to evaluate hydrologic impacts. Although GCMs are the most advanced and complex climate models, it is acknowledged they are limited in their ability to provide accurate working precipitation and temperature variables at relevant spatial and temporal resolutions, thereby rendering many hydrological climate change impact studies vague at best (e.g., Prudhomme et al., 2002; Sharma et al., 2011; Xu et al., 1999). Dynamic and statistical downscaling of GCM outputs can provide finer spatial resolution information relevant for climate change impact assessment (Wilby and Fowler, 2010), but the ability to provide detailed accurate predictions at relevant resolutions is debatable (Brown, 2010; Kerr, 2011; Pielke and Wilby, 2012). Furthermore, impact assessment is complicated by the variety of climate and hydrological models available.

A large number of hydrologic models, e.g., HEC-HMS (USACE, 2010), LBRM (Croley, 2002), SWAT (Rosenthal et al., 1995), VIC (Liang et al., 1994), and CEQUEAU (Couillard et al., 1988), have been developed and used for different water resources applications and hydro-climatic settings. These models range in complexity, but generally use precipitation and temperature as inputs and provide runoff as the primary output. Physically based models representing processes including base flow, snowmelt, evapotranspiration, surface runoff, and channel routing may either simulate individual events or employ continuous simulations over longer timeframes. The various hydrologic models and choice of associated loss, snowmelt, and PET computation methods can yield significant differences in runoff predictions under the same climate change scenarios. Predicted runoff may also show seasonal variations, e.g., smaller changes in the wet period and larger changes in the dry period (e.g. Bae et al., 2011). Moreover, significant uncertainty may already exist in hydrologic predictions, even in the absence of climate change. For instance, Neff and Nicholas (2005) estimated that the uncertainty in lake level changes of the Great Lakes, using residual and component methods for net basin supply, varied from 5,000 to 21,000 cfs/month (approximately $7 \%$ to $60 \%$ of average net basin supply).

Many hydro-climate modeling studies have used a scenario-based approach (Mearns et al., 2001), typically forcing a single watershed model with a small number of downscaled GCM or RCM outputs. Because uncertainties are associated with every anticipated change in climate, as well as model selection and data inputs (Anderson et al., 2003; Bae et al., 2011; Déqué et al., 2007; Jones et al., 2000), a scenario-based approach using only a few downscaled projections provides a limited 
basis for hydrologic impact assessment. With downscaled climate model outputs from several GCMs and RCMs being more readily available, a multi-model ensemble approach using a suite of climate and hydrologic models is increasingly being used (Bae et al., 2011; Bastola et al., 2012).

Regional regression models are a potential alternative to estimating future streamflow by forcing hydrological models using climate model outputs. Regression models which incorporate basins' physiographic and climatic characteristics are developed herein and applied to directly estimate selected streamflow quantiles under historical and future climates (Fennessey, 2011). Like physically based hydrologic models, regression models are not without limitations. An important limitation of regression models is that they are only truly applicable over the range of parameter values employed in their development. However, this issue can be addressed using regression models in a regional context wherein space is traded for time (e.g. Singh et al. 2011). Herein, regression models are developed over the regional domain of the western Great Lake States, thereby covering a wide range of climate variables. The applicability of these models to predict flows in the near future period (2046-2065) is discussed in more detail in subsequent sections of this paper. In addition, it is implicitly assumed herein that the linear relation between streamflow percentiles and explanatory variables identified for the historical time period will hold under future climates; the extent to which this may affect model results is not addressed.

Predicting streamflow statistics of ungauged basins using regional regression models is not a new topic in hydrology. For hydro-climatic applications, previous regional regression studies (e.g., Ahearn, 2010; Archfield and Vogel, 2010) have used physical and meteorological information from the USGS hydro-climatic data network (HCDN) developed by Slack and Landwehr (1988). HCDN identifies high quality streamflow data at over 1500 gauges throughout the United States which were relatively unimpaired by human activities and regulation through water year 1988 . Although post-1988 diversions and streamflow regulations are not reflected in the HCDN, many studies, including Vogel et al. (1999), Douglas et al. (2000), Kroll and Vogel (2002), and Kroll et al. (2004), continued to employ the HCDN dataset to understand hydrologic responses to fluctuations in climate. This study uses the more recent dataset, Geospatial Attributes for Evaluating Streamflow, version II (GAGES II), compiled by Falcone et al. (2010b). Within the GAGES II dataset, unimpaired gauges with natural and near natural flows are identified as "reference gauges". Within the eight Great Lakes states, GAGES II identifies 292 reference gauges, while HCDN identifies 155 gauges with relatively unimpaired flow. Additional gauges in the GAGES II database are those that were added after water year 1988 or not included in the HCDN because of minimum length requirements (Falcone et al., 2010b). GAGES II also includes a more comprehensive set of watershed geo-spatial characteristics which will be used for development of the regression models. 
I $\mathrm{n}$ order to interpret climate change results and allow for a larger suite of climate and hydrological models, two physically based hydrologic models are applied in this study. The first, the $\mathrm{N} O \mathrm{OA} L \operatorname{arge~B}$ asin $\mathrm{R}$ unoff $\mathrm{M}$ odel (L B R M ), has been applied to the entire $\mathrm{G}$ reat $\mathrm{L}$ eslbasin (C roley, 2002). The second, the $U \mathrm{~S}$ AC E H EC $\mathrm{H}$ ydrologic $\mathrm{M}$ odeling $\mathrm{S}$ ystem $(\mathrm{H} \quad \mathrm{M} \quad \mathrm{S}$ ), has been applied to selected Great Lakes watersheds ( $\mathrm{G}$ yawali and $\mathrm{W}$ atk ins, 2013). B oth are forced using 1/ 8-degree resolution $(\sim 12 \mathrm{~km})$ bias-corrected constructed analogs (B C C A) from the World Climate R esearch Programme's (W C R P's) C oupled M-complarisoerProj ect phase 3 (C M I P3) rmbtilel climate dataset. $\mathrm{R}$ esults are compared with those from the regional regression approach. The proposed hydro-climatic framework is illustrated in $\mathrm{F}$ igure 3-1.

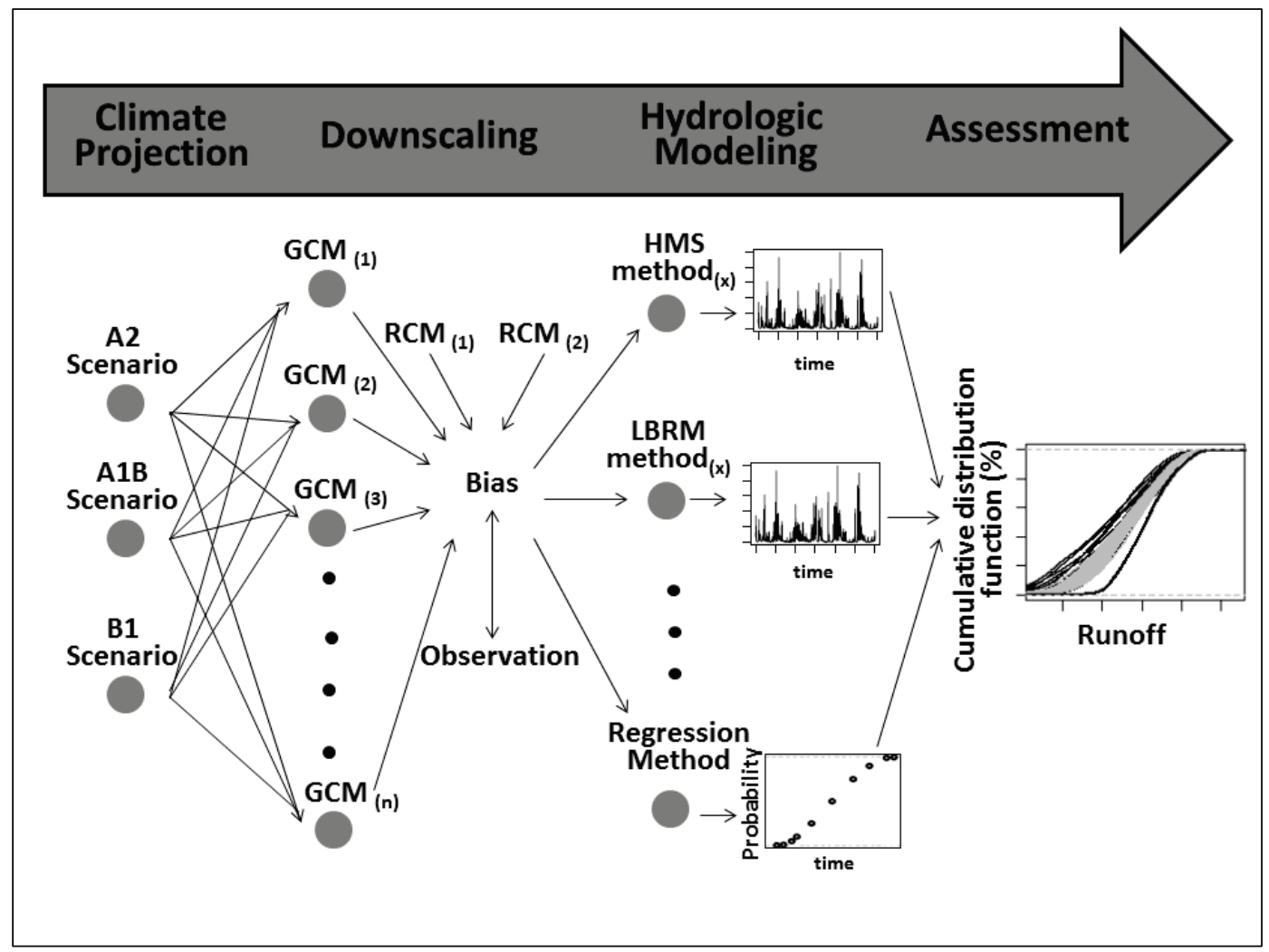

F igure 3-1 A schematic of the hydro-climatic modeling framework, including physically based and regression based hydrologic modeling approaches (Adapted from B ae et al., 2011).

The rest of the paper is divided into the following sections: The " $\mathrm{M}$ ethods" section details $\mathrm{G} \quad \mathrm{C}$-dArived climate simulations and the associated bias correction procedure, provides a brief overview of the physically based hydrologic models used herein, and describes ordinary least sq uares $\left(\begin{array}{lll}O & L & S\end{array}\right)$ and weighted least sq uares $\left(\begin{array}{lll}W & L\end{array}\right)$ 
techniques and data used for the development of regional regression models. The "Results" section presents a comparison of OLS and WLS model results with the results of the physically based watershed models in selected Great Lakes watersheds. Finally, limitations of physically based and regression models, conclusions of this work, and future research directions are presented.

\subsection{Methods}

\subsubsection{GCM derived climate simulations and bias correction}

An ensemble approach, based on CMIP3 projections for 53 climate scenarios derived from 16 different GCMs, was used to project the hydrological implications of climate change for two future periods, 2046-2065 and 2081-2100. CMIP3 multi-model projections at a daily time step were downscaled and bias corrected at $1 / 8^{\text {th }}$ degree $(\sim$ $12 \mathrm{~km}$ ) resolution over the contiguous United States using the BCCA technique (Maurer et al., 2010). BCCA is a hybrid method which first uses a quantile mapping bias correction on large scale data prior to using a constructed analogues (CA) approach at finer scales. The CA method is based on the premise that an analogue for a given coarse-scale daily weather pattern for a given GCM simulation can be constructed by combining the weather patterns from a library of historic patterns (Hidalgo et al. 2008). Although the BCCA procedure was already applied to the data compiled for the Great Lakes region, significant precipitation biases still exist, likely due to scale effects. Thus, for the purposes of this study, the residual precipitation bias was corrected using the delta correction method of the following form (Rasmussen et al. 2012):

$$
P_{\text {corr }}(i, j)=\Delta p(j) * P_{o b s}(i, j)
$$

where $P_{c o r r}$ is the daily precipitation after bias correction, $P_{o b s}$ is the observed daily precipitation in the historic period (1980-1999), and the index $i$ denotes the day $(i=1$, $2, \ldots 31)$ within month $j(j=1,2, \ldots 12)$. The correction factor $\Delta p(j)$ is calculated as the ratio of the climatological average of the GCM simulated future and historic precipitation of the $j^{\text {th }}$ month. As an example, ensemble mean monthly precipitation and standard deviations of 53 GCM simulations for historic and future periods, before and after residual precipitation bias correction, are presented for the Kalamazoo River basin in Michigan (Figure 3-2). 


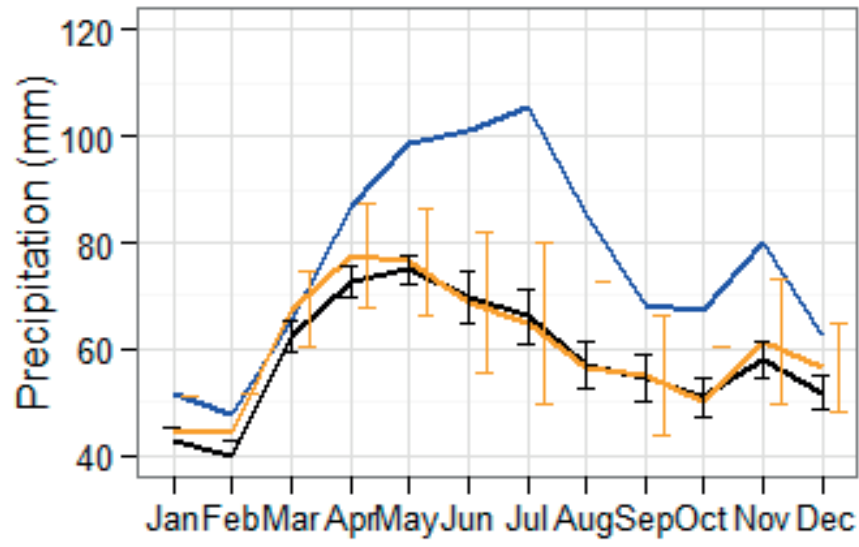

Period

- Observed (1/8 degree)

- CMIP3 (1980-1999)

- CMIP3 (2046-2065)

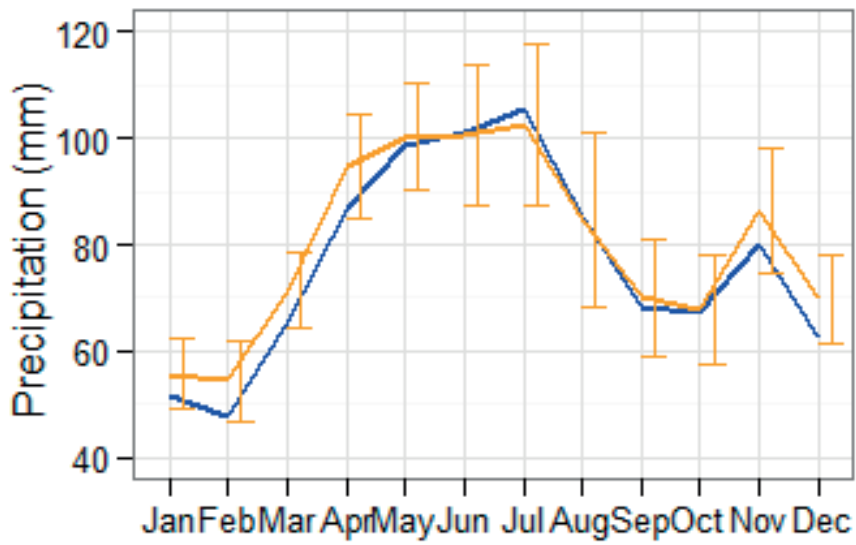

Period

- Observed (1/8 degree)

CMIP3 (2046-2065)

Figure 3-2 GCM projected precipitation changes showing observed 1/8th degree resolution precipitation (1980-1999), CMIP3 ensemble means (1980-1999, 2046-2065), and standard deviations about 53 climate scenarios: before correction for residual BCCA bias, a); after residual bias correction applying the change factor method, $b$ ). 


\subsubsection{Physically based hydrologic models}

As with climate models, no hydrological model convincingly claims superiority over other models for all types of applications and conditions (Beven, 2006; Duan et al., 2006; Smith et al., 2004). Different models have different strengths in capturing hydrologic processes, so relying on one model may misrepresent some hydrologic processes while accurately representing others (Duan et al., 2006). For example, a model with low percent error in peak discharges may be preferred for floodplain management and flood control design purposes, but model selection based on other objectives would likely be appropriate for streamflow depletion or drought studies.

This concept has motivated this study to better understand hydrologic uncertainty using multi-model methods, with two physically based hydrologic models-HEC-HMS and LBRM--and a regional regression model used for hydrological predictions. LBRM is an established hydrologic model for the Great Lakes region that has been used for a number of applications (e.g., Angel and Kunkel, 2010; Croley et al., 2005; DeMarchi et al., 2010; He et al., 2007; Lofgren et al., 2002; Watkins et al., 2007). It has been calibrated for a period of more than 30 years and validated for the land portion of the Great Lakes basin. The HMS models employed in this study were calibrated manually at multiple gauges using only three years of data (Gyawali and Watkins, 2013). Both the LBRM and HMS models use soil moisture accounting (SMA) loss methods, but they account for soil moisture in different ways -- LBRM considers two soil layers, while HMS considers tension soil moisture storage separately from soil moisture which may drain by gravity. LBRM is a 9-parameter model while the HMS models herein have 14 parameters and an additional 9 snowmelt parameters. In addition to being calibrated over different time periods, the models were developed at different spatial resolutions. Comparison of simulated and observed daily snow water equivalent (SWE) and streamflow hydrographs showed that both HMS and LBRM models can be used to make water availability predictions. Both models simulate seasonal snow processes reasonably well for the Kalamazoo and Maumee River watersheds, but HMS more accurately simulates snowmelt in the snow-dominated St. Louis watershed because of its ability to account for varying melt rates, cold content and antecedent conditions. For additional details of the development of HMS models and their comparison with LBRM, see Gyawali and Watkins (2013).

\subsubsection{Regional regression models}

Regional statistical streamflow models based on USGS National Water Information System (NWIS) gauged records are developed as an alternative to the more complex physically based hydrologic models. Selected streamflow quantiles are regressed against topographic, climatic and geological characteristics of the unimpaired watersheds with natural and near natural flows, identified as "reference 
gauges" within the GAGES II dataset. Relationships between daily streamflow quantiles and physical basin characteristics are developed using OLS and WLS regression using the statistical software package CRAN R (2012).

\subsubsection{OLS and WLS regression}

Given a dependent variable $Q$ and a number of independent variables $X_{1}, X_{2}$, ..., $X_{m}$; that may be related to $Q$, a linear regression analysis is applied to quantify the strength of the relationship between $Q$ and $X_{j}(j=1,2, \ldots . m)$. The OLS method is used to estimate parameters in the linearized regression model of the form in equation 3-2:

$$
\ln \left(Q_{p i}\right)=\ln \left(\beta_{o}\right)+\beta_{1} \ln \left(X_{1 i}\right)+\beta_{2} \ln \left(X_{2 i}\right)+\ldots \ldots+\beta_{m} \ln \left(X_{m i}\right)+\varepsilon_{i}
$$

where $Q_{p i}$ is the $p^{\text {th }}$ streamflow quantile estimated at site $i$ based on gauged flow data; $i=1,2,3 \ldots, n ; n=$ number of sites considered; $\beta_{j}$ is the coefficient of the corresponding independent variable $X_{j} ; m=$ number of independent variables considered; and $\varepsilon$ denotes model error. In this study, $n=93$ sites, and $m=39$ independent variables were considered for model development. A backward stepwise regression method was employed to develop the regression equations. The least significant variables were dropped iteratively to obtain a smaller set of significant explanatory variables $(k \leq m)$. The final regression models converted back to real space are of the form shown in equation 3-3.

$$
Q_{p i}=\exp ^{b_{o}} * X_{1 i}^{b_{1}} * X_{2 i}^{b_{2}} \ldots \ldots * X_{k i}^{b_{k}} * \exp ^{B C F}
$$

where $B C F$ is the bias correction factor computed using the smearing estimator (Duan, 1983 ) to remove bias in the estimated streamflow quantile; $X_{j}$ is a statistically significant drainage basin characteristic $(j=1,2, \ldots . k)$, and $b_{j}$ is the estimate of the corresponding regression coefficient.

A WLS regression approach, which is used to improve estimates of the regression coefficients by assigning higher weights to observations with lower variance, was compared with the (equal weighting) OLS approach. Site-specific quantile estimates have different accuracies, depending upon streamflow record length and variance, which are commonly used to develop weights in WLS models (Montgomery and Peck, 1982; Tasker, 1980). The weighting scheme used in this study is adapted from Ries and Friesz (2000). The weight $W_{i}$ assigned to site $i$ is computed using equation 3-4. 


$$
W_{i}=\frac{N_{i} / \operatorname{Mean}(N)}{V_{c i} / \operatorname{Mean}\left(V_{c}\right)}
$$

where $N_{i}$ is the years of complete record available at site $i$; $\operatorname{Mean}(N)$ is the average record length available across all $n$ sites considered in the model; $V_{c i}$ is the fitted variance at site $i$; and Mean $\left(V_{c}\right)$ is the average of the fitted variances across all $n$ sites. To avoid inducing correlation among the residuals and the fitted quantiles obtained using equation 3-3, the fitted variance is based on a log-log regression of the variance of annual streamflow quantiles to drainage area. For example, considering a given streamflow quantile (e.g., $Q_{0.90}$ ) and $N_{i}$ years of continuous record at site $i$, the variance of $N_{i}$ estimates of the $90^{\text {th }}$ quantile computed on an annual basis defines one observation for the dependent variable of the regression model. Following estimation of the regression coefficients by OLS, the fitted variance $\left(V_{c i}\right)$ was obtained as a function of the site's associated drainage area. Compared to linear and log-linear relationships, the log-log relationship resulted in the most reasonable weighting scheme; smoothing disproportionate weights from stations with a wide range of variances (see Table 3-3).

\subsubsection{At-site streamflow statistics}

Regional regression models are developed based on reference gauges within an areal extent comprising five western Great Lakes States with varied climate (Table 3-1).

Table 3-1 Range of historic climate variables upon which the regression models are based and the future climate variables for the watersheds considered.

\begin{tabular}{lllll}
\hline & $\begin{array}{c}\text { Regional model } \\
\mathbf{( 1 9 8 0 - 1 9 9 9 )}\end{array}$ & $\begin{array}{l}\text { Kalamazoo } \\
\mathbf{( 2 0 4 6 - 2 0 6 5 )}\end{array}$ & $\begin{array}{l}\text { Maumee } \\
\mathbf{( 2 0 4 6 - 2 0 6 5 )}\end{array}$ & $\begin{array}{l}\text { St. Louis } \\
\mathbf{( 2 0 4 6 - 2 0 6 5 )}\end{array}$ \\
\hline Annual Precip (cm) & $59-107$ & $88-101$ & $90-102$ & $71-88$ \\
Annual Temp. ( C) & $2.92-11.86$ & $11.0-12.8$ & $11.5-13.3$ & $5.04-6.59$ \\
\hline
\end{tabular}

The locations of selected streamflow gauges used in this study and the basins where the regional regression models are compared to other approaches are shown in Figure 3-3. Of the 143 reference gauges identified in the five states of IL, IN, MI, MN, and WI, only 93 were selected based on a requirement of at least 10 years of continuous record. Also, stations recording zero flows were not considered as natural log-log regression analysis was employed. Kroll and Stedinger (1999) show that when sites have zero quantile estimates, dropping these does not adversely impact regression model parameters. All streamflow records of reference gauges were obtained from 
U S G S N W I S , and the average record length of the gauges used in this analysis is 45 years.

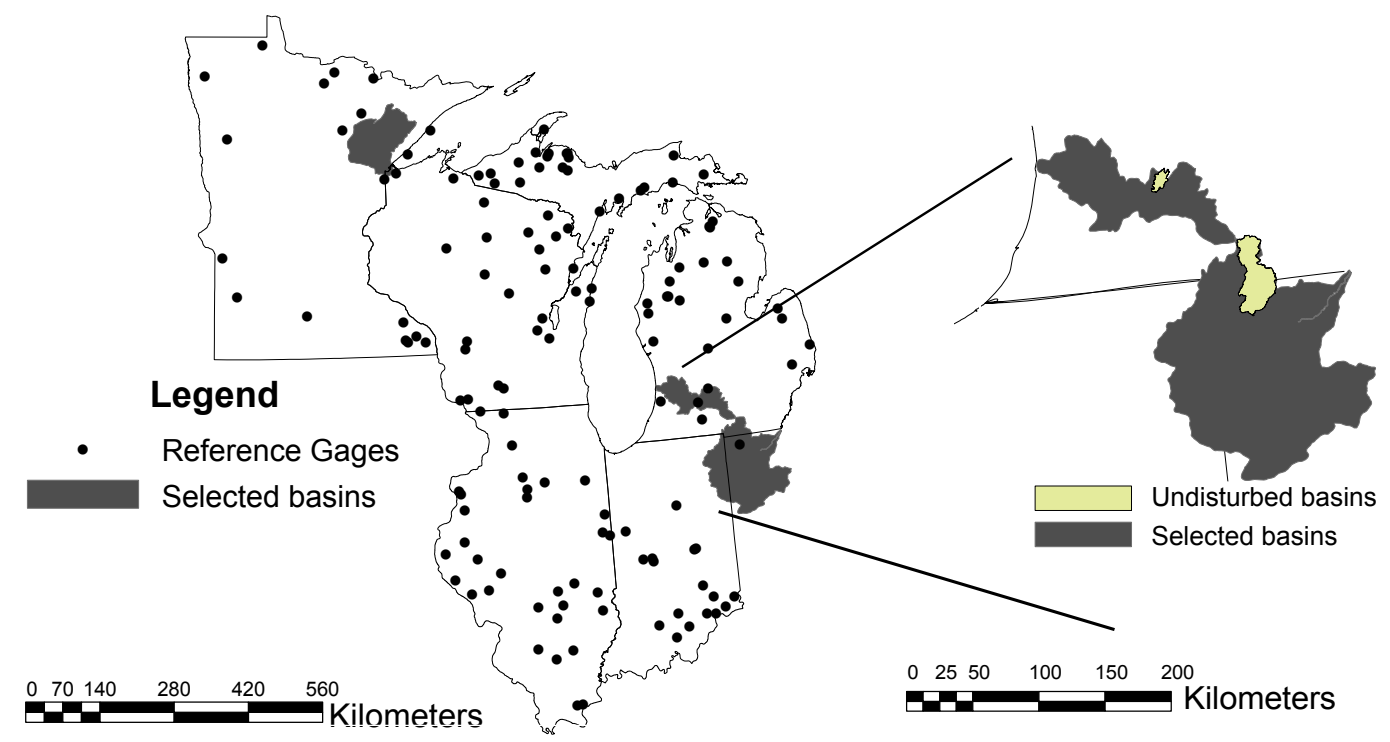

$\mathrm{F}$ igure 3-3 $\mathrm{R}$ eference streamflow gauges in the $\mathrm{W}$ estern $\mathrm{G}$ reat $\mathrm{L}$ ak es $\mathrm{S}$ tates used to develop the regional regression models and watershed boundaries of regulated and undisturbed basins where hydrologic and regression models are applied.

$\mathrm{C}$ ontinuous daily flow duration curves ( $\left(\begin{array}{llll}\mathrm{F} & \mathrm{D} & \mathrm{C} & \mathrm{s}\end{array}\right)$ developed using the $\mathrm{W}$ eibull plotting position at each of the selected 93 sites were used to determine the flowduration statistics. F D C s represent the percent of time streamflows, for a given time step, are eq ualed or ex ceeded over a specifiectriod of record ( $\mathrm{PO} R$ ). R ather than use the entire PO $\mathrm{R}$ to estimate flow duration statistics, an alternative approach is to determine flow-duration statistics of individual years with complete record (V ogel and F ennessey, 1994). This alternate method employing annual flow duration statistics was used in this study.

The F D C s in this study were based on U S G S water years $(1 \mathrm{O}$ ctober through $30 \mathrm{~S}$ eptember). $\mathrm{F}$ rom these $\mathrm{F} \mathrm{D} \mathrm{C}$ s, daily streamfllotike $\left(Q_{\min }, Q_{1}, Q_{5}, Q_{10}, Q_{25}\right.$, $\left.Q_{50}, Q_{75}, Q_{90}, Q_{99}, Q_{\max }\right)$ were determined for each individual year within the entire PO R miQand $Q_{\max }$ correspond to the minimum and maximum daily flow observed in an individual year with non-exceedance probabilities of $0.273 \%$ and $99.726 \%$, respectively. $\mathrm{F}$ or a given site, the median annual values of each quantile are used to represent the long-term flow duration statistics. F or ex ample, if $f_{i}$ lears of continuous record were available at site $i$, the median of $N_{i}$ annual estimates of the $p^{\text {th }}$ quantile was used as the dependent variable in the regression model for that quantile. Median 
annual flow duration statistics determined from the annual FDC method have reduced variability compared to those calculated for the entire POR (Figure 3-4). Summary statistics indicating the range and variability of the at-site quantile estimates are reported in Table 3-2.

Table 3-2 Summary statistics of significant physical variables in the regional regression model and flow quantiles.

\begin{tabular}{|c|c|c|c|c|}
\hline & Maximum & Minimum & Average & $\begin{array}{c}\text { \% Standard } \\
\text { deviation }\end{array}$ \\
\hline $\begin{array}{c}\text { Drainage Area } \\
\left(\mathbf{k m}^{2}\right)\end{array}$ & 4383.51 & 6.21 & 825.42 & 109.43 \\
\hline $\begin{array}{c}\text { Average } \\
\text { permeability } \\
(\mathrm{cm} / \mathrm{hr})\end{array}$ & 12.05 & 0.58 & 4.53 & 69.84 \\
\hline $\begin{array}{l}\text { Mean watershed } \\
\text { slope }(\%)\end{array}$ & 10.91 & 0.22 & 2.24 & 84.45 \\
\hline $\begin{array}{l}\text { Mean Annual } \\
\text { Precip. (cm) }\end{array}$ & 106.72 & 59.38 & 84.83 & 9.87 \\
\hline $\begin{array}{l}\text { Mean annual } \\
\text { Temp. (C) }\end{array}$ & 11.86 & 2.92 & 6.49 & 35.06 \\
\hline $\begin{array}{l}\text { Stream density } \\
\left(\mathbf{k m} / \mathbf{k m}^{2}\right)\end{array}$ & 1.14 & 0.2 & 0.62 & 37.21 \\
\hline Flow years & 94 & 10 & 45.55 & 48.13 \\
\hline $\operatorname{Qmin}\left(m^{3} / \mathrm{sec}\right)$ & 21.52 & 0.01 & 1.96 & 174.17 \\
\hline$Q 1\left(\mathrm{~m}^{3} / \mathrm{sec}\right)$ & 21.92 & 0.01 & 2.04 & 172.65 \\
\hline$Q 5\left(\mathrm{~m}^{3} / \mathrm{sec}\right)$ & 22.74 & 0.01 & 2.24 & 167.08 \\
\hline$Q 10\left(\mathrm{~m}^{3} / \mathrm{sec}\right)$ & 23.47 & 0.01 & 2.41 & 162.35 \\
\hline$Q 25\left(\mathrm{~m}^{3} / \mathrm{sec}\right)$ & 24.83 & 0.02 & 2.97 & 150.81 \\
\hline$Q 50\left(m^{3} / \mathrm{sec}\right)$ & 28.06 & 0.05 & 4.23 & 128.62 \\
\hline$Q 75\left(\mathrm{~m}^{3} / \mathrm{sec}\right)$ & 40.63 & 0.12 & 7.14 & 112.23 \\
\hline$Q 90\left(\mathrm{~m}^{3} / \mathrm{sec}\right)$ & 77.7 & 0.2 & 14.15 & 112.42 \\
\hline Q99 $\left(\mathrm{m}^{3} / \mathrm{sec}\right)$ & 215.81 & 0.49 & 44.64 & 105.67 \\
\hline $\operatorname{Qmax}\left(m^{3} / \mathrm{sec}\right)$ & 264.06 & 0.81 & 63.92 & 100.48 \\
\hline
\end{tabular}




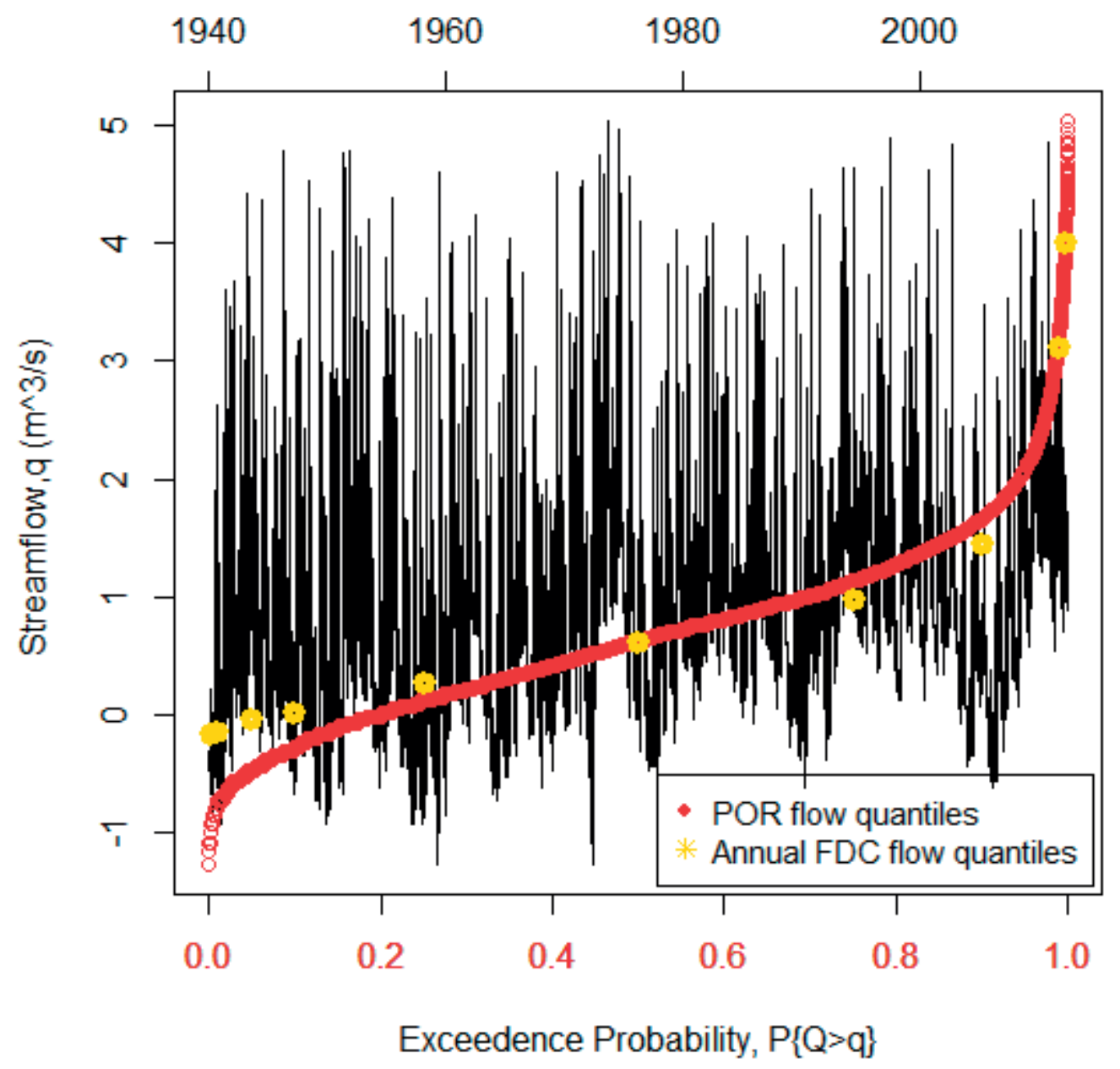

Figure 3-4 Logarithm of streamflow time series and flow duration curve, (FDC) of the USGS site 04105000 showing flow quantiles used in regression modeling (drainage area $\left.18,821 \mathrm{~km}^{2}\right)$.

\subsection{Results}

Two performance metrics are calculated to compare the performance of OLS and WLS regional regression models--the adjusted coefficient of determination (Adj$\mathrm{R}^{2}$ ) (Devore, 1994) and the standard error (SE) of prediction (Table 3-3). Based on these metrics, WLS regression models were better predictors of streamflow than OLS models; therefore, WLS models are used for climate change projections in this study. The significant variables, associated regression coefficients, and BCFs of all WLS models are shown in Table 3-3; summary statistics describing these variables are reported in Table 3-2. With the exception of the lowest flow quantile (Qmin), climate variables were significant in all models. Similar to the findings of Fennessey (2011) in 
a study of northeastern U.S. watersheds, mean annual precipitation was found significant for low flow models, while both mean annual precipitation and mean annual temperature were significant predictors of high flow quantiles. As expected, temperature variables are negatively correlated with streamflow, while precipitation variables have a positive correlation with streamflow. Drainage area (DA), the most significant predictor has a positive correlation with the flow quantile, while the mean watershed slope (S), a less significant predictor, has both positive and negative coefficients. It may seem that negative slope coefficients for high flow quantiles are counter intuitive, but it should be noted that each coefficient in a regression model is also influenced by other predictor variables. Thus, the flow quantiles (response) are explained by the combination of predictor variables rather than each coefficient explaining the total effect of that variable on a given flow quantile. Similar to the results herein, negative slope coefficients are also reported in high flow annual and monthly regression models of unregulated flows in Oregon (see Table 9 and Table 11, Risley et al. 2008).

Although the GAGES II dataset includes many potential predictor variables, highly correlated variables were screened and dropped to minimize potential multicollinearity problems. A variation inflation factor (VIF) threshold of 10 was initially imposed for the variables in the model (Rawlings et al., 1998). For example, collinear variables such as average temperature and minimum temperature would exceed the VIF threshold when both variables were in the model. In such cases, both variables were entered into the model individually, and the variable giving the higher VIF was dropped. Each explanatory variable employed in the final regression model had a $p$-value of less than 0.000148 , along with a VIF of less than 2.5 , indicating minimal multicollinearity. It is acknowledged that it is not clear how to best address multicollinearity in hydrologic regression models (Kroll and Song, 2013). However, for model predictions, Kroll and Song (2013) demonstrate that use of stepwise regression with VIF is competitive with more complicated techniques, e.g. principal component regression and partial least squares regression, within the range of parameter values used for model development.

To evaluate the robustness and expected predictive accuracy of the WLS models, a six-fold cross validation technique was employed. This involved randomly partitioning the data into six subsets and holding out each subset for validation. The remaining data was regressed to their predictor variables and resulting models were tested on the subset not used in regression. Cross validations indicate a reasonable predictive accuracy for all models. Due to space limitations only cross-validation results for the $Q_{\min }, Q_{50}$ and $Q_{\max }$ models are shown (Figure 3-5). Overall, the predictive capability of the regression models decreases with flow magnitude. 

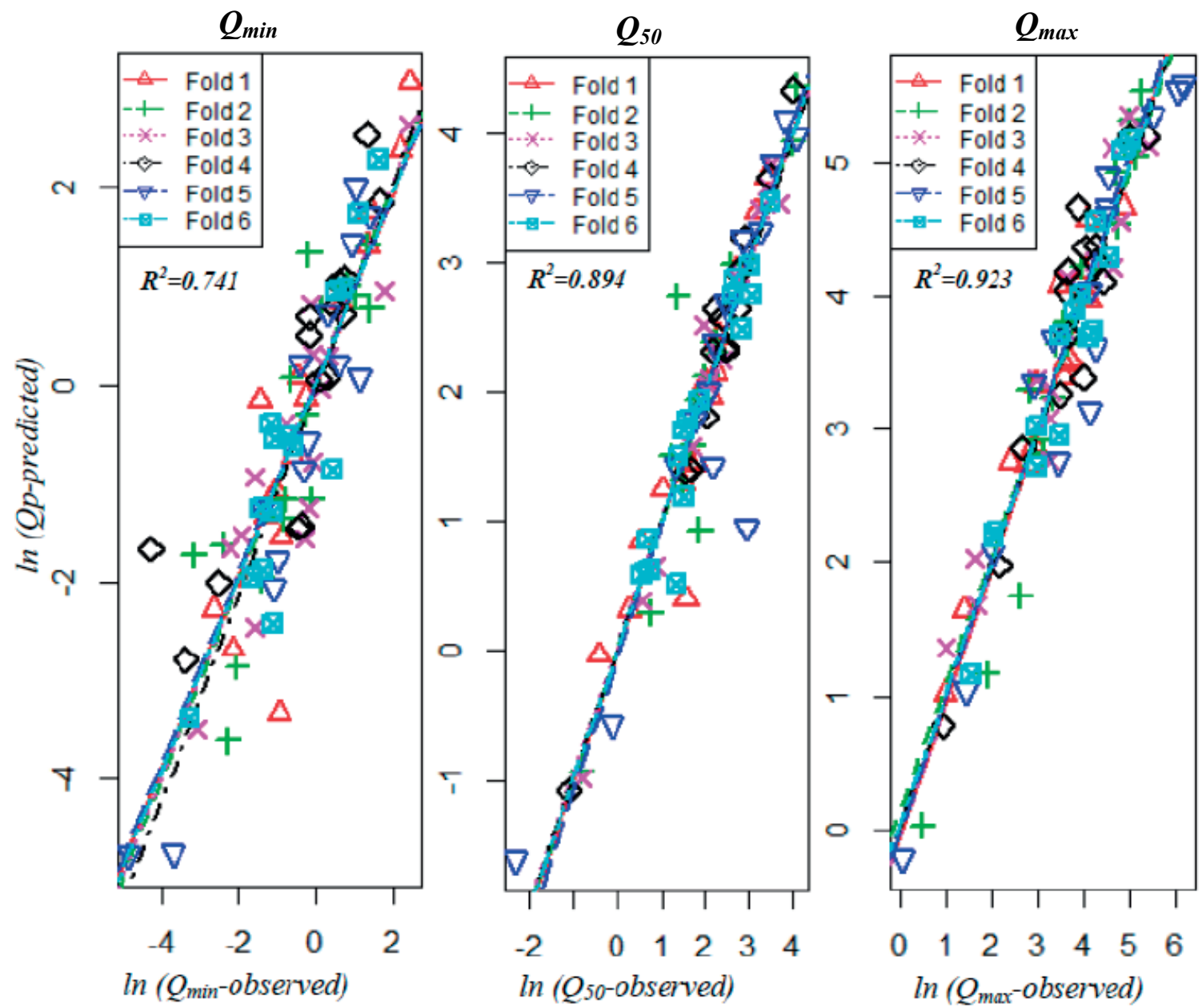

Figure 3-5 Cross validated regression models and average correlations $\left(R^{2}\right)$ over six folds of selected stream flow quantiles $\left(Q_{\min }, Q_{50}\right.$ and $\left.Q_{\max }\right)$.

An application of the regression models for climate change impact assessment is to evaluate the sensitivity or elasticity of streamflow quantiles $\left(Q_{p}\right)$ to mean annual precipitation $\left(P_{A}\right)$ and mean annual temperature $\left(T_{A}\right)$ (e.g., Sankarasubramanian et al., 2001; Fu et al., 2007). The elasticities are given by equations 3-5 and 3-6:

$$
\begin{aligned}
& \operatorname{Elasticity}\left(Q_{p}, P_{A}\right)=\frac{P_{A}}{Q_{p}}\left(\frac{\partial Q_{p}}{\partial P_{A}}\right) \\
& \text { Elasticity }\left(Q_{p}, T_{A}\right)=\frac{T_{A}}{Q_{p}}\left(\frac{\partial Q_{p}}{\partial T_{A}}\right)
\end{aligned}
$$


$\mathrm{F}$ or the western $\mathrm{G}$ reat $\mathrm{L}$ ak e $\mathrm{S}$ tates, these elasticities are estimated based on the regional sensitivity of selected streamflow q uantiles $(Q)$ to $P_{A}$ and $T_{A}$. F or examle, elasticity $\left(Q_{50}, T_{A}\right)=-0.85$ indicates that a $10 \%$ increase in(何 degrees $\mathrm{C}$ yill result in an $8.5 \%$ reduction in the median daily streamflow, $Q$. S imilarly, elasticity (Q6), $\left.P_{A}\right)=1.1$ indicates that a $10 \%$ increase in will result in an $11 \%$ increase in the median daily streamflow, $Q_{50}$. O nly annual precipitation was found significant in low flow models $\left(Q_{1}, Q_{5}, Q_{10}, Q_{25}\right.$, and $\left.Q_{50}\right)$, while both precipitation and temperature variables were found significant in high flow models $\left(Q_{75}, Q_{90}, Q_{99}\right.$ and $\left.Q_{\max }\right)$ (Table 3-3). The models show a positive correlation with precipitation and a negative correlation with temperature, which is consistent with the signs of the associated regression parameters ( $\mathrm{F}$ igure 3- 6

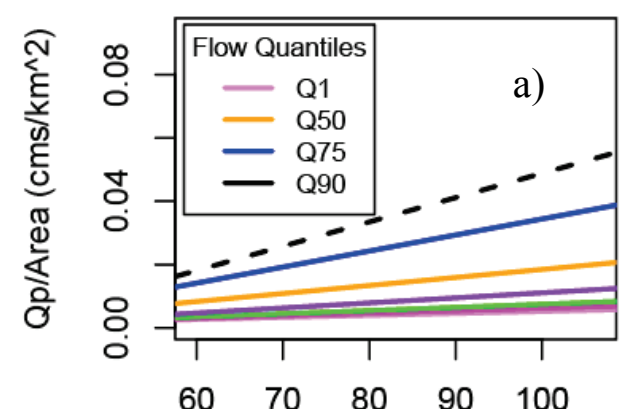

Mean Annual Precipitation (cm)

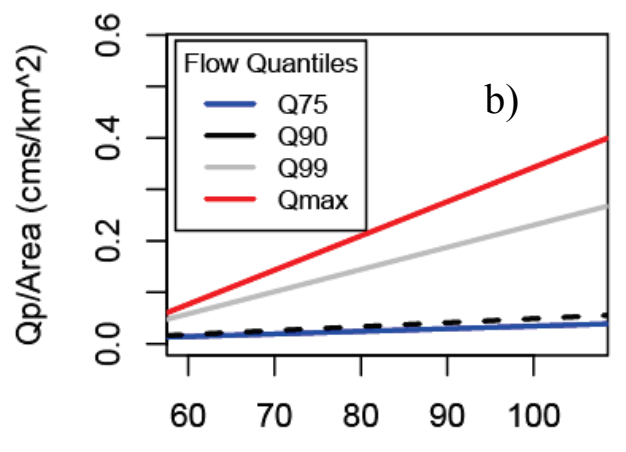

Mean Annual Precipitation (cm)

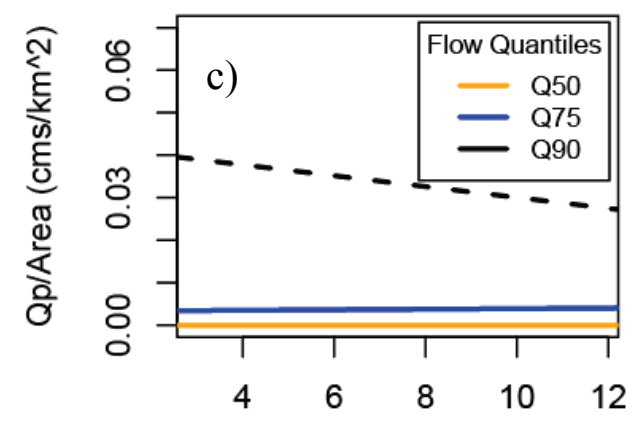

Mean Annual Temperature (Celsius)

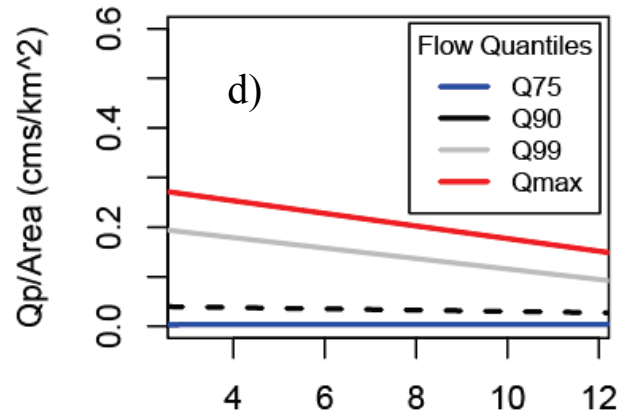

Mean Annual Temperature (Celsius)

F igure 3-6 R elation of low streamflow q uantiles to precipitation (a); high streamflow q uantiles to precipitation (b); low stream flow q uantiles to temperature (c); and high stream flow q uantiles to temperature $(\mathrm{d})$. 
Table 3-3 Goodness of fit metrics of OLS and WLS regressions, and significant variables and associated coefficient values of WLS models. Metrics are calculated based on the natural logarithms of stream flows.

\begin{tabular}{|c|c|c|c|c|c|c|c|c|c|c|}
\hline Flow quantiles & $Q_{\min }$ & $Q_{1}$ & $Q_{5}$ & $Q_{10}$ & $Q_{25}$ & $Q_{50}$ & $Q_{75}$ & $Q_{90}$ & $Q_{9 g}$ & $Q_{\max }$ \\
\hline & \multicolumn{10}{|c|}{ OLS and WLS regressions } \\
\hline OLS Adjusted $\mathrm{R}^{2}$ & 0.788 & 0.820 & 0.835 & 0.853 & 0.884 & 0.909 & 0.910 & 0.899 & 0.911 & 0.919 \\
\hline WLS Adjusted $\mathbf{R}^{2}$ & ${ }^{2} 0.794$ & 0.819 & 0.846 & 0.867 & 0.916 & 0.942 & 0.947 & 0.949 & 0.936 & 0.929 \\
\hline OLS (S.E) & 0.768 & 0.699 & 0.636 & 0.573 & 0.464 & 0.376 & 0.360 & 0.396 & 0.384 & 0.365 \\
\hline \multirow[t]{2}{*}{ WLS (S.E) } & 0.764 & 0.681 & 0.616 & 0.544 & 0.435 & 0.367 & 0.308 & 0.315 & 0.317 & 0.316 \\
\hline & \multicolumn{10}{|c|}{ Significant variables in WLS regression and coefficient value } \\
\hline Constant term & -8.9 & -24.3 & -24.2 & -24.6 & -24.6 & -22.4 & -21.0 & -19.7 & -20.4 & -20.3 \\
\hline $\begin{array}{l}\text { Drainage Area } \\
\left(\mathrm{km}^{2}\right)\end{array}$ & 0.85 & 0.92 & 0.912 & 0.91 & 0.89 & 0.87 & 0.90 & 0.92 & 0.94 & 0.88 \\
\hline $\begin{array}{l}\text { Average } \\
\text { permeability } \\
(\mathrm{cm} / \mathrm{hr})\end{array}$ & 1.24 & 1.40 & 1.31 & 1.22 & 0.98 & 0.65 & 0.34 & $* *$ & -0.25 & -0.36 \\
\hline $\begin{array}{l}\text { Mean } \\
\text { watershed slope } \\
\text { (\%) }\end{array}$ & $e^{0.89}$ & 0.87 & 0.80 & 0.73 & 0.54 & 0.30 & $* *$ & -0.19 & -0.31 & -0.27 \\
\hline $\begin{array}{l}\text { Mean Annual } \\
\text { Precip. }(\mathrm{cm})\end{array}$ & $* *$ & 3.33 & 3.41 & 3.60 & 3.82 & 3.68 & 3.89 & 4.12 & 4.84 & 5.026 \\
\hline $\begin{array}{l}\text { Stream density } \\
\left(\mathrm{km} / \mathrm{km}^{2}\right)\end{array}$ & $* *$ & $* *$ & $* *$ & $* *$ & $* *$ & $* *$ & $* *$ & $* *$ & 0.57 & 0.83 \\
\hline $\begin{array}{l}\text { Mean annual } \\
\text { Temp. (C) }\end{array}$ & $* *$ & $* *$ & $* *$ & $* *$ & $* *$ & $* *$ & -0.61 & -1.13 & -1.43 & -1.32 \\
\hline B.C.F factort & 1.430 & 1.327 & 1.258 & 1.202 & 1.112 & 1.056 & 1.037 & 1.039 & 1.039 & 1.034 \\
\hline
\end{tabular}

$[* *$, parameters not included in regression equation; $\uparrow$, Bias correction factor computed from Duan (1983); WLS, weighted least squares; OLS, ordinary least squares; S.E, standard error; p-values less than 0.00015 were obtained for all significant variables]

Next, the regression model predictions are compared to the results of the two physically based hydrologic models, LBRM and HMS. The models are applied to three HUC-8 scale watersheds (Kalamazoo River, Maumee River, and interior St. Louis River basins) and two undisturbed (reference) interior basins of the Kalamazoo and Maumee River watersheds (Figure 3-3). Since the regression models provide regional predictions, biases may result when applied to specific watersheds.

Regression models were bias corrected such that the predicted regression quantiles were multiplied by the ratio of the observed to predicted quantiles for the historic period. In unregulated watersheds, the ratios ranged from 0.35 to 1.71 but were generally close to 1.0 for high flow quantiles. For regulated watersheds, the ratios in some cases were substantially different than 1.0 and ranged from 0.25 to 2.5. Figure 3-7 shows the cumulative distribution functions (CDFs), prior to bias correction, of the 
observed and simulated flows in both the regulated and undisturbed basins. $\mathrm{F}$ or a consistent comparison with regression models based on annual statistics, the streamflow time series generated from the physically based models and observed record were converted to median annual flow series. Each year of daily outputs was rank ed and the median value of each annual quatile was used to develop a median annual flow series from which a median annual median $\mathrm{C} D \mathrm{~F}$ is estimated.
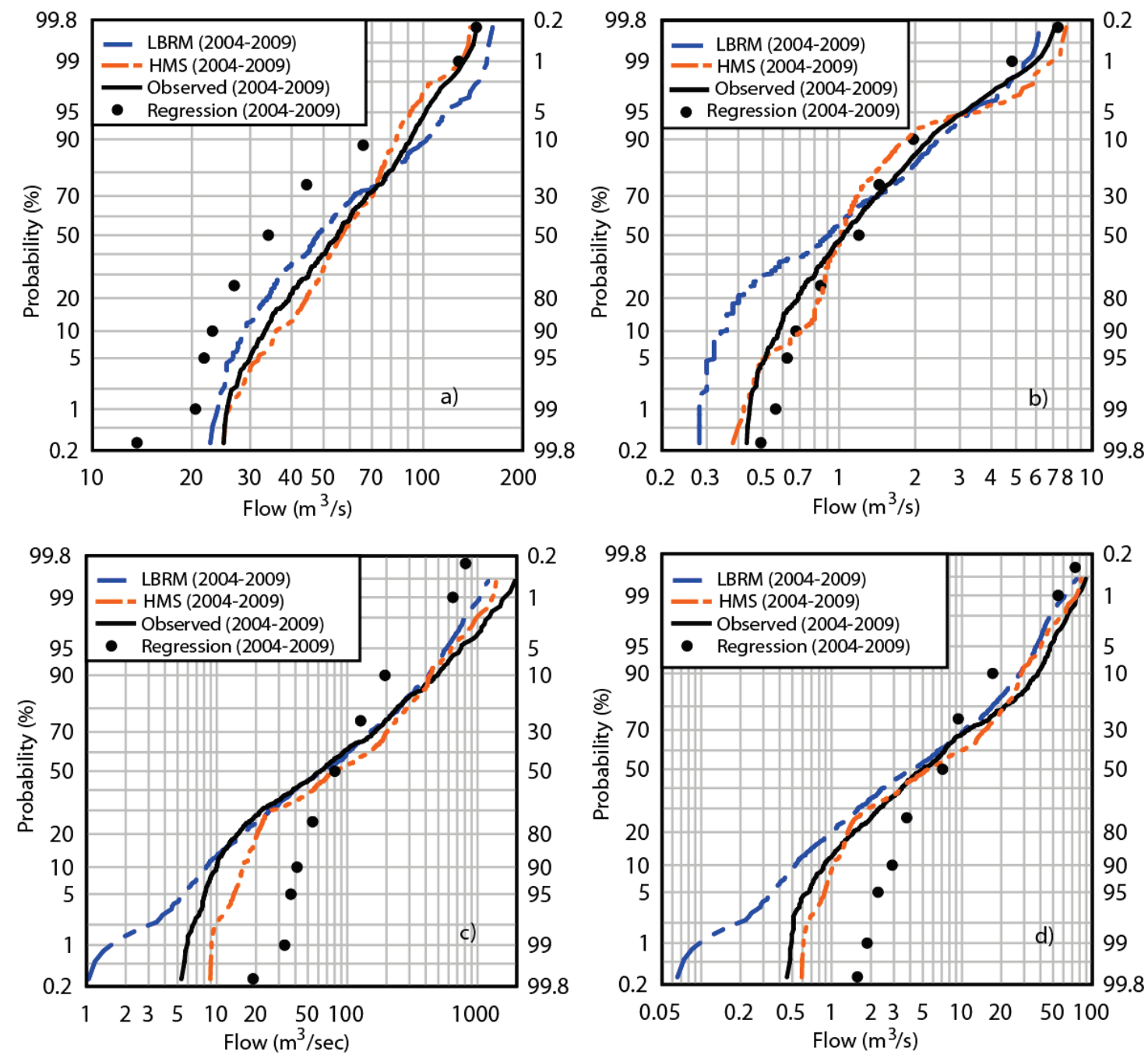

F igure 3-7 C D F s of observed historic, L B R M , H M S and regression flows, at the outle of $\mathrm{K}$ alamz oo watershed, a); at the interior subbasin of $\mathrm{K}$ alamaz oo watershed, $\mathrm{b}$ ); at the outlet of $\mathrm{M}$ aumee watershed, c); and the interior subbasin of $\mathrm{M}$ aumee watershed, $\mathrm{d}$ ). 
For a consistent comparison with regression models based on annual statistics, the streamflow time series generated from the physically based models and observed record were converted to median annual flow series. Each year of daily outputs was ranked and the median value of each annual quantile was used to develop a median annual flow series from which a median annual median CDF is estimated.

Four GCM projections, representing warm-dry, warm-wet, cool-dry and coolwet future climates, are used to generate hydrologic impacts in each basin. As an example, selected GCM projections and the corresponding changes in precipitation and temperature inputs to the Maumee River watershed models are shown in Figure 3-8. The selected scenarios are based on the temperature and precipitation change between the observation (1980-99) and the future period (2046-65). The perpendicular lines indicate the median change in precipitation and temperature and divide the four quadrants as shown. The dotted lines intersect at the midpoint of the range of each bisector, and the nearest neighbor from the point of intersection is identified as the climate scenario to represent average warm-dry, warm-wet, cool-dry and cool-wet future climates. A similar scenario selection approach based on precipitation and temperature changes is employed in Brekke et al. (2009). 


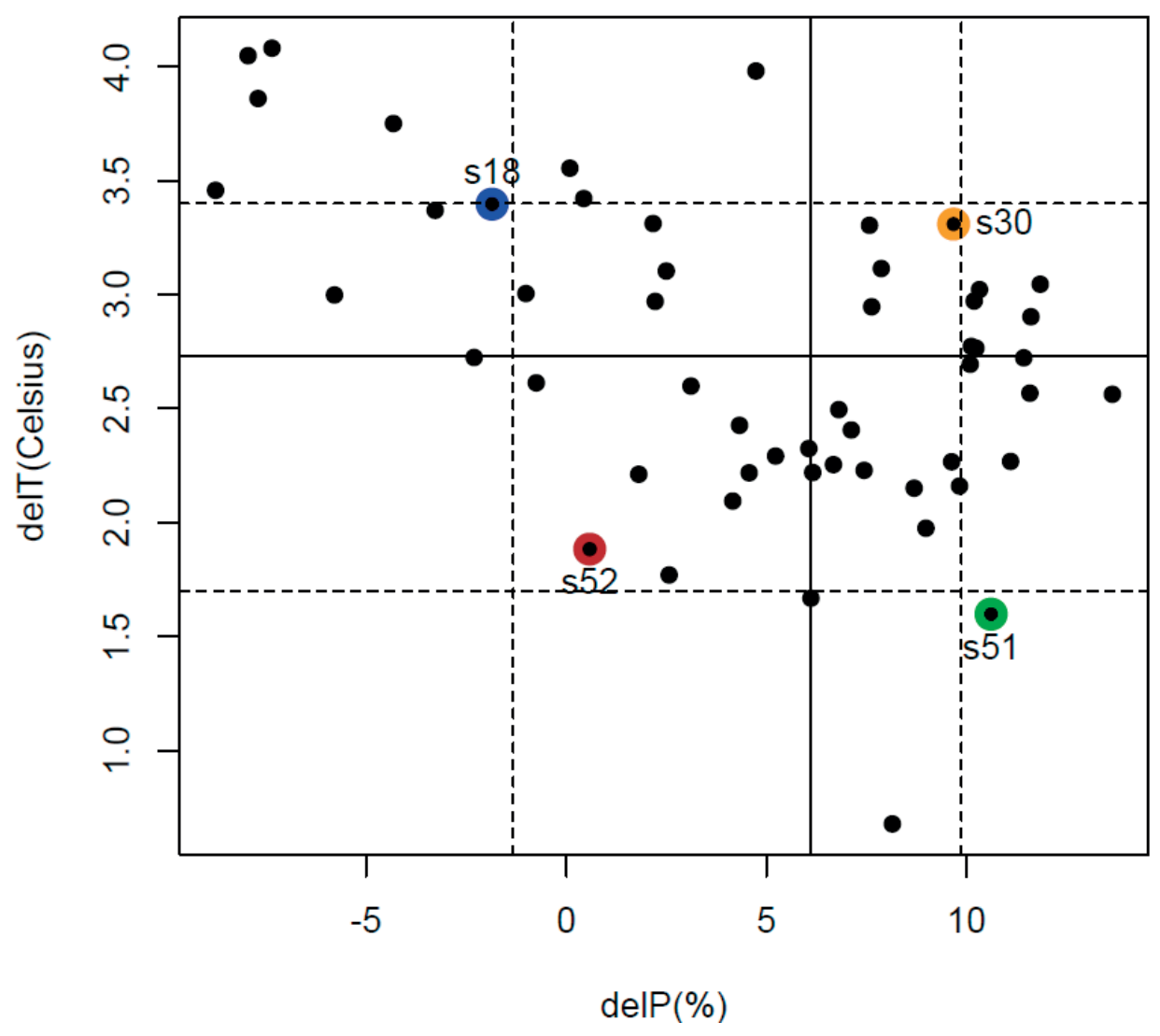

$\mathrm{F}$ igure 3-8 $\mathrm{S}$ elected watarm average (s30), dry-cool average (s52), dry-warm average (s18) and wet-cool average (s51) climate scenarios of $\mathrm{M}$ aumee river watershed from 53 B C C A C M I P3 proj ections, based on percent change in precipitation and absolute change in temperature (in degree $\mathrm{C}$ elsius) between the historic and the near future period 2046-2065.

The model simulations of the historic (1980-1999) and a future period (20462065), presented in the form of cumulative distribution functions (C D F s), show how hydrologic proj ections vary based on different modeling approaches. $\mathrm{R}$ esults of $\mathrm{K}$ alamaz oo, $\mathrm{M}$ aumee and the interior $\mathrm{S}$ t. $\mathrm{L}$ ouis watersheds are shown in $\mathrm{F}$ igure 3-9. The dashed lines represent the C D F s obtained from each of the four selected G C M scenarios used to drive $\mathrm{L} B \mathrm{R} \quad \mathrm{M}$ and $\mathrm{H} \quad \mathrm{M}$ S models; the black dots and associated error bars represent the median and range of values simulated for each streamflow q uantile using regression models under the four future scenarios. 

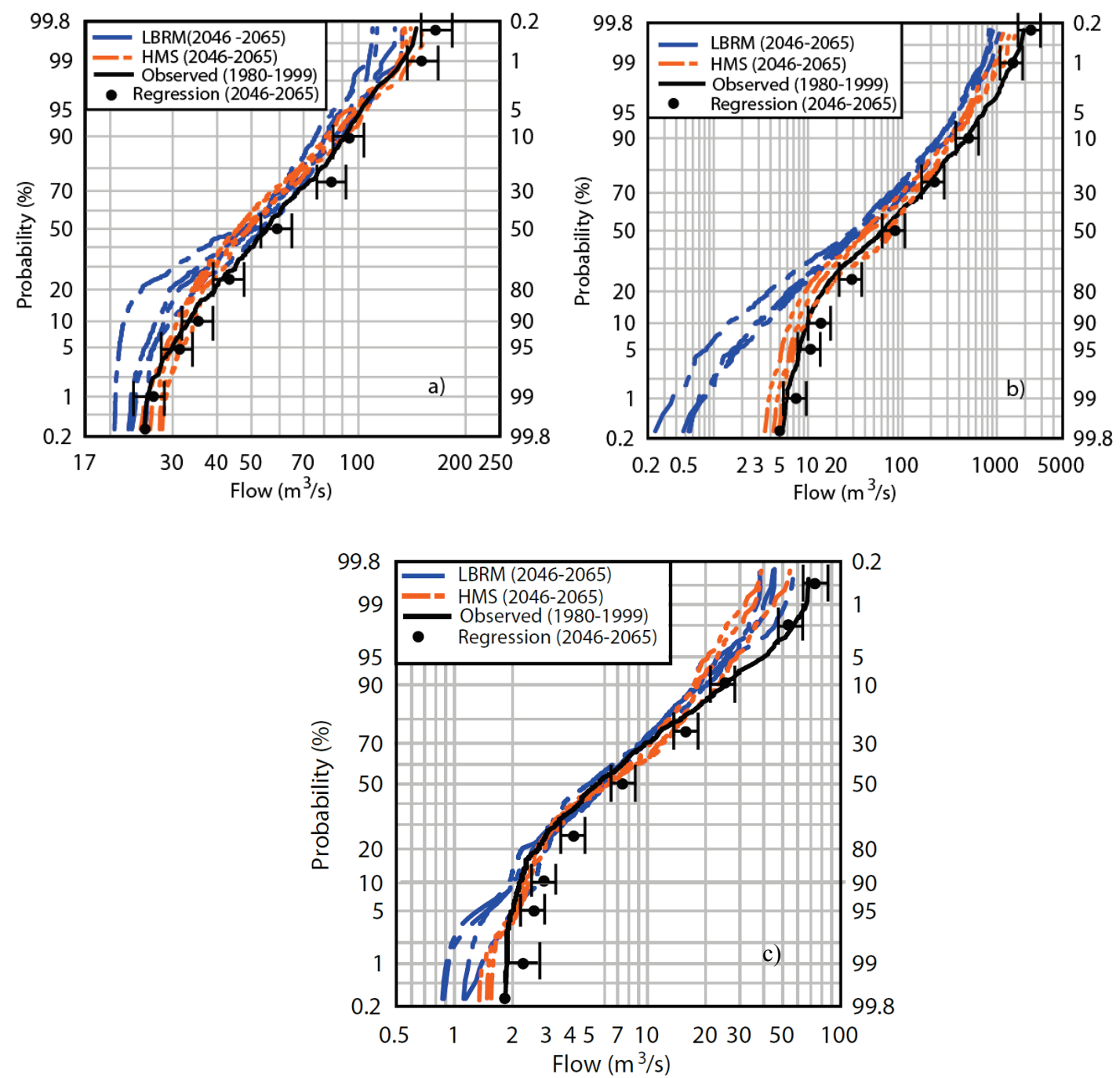

$\mathrm{F}$ igure 3-9 C D F s of observed historic and future $\mathrm{L} B \mathrm{R} M, \mathrm{H} M \mathrm{~S}$ and regression flows, driven by $\mathrm{G} \quad \mathrm{C} \quad \mathrm{M}$ scenarios at the outlet of $\mathrm{K}$ alamaz oo (a), $\mathrm{M}$ aumee (b) and interior $\mathrm{S} t$. $\mathrm{L}$ ouis (c) watersheds.

L B R M and $\mathrm{H} \quad M \quad S$ models predict reduced streamflow in the future period, with larger reductions predicted by $\mathrm{L} B \mathrm{R} \quad \mathrm{M}$ than $\mathrm{H} \quad \mathrm{M} \quad \mathrm{S}$. I n contrast, regional regression models generally predict increased streamflow in the future for all scenarios.

$\mathrm{S}$ tructural differences between the hydrologic models result in more pronounced differences in streamflow predictions than do differences in climate inputs from the various climate scenarios considered. The range of significant future climate variables 
in the near future period (2046-2065) is generally within that observed across the region in the historic period over which the regression model coefficients are derived (Table 3-1). The mean annual temperatures for the Kalamazoo River and Maumee River and basins are slightly above (by up to 1.0 and $1.5 \mathrm{C}$, respectively) the historic range of temperatures in the regional model developed herein.

\subsection{Discussion}

In the Great Lakes basin, climate change predictions include rising temperatures, especially in winter; shorter winters; early spring; shorter ice cover duration; and more frequent extreme rainfall events (Maurer et al., 2010; Scavia, 2007; Solomon et al., 2007). There is potential for these occurrences to pose a wide range of challenges in water resources management, e.g., extreme lake levels, increased sewer overflows, ecological water stress, and others. However, adaptive management planning in the water resources sector is hindered by the complexity and uncertainty in using different combinations of climate projections and hydrologic methods and models. Perhaps due to the difficulty in quantifying the uncertainty of hydro-climate projections, the vast majority of climate change studies in the last decade have stopped at the impact assessment stage (Wilby, 2009; Wilby and Dessai, 2010).

Ensemble-based multi-model approaches are gaining acceptance for impact assessment and decision support (Manning et al., 2009; New et al., 2007; Tebaldi and Knutti, 2007). Predictions generated from a single model, run for a single or small number of scenarios, are prone to statistical biases, while predictive distributions from an ensemble of models differ in spread, shape and central moment (Neuman, 2003; Rojas et al., 2010). Moreover, multi-model ensemble predictions produced by a combination of hydrologic model structures and meteorological inputs have been shown to have higher skill and reliability than predictions from individual models (Rojas et al., 2010; Velazquez et al., 2011).

This study does not imply that any of the presented models are superior to the others, but rather important insights may be gained through comparison of model results. For example, one reason for differences in hydrologic projections is differences in calibration methods. LBRM uses an automated calibration procedure (univariate gradient search), minimizing RMSE at the most downstream gauge in each watershed. The RMSE objective function weights high flows more than low flows, and thus LBRM better reproduces peak flows than low flows. In contrast, the HMS models used in this study are calibrated manually to get an overall best fit between the observed model hydrographs, and user-defined base-flow recession and ground water coefficients allowed a better match of low flows in the calibration period. This partly explains why HMS shows less reduced runoff than LBRM for the same climate scenarios. However, both models consistently simulate reduced runoff into the future. This may be an artifact of the temperature proxy PET computation method in each 
model, which only uses GCM temperature inputs to estimate PET and results in an inconsistent energy budget between climate and hydrologic models (Lofgren et al., 2011; Milly and Dunne, 2010; Shaw and Riha, 2011). Lofgren et al. (2011) shows how ET responses in the Great Lakes region can be exaggerated when the watershed models are forced only by temperature and precipitation from GCMs, as opposed to when ET is directly simulated from the same GCMs with integrated land surface models.

The empirical temperature relationships to compute PET in LBRM and HMS are as follows. LBRM uses a PET formulation of the form shown in equation 3-7:

$$
P E T=A * \exp \left(T / T_{b}\right)
$$

where $T_{b}$ is a parameter fitted through calibration and computed internally in LBRM, $T$ is the daily mean air temperature, and $A$ is a parameter with units of $\mathrm{cm} / \mathrm{day}$. In the calibration process, for parameter $T_{b}$, a value of $A$ is uniquely determined based on a solar energy and latent heat relationship (see Lofgren et al. 2011). In HEC-HMS, PET is user-defined. Due to limited energy budget data, the Hamon method (1963) was used to estimate PET in this study as shown in equations 3-8 and 3-9:

$$
\begin{aligned}
& P E T=29.8 D \frac{e_{a}^{*}\left(T_{a}\right)}{T_{a}+273.2} \\
& e_{a}^{*}\left(T_{a}\right)=\left(2.7489 * 10^{8}\right) * \exp \left(\frac{-4286}{T_{a}+242.79}\right)
\end{aligned}
$$

where $D$ is the average daylight hours for each month, $e_{a} *\left(T_{a}\right)$ is the saturated vapor pressure in millibars, and $T_{a}$ is the average temperature with units of ${ }^{\circ} C$. The estimated PET has units of mm. Thus, in LBRM and HMS, PET is estimated solely based on temperature projections under future climate scenarios, and neither model accounts for the surface energy budget. Admittedly, the regression models are also limited in this way as they do not include measures of PET under either historic or future climates.

Comparison of multi-model projections also provides insight to other potential limitations of the regional regression approach. In this study, cross-validation of the regression models indicated more variable low flow quantiles than high flow quantiles in both regulated and unregulated basins, and this variability was more pronounced in smaller basins. Furthermore, use of WLS rather than OLS models did not significantly improve the prediction of low flow quantiles. In all regression models, drainage area was found to be the most significant predictor of streamflow quantiles. However, baseflow from subsurface watersheds can also strongly influence low flow regimes, and data limitations precluded consideration of subsurface drainage areas. The smaller the watershed, the more likely it is that surface and subsurface drainage areas 
differ substantially, which may partly explain why variability in low flow quantiles was more pronounced for smaller watersheds.

\subsection{Conclusions}

Given future climate projections from downscaled GCM outputs, physically based hydrological models can be valuable tools to address impending water resources management problems. Although these models represent physical processes at a range of spatial and temporal scales, there is typically significant uncertainty in hydrologic model predictions, particularly in a changing climate (Harding et al., 2012; Manning et al., 2009). In a multi-model framework, regression models can be used to complement physically based hydrologic models (Fennessey, 2011). Regression models can estimate selected flow statistics at ungauged locations, and unlike physically based models, regional regression models do not require calibration on a site by site basis, which is often recognized as a complicated process and a potentially onerous task (Beven and Freer, 2001; Montanari and Brath, 2004).

In this study, regional regression models were developed using OLS and WLS techniques to predict future streamflow quantiles using the recently developed GAGES II dataset. The dataset includes detailed geo-spatial physiological and meteorological characteristics of basins throughout the United States, allowing a larger set of potential predictor variables to be considered than in many previous studies. BCCA CMIP3 climate model outputs were used as inputs to both regression and hydrologic models, with residual precipitation biases corrected by applying the delta method.

Comparison of model results showed significant differences in hydrologic projections and provided insights to potential limitations of each model. A potential limitation of the physically based models is their temperature proxy PET methods, which may lead to underestimation of runoff in a warming climate. Different calibration methods may also have contributed to different flow projections. A limitation of the regression approach is that temperature is not a significant predictor of low flow quantiles, limiting its usefulness in climate change impact assessment. Flow comparisons also indicated that regional regression models resulted in more variable estimates of low flow quantiles than high flow quantiles, which may be attributed to the data limitations associated with ground watershed divides and dominant baseflow regimes, especially in watersheds with smaller drainage areas. Finally, the regression models also need to be corrected for watershed specific biases, and as expected, regulated watersheds have larger biases relative to undisturbed watersheds.

Development and application of regional regression models in conjunction with physically based hydrologic models can contribute to more robust multi-model approaches for climate change impact assessment. It is recommended that the 
limitations and strengths of these models be more carefully evaluated in future climate risk assessment and adaptive management studies. A future direction of this work is to investigate how the use of different models for impact assessment could affect water resources management decision making. 


\section{Energy Budget Considerations for Hydro-climatic Impact Assessment ${ }^{3}$}

\subsection{Abstract}

Routinely, hydrologic models use temperature proxy relationships to estimate potential evapotranspiration (PET) when forced using GCM/RCM projections of precipitation and temperature. A limitation of this approach is that the temperature proxy relationships for PET do not account for the conservation of energy needed to estimate evapotranspiration (ET) consistently in climate change scenarios (Lofgren et al. 2011). In particular, PET methods using temperature as a proxy fail to account for the negative feedback of ET on surface temperature. Using several GCM projections and a hydrologic model developed for the Great Lakes basin watersheds, the NOAA Large Basin Runoff Model (LBRM), the importance of maintaining a consistent energy budget in hydrologic and climate models is demonstrated by comparing runoff projections from temperature proxy and energy conservation methods. Differences in hydrologic responses are evaluated using watershed characteristics, hydrologic model parameters and climate variables. It is shown that the temperature proxy approach leads to prediction of relatively large reductions in runoff, which may not be realistic. Therefore, the hydrologic projections based on the energy conservation principles, which provide a more consistent evaporation formulation, are recommended for use in climate change impact studies.

\footnotetext{
${ }^{3}$ The material contained in Chapter 4 is being submitted to the Journal of Great Lakes Research
} 


\subsection{Introduction}

In the upper Midwestern U.S., annual evapotranspiration (ET) is approximately 30-50\% of annual rainfall (Sanford and Selnick, 2013). Given the large share of the water budget composed of ET, accurately estimating ET is critical for hydro-climate change studies. As direct measurements of ET (e.g. using pans, eddy covariance flux towers, and weighing lysimeters) are expensive and not frequently available, ET is commonly estimated as a function of moisture storages and potential evapotranspiration (PET), i.e., the evaporative potential given unlimited moisture availability. PET, in turn, is often estimated only as a function of daylight hours (season) and temperature (Hamon, 1963), and sometimes as a function of humidity, windspeed, and surface radiative fluxes as well (Pennman, 1948; Priestley and Taylor 1972). Full energy budget approximations are seldom used due to intensive data requirements.

Contrary to the expectation that increased air temperature would lead to increased evapotranspiration, pan ET measurements around the world show a steady decrease over the last 50 years (Peterson et al. 1995, Golubev et al. 2001), while a necessary condition for the evident increase in precipitation is increased evapotranspiration. An explanation of this 'pan evaporation paradox' is that increased land surface evaporation alters the humidity regime, causing air over the pan to be cooler and more saturated, hence recording lower pan evaporation (Brutsaert and Parlange, 1998). The other argument is that increased cloudiness and decreased solar irradiance due to aerosol deposition have in fact resulted in reduced actual ET, also reflected in pan evaporation records (Stanhill and Cohen, 1998, Cohen et al. 2002 and Ramanathan et al. 2001). Further, it is claimed that aggregated groundwater depletion has accelerated significantly since the mid-twentieth century, affecting the terrestrial evaporative budget, as well as contributing to sea-level rise (Aeschbach-Hertig and Gleeson, 2012; Konikow et al., 2012; Pokhrel et al. 2012; Wada et al., 2010). In any case, limited understanding and agreement in historical evapotranspiration trends have complicated accurate actual ET quantification (Barnett et al. 2005). It is suggested that the components of the hydrological cycle should be considered together to interpret inter-relationships of pan, potential, and actual evapotranspiration to estimate the net evaporative budget (Sumner and Jacobs, 2005).

A general method to estimate ET uses a water balance equation given by $\Delta \mathrm{S}=\mathrm{P}-\mathrm{Q}-\mathrm{ET}$, where $\Delta \mathrm{S}$ is the change in water storage over the basin and $\mathrm{P}, \mathrm{Q}$ and ET are precipitation, runoff and evapotranspiration, respectively. For water budget analyses on annual or longer time scales, the net change in annual storage may be assumed zero. In order to estimate runoff at finer timescales, using precipitation and temperature as inputs to hydrologic models, ET is typically estimated as a function of PET. PET may be an exogenous input to hydrologic models, as in HEC-HMS, or it 
may be computed internally, as in LBRM which uses the Thornthwaite (1948) method.

As climate model outputs other than precipitation and temperature have received only moderate attention among hydrologists, hydrologic projections have continued to use empirical temperature proxy relationships to estimate PET (e.g. Croley, 2002; Hartmann, 1990; Chao, 1999; Lofgren et al., 2002; and Angel and Kunkel, 2010). Recent findings have shown that the temperature proxy methods fail to account for the surface radiation balance within the GCMs, including the negative effect of increased ET on surface temperature (Lofgren et al., 2011; Milly and Dunne, 2010; Shaw and Riha, 2011). A potential artifact of the temperature proxy approach is that reduced runoff is projected into the future as a result of an inconsistent energy budget between climate and hydrologic models. Among other studies describing limitations of temperature-based PET estimation, Shaw and Riha (2011) argue that temperature-based equations will shift with climate change and likely exaggerate PET in a warmer climate. Wild and Liepert (2010) illustrate that the improved knowledge of surface radiation balance is the key to better understanding variations in the hydrologic cycle, and shortcomings in the simulation of the surface radiation balance in climate models may contribute to the poor simulation of decadal variations in precipitation during the 20th century. Haddeland et al. (2012) demonstrate that radiation, humidity and wind speed estimates have potentially large effects on simulated water fluxes, and that using these values directly from climate models can result in very different evapotranspiration and runoff estimates than when using values based on reanalysis and observational data.

Lofgren et al. (2011) show how ET responses in the Great Lakes region can be exaggerated when the watershed models are forced only by temperature and precipitation from GCMs, as opposed to when ET is directly simulated from the same GCMs with integrated land surface-atmosphere models. ET predictions using LBRM driven by GCM temperature outputs (the temperature proxy method) were compared to the ET directly simulated by the same GCM. The results, presented in terms of latent heat flux, show considerable differences in ET simulations for the Great Lakes drainage basins. (In the months where mean temperature is above 0 degree Celsius, 1 $\mathrm{mm}$ /day of evaporation is considered equivalent to $29.07 \mathrm{~W} / \mathrm{m}^{2}$. For temperatures below 0 degree Celsius, $1 \mathrm{~mm}$ /day of evaporation is considered equivalent to 32.95 $\mathrm{W} / \mathrm{m}^{2}$ as a higher amount of latent heat is required to account for sublimation.) The results for the Lake Michigan drainage basin show a greater increase in the latent heat flux between the periods (1981-2000) and (2081-2100) when simulated by LBRM than when simulated directly from the GCMs. The annual mean difference in the latent heat flux is equivalent to $15 \mathrm{~W} / \mathrm{m}^{2}$, approximately $0.5 \mathrm{~mm} /$ day or $182 \mathrm{~mm} /$ year. These discrepancies were found to be even higher during spring when the soil moisture is abundant. In a similar experiment conducted by Milly and Dunne (2010), it was shown that the temperature-based modified Jensen-Haise formula, used in the 
hydrologic model Precipitation Runoff Modeling System (PRMS), estimates a change in PET that is typically 3 times the change implied by the climate models with surface energy budget considerations. These findings warrant caution when projecting changes in PET using hydrologic models to evaluate climate change impacts on water resources.

This study presented herein is similar to Lofgren et al. (2011), but a larger array of GCM projections is included to inform a multi-model ensemble approach to climate change impact assessment. Furthermore, unlike the lake level responses evaluated by Lofgren et al., watershed specific responses are evaluated by comparing precipitation, snow water equivalent, runoff and PET projections from the temperature proxy and energy conservation approaches. In the energy conservation approach, latent plus sensitive heat fluxes are used as surrogates for the net radiation budget, and comparisons are made to temperature-proxy based projections for the Great Lakes watersheds shown (Figure 4-1).

The following "Methods" section describes the overall radiative energy budget, including latent and sensible heat fluxes, to estimate PET from respective GCMs for input to LBRM; selection of representative future climate scenarios; and LBRM simulations using either the temperature proxy method or the energy conservation approach. The "Results" section discusses the streamflow and snow water equivalent (SWE) projections of three representative watersheds across the Great Lakes basin. Differences in hydrologic projections are evaluated in relation to watershed characteristics, hydrologic model parameters and climate projections. Finally, the "Conclusion" section includes a discussion of seasonal and regional variability of flow regimes, the conclusion of the overall study, and future directions of research to look more closely at the annual water budget in the Great Lakes basin. 


\section{Legend}

1. St. Louis

2. Bad

3. Fox

4. Au Sable

5. Black

6. Saginaw

7. Milwaukee

8. Grand

9. Clinton

10. Cattaraugus

11. St. Joseph

12. Cuyahoga

13. Maumee

14. Sandusky
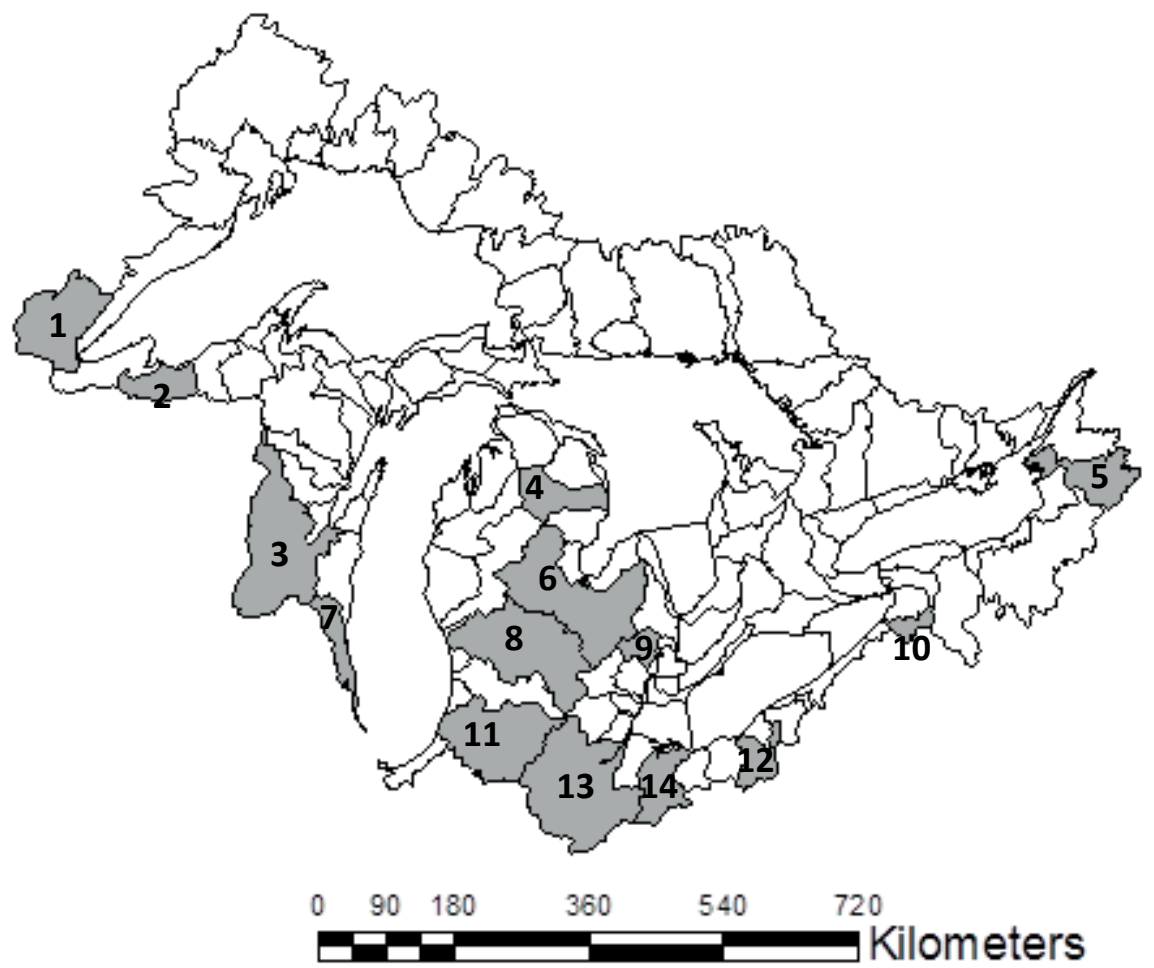

Figure 4-1 Selected watersheds in the Great Lakes basin

\subsection{Methods}

This section focuses on the energy conservation PET formulation and inputs to LBRM. The temperature-proxy PET formulation and the model structure of LBRM are described in greater detail in Chapters 2 and 3, as well as in Lofgren et al. (2011).

\subsubsection{Radiative energy budget}

In order to maintain a balance between incoming and outgoing energy at the surface, the following equation must be satisfied:

$$
S W-L W-S H-L H-G-S M=0
$$

Here, SW is net shortwave radiation; LW is net long-wave radiation; $\mathrm{SH}$ is sensible heat flux; LH is latent heat flux of evapotranspiration and sublimation; $\mathrm{G}$ is heat flux into the ground; and SM is latent heat of snowmelt. As discussed in Lofgren et al. (2011) and Milly and Dunne (2010), PET is explicitly dependent on the quantity (SW - LW - G $\mathrm{SM}$ ). For estimation of PET as input to LBRM using the energy conservation approach, this quantity is equated to the sum of latent and sensible heat fluxes 
$(\mathrm{LH}+\mathrm{SH})$ as derived from the respective GCMs. Latent heat flux is the energy required for the separation of attractive intermolecular forces to vaporize water to a gaseous phase. Sensible heat flux is the portion of radiant energy intercepted at the Earth's surface not used for evaporation, but used in warming the air in contact with the ground. The direction of sensible heat energy is upward from the ground during the day and downward at night (Maidment, 1992). Together, latent and surface heat fluxes constitute the physics of potential evapotranspiration.

\subsubsection{Climate scenario selection}

Climate scenarios are selected from an ensemble of 53 projections archived in World Climate Research Programme's Coupled Model Inter-comparison Project phase 3 (WCRP CMIP3) database (Meehl et al., 2007). These 53 projections come from 16 GCMs, downscaled using the bias-corrected construction analog (BCCA) method. The BCCA CMIP3 projections include maximum temperature, minimum temperature and precipitation downscaled at $1 / 8$ th of a degree $(\sim 12 \mathrm{~km}$ resolution) and a daily time step. Although the downscaled data are already bias-corrected, residual precipitation biases were found to exist in the U.S Great Lakes region (Gyawali et. al 2013). These biases were corrected using the change factor method prior to input to LBRM.

Climate scenario selection is based on percent changes in precipitation and absolute changes in temperature between the historical baseline period (1980-1999) and a future period (2046-2065), as shown in Figure 4-2. The quadrants are divided according to median changes in precipitation and temperature. A total of nine scenarios were selected to be representative of the entire ensemble. A few scenarios which reported outlier future radiative fluxes were not included in the analysis. Table 4-1 summarizes the selected scenarios, including the GCM runs, corresponding grid sizes and representative future climates. 


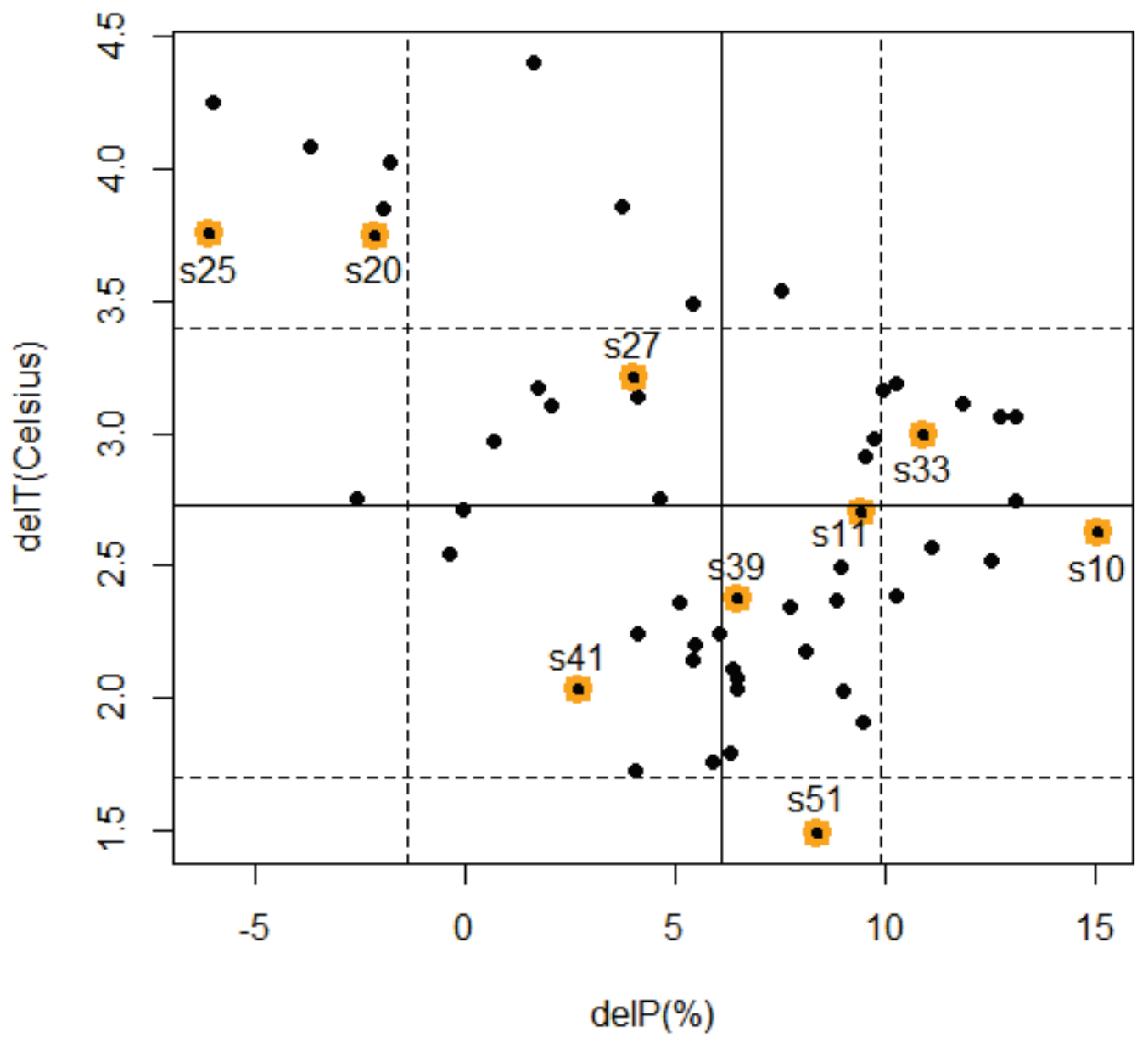

$\mathrm{F}$ igure 4-2 $\mathrm{F}$ uture climate scenarios in the $\mathrm{G}$ reat $\mathrm{L}$ ak esdpasisented by percent change in precipitation and absolute change (degree $\mathrm{C}$ elsiusin temperature between the historic and the near future period 2046-2065 from 53 B C C A C M I P3 projections selected climate scenarios representative of characteristic future climates are highlighted. 
Table 4-1 Selected GCMs runs, corresponding grid size, emission scenario and representative future climate used as inputs to LBRM

\begin{tabular}{lllll}
\hline S.N & GCM runs & $\begin{array}{l}\text { Emission } \\
\text { Scenario }\end{array}$ & Grid size & $\begin{array}{l}\text { Representative } \\
\text { future climate }\end{array}$ \\
\hline S10 & cnrm_cm3.1. & a1b & $2.81^{\circ} \mathrm{X} 2.79^{\circ}$ & wet cool extreme \\
S11 & cnrm_cm3.1. & a2 & $2.81^{\circ} \mathrm{X} 2.79^{\circ}$ & wet warm average \\
S20 & ipsl_cm4.1. & a 2 & $3.75^{\circ} \mathrm{X} 2.54^{\circ}$ & dry warm average \\
S25 & miroc3_2_medres.2. & a 2 & $2.81^{\circ} \mathrm{X} 2.79^{\circ}$ & dry warm extreme \\
S27 & miroc3_2_medres.2. & b1 & $2.81^{\circ} \mathrm{X} 2.79^{\circ}$ & dry cool extreme \\
S33 & miub_echo_g.3. & a2 & $3.75^{\circ} \mathrm{X} 3.71^{\circ}$ & wet warm extreme \\
S39 & mri_cgcm2_3_2a.1. & a1b & $2.81^{\circ} \mathrm{X} 2.79^{\circ}$ & wet cool average \\
S41 & mri_cgcm2_3_2a.3. & a1b & $2.81^{\circ} \mathrm{X} 2.79^{\circ}$ & dry cool average \\
S51 & mri_cgcm2_3_2a.3. & b1 & $2.81^{\circ} \mathrm{X} 2.79^{\circ}$ & wet cool extreme \\
\hline
\end{tabular}

\subsubsection{LBRM simulation using temperature and energy adjustment approaches}

The distinction between the temperature adjust and the energy adjust methods for simulating hydrologic impacts of climate change with LBRM is based on potential evapotranspiration (PET) inputs to the model. The temperature adjustment approach uses a temperature proxy relationship (Thornthwaite method) to estimate PET directly using the bias-corrected temperature inputs from the GCMs, as described in Chapter 3. An assembly of boundary conditions, parameter and meteorological inputs, based on the GCM and observed climatology, is then used to simulate LBRM in historic and future periods.

As a variant of the temperature adjustment method, the energy adjust method requires an additional input from the GCMs: monthly latent plus sensible heat flux. To compute PET, the energy adjust method first calculates PET based on the historical air temperatures. The future monthly PET is then adjusted by the ratio of future to historical latent plus sensible heat flux, instead of being adjusted using the change factor of temperature.

LBRM estimates PET internally using maximum and minimum daily temperature inputs. In order to adjust PET in LBRM using the principle of energy conservation, virtual temperature series are constructed for calculating PET within the model based on the Thornthwaite method (rather than changing the model code). The virtual change in temperature $\Delta \mathrm{T}$, obtained using equation (4) is applied to the maximum and minimum temperature inputs to run LBRM in the energy adjustment mode. 
In LBRM, PET is given by:

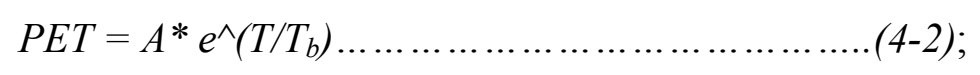

where $A$ and $T_{b}$ are parameters fitted by the calibration, which do not change in simulations. Given the non-stationary nature of stream flows in the future, assuming the calibrated parameters would remain unchanged is a common limitation for most hydrologic models, including this effort. Further, the correlation between the calibrated parameters $A$ and $\mathrm{T}_{\mathrm{b}}$ (Figure 4-3) indicates the non-uniqueness of the calibration process. Higher values of $A$ are offset by higher values of $T_{b}$, indicating that there is not much variation in historic PET across the region.

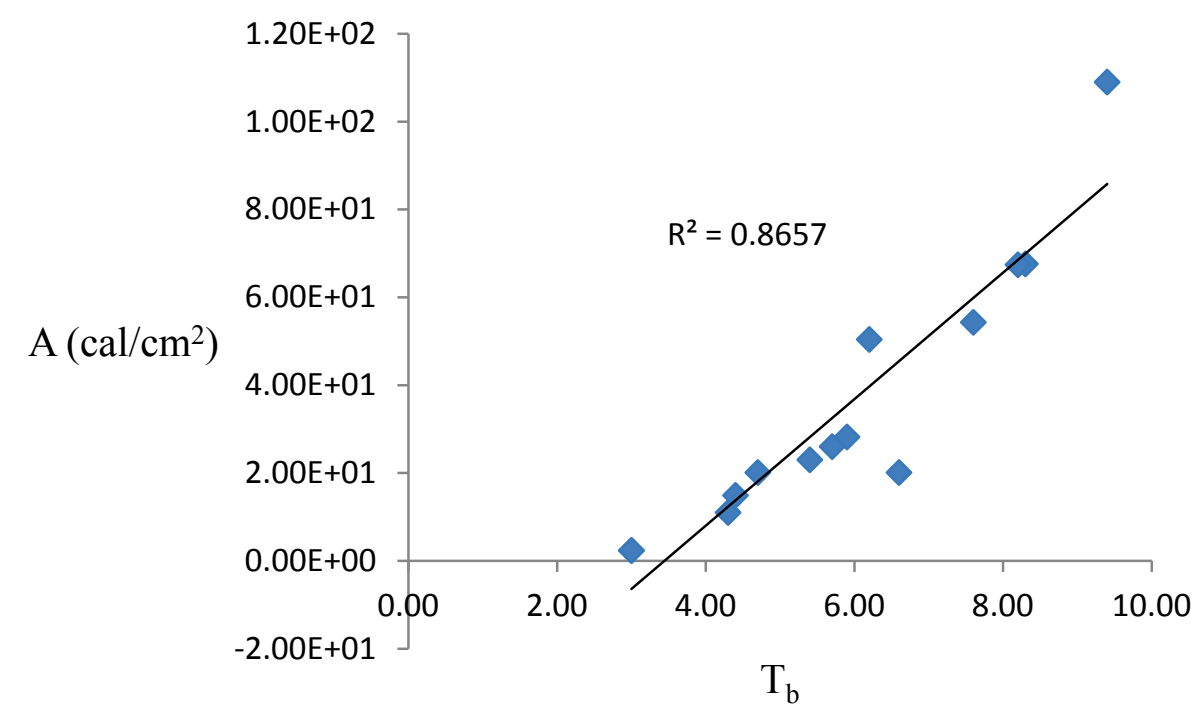

Figure 4-3 Relationship between parameters $\mathrm{T}_{\mathrm{b}}$ and A for 14 Great Lakes watersheds

The ratio of future to historic PET based on equation (4-2) can be equivalently stated as in equation (3):

$$
\begin{aligned}
P T_{\text {ratio }} & =\left(P E T_{\text {future }} / P E T_{\text {historic }}\right)=\left\{A^{*} e^{\wedge}\left(T_{\text {future }} / T_{b}\right)\right\} /\left\{A^{*} e^{\wedge}\left(T_{\text {historid }} / T_{b}\right)\right\} \\
& =e^{\wedge}\left\{\left(T_{\text {future }}-T_{\text {historic }}\right) /\left(T_{b}\right)\right\} \ldots \ldots \ldots \ldots \ldots \ldots \ldots \ldots \ldots \ldots \ldots \ldots \ldots \ldots \ldots \ldots \ldots \ldots
\end{aligned}
$$

Rearranging and solving for the "virtual" change in temperature gives the following:

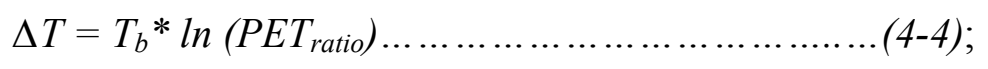

where $\Delta T=T_{\text {future }}-T_{\text {historic }}$. 
The TA method uses GCM-derived temperature to estimate PET directly using equation. (4-2). In contrast, the EA method derives PET directly from the GCMs using radiative fluxes as surrogates, and the virtual temperature change in equation (44 ) is used to derive corresponding temperature inputs to LBRM. This requires a twostep method to estimate runoff with the EA method. First, the TA method is run to determine periods with snow, and then the virtual temperature adjustment is applied for the EA method on snow-free days.

The hydrology of 14 selected watersheds is simulated using both temperature adjust (TA) and energy adjust (EA) methods to evaluate projections for climate change impact assessment. Figure 4-4 shows an example of EA and TA PET estimates of the Maumee River watershed. As shown, the TA method results in a significantly increased PET in the future periods, whereas the future EA PET estimates result in a more moderate increase. 


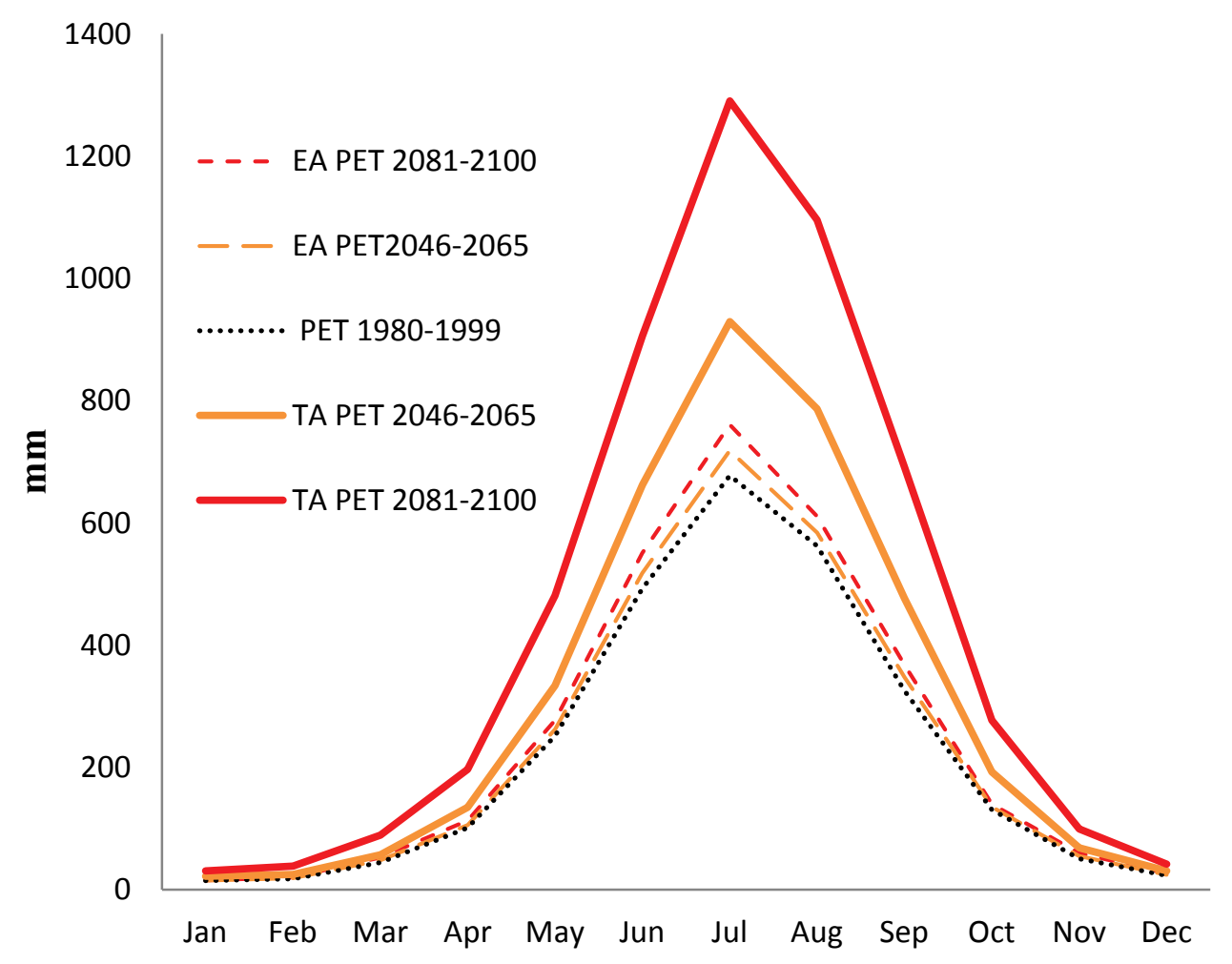

Figure 4-4 Comparison of temperature adjust (TA) and energy adjust (EA) method estimated PET of the baseline (1980-1999) and the ensemble mean of the future periods (2046-2065) and (2081-2100) for Maumee River watershed

\subsection{Results}

The results from the hydrologic simulations based on TA and EA methods are presented as a function of impacts on streamflow and SWE. The hydrologic responses of the selected 14 watersheds are further evaluated in relation to watershed characteristics, hydrologic model parameters and climate projections.

\subsubsection{Comparison of streamflow projections}

Table A-1 to Table A-8, (in Appendix B) and Figure 4-7 summarize the mean annual percent change in runoff, precipitation and PET across 9 selected scenarios between the baseline (1980-1999) and the ensemble mean of near-future (2046-2065) and far-future (2081-2100) periods, based on simulations using the EA method. To evaluate the role of specific watershed characteristics in varied flow responses, significant physical variables of the regional regression model (Gyawali et al., 2013) based on the GAGES II dataset (Falcone et al., 2012) are reviewed (Table 4-2). 
Table 4-2 Significant physical variables of the regional regression model (Gyawali et. al., 2013) based on GAGES II dataset (Falcone et al., 2012)

\begin{tabular}{ccccc}
\hline Watershed & $\begin{array}{c}\text { Area } \\
\left(\mathbf{k m}^{\mathbf{2}}\right)\end{array}$ & $\begin{array}{c}\text { Average } \\
\text { permeability } \\
\mathbf{( c m} / \mathbf{h r})\end{array}$ & $\begin{array}{c}\text { Mean } \\
\text { watershed } \\
\text { slope } \mathbf{( \% )}\end{array}$ & $\begin{array}{c}\text { Stream } \\
\text { density } \\
\left(\mathbf{k m} / \mathbf{k m}^{\mathbf{2}}\right)\end{array}$ \\
\hline Sandusky & 4607 & 2.51 & 0.52 & 0.87 \\
Maumee & 16806 & 2.03 & 0.42 & 0.85 \\
Cuyahoga & 2070 & 4.65 & 0.52 & 0.82 \\
St. Joseph & 12114 & 20.2 & 0.97 & 0.54 \\
Cattaraugus & 1427 & 5.90 & 6.85 & 0.71 \\
Clinton & 1921 & 2.82 & 0.99 & 0.70 \\
Lower Grand & 12114 & 9.24 & 1.22 & 0.63 \\
Milwaukee & 2224 & 10.5 & 1.98 & 0.56 \\
Saginaw & 15761 & 13.2 & 0.74 & 0.79 \\
Black & 5768 & 13.5 & 5.54 & 0.84 \\
Au Sable & 5159 & 28.6 & 1.91 & 0.31 \\
Lower Fox & 16383 & 12.0 & 1.55 & 0.61 \\
Bad & 3427 & 5.05 & 3.45 & 0.76 \\
St. Louis & 9707 & 10.6 & 1.03 & 0.54 \\
\hline
\end{tabular}

The watersheds presented are ordered by the latitude of basin centroids in Figure 4-5 and Figure 4-6, with the southern watersheds followed by the northern ones. The range of projected streamflow changes across the 9 selected scenarios are presented in Table 4-3; the monthly average percent changes in runoff, precipitation and PET, as well as projected change in temperature, are shown in Table A-1 through Table A-8 in Appendix B. 
Table 4-3 The range of projected changes in runoff in the study watersheds across nine climate change scenarios

\begin{tabular}{ccc}
\hline Watershed & $\begin{array}{c}\text { Range of \% change in } \\
\text { projected runoff between } \\
(\mathbf{1 9 8 0 - 1 9 9 9 )} \text { and }(\mathbf{2 0 4 6 - 2 0 6 5 )})\end{array}$ & $\begin{array}{c}\text { Range of \% change in } \\
\text { projected runoff between } \\
(\mathbf{1 9 8 0 - 1 9 9 9 )} \text { and (2081-2100) }\end{array}$ \\
\hline Sandusky & -6.5 to -12.5 & -4.2 to -19.1 \\
Maumee & -11.7 to -18.1 & -10.1 to -23.3 \\
Cuyahoga & 0.3 to -5.6 & -0.7 to -13.5 \\
St. Joseph & 1.0 to -8.8 & 3.1 to -16.1 \\
Cattaraugus & 7.3 to 14.3 & 5.4 to 16.1 \\
Clinton & -2.5 to 6.3 & -4.4 to 4.9 \\
Lower Grand & -2.9 to -5.9 & 4.7 to -10.5 \\
Milwaukee & 1.9 to -0.1 & 3.9 to -1.4 \\
Saginaw & 4.2 to 10.1 & 4.2 to 8.8 \\
Black & -2.6 to 3.1 & -4.9 to 10.4 \\
Au Sable & -6.4 to -15.4 & -8.2 to -15.2 \\
Lower Fox & 10.2 to 2.3 & 12.1 to -1.0 \\
Bad & 7.01 to -2.1 & 10.0 to 3.6 \\
St. Louis & 8.4 to 0.5 & 6.0 to 14.8 \\
\hline
\end{tabular}

Overall, the Great Lakes watersheds appear to respond differently to climate change. For instance, the southern watersheds (Maumee and Sandusky) have large reductions in summer flows under future climates; whereas the northern watersheds (St. Louis and Bad) show relatively small reductions in summer flows. Other basins (Cattaraugus, Fox and Cuyahoga) show moderate to large increases in winter/spring flows (Table A-1 and Table A-8). Differences in flow regimes are related to differences in watershed characteristics, including physiographic factors, storage and land-use characteristics, aridity or future climate projections. For example, higher spring peak flows in the watersheds considered, excluding Au Sable, could be a result of increased winter precipitation and warmer springs leading to increased snowmelt rates. 


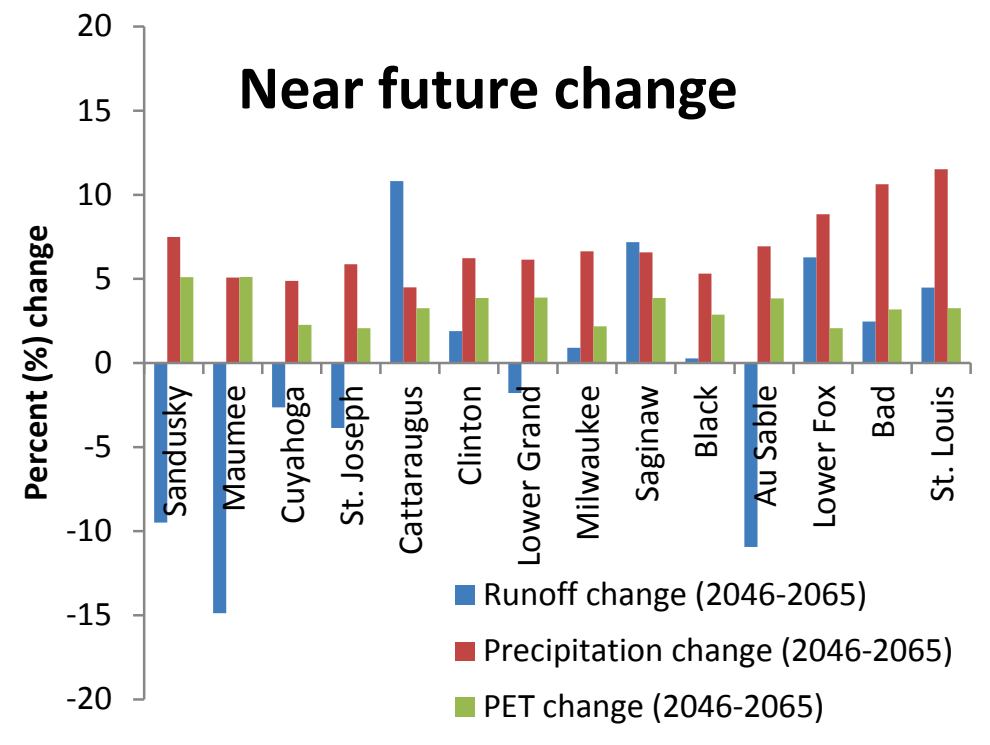

Figure 4-5 Annual average percent changes in runoff, precipitation and PET of the selected watersheds between the baseline period (1980-1999) and the ensemble mean of the near-future period (2046-2065)

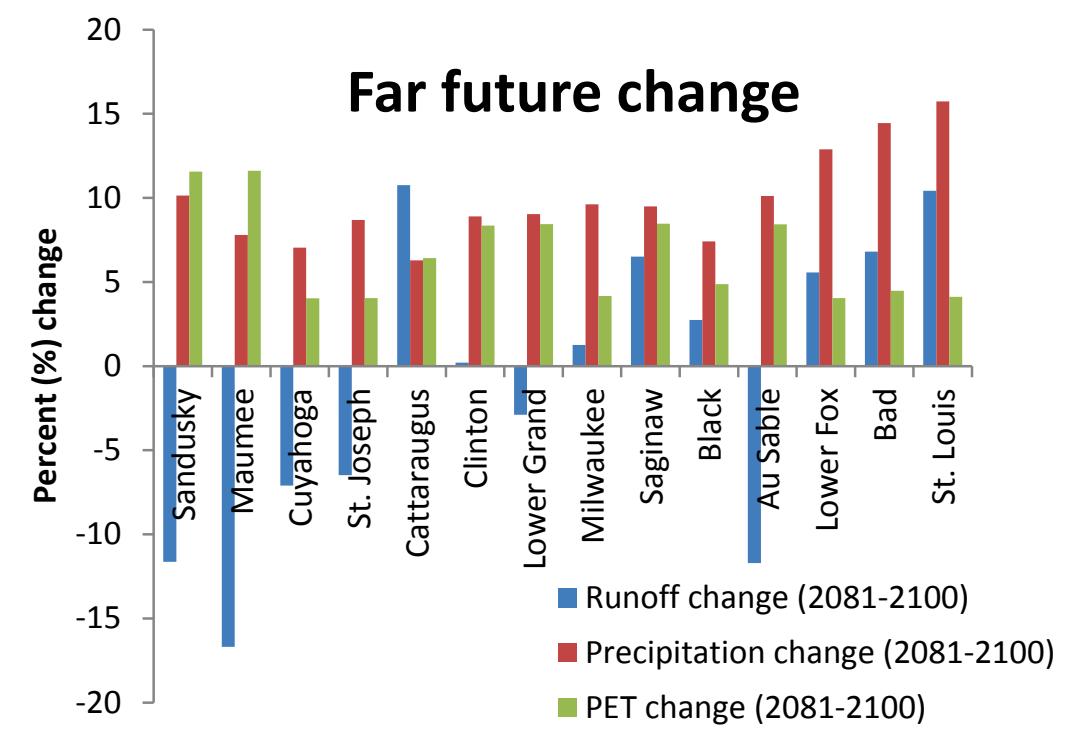

Figure 4-6 Annual average percent changes in runoff, precipitation and PET of the selected watersheds between the baseline (1980-1999) and the ensemble mean of farfuture period (2081-2100) 


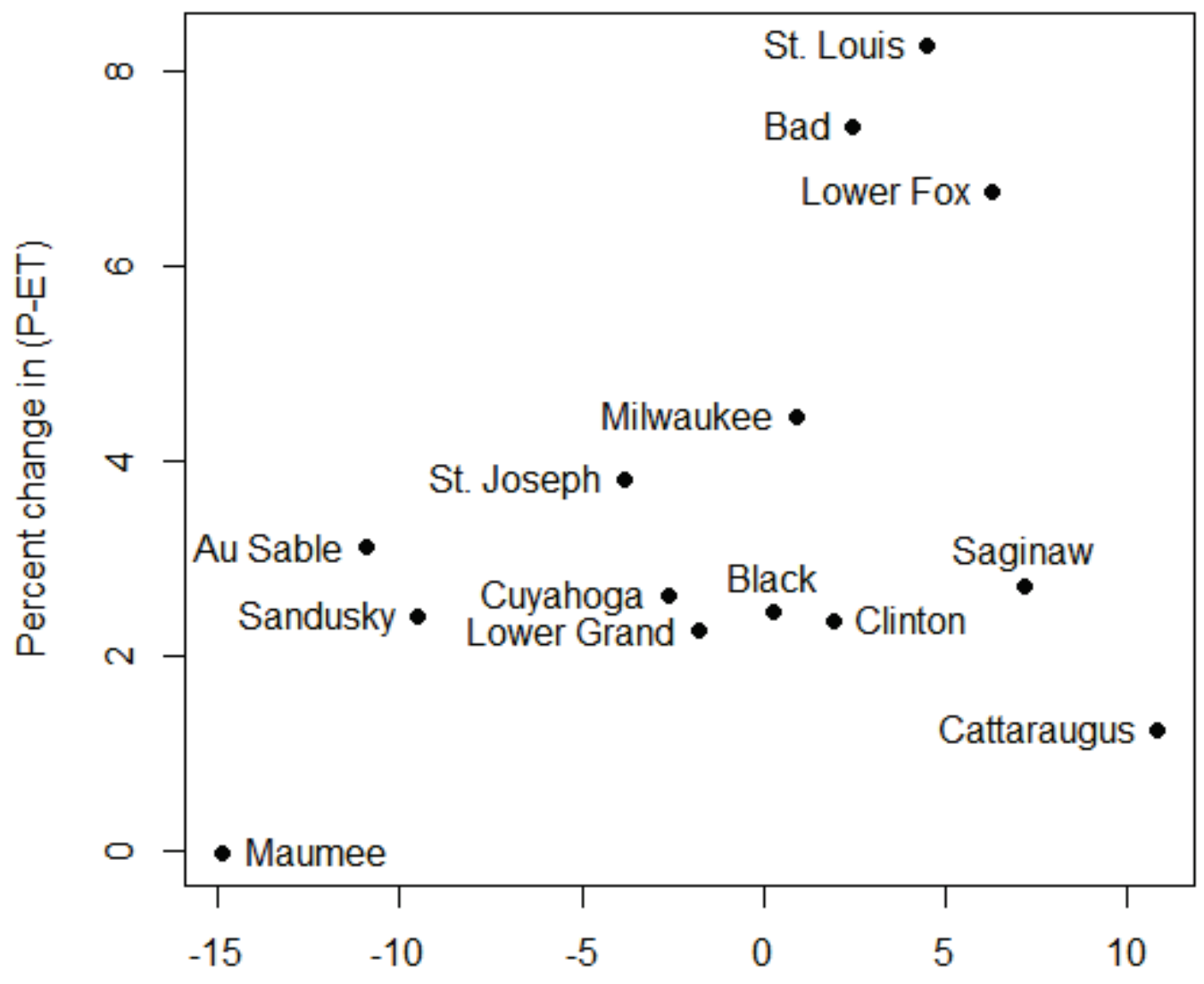

Percent runoff change between(1980-1999) and (2046-2065)

$\mathrm{F}$ igure 4-7 $\mathrm{R}$ elationship of percent change in runoff and the difference in percent change in precipitation and evapotranspiration between the periods (1980-1999) and (2046-2065)

I $t$ is found that EAbased simulations of the $G$ reat $L$ ak es watersheds yield variable average annual runoff changes for similar precipitation and PET changes ( $F$ igure 4-5nd $F$ igure 4- $6 \mathrm{~F}$ igure 4-7 shows the relationship between percent change in runoff $(\mathrm{Q})$ and the difference between percent change in precipitation and evapotranspiration $(\mathrm{P}-\mathrm{ET})$ in the watersheds considered. I $\mathrm{t}$ can be inferred from the relationship that runoff change may be affected by other watershed characteristics, in addition to the precipitation and evapotranspiration $(\mathrm{P}-\mathrm{ET})$ differences. $\mathrm{F}$ or ex ample, $\mathrm{C}$ attaraugus, $\mathrm{C}$ linton and $\mathrm{S}$ aginaw show increased runoff response althoughPГ-is 
not large relative to other watersheds. $\mathrm{F}$ urther, watersheds with smaller $\mathrm{P}$ ET values may be vulnerable to droughts while those with larger P - ET may be susceptible to floods. Among the southernmost watersheds, Sandusky, $\mathrm{M}$ aumee, $\mathrm{C}$ uyahoga and $\mathrm{S} \mathrm{t}$. $\mathrm{J}$ oseph, which experiencerelatively high temperatures and PET in the baseline period given their lower latitude, the largest flow reductions are ex pected in $\mathrm{M}$ aumee $\mathrm{R}$ iver watershed. This could be a conseq uence of its dominant surface flow regira (i.e., low baseflow contribution), resulting in a higher potential for evaporative losses. $\mathrm{F}$ igure 4-8 shows the analysis of L B R M baseflow coefficients, indicatianglercolation and interflow coefficients in the $\mathrm{M}$ aumee $\mathrm{R}$ iver watershed compared to other watersheds. S imilarly, C attaraugus, $\mathrm{C}$ uyahoga, $\mathrm{S}$ t. J oseph, $\mathrm{C}$ linton, B ad and Milwaukee are found to have larger percolation and inter-flow coefficients, indicating more sustained baseflow regimes, consistent with the estimates of baseflow index (BFI) of the $\mathrm{G}$ reat Lakes basin ( $\mathrm{N}$ eff, 2005).

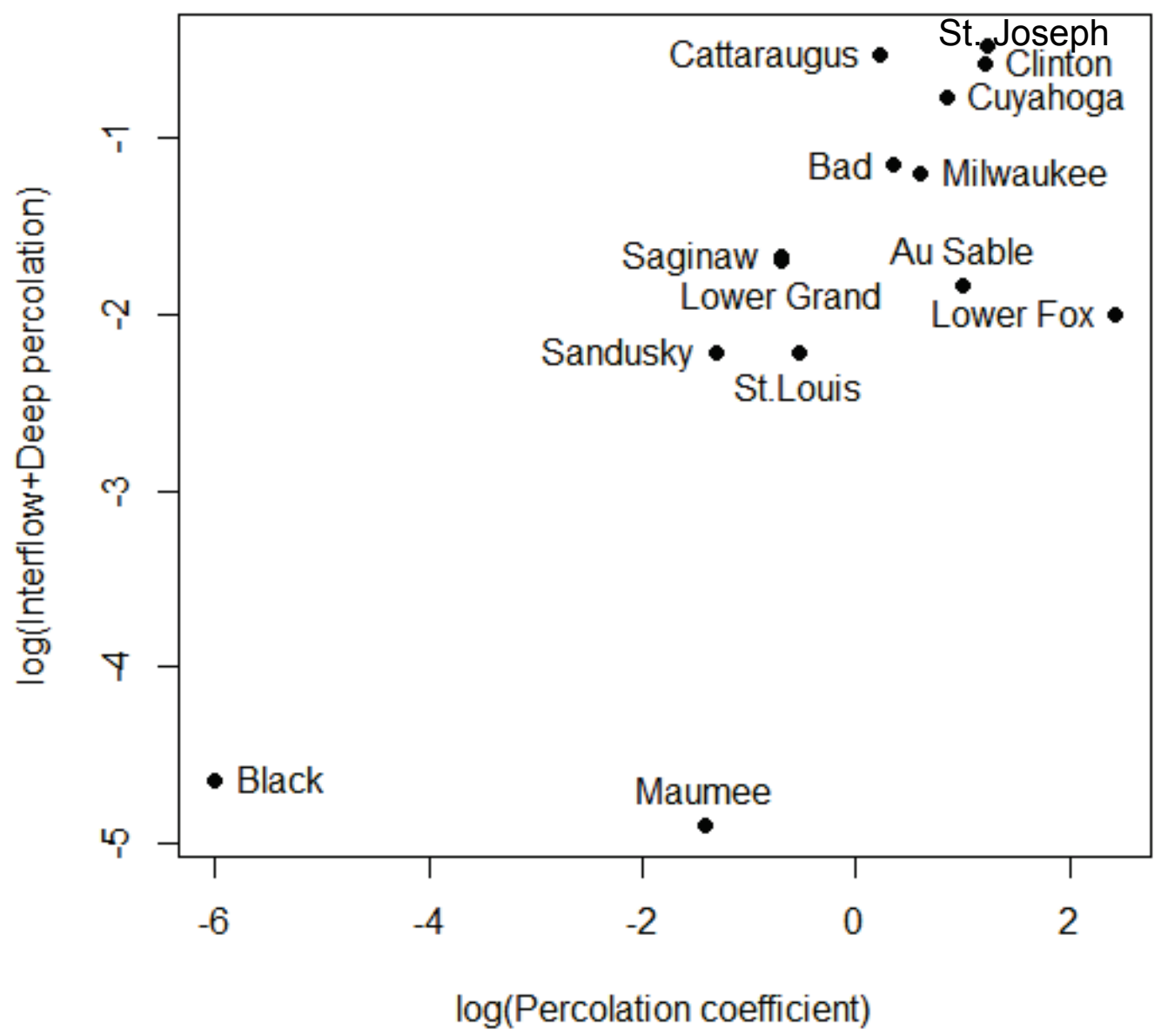

F igure 4-8 R elationship of interflow and deep percolation coefficients to percolation coefficient, indicating base flow regime in $L \quad B \quad R \quad M$ 
The Maumee basin has the lowest average permeability rate $(2.03 \mathrm{~cm} / \mathrm{hr})$ and minimum watershed slope $(0.42 \%)$ of the basins considered, and thus more water is available on the surface for ET, resulting in a larger reduction in flows as observed in Figure 4-14 and Figure 4-15. Similarly, a larger increase in runoff is seen for the St. Louis basin than the neighboring Bad watershed, despite the higher mean watershed slope of Bad. This could be a result of the larger increase in precipitation projected for St. Louis, offsetting the influence of this watershed characteristic. In addition, the larger average permeability $(10.6 \mathrm{~cm} / \mathrm{hr})$ in St. Louis than Bad may contribute to more sustained baseflow and less water available for evaporative losses in the St. Louis basin. Similarly, the larger flows predicted in the Saginaw River watershed may be attributed to its high stream density and relatively high base flow (average permeability $\sim 13.2 \mathrm{~cm} / \mathrm{hr}$ ). Cattaraugus has the largest net increase in runoff, and this could be a consequence of its high runoff velocity due to its steep topography, indicated by the largest mean watershed slope $(6.85 \%)$ of all the watersheds.

The Black River basin has a relatively steep slope and reasonably high stream density and permeability, and relatively little change in runoff is projected compared to other watersheds. It is observed that the major tributary of Black is more elongated than other watersheds which are projected to have higher flows, e.g. Cattaraugus, Lower Fox and Saginaw (Figure 4-9). Among these watersheds, Black has the largest main channel flow length per unit area $\left(0.036 \mathrm{~km} / \mathrm{km}^{2}\right)$ compared to Cattaraugus $\left(0.031 \mathrm{~km} / \mathrm{km}^{2}\right)$, Saginaw $\left(0.005 \mathrm{~km} / \mathrm{km}^{2}\right)$ and Fox $\left(0.007 \mathrm{~km} / \mathrm{km}^{2}\right)$. The relatively long flow length given the area of the watershed increases the residence time of flow within the watershed, allowing an increased potential for infiltration and evaporative losses. In addition, the main channel slope relative to average watershed slope of the Black watershed (0.077) was found to be lower than Cattaraugus (0.094), Saginaw (0.298) and Fox (0.290) watersheds. Figure 4-9 shows the river networks in watersheds for which higher flows are projected, including the Black River watershed. 


\section{a) Saginaw}

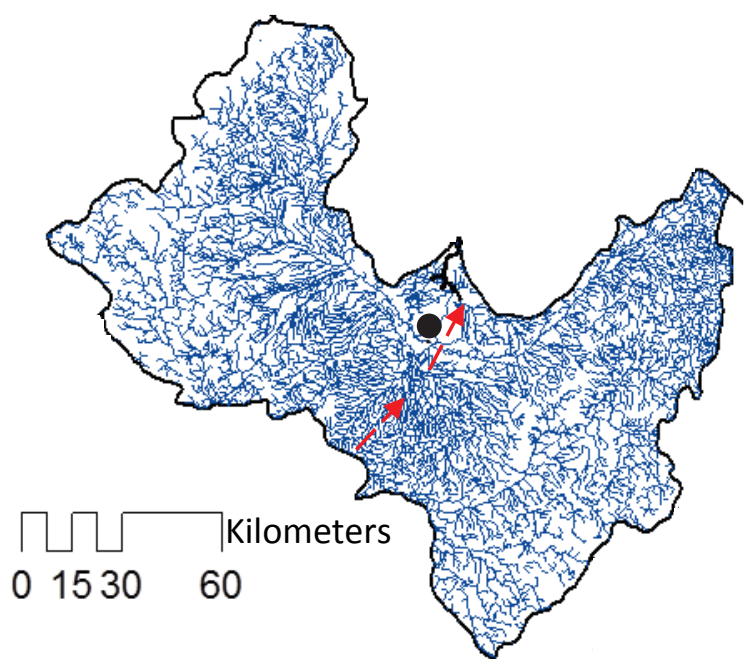

c) Black

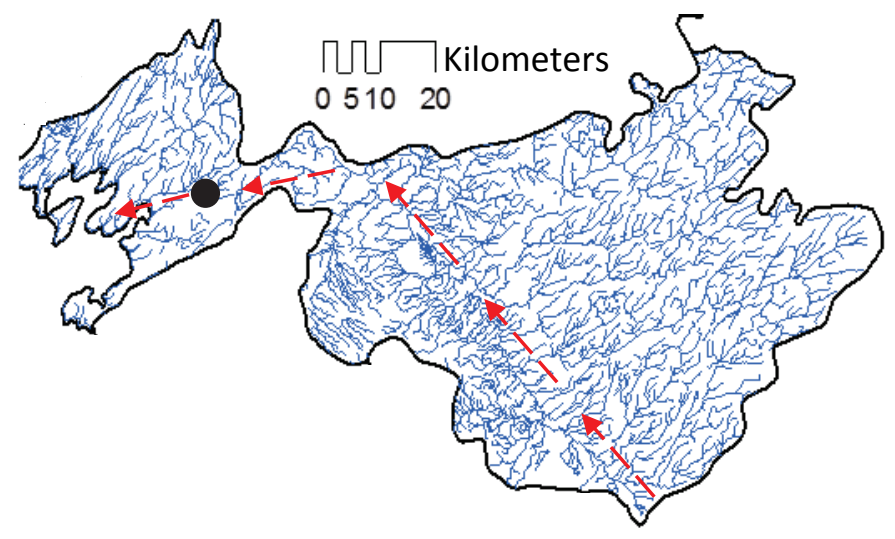

b) Fox

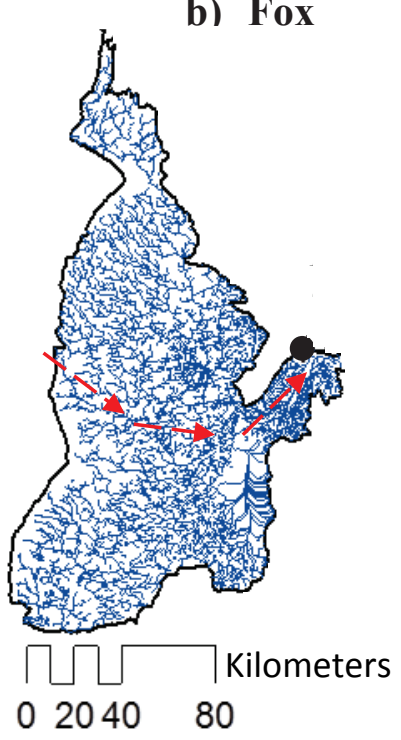

d) Cattaraugus

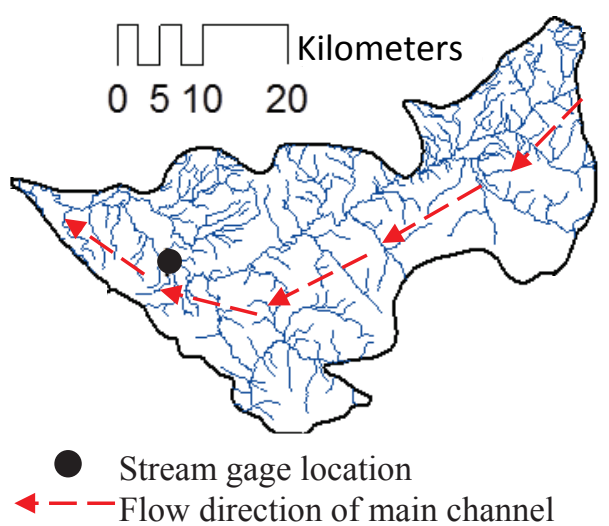

Figure 4-9 River networks, flow directions and the most downstream USGS streamflow locations for Saginaw, a); Fox, b); Black, c) and Cattaraugus, d) watersheds.

Unlike other watersheds, projections for the Au Sable River watershed in MI indicated reduced ensemble mean runoff throughout the year, as shown in Figure 4-10. During the baseline period, the Au Sable had consistent runoff throughout the year, possibly due to its dominant baseflow regime, with discharges ranging from 23 to 36 millimeters. For comparison, the surface flow dominated Maumee River watershed--a watershed thrice as large--has monthly discharges ranging from 10 to 48 millimeters. The average permeability in the Au Sable watershed $(28.6 \mathrm{~cm} / \mathrm{hr})$ is the largest of all watersheds considered, and it has the smallest streamflow density $\left(0.31 \mathrm{~km} / \mathrm{km}^{2}\right)$. 
Therefore, the watershed has the potential to hold moisture for a longer period before it finally drains into the streams. Table A-6 shows that the largest decrease in summer precipitation occurs in Au Sable, with especially large decreases in July and August. Therefore, there is a larger infiltration potential for the precipitation that occurs in fall, resulting in reduced runoff response in this season. However, as shown in Figure 4-10 there is less flow reduction in winter as the soils get more saturated in the fall than summer.

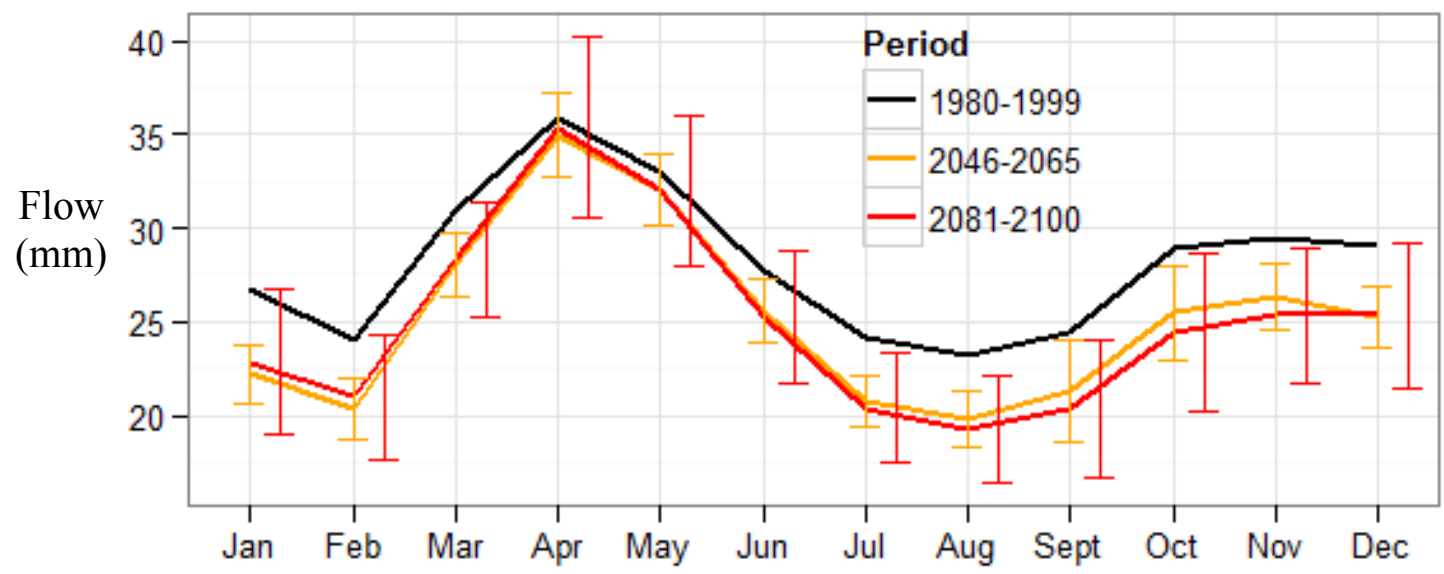

Figure 4-1 Energy adjust (EA) projections of Au Sable River watershed as simulated by LBRM. Standard deviations are shown about ensemble means of near future (2046-2065) and far future (2081-2100) periods.

Relative humidity also has an important influence on the ET of the watershed, as ET is directly related to the moisture deficit in the air. The moisture availability in all 14 watersheds in the Great Lakes is assessed based on the Budyko hypothesis (Budyko, 1974), which relates the ratio of ET to precipitation to climate through an aridity index, defined as the ratio of PET to precipitation. Figure 4-11 indicates the humid and arid climates in the Great Lakes basin, showing the Au Sable watershed to have the most arid climate and hence the most potential for evaporative losses in warmer climates. The PET/P estimates calculated herein are typically higher than those estimated by Milly and Dunne (2010), but this could be due to the different PET estimation methods used in these studies. 


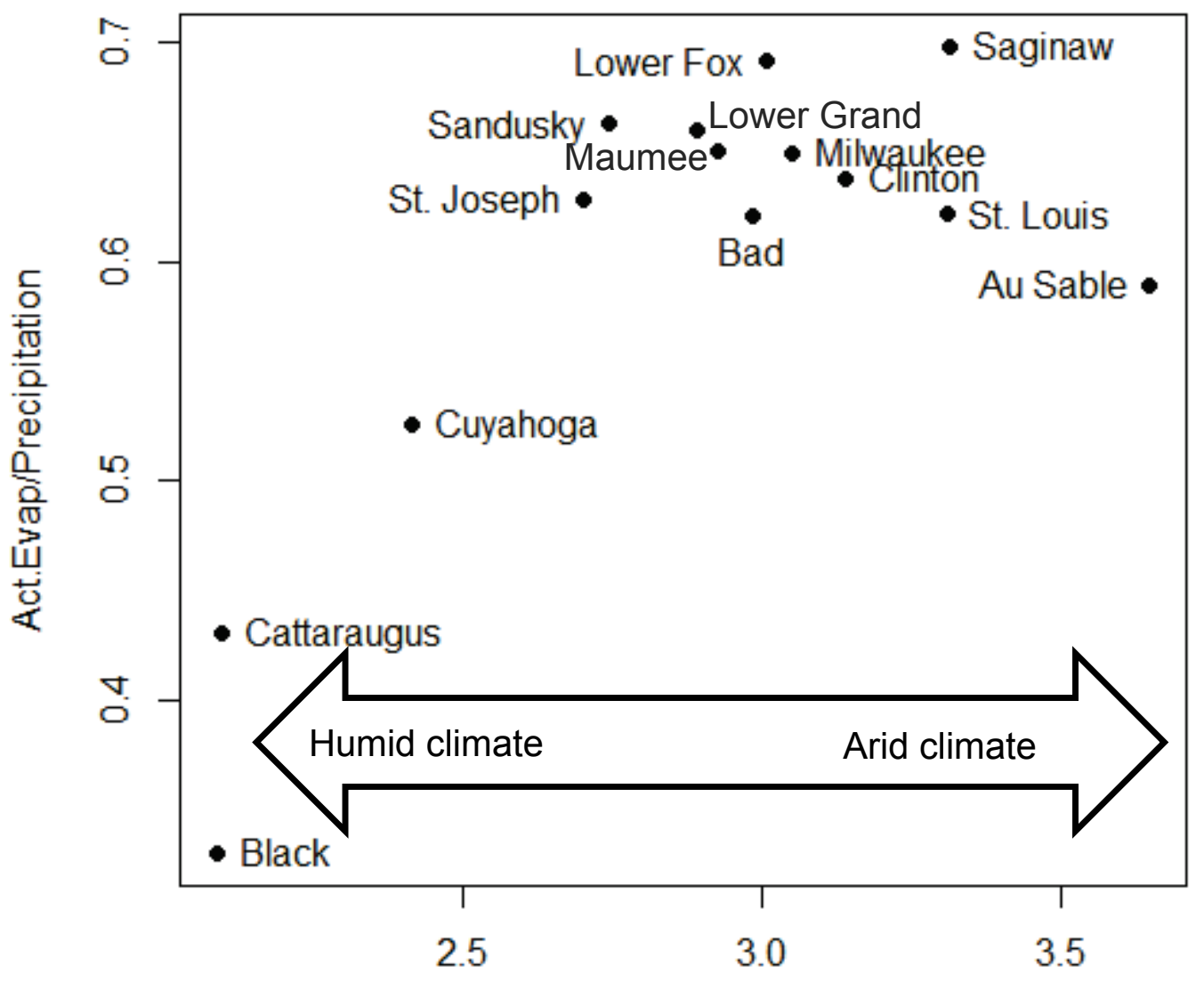

PET/Precipition

F igure 4-11C haracteriz ation of the humidity regime of the selected watersheds in the $\mathrm{G}$ reat $\mathrm{L}$ ak es basin based on the ratio of ET to precipitation as a function of ratio of PET to precipitation. V alues are based on $\mathrm{L} B \mathrm{R}$ M simulations, calibrated to observations (1961-1999).

To compare proj ections based on $\mathrm{L} \quad \mathrm{B} \quad \mathrm{R} \quad \mathrm{M}$ simulations using the EA and TA methods, results for the following three watersheds are shown in greater detail to represent three identified flow regimes in the $\mathrm{G}$ reat $\mathrm{L}$ ak es basin: $\mathrm{M}$ aumee, representing larger summer flow reductions; $\mathrm{S}$ t. $\mathrm{L}$ ouis, representing relatively small reductions in summer flows and large increases in spring/ winter flows; and Fox, representing moderate reductions in summer and moderate increases in spring/ winter flows.

Two approaches are used to present and evaluate hydrologic proj ections from the TA and EA methods. F irst, average monthly proj ections of L B R M model inputs (precipitation, temperature, PET) and output (runoff) are compared. S econd, simulated time series of runoff under the selected G C M scenarios (Table 4-1) are presented 
using empirical cumulative distribution functions (CDFs). LBRM simulated input and output variables of the baseline (1980-1999), near-future (2046-2065) and far-future (2081-2100) periods including monthly precipitation, maximum temperature, PET, ET, and runoff, along with CDFs of runoff are shown in Figure 4-12 through Figure 4-23. It is found in all instances that the TA approach leads to more severe decreases in simulated runoff than the EA method. The decrease in runoff is more pronounced in spring and summer seasons, as PET estimates are significantly higher during these seasons. In addition to more moderate runoff changes, EA projections have wider seasonal and regional variations with respect to precipitation, temperature and PET changes. There is larger variability in precipitation than temperature across all the scenarios concerned. The variability in TA PET is much larger, which leads to more uncertainty in future flow estimates. 
a) P ecipitation ( $\mathbf{m m})$

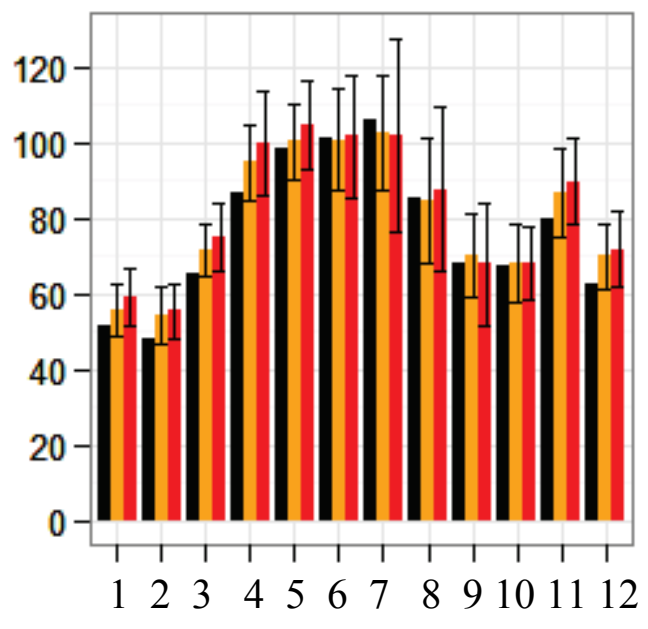

b) Maximum $\mathbf{T}$ emperature $\mathbf{C})$

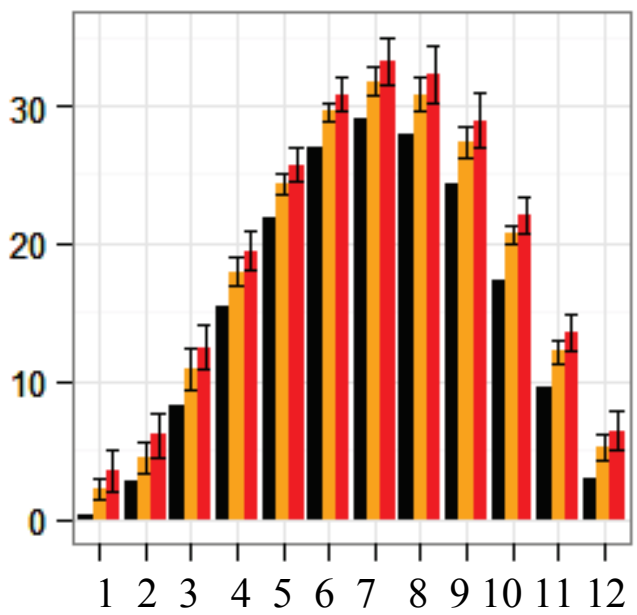

d) E nergy Adj ust P $E$ T （ mI

\section{c) $T$ emperature Adj ust $P$ E $T \quad(n$}
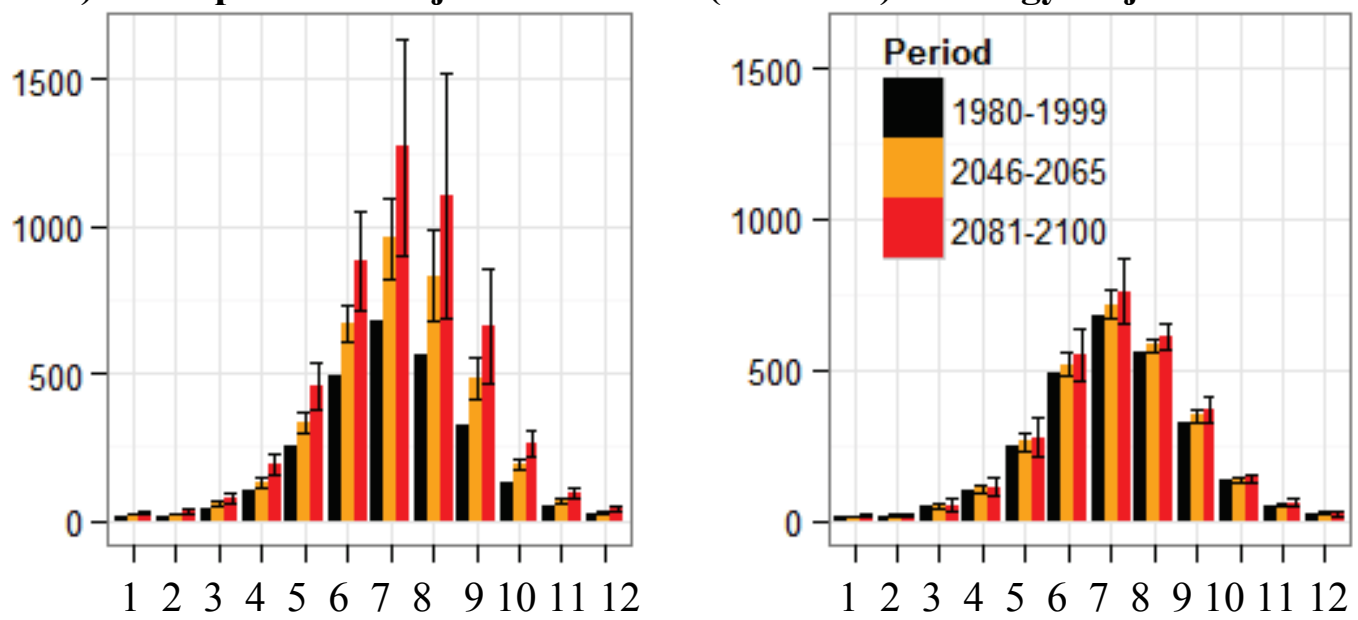

$F$ igure 4-12M aumee watershed inputs to the $\mathrm{L}$ arge $\mathrm{B}$ asin $\mathrm{R}$ unoff $\mathrm{M}$ odel ( $\mathrm{L} B \mathrm{R} \quad \mathrm{M}$ ). $\mathrm{S}$ hown are biasorrected monthly precipitation, $\mathrm{a}$ ); max imum temperature, $\mathrm{b}$ ); temperature adj ust PET, c); and energy adj ust PET, d); proj ections. S tandard deviations are shown about ensemble means of near future (2046-2065) and far future (2081-2100) periods. 


\section{a) $\mathbf{T}$ emperature Adj ust $\mathbf{E} \quad \mathbf{T}$ ( $\mathbf{m m})$}

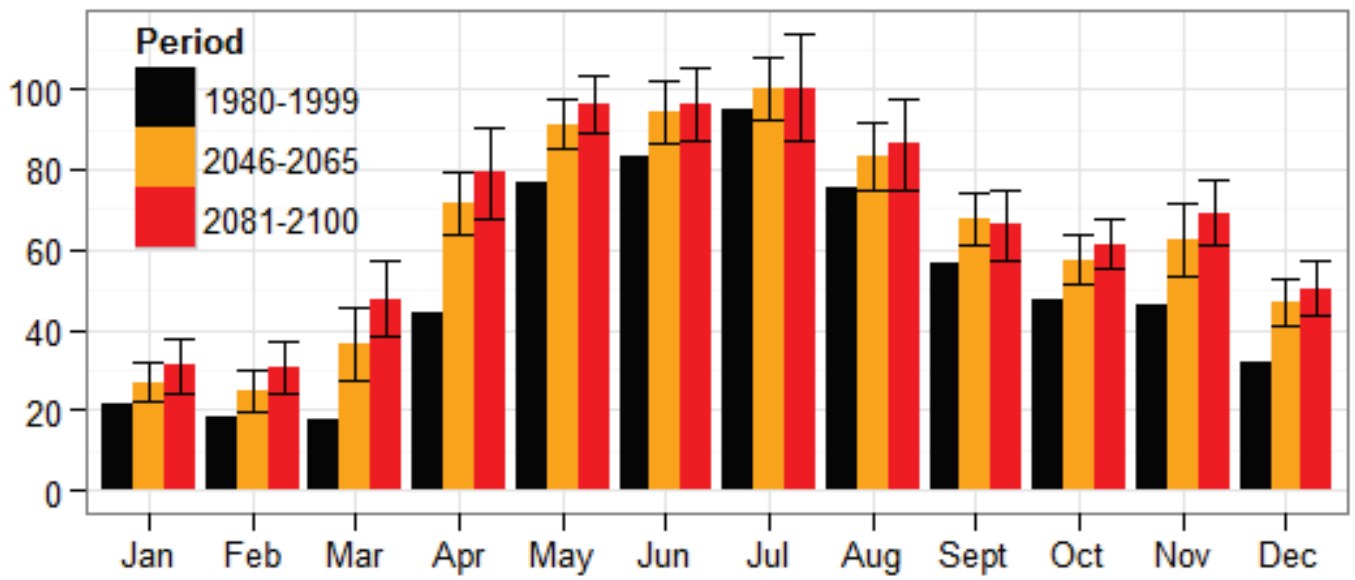

b) E nergy Adj ust E T ( $\mathbf{m m})$

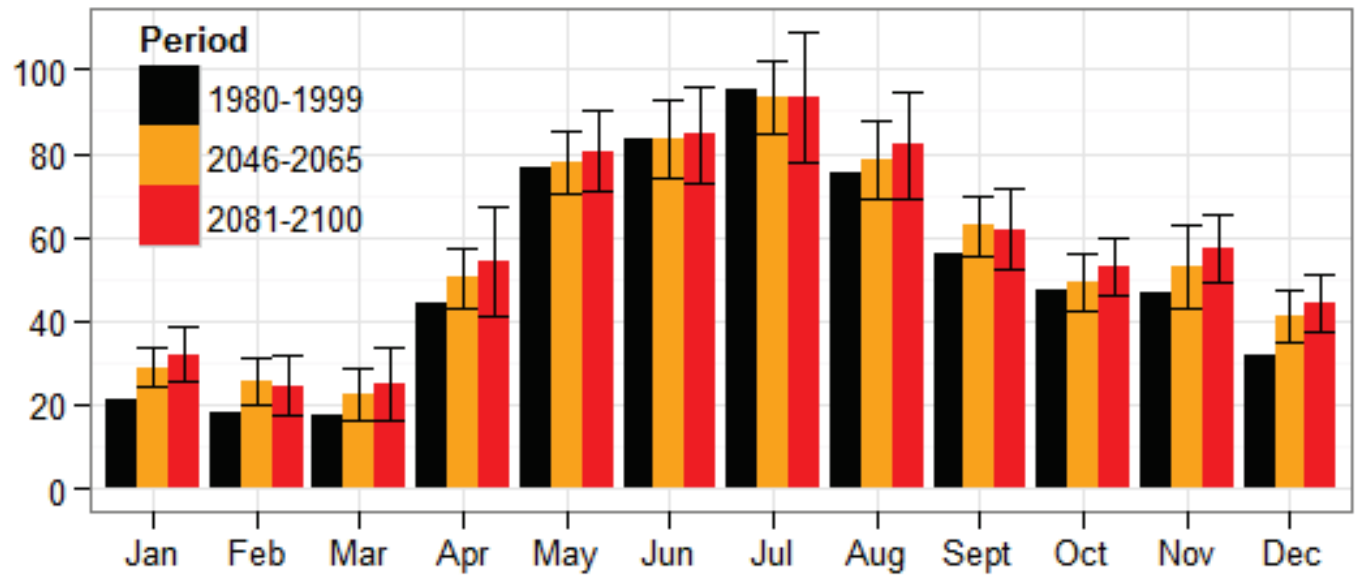

F igure 4-13 Temperature adj ust, a); and Energy adj ust, b); evapotranspiration (ET) proj ections for $\mathrm{M}$ aumee $\mathrm{R}$ iver watershed as simulated by $\mathrm{L}$ arge $\mathrm{B}$ asin $\mathrm{R}$ unoff $\mathrm{M}$ odel (L B R M ). S tandard deviations are shown about ensemble means of near future (20462065) and far future (2081-2100) periods. 
a) $T$ emperature Adj ust $R$ unof f ( $\mathbf{m m})$

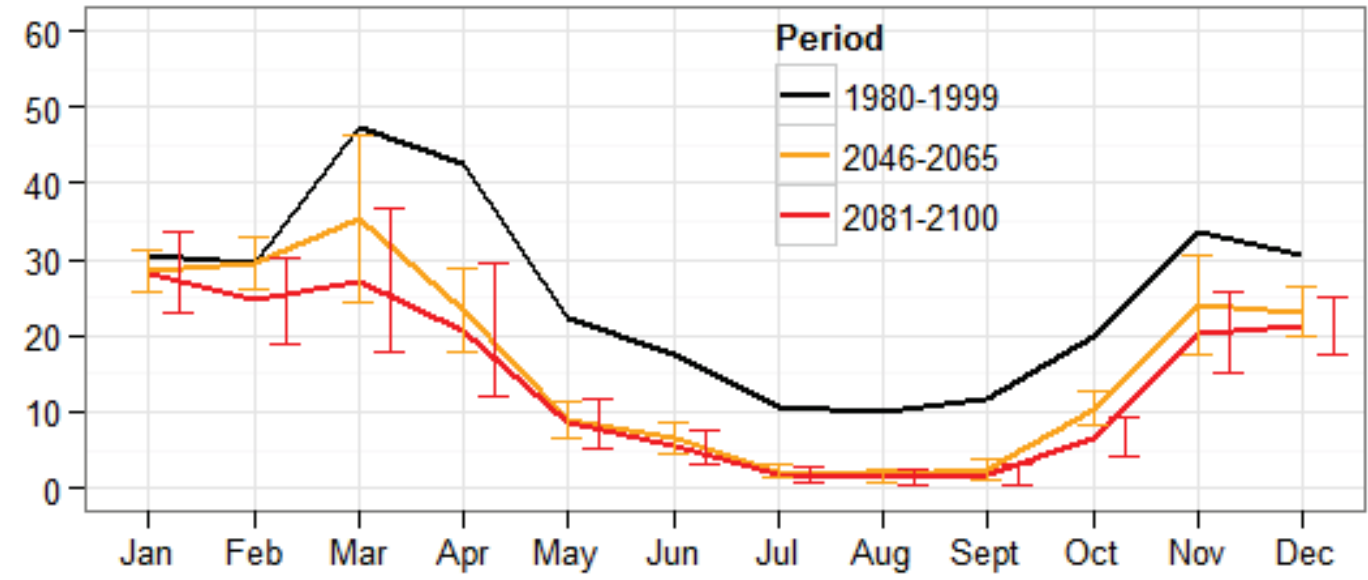

b) $E$ nergy Adj ust $R$ unof f ( $\mathbf{m m}$ )

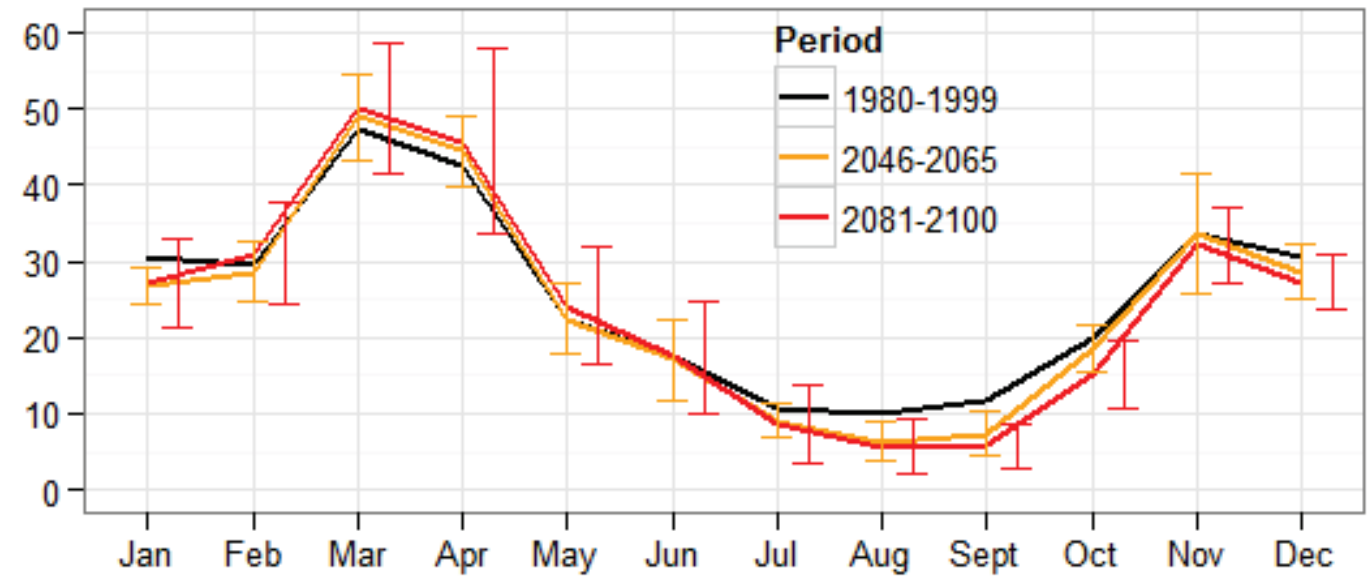

F igure 4-14 Temperature adj ust, a); and Energy adj ust, b); runoff hydrographs for $M$ aumee $R$ iveatershed as simulated by $L$ arge $B$ asin $R$ unoff $M$ odel (L B R M ). $\mathrm{S}$ tandard deviations are shown about ensemble means of near future (2046-2065) and far future (2081-2100) periods. 


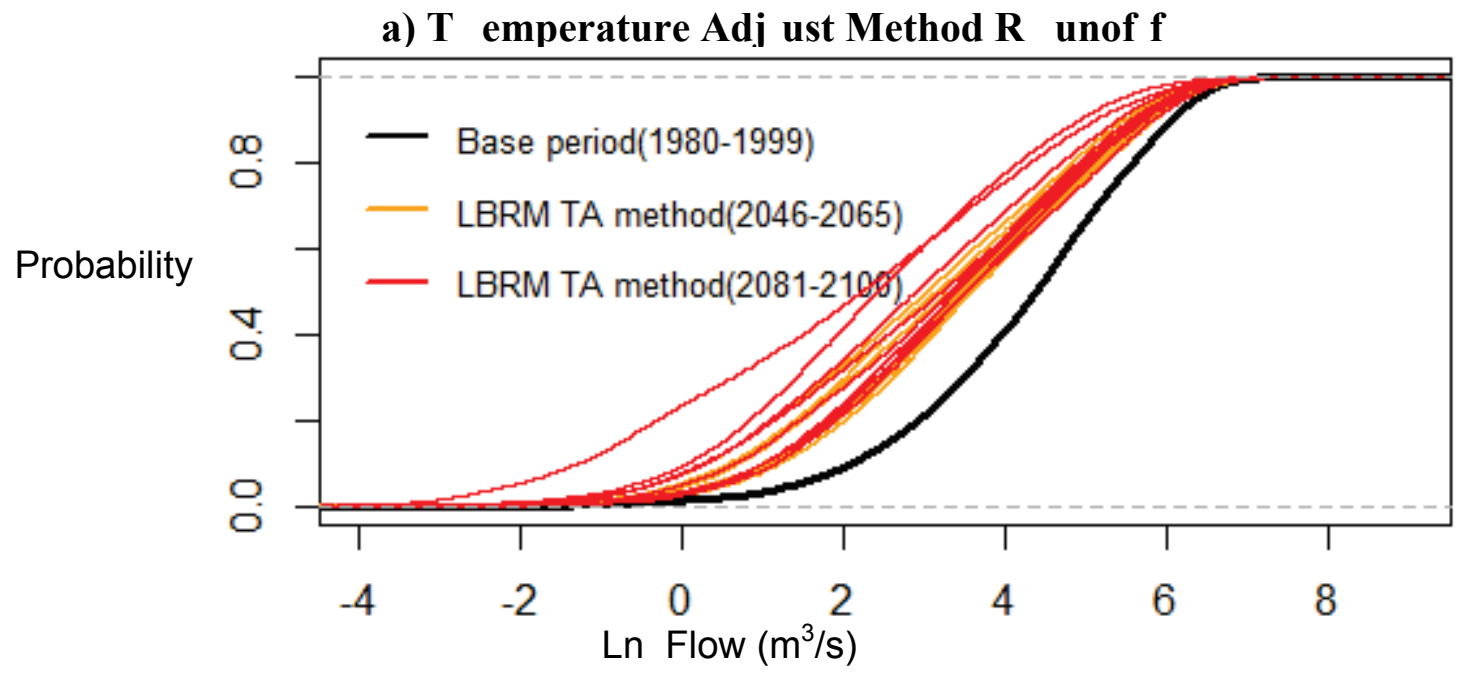

b) E nergy Adj uAfethod $R$ unof $f$

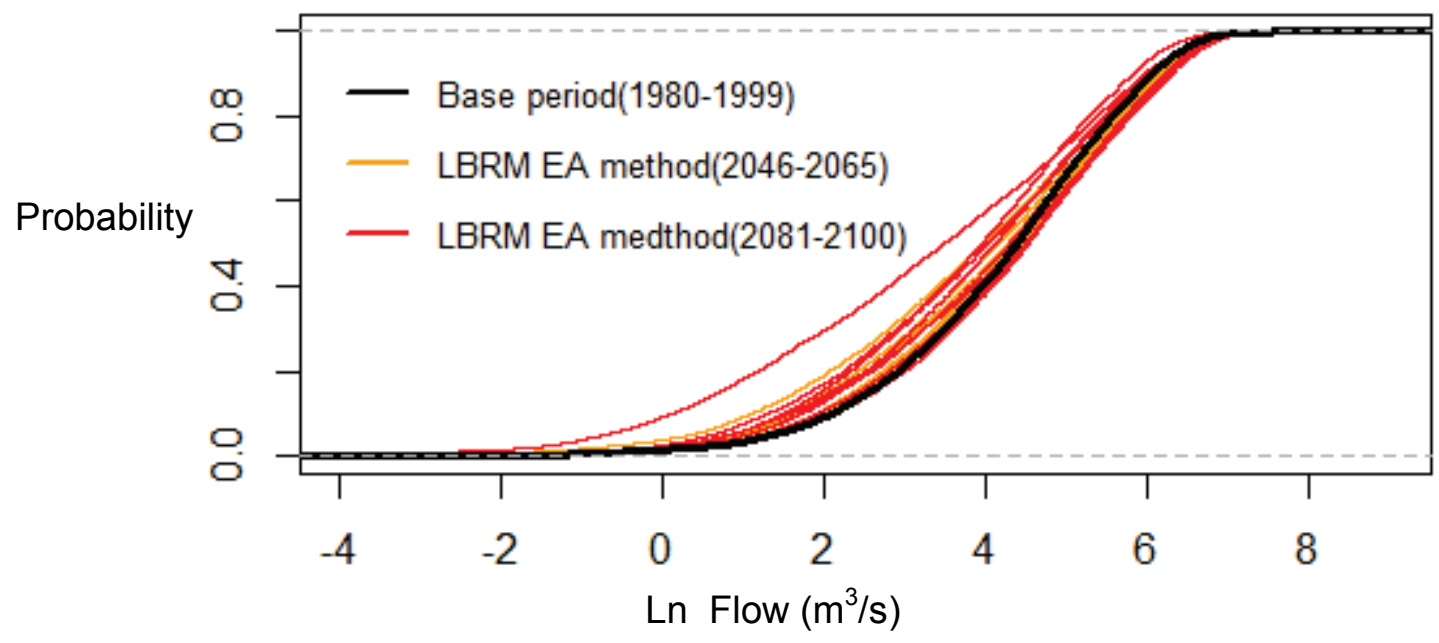

$\mathrm{F}$ igure 4-15 $\mathrm{C}$ umulative distribution functions (C D F s) of $\mathrm{L}$ arge $\mathrm{B}$ asin $\mathrm{R}$ unoff $\mathrm{M}$ odel (L B R M ) simulated runoff based on Temperature Adj ust (TA), a); and Energy Adj ust (EA), b) methods for $\mathrm{M}$ aumee $\mathrm{R}$ iver watershed. S hown are the base period (19801999) and two future periods (2046-2065) and (2081-2100) from selected climate scenarios. 
a) $\mathbf{P}$ recipitation $(\mathrm{mm})$

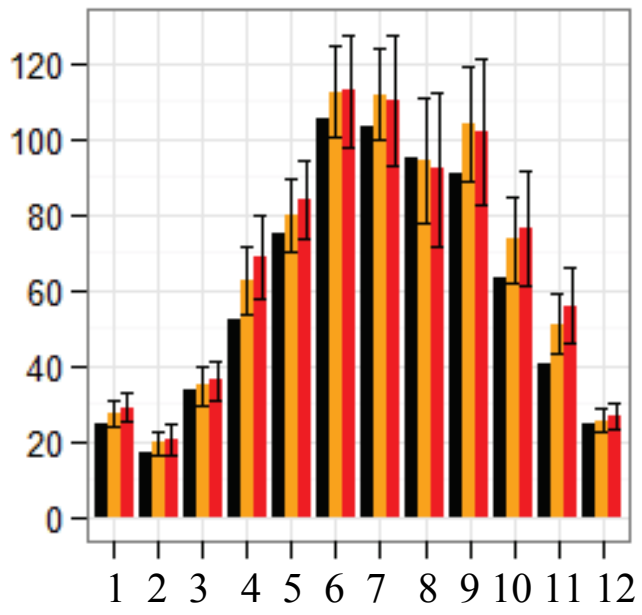

c) $T$ emperature Adj ust $P$ E $T$ ( $n$ b) Maximum $\mathbf{T}$ emperature $\mathbf{C})$

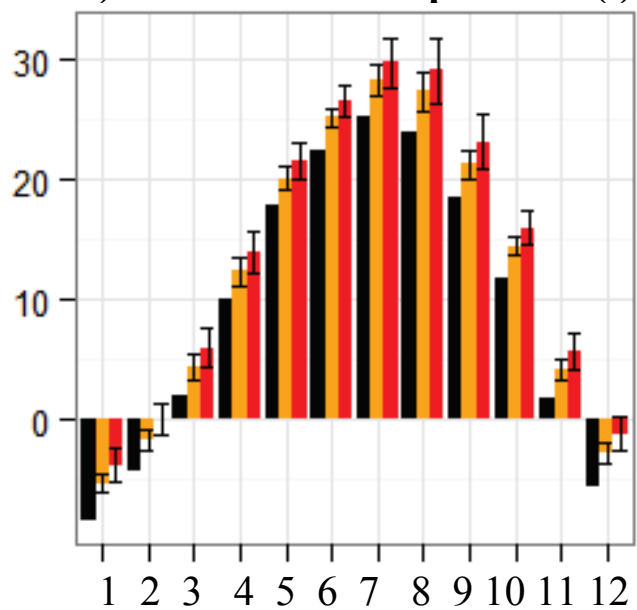

d) $E$ nergydj ust $P$ E T ( mm'

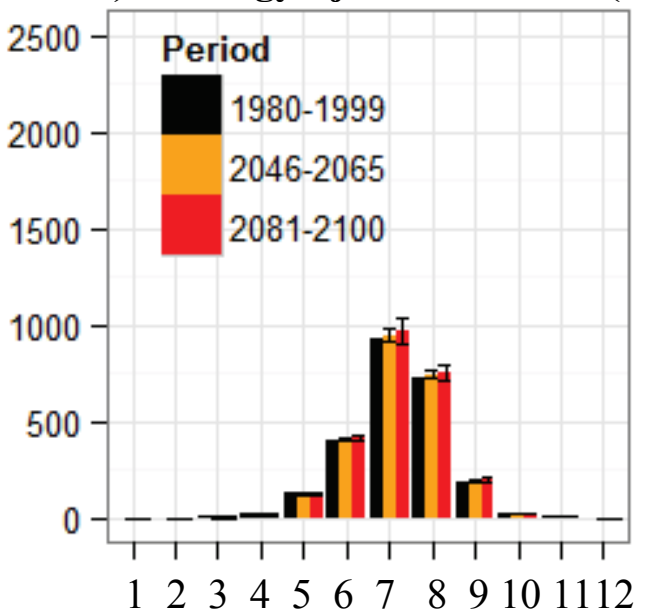

$\mathrm{F}$ igure 4-16 S t. L ouis watershed inputs to the $\mathrm{L} \operatorname{arge} \mathrm{B} \operatorname{asin} \mathrm{R}$ unoff $\mathrm{M}$ odel (L B R $\mathrm{M}$ ). $\mathrm{S}$ hown are biasorrected monthly proj ections of precipitation, a); max imum temperature, b); temperature adj ust PET, c); and energy adj ust PET, d). S tandard deviations are shown about ensemble means of near future (2046-2065) and far future (2081-2100) periods. 


\section{a) $\mathbf{T}$ emperature Adj ust $\mathbf{E} \mathbf{T}$ ( $\mathrm{mm})$}

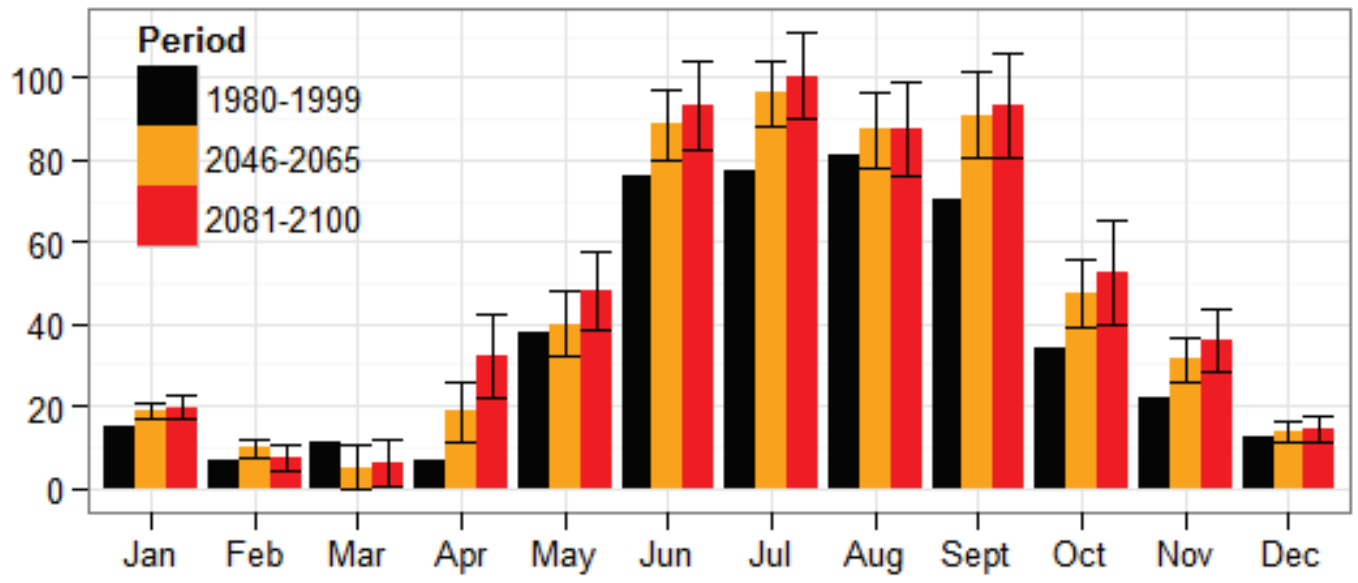

b) E nergy Adj ust E T ( mm)

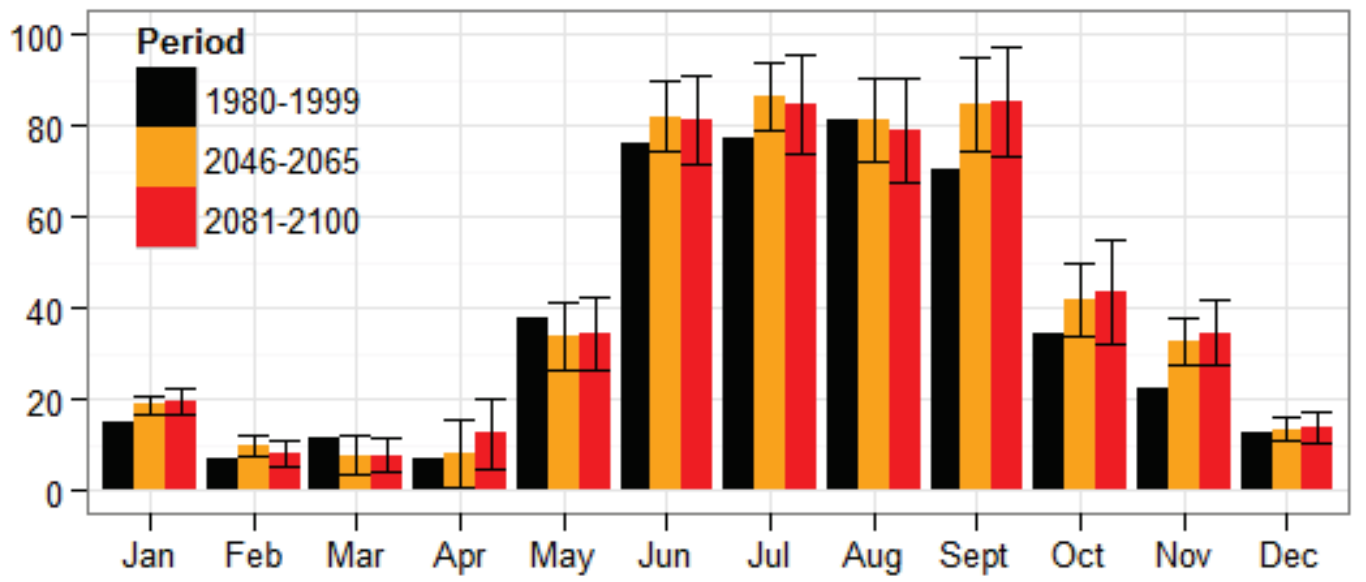

F igure 4-17 Temperature adj ust, a); and Energy adj ust, b); evapotranspiration (ET) proj ections for $\mathrm{S}$ t. L oRisiver watershed as simulated by $\mathrm{L}$ arge $\mathrm{B}$ asin $\mathrm{R}$ unoff $\mathrm{M}$ odel (L B R M ). S tandard deviations are shown about ensemble means of near future (20462065) and far future (2081-2100) periods. 
a) $T$ emperature Adj ust $R$ unof f ( $\mathbf{m m})$

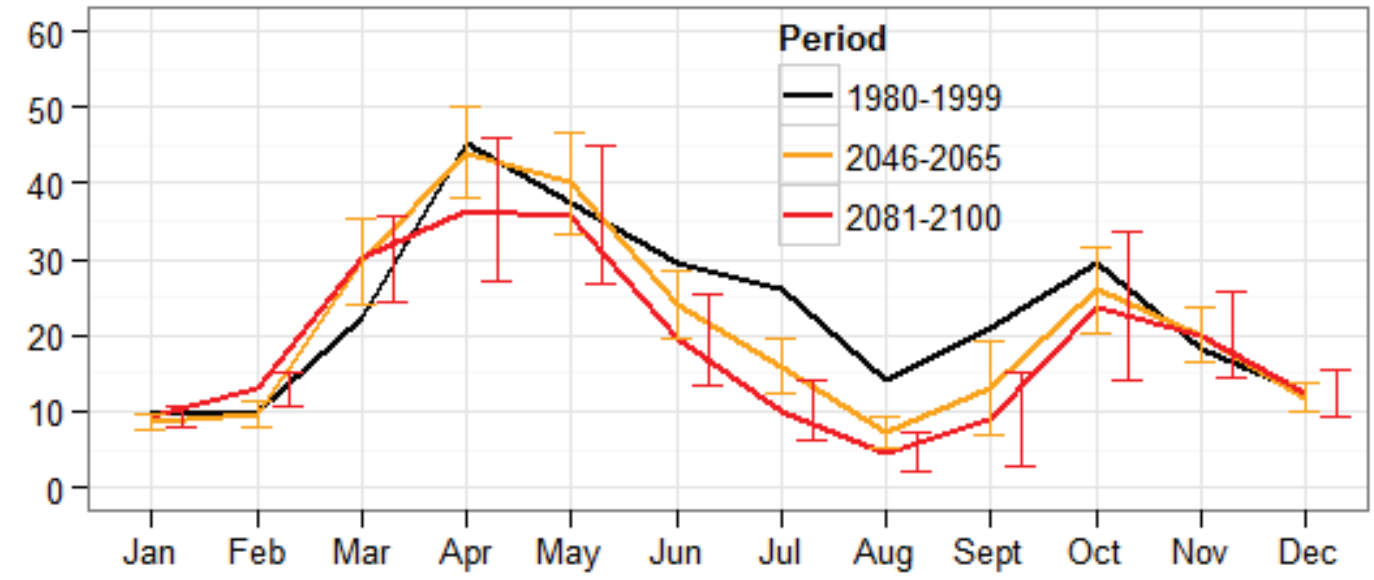

b) E nergy Adj ust $R$ unof f ( mm)

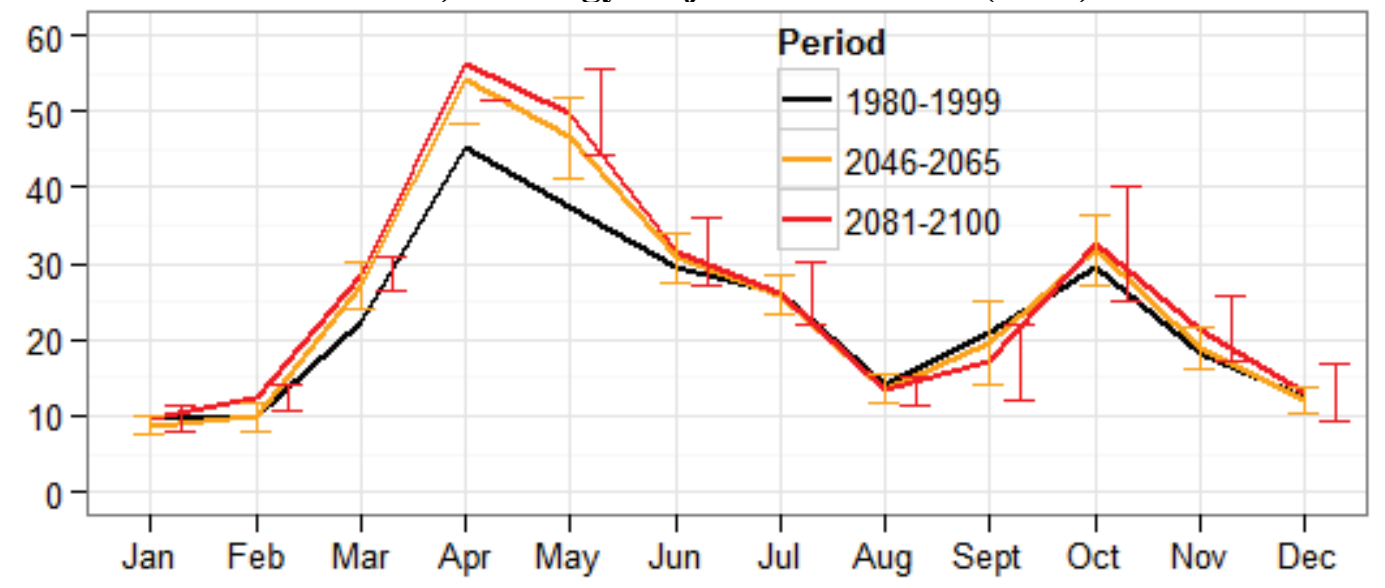

F igure 4-18 Temperature adj ust, a); and Energy adj ust, b); runoff hydrographs for S t.

$\mathrm{L}$ ouis $\mathrm{R}$ iver watershed as simulated by $\mathrm{L} \operatorname{arge} \mathrm{B}$ asin $\mathrm{R}$ unoff $\mathrm{M} \operatorname{odel}(\mathrm{L} B \quad \mathrm{R} \quad \mathrm{M}$ ). $\mathrm{S}$ tandarc deviations are shown about ensemble means of near future (2046-2065) and far future (2081-2100) periods. 
a) $T$ emperature Adj ust Method $R$ unof $f$

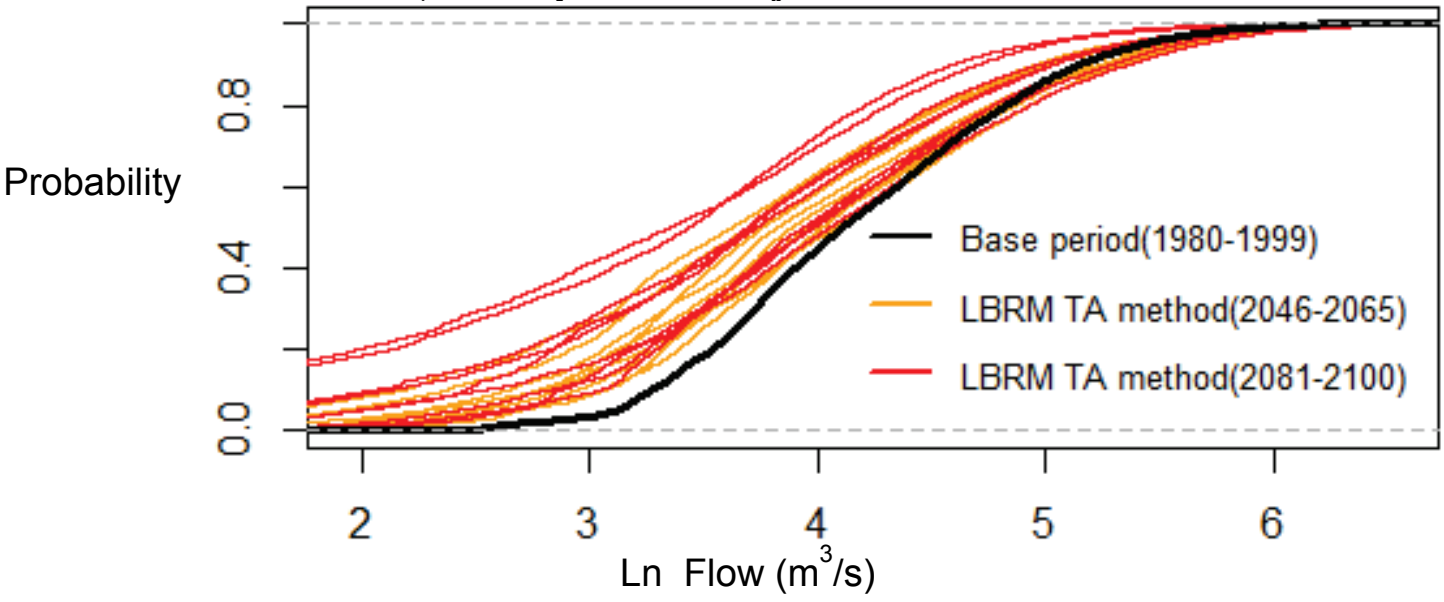

b) E nergy Adj ust Method R unof $f$

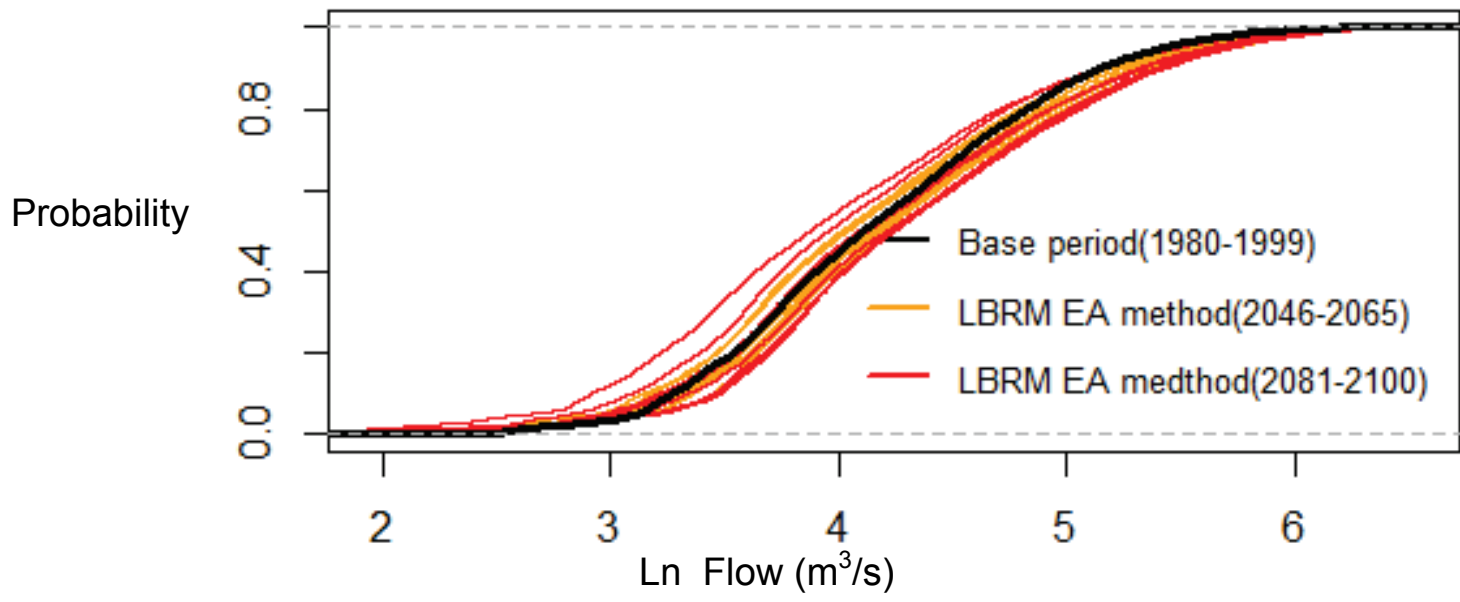

F igure 4-19 C umulative distribution functions (C D F s) of $\mathrm{L}$ arge $\mathrm{B}$ asin $\mathrm{R}$ unoff $\mathrm{M}$ odel (L B R M ) simulated runoff based on Temperature Adj ust (TA), a); and Energy Adj ust (EA), b) methods for S t. L ouis R iver watershed. S hown are the base period (1980$1999)$ and two future periods (2046-2065) and (2081-2100) from selected climate scenarios. 
a) $\mathbf{P}$ recipitation $(\mathbf{m m})$

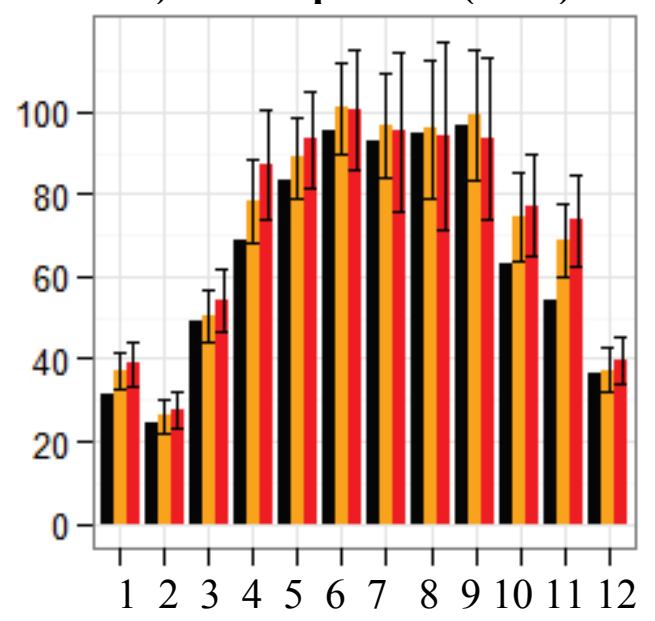

c) $\mathbf{T}$ emperature Adj ust $\mathbf{P} \mathbf{E} \mathbf{T}$

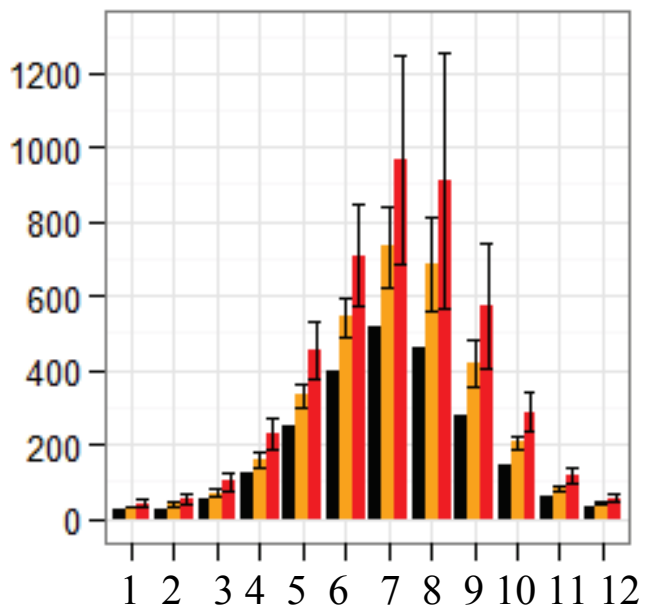

b) Maximum $\mathbf{T}$ emperaturé()

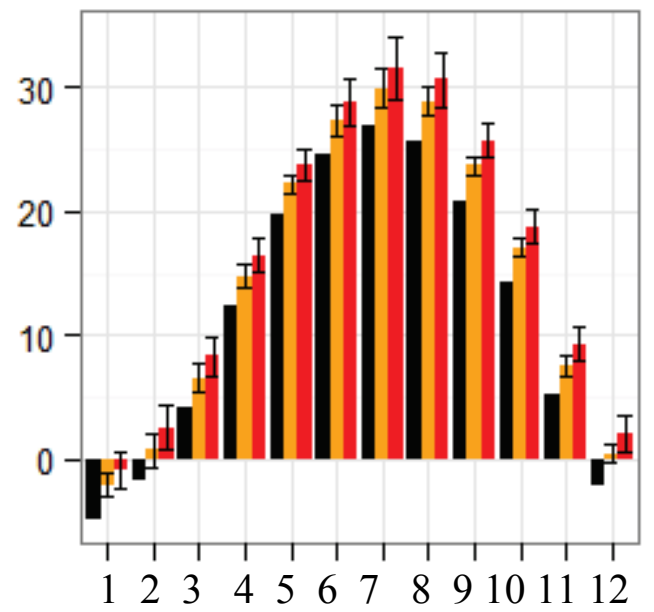

d) $E$ nergy Adj ust $P$ E T ( mm)

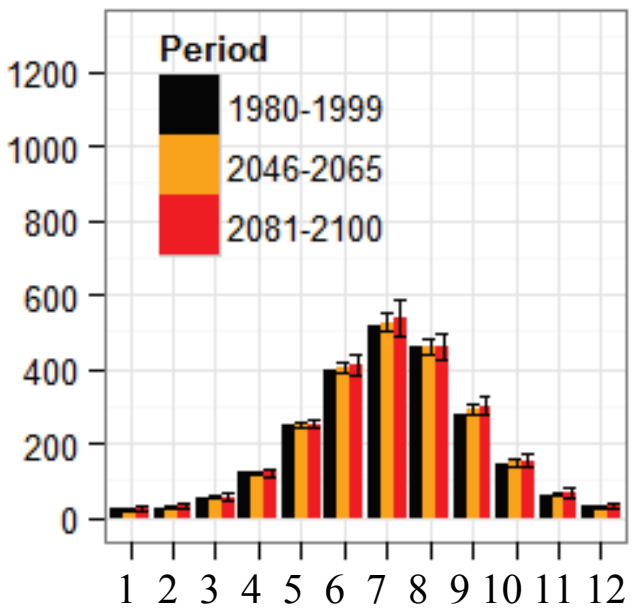

F igure 4-20 Fox River watershed inputs to the $L$ arge B asin R unoff (IIOBAM). $\mathrm{S}$ hown arbias-corrected monthly precipitation, a); max imum temperature, $\mathrm{b}$ ); temperature adj ust PET, c); and energy adj ust PET, d); proj ections. S tandard deviations are shown about ensemble means of near future (2046-2065) and far future (2081-2100) periods. 
a)T emperature Adj ust $\mathbf{E}$ T ( mm)

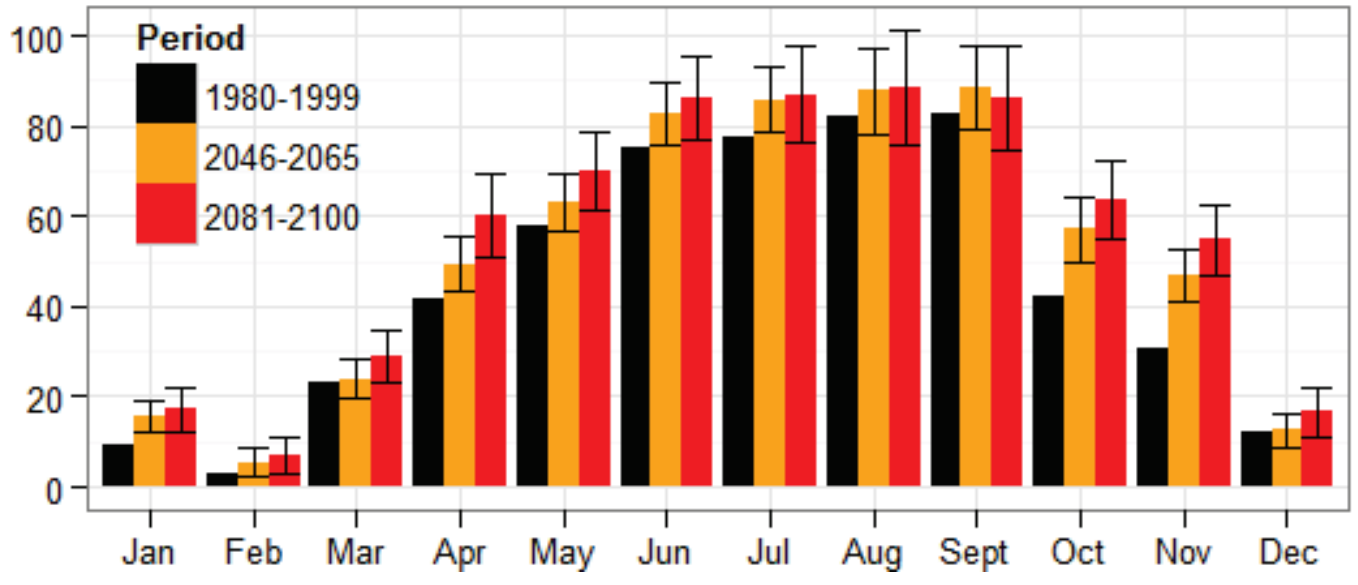

b) E nergy Adj ust E T ( mm)

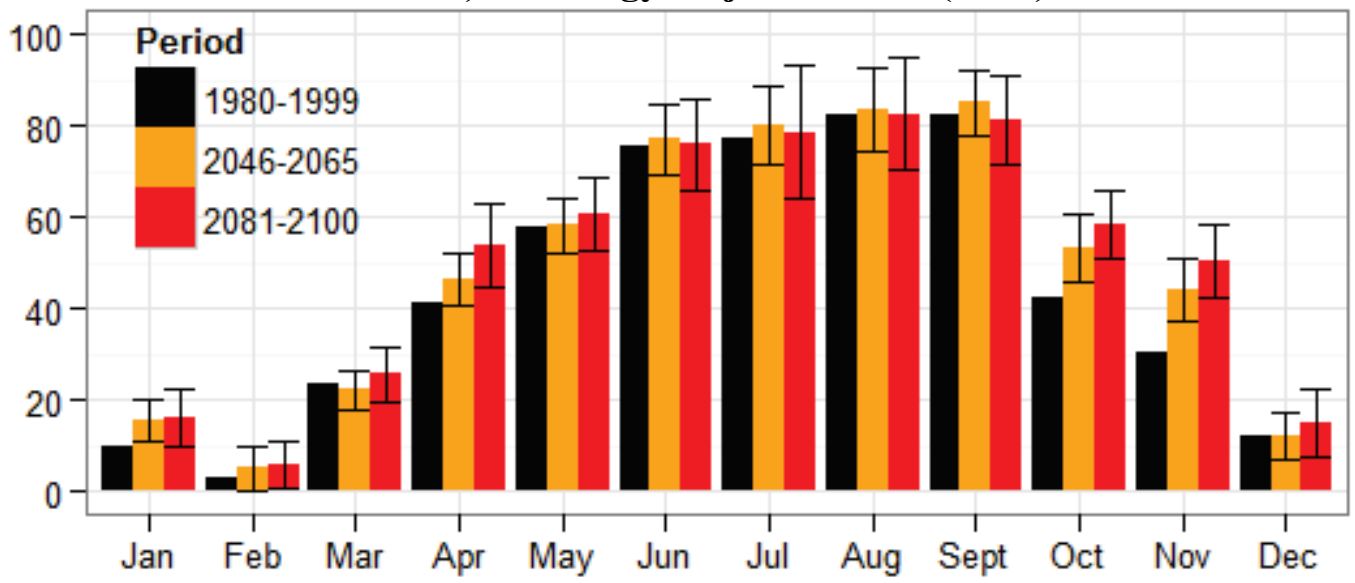

F igure 4-21 Temperature adj ust, a); and Energy adj ust, b); evapotranspiration (ET) proj edions for Fox River watershed as simulated by L arge B asin R unoff Model (L B R M ). S tandard deviations are shown about ensemble means of near future (20462065) and far future (2081-2100) periods. 
a) $T$ emperature Adj ust $R$ unof f ( $\mathbf{m m})$

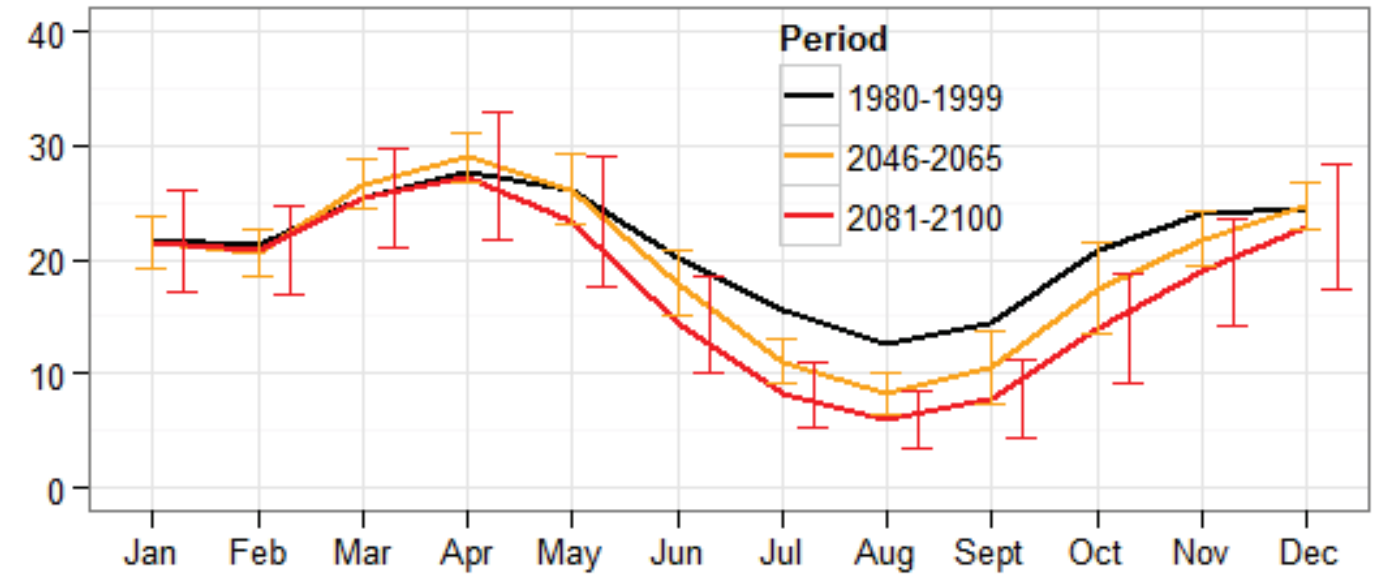

b) E nergy Adj ust $R$ unof $f$ ( $\mathbf{m m}$ )

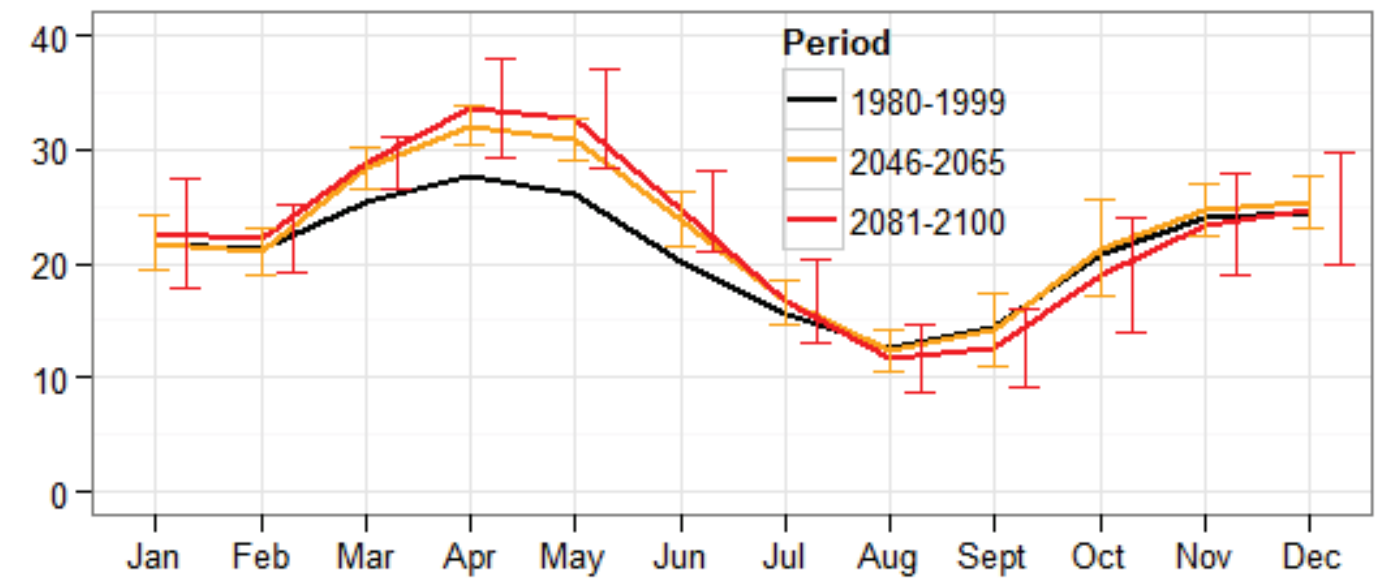

$\mathrm{F}$ igure 4-22 Temperature adj ust, a); and Energy adj ust, b); runoff hydrographs for $\mathrm{F}$ ox $R$ iver watershed as simulated by $L$ arge $B$ asin $R$ unoff $M$ odel ( $L B \quad R \quad M \quad$ ). $S$ tandard deviations are shown about ensemble means of near future (2046-2065) and far future (2081-2100) periods. 


\section{a) $\mathbf{T}$ emperature Adj ust Method $\mathbf{R}$ unof $\mathbf{f}$}

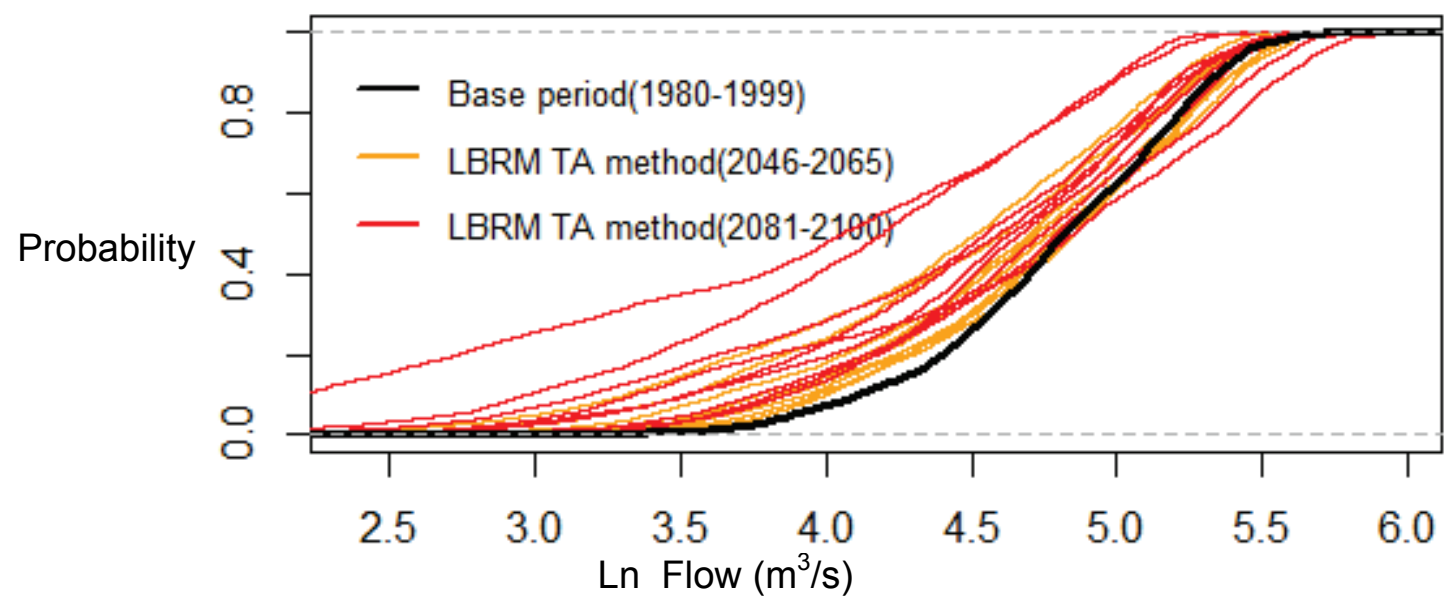

b) E nergy Adj ust Method $R$ unof $f$

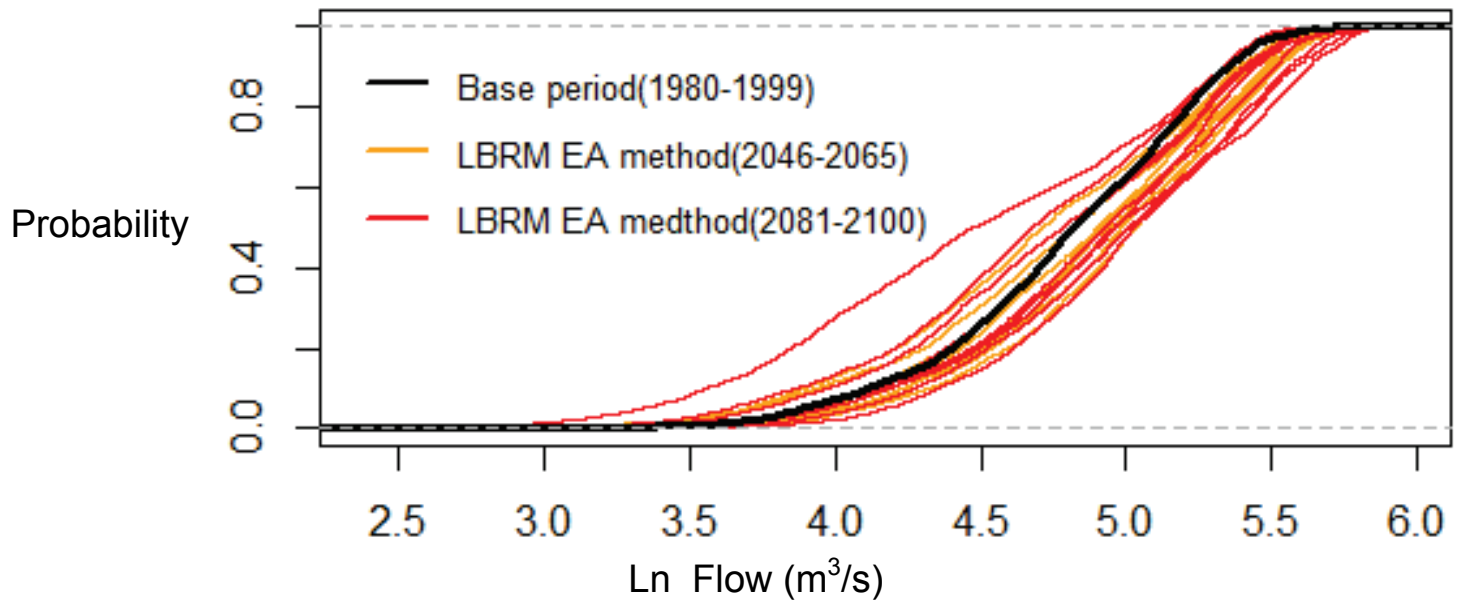

$\mathrm{F}$ igure 4-23 $\mathrm{C}$ umulative distribution functions ( $\mathrm{C} \quad \mathrm{D} \quad \mathrm{F}$ s) of $\mathrm{L}$ arge $\mathrm{B}$ asin $\mathrm{R}$ unoff $\mathrm{M}$ odel (L B R M ) simulated runoff based on Temperature Adj ust (TA), a); and Energy Adj ust (EA), b) methods for F oæ iver watershed. S hown are the base period (198999) and two future periods (2046-2065) and (2081-2100) from selected climate scenarios. 


\subsubsection{Snow water equivalent (SWE) projections}

$S$ imilar to the streamflow proj ections, snow water eq uivalent $\left(\begin{array}{lll}S & \mathrm{~W}\end{array}\right)$ proj ections representing warm ( $\mathrm{M}$ aumee), moderate (Foar)d cold ( $\mathrm{S}$ t. L ouis) climatic regions in the $\mathrm{G}$ reat $\mathrm{L}$ ak es basin are shown in $\mathrm{F}$ igure 4-24 through $\mathrm{F}$ igure 4-26.

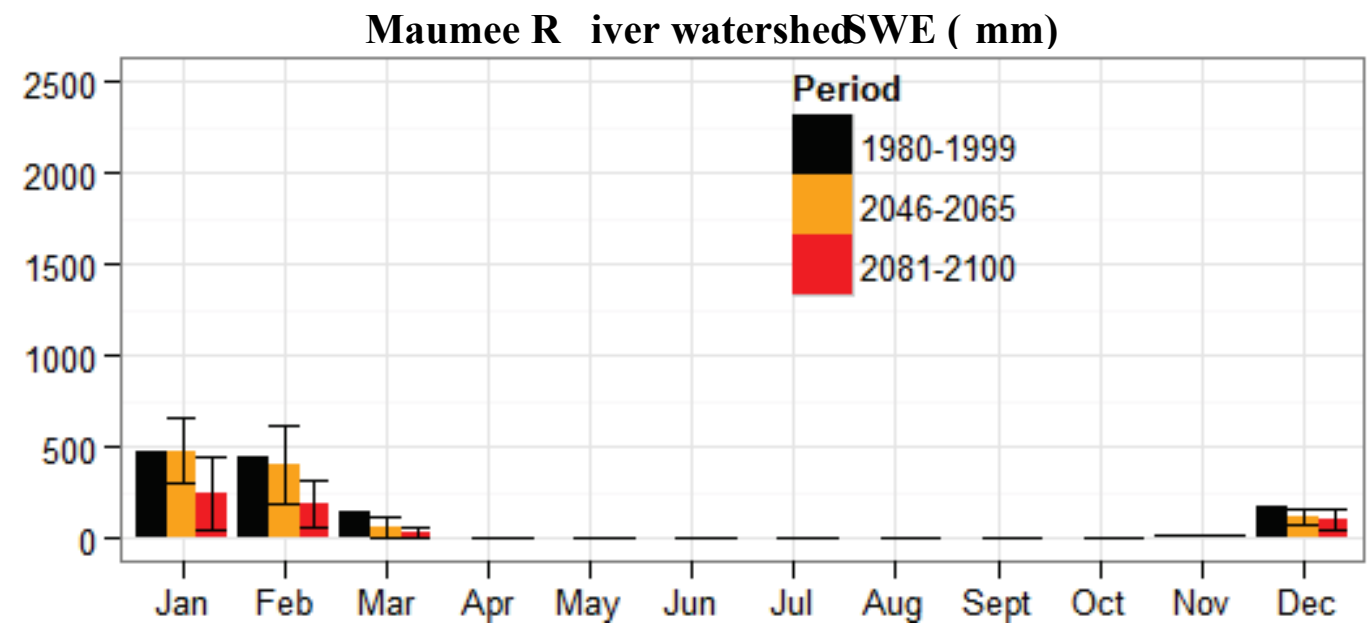

$\mathrm{F}$ igure 4-24 S now water equivalent proj ections of Mamee $\mathrm{R}$ iver watershed as simulated by $\mathrm{L}$ arge $\mathrm{B}$ asin $\mathrm{R}$ unoff $\mathrm{M}$ odel (L B R M ). S tandard deviations are shown about ensemble means of near future (2046-2065) and far future (2081-2100) periods.

St. Louis $\mathbf{R}$ iver watershedWE ( $\mathbf{m m}$ )

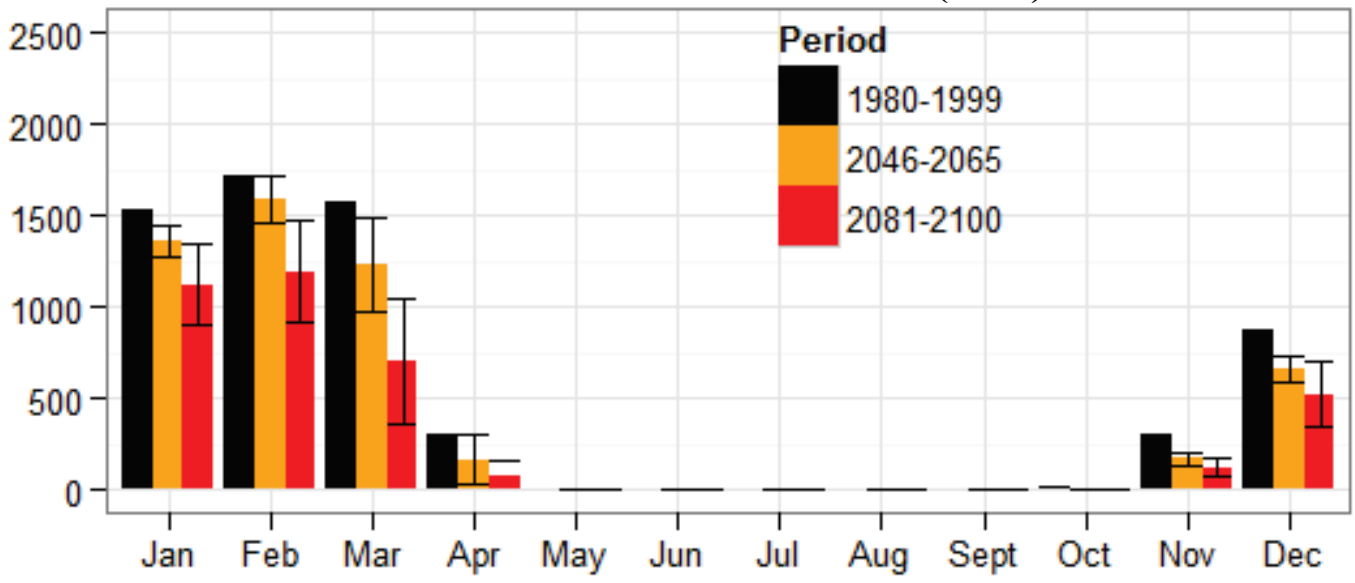

$\mathrm{F}$ igure 4-25 $\mathrm{S}$ now water equivalent (SWFroj ections for $\mathrm{S}$ t. $\mathrm{L}$ ouis $\mathrm{R}$ iver watershed as simulated by $\mathrm{L}$ arge $\mathrm{B}$ asin $\mathrm{R}$ unoff $\mathrm{M}$ odel ( $\mathrm{L} B \mathrm{R}$ M ). S tandard deviations are shown about ensemble means of near future (2046-2065) and far future (2081-2100) periods. 
Fox $R$ ivesWE ( mm)

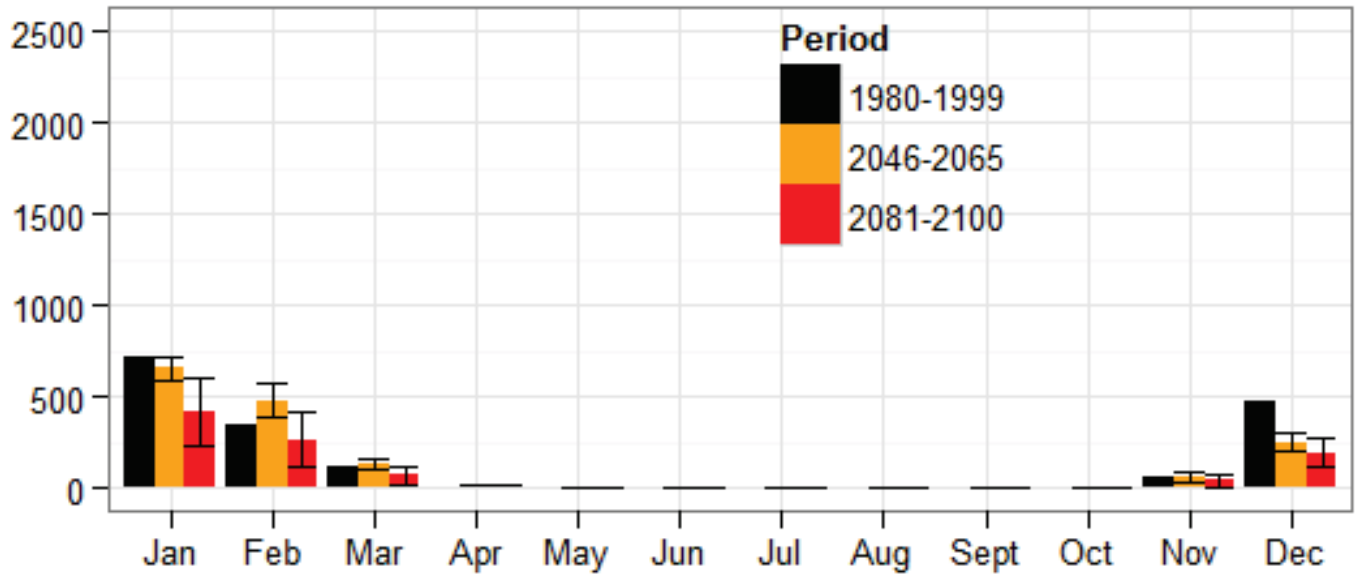

$\mathrm{F}$ igure 4-26 S now water equivalent (SWE) proj ections for FRoxiver watershed as simulated by Large B asin R unoff $M$ odel (L B R M ). S tandard deviations are shown about ensemble means of near future (2046-2065) and far future (2081-2100) periods.

L $\quad$ B $\quad$ R $\quad M \quad$ uses a degree day approach to estimate snowmelt, given by eq uation 5 .

$$
\begin{array}{rlrl}
\frac{d}{d t} P & =-m, & & T>0 \\
& =p, & T<=0 \ldots \ldots \ldots(4-5)
\end{array}
$$

where $t=$ timed $), P=$ equivalentwater volume present in the snow pack $\left(\mathrm{m}^{3}\right)$, $\mathrm{m}=$ snowmelt rate $\left(\mathrm{m}^{3} \mathrm{~d}^{-1}\right), p=$ precipitation rate $\left(\mathrm{m}^{3} \mathrm{~d}^{-1}\right)$, and $T=$ air temperature $\left({ }^{\mathrm{o}} \mathrm{C}\right)$. Additional details are provided in $\mathrm{C}$ roley (2002). The degree day approach is governed by the principle that snowmelt is allowed only during periods with above-z ero air temperatures. As the temperature index method does not consider evaporation and sublimation from the snowpack, both EA and TA methods use the same temperature feed from the $\mathrm{G} \quad \mathrm{C} \quad \mathrm{M}$ s to estimate $\mathrm{S} W \quad \mathrm{E}$ in the $\mathrm{L} \quad \mathrm{B} \quad \mathrm{R} \quad \mathrm{M}$.dulerglilbadacetailed approaches (Tarboton et al., 1995; Y ou et al., 2004), the temperature index approach ignores other complexities affecting snowmelt including the effects of slope and aspect, heat exchanges with the ground, heat input by rain, effects of radiative heat flux es and evaporation and condensation to the snowpack. Ealuating differences in snowmelt budget using the temperature index and energy balance approach is beyond the modest scope of this chapter but is a subj ect for future research.

C ompared to the streamflow proj ections, there is larger variability in S W E proj ections. S W E proj ections for both 2046-2065 and 2081-210Dodershow a net decrease in the future periods ( $\mathrm{F}$ igure 4-24 to $\mathrm{F}$ igure 4-26espite the consistent 
increase in precipitation during the winter months (Table A-2 and Table A-7). As snowmelt is more sensitive to changes in temperature and precipitation than runoff, more extreme changes in snowmelt are expected under future climates, including shorter snow seasons and earlier spring runoff. For example, a more pronounced decrease in snowmelt is seen in the near and far future periods in the Maumee basin than in the St. Louis or Fox basins. Although winters warm across the region, the St. Louis watershed (and also the Fox watershed in January) continues to experience subzero monthly average temperatures under future climates (Figure 4-16 and Figure 4-20). It expected that the degree-day snowmelt model based on the temperature index method may not capture the effects of warmer yet below zero temperatures under future climate. With radiative fluxes readily available from GCM outputs, including a more robust energy-balance snowmelt algorithm in hydrologic models would be an important advancement in hydro-climatic impact assessment in snow-affected regions such as the Great Lakes basin.

\subsection{Conclusion}

A more careful consideration of ET methods is needed for hydrologic impact assessment studies. Results show that in warmer future climates, temperature proxy PET methods are likely to overestimate ET and thus underestimate runoff in hydroclimatic projections. As the validity of temperature-based PET methods is challenged, latent and sensible heat fluxes derived from the GCM projections are employed herein to estimate PET in a future climate. As such, a consistent energy budget is maintained between climate and hydrologic models. In order to estimate future PET using the energy adjustment method, a virtual temperature time series was constructed and used as an input to adjust the PET internally computed by LBRM. An alternative approach would be to revise the LBRM code to allow direct input of sensible and latent heat flux data (Lofgren et al., 2011).

Unlike the temperature proxy approach, which predicts large decreases in runoff in all watersheds and all seasons, the energy adjust approach resulted in flow responses showing both regional and seasonal variability. The responses of 14 selected Great Lakes watersheds are characterized by three flow regimes: (1) large reductions in summer flows; (2) small reductions in summer flows and relatively large increases in spring/winter flows; and (3) moderate reductions in summer flows and moderate increases in spring/winter flows. It is argued that the differences in flow regimes may stem from differences in watershed characteristics, aridity index, and future climate projections. For example, the agriculture-dominated southern watersheds (e.g. Maumee and Sandusky) have a flashy response to precipitation (Croley 2006; Gyawali and Watkins 2013), increasing surface flows and evaporative losses compared to more baseflow-dominated watersheds. Overall, it is seen that the hydrologic impacts of climate change become more severe in the far future period (2081-2100) compared to 
the near future period (2046-2065) period, although in some instances PET increases offset precipitation increments.

The EA based simulations show that the watersheds are prone to both flood or drought conditions depending on watershed characteristics and future climate projections. In some watersheds (e.g. Maumee, Sandusky, Fox, Clinton and Lower Grand) the lower flows in summer and fall seasons in the future periods relative to the historic period indicate increased vulnerability to droughts, while the higher flows in the wet season in the same watersheds indicate increased vulnerability to flooding. With the exception of Au Sable, all the watersheds considered show a consistent increase in spring streamflow in the future periods. Overall, this could result in higher lake levels in the spring while the lower runoff in summer and fall could increase the range of lake levels of the Great Lakes.

As there are many empirical PET estimation methods, a future direction of this work is to evaluate the sensitivity of evaporative responses using additional methods (e.g., Hamon, Jensen and Haise, Penman-Monteith and Priestley and Taylor). These PET equations include either temperature-proxy methods (e.g. Jensen and Haise) or hybrid temperature-energy methods (e.g. Priestly and Taylor, Penman-Monteith), as defined in Bae et al. (2011). It should be noted that the energy balance variables (e.g. short wave and long wave radiation, wind speed, atmospheric vapor pressure, and drought moisture indices) have also been expressed in terms of temperature-based relationships (Maurer et al. 2002; Dai et al. 2004). The validity of these approaches should be scrutinized using GCM-derived variables that maintain an energy balance within the models.

In addition to streamflow, snow water equivalent (SWE) and other moisture storages of the selected watersheds are simulated. Compared to streamflow projections, larger variability is observed in SWE simulations due to increased sensitivity of snowmelt to temperature increases. As inputs to the surface energy budget are becoming more readily available from climate models, energy balance methods should be developed for more accurately representing snowmelt in hydrologic models compared to current degree-day methods.

For this analysis, the ratio of latent and sensible heat fluxes from coarse-grid GCMs was applied at the resolution corresponding to the HUC8 watershed scale. Regional factors such as the influence of the Great Lakes could impact the radiative budget at the watershed scale significantly, and thus an area of future research is to use regional climate models (RCMs) rather than GCMs to account for local and regional factors. 


\section{Conclusions and Future Work}

This research contributes to water resources planning and management in the Great Lakes basin by developing a multi-model framework for climate change impact assessment. In addition, the framework may be used to quantify the consequences and evaluate the appropriateness of different choices of models and methods used in integrated assessments. The overall effort entailed applying downscaled climate model projections and developing both physically based and regional regression hydrologic models to assess hydrological response to climate change. Further, hydrologic simulations using different potential evapotranspiration schemes were evaluated, and it is recommended that a consistent surface energy budget be maintained between climate and hydrologic models for use in climate change impact studies.

\subsection{Major findings and contribution}

\subsubsection{Development of continuous hydrologic modeling of snow affected watersheds in the Great Lakes basin using HEC-HMS}

In this research, soil moisture accounting and the temperature index (degreeday) snowmelt models embodied in the Hydrologic Engineering Center's Hydrologic Modeling System (HEC-HMS) were applied to three Great Lakes watersheds Kalamazoo, Maumee and St. Louis - with different climatic and land use characteristics. Watershed and sub-watershed models were calibrated and validated on a daily time step using gauge precipitation measurements, measured stream flows, and observed snow water equivalent (SWE) data, along with physically based parameters estimated using geospatial databases. Results compared to area-scaled outputs from the NOAA Large Basin Runoff Model (LBRM) showed improvements resulting from the increased spatial resolution of the HEC-HMS models, as well as the benefits of the more process-based snow algorithm in HEC-HMS, particularly for the snowdominated St. Louis watershed. However, both LBRM and HEC-HMS models had difficulty reproducing peaks in late winter and early spring runoff, and discrepancies could not be attributed to any systematic errors in the snowmelt models.

Climate and land use change studies require watershed models with physicallybased parameters, rather than empirical models which are simply calibrated to reproduce historical stream flows. To this end, the models developed herein have a more physical basis than some previous models (e.g., LBRM), due to use of an advanced snowmelt algorithm and improved characterization of other hydrologic processes, including subsurface flows and evapotranspiration from canopy, soil and subsurface. 


\subsubsection{Development of regional regression models for hydro-climate}

\section{change impact assessment}

A typical approach to project climate change impacts on water resources systems is to downscale a number of general circulation model (GCM) or regional climate model (RCM) outputs and force a watershed model to evaluate hydrologic impacts. In this research, an alternate approach was to directly predict selected streamflow quantiles from regional regression models that include physical basin characteristics as well as meteorological variables output by climate models. Regional regression models developed for the western Great Lakes States (both Ordinary Least Squares and Weighted Least Squares regional regression models) were compared to physically based hydrologic modeling approaches for selected Great Lakes watersheds (both HEC-HMS and LBRM), using readily available downscaled outputs from the Coupled Model Inter-comparison Project (CMIP3) as inputs to the models. The model results, presented in a probabilistic context of multi-model predictions, provide insights to potential model weaknesses, including comparatively low runoff predictions from hydrologic models using temperature proxy potential evapotranspiration (PET) approaches. Comparison of regression models against physically based hydrologic models driven using the same GCM outputs reveals regression models can serve as potential surrogates for both regulated and unregulated basins, although they were found to have limited accuracy for small, groundwaterdominated watersheds.

\subsubsection{Significance of energy budget considerations for assessment of climate change impacts on water resources.}

Climate change impact studies commonly use "temperature proxy" evapotranspiration methods in hydrologic models, whereby PET is primarily or solely a function of surface air temperature. This can result in an inconsistent energy budget between climate and hydrologic models. It is shown in this research that temperature proxy PET estimation methods in hydrologic models may tend to overestimate ET and hence underestimate runoff in a warming climate. Unlike the commonly used empirical PET relationships, an energy conservation approach is applied herein using radiative fluxes, derived directly from output of the GCMs, to estimate PET in hydrologic models. It was found that PET based on energy adjustment for future climate scenarios is a more consistent method of ET estimation, as it adheres to both conservation of mass and energy principles.

The energy adjusted simulations of 14 selected Great Lakes watersheds showed both regional and seasonal variability in hydrologic projections which were characterized by three flow regimes: (1) large reductions in summer flows; (2) small reductions in summer flows and larger increase in spring/winter flows; and (3) moderate reduction in summer flows and moderate increase in spring/winter flows. 
The differences in flow regimes may stem from differences in watershed characteristics, including geology, land cover, and aridity index, or spatial variability in the future climate projections themselves. Large reductions in summer flows as a result of larger evaporative losses were projected for the agriculture-dominated southern watersheds (e.g. Maumee and Sandusky), which have a flashy response to precipitation (Croley 2006; Gyawali and Watkins 2013), compared to baseflowdominated watersheds. Au Sable flow simulations resulted in reduced mean runoff throughout all seasons under future climates; this is explained by its more arid climate regime than other watersheds, leading to higher evaporative losses. The largest net increase in runoff is simulated for Cattaraugus watershed, and this could be attributed to its steep topography, indicated by the largest mean watershed slope of all watersheds. As a result, the increased precipitation quickly translates into runoff and is not offset by increased ET. Similarly, a larger increase in runoff of St. Louis basin than the neighboring Bad watershed could be related to a larger increase in precipitation and a smaller increase in PET.

\subsection{Future work}

Several opportunities for further research have been identified, including improvements in physically based hydrologic models and the application of hydroclimate framework in an adaptive decision making context.

\subsubsection{Adaptive decision modeling using hydro-climate projections}

Given the considerable uncertainties in future climate change impacts from emissions scenarios, climate models, hydrologic models and the inherent variability of the climate system, it is questioned whether accurate or precise information relevant for impact assessment and planning can be delivered (Dessai and Hulme 2007). Yet, decisions must be made, even if "no action" is one of the alternatives. The multimodel framework developed herein presents a probabilistic approach to impact assessment, but in order to integrate climate change uncertainties into decision making, the planning process needs to be redefined. In this effort, a multi-stage, adaptive decision making framework is conceptualized based on probabilistic hydrologic projections to inform water resources planning in the Great Lakes basin. Hydrologic projections, generated using future climate change scenarios from climate model outputs in Chapters 3 and 4, are structured as "trees" in order to represent proposed decision stages as hydro-climate projections unfold into the future. As an example, a scenario tree for $21^{\text {st }}$ century temperatures in the Kalamazoo watershed is shown in Figure 5-1, based on CMIP3 climate model outputs.

The following steps outline the proposed adaptive decision making framework, including scenario tree generation, hydrologic outcome evaluation and decision criteria. Section 5.2.2 proposes two applications of the decision making framework: 1) Water withdrawal permitting in the Kalamazoo River basin in Michigan, and 2) Best management practices (BMP) implementation in the Kalamazoo River basin under future climate scenarios. 


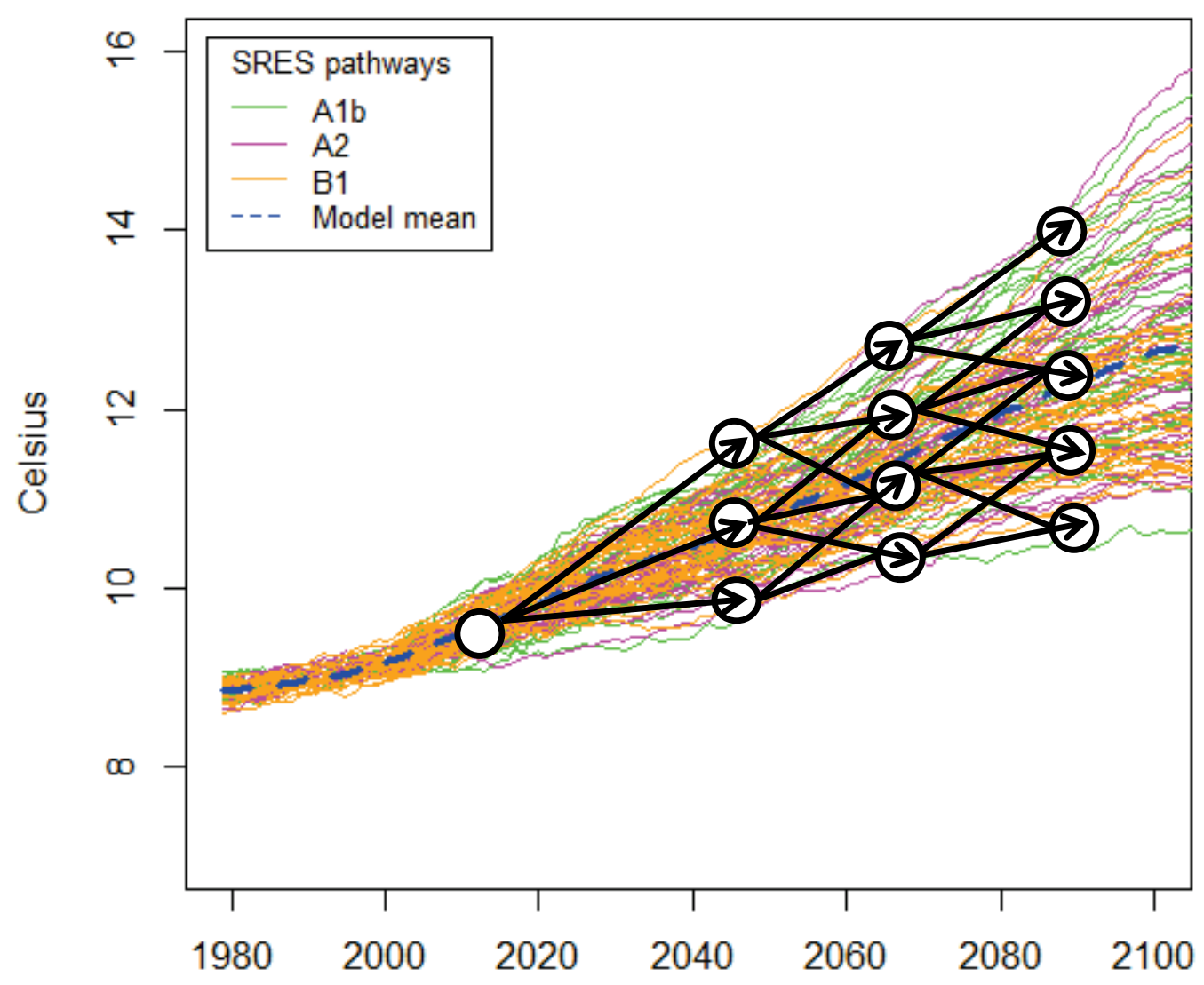

$\mathrm{F}$ igure 5-1 S cenario tree corresponding to C M I P3 proj ections of 21st century temperature in the $\mathrm{K}$ alamaz oo $\mathrm{R}$ iver waters $\mathbb{M e d}$ odes in the tree represent decision stages, and branches represent uncertain states of nature that will become known after each decision stage.

\section{Step 1. Adaptive decision making framework}

The framework for adaptive decision making begins by identifying two or more decision stages and developing a structured representation of uncertainty and how it unfolds over these stages. At least two decision stages are req uired for " adaptive" decision mak ing, represented by a decision at the present time that considers the ability to adapt in the future. A scenario tree (F igure 5-1) provides this structure, with nodes representing decision stages and branches representing scenarios, 
or uncertain states of nature, that affect decision outcomes. In generating a scenario tree from ensemble projections, it is important that the tree retain key statistical properties of the ensemble. Based on the set of discrete scenarios, a simulation model may be used to evaluate outcomes of various decisions under the possible states of nature. Finally, the specification of decision criteria and constraints allows an "optimal" decision to be selected, or trade-offs to be evaluated with respect to multiple objectives.

\section{Step 2. Scenario tree generation}

Several previous studies have developed methods for weighting, merging, or culling scenarios from multi-model ensembles of climate projections (Gleckler et al. 2008, Brekke et al. 2008). However, studies have shown that model ranking or culling may not necessarily lead to more robust future projections (Pierce et al. 2009, Knutti et al. 2010, Santer et al. 2009, Mote and Salathe 2010). In contrast to these previous efforts, our goal is simply to provide a coherent representation of the uncertainty captured in a particular projection ensemble (e.g., the CMIP3 multi-model ensemble) for input to a multi-stage decision model. One approach is to generate a scenario tree, in which the joint distribution of a set of random variables (e.g., future temperature and precipitation) is approximated by a moderate number of discrete outcomes, or scenarios. To represent multi-stage decision making (or the ability to adapt to future observations), the scenarios are structured in a tree-like form, with new scenarios branching from old at each decision stage (Figure 5-1).

A number of approaches have been developed for generating scenario trees, primarily for financial planning applications (e.g., Mulvey and Vladimirou 1992; Nielsen and Zenios, 1996; Dupacova et al., 2000; Pflug, 2001). Herein, an optimization-based approach is proposed to generate a scenario tree that preserves key statistical properties of the (larger) ensemble (Hoyland and Wallace, 2001; Gulpinar et al., 2004). This is done by letting the discrete values (e.g., mean average temperature and precipitation) and their probabilities be the decision variables in a nonlinear optimization model that seeks to minimize the squared deviations between the statistical properties of the scenario tree and the statistical properties of the ensemble. Alternatively, a fixed set of scenarios may be selected and only the probabilities adjusted by the optimization model, but this may reduce the ability to capture the key statistical properties. With both the discrete values and probabilities as decision variables, the optimization model is formulated as follows:

subject to

$$
\operatorname{Min} \sum_{i \in S}^{n} w_{i}\left[f_{i}(x, p)-S V_{i}\right]^{2}
$$

$$
\sum_{j}^{n} p_{j}=1, \mathrm{p} \geq 0
$$


where $S$ is the set of all statistical properties of interest, $S V_{i}$ is the value of the specified statistical property of the ensemble, $x$ is the vector of climate values, $p$ is the vector of scenario probabilities, $f_{i}(x, p)$ is the mathematical expression of statistical property $i$ as a function of $x$ and $p$, and $w_{i}$ is the weight for statistical property $i$.

The statistical properties reproduced in the scenario tree will be central moments (mean, standard deviation, skewness and kurtosis) and co-moments, including the correlation between temperature and precipitation and autocorrelations between stages. For a multi-stage scenario tree, a separate optimization model may be solved at each node in the tree to determine the climate values and probabilities on each branch from that node, or else a single (large) optimization model may be solved for the entire tree. It is expected that solving separate models, sequentially for each node, will be more tractable for solution in available spreadsheet software.

\section{Step 3. Hydrologic outcome evaluation}

Chapters 2-4 provide details of hydrologic modeling approaches which include two physically based models, LBRM and HMS (simulated at a daily time step), and a regression-based model for simulating the hydrology of the Great Lakes basin. Hydrologic projections in the Great Lakes region have been generated under future climate scenarios by forcing these models using CMIP3 climate model outputs. Using these projections, the outcomes of various water management decisions (e.g., withdrawal permits, infrastructure investments) can be evaluated probabilistically. For some decision applications, the hydrologic projections need to be coupled to other models. For example, to evaluate outcomes from BMP implementation for water quality management, the hydrologic projections need to be coupled to loading and stream delivery ratio models, e.g. SPARROW (Robertson and Saad, 2011).

\section{Step 4. Decision criteria}

Once the scenario tree is generated and outcomes are evaluated, decision criteria are needed. For a general water resources application, it will be assumed that decision makers seek to maximize net benefits from water use subject to environmental limits. However, in many cases it will not be possible to meet environmental limits with $100 \%$ reliability, or under all climate change scenarios. For example, the analysis in Mayer et al. (2012) has shown that ecological flow limits are already being violated in some cases, and under future climate uncertainty there is always some risk of violation due to water withdrawals (even if small). Therefore, these ecological limits cannot be treated as "hard" constraints, and a penalty-function approach is proposed, whereby violations of environmental constraints are penalized, thus reducing the net benefits of water use. Precise quantification of these penalties is beyond the scope of this research, however, as this is essentially a policy decision to be made by regulatory authorities. Thus, a sensitivity analysis will be conducted in 
which penalty weights are varied to represent a range of risk aversion levels. Results will be presented in the form of trade-off curves (expected water use benefits vs. risk of environmental violations) for cases of "static" decision making (e.g., one-time permitting) and adaptive decision making (e.g., adjustable permits). Based on these results, the expected benefits of adaptive approaches to decision making will be evaluated, and recommendations will be made for incorporating climate change considerations in water use policy.

\subsubsection{Adaptive management applications}

Application of the adaptive decision making framework is expected to increase the economic benefits of water use while reducing ecological risks compared to traditional decision making methods. The framework may also be applied to generate trade-off relationships to support decision making. A number of potential applications of the framework are discussed herein.

One potential application is adaptive water withdrawal permitting for ecological flows. As a part of a collaborative effort presented in Mayer et al. (2012), a procedure was developed for calculating ecological stress indices on a relatively small watershed scale (HUC-12), based on point estimates of water withdrawals, regional estimates of consumptive use coefficients, and local stream discharges. This procedure was applied to the Kalamazoo River watershed in MI, which includes 75 HUC-12 basins. To estimate ecological stress at the outlet of each HUC-12 basin, flow depletion caused by withdrawals and consumptive use in relation to renewable supply was estimated. The flow depletions were then compared to the location-specific allowable flow depletions based on avoiding "adverse ecosystem impairment," as defined for the Michigan Water Withdrawal Assessment Process (WWAP, Zorn et al. 2008, Hamilton and Seelbach, 2010). The impacts of temporal scale were assessed by calculating indices on an average annual basis and during the month of July, when withdrawals are highest and flows are lowest. Flow depletions based on annual and July withdrawals and corresponding consumptive use coefficients were aggregated by HUC-12 watershed and were accumulated downstream using the same flow pathways developed for estimating HUC-12 stream discharges. Comparision of flow depletions associated with consumptive use to allowable flow depletions based on avoiding ecosystem impairment showed that calculated flow depletions exceeded allowable limits in 10 HUC-12 watersheds (Figure 5-2). 


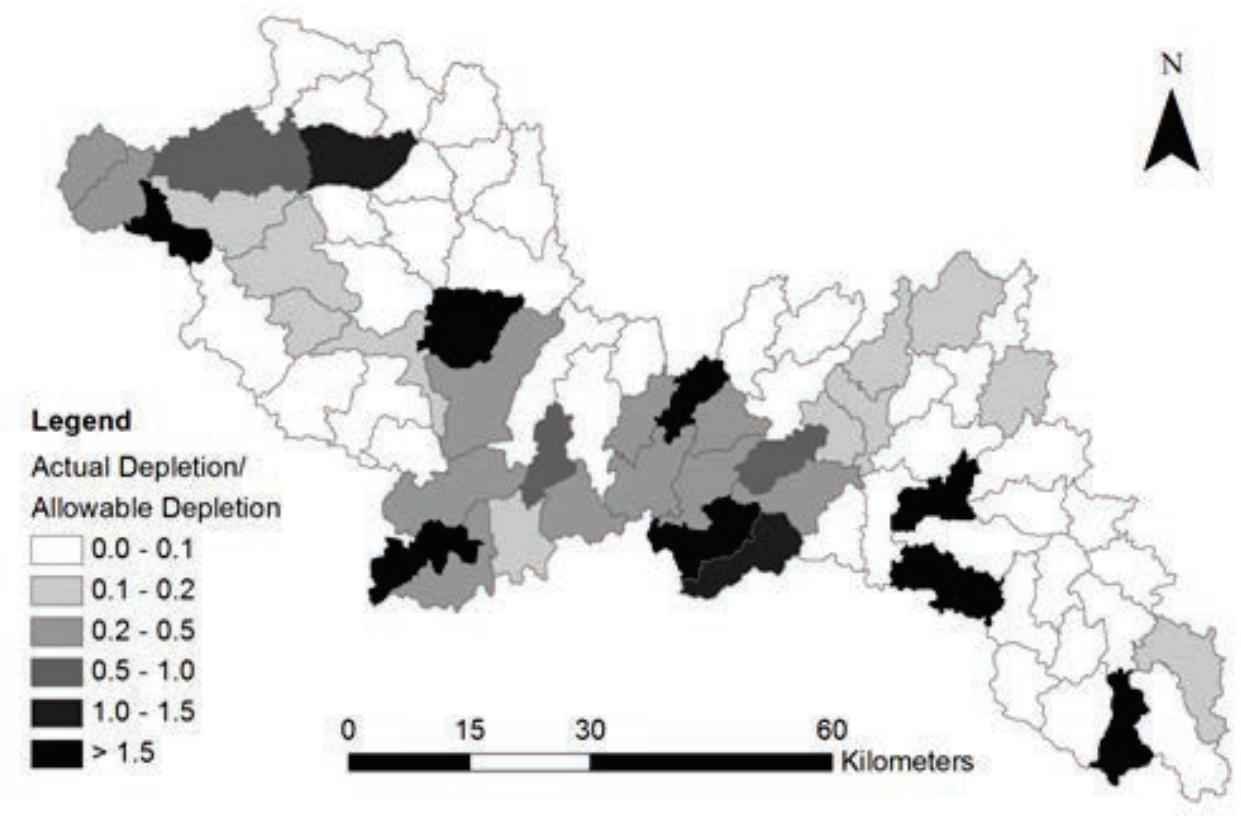

F igure 5-2H U-12 ratios of flow depletions to maximum allowable flow depletions for $\mathrm{J}$ uly $Q_{0}$ (low) flows and upper-limit consumptive use coefficients (M ayer et al. 2012).

As an extension of this effort, hydrologic proj ections from both regional regression models (described in $\mathrm{C}$ hapter 3) and L B R M withadinergyment PET (described in $\mathrm{C}$ hapter 4 ) are proposed to compute ecologicastress indices under future climate scenarios. $\mathrm{U}$ sing a scenario tree constructed from $\mathrm{C} \quad \mathrm{M}$ I P3 ensemble proj ections, esults will be presented for cases of " static" decision mak ing (e.g., onetime permitting) and adaptive decision making (e.g., adj ustable permits) to evaluate the importance of climate change monitoring and adaptation.

A second application is adaptive $\mathrm{B} \quad \mathrm{M} \quad \mathrm{P}$ implementation for water quality management at the watershed scale. $\mathrm{B}$ est management practices (B $\mathrm{M}$ Ps) are procedures used to control and treat water pollution and are typically used to facilitate the implementation of Total $M$ ax imum D aily load (TM D L ) plans (S harpley et al., 1994; B ottcher et al., 1995; C enter et al., 1999; K leinman et al., 2011). Total phosphorus (TP) loads have received a particular focus, as phosphorus is often a limiting nutrient affecting anthropogenic eutrophication in aq uatic systems ( $\mathrm{L}$ ee et al., 1978; S harpley et al., 1994).

F uture climate scenarios and hydrologic responses will affect theP loads from different land use types, which will ultimately affect the effectiveness of the 
BMP implementation plan. As an extension of long-term BMP implementation planning in the Kalamazoo River watershed, the hydro-climate projections will be used to inform an adaptive BMP implementation approach, the benefits of which can be evaluated using the system dynamics approach being used by Mirchi and Watkins (2012). The explicit consideration of climate uncertainty in conjunction with the added flexibility of adaptive decision making is expected to improve the cost-effectiveness of mitigating eutrophication through BMP implementation. An expected outcome of this effort will be the development of BMP cost-reliability tradeoff curves for both longterm ("static") and adaptive planning processes.

Other applications of the adaptive decision making framework for water resources planning and managemnt in the Great Lakes basin include the development of new lake level regulation plans (e.g., Eberhardt et al. 2009) and investments in water resources infrastructure (e.g., Venkatesh and Hobbs 1999, Kang and Lansey 2012). Each of these decisions can be formulated as a multi-stage decision problem. For water resources infrastructure investments, decisions to build new facilities may be staged into the future, and also adjustments to facilty operations may be made to better accommodate changing conditions. In the case of lake level management, regulation plans implemented today can incorporate flexibity to adapt to changing hydroclimatic conditions, or else "triggers" that identify when the plan should be revised (IJC 2012).

\subsubsection{Snowmelt modeling opportunities in the Great Lakes basin}

In the research presented in Chapter 2, it was found that hydrologic models at a daily time step showed poorer performance for smaller drainage areas, and also missed a number of peak discharges in late winter and early spring. It is expected that a shorter time step would capture diurnal variability in temperature and varying effects of temperature on snowmelt. In snow dominated areas, additional challenges that need to be addressed in hydrologic modeling studies include estimating ET, sublimation and condensation to snowpack; quantifying the effects of slope, aspect and forest cover on snowmelt; and modeling energy transfer from rain on snow. For accurate representation of snow processes, especially for climate change studies in Great Lakes watersheds, it is recommended to use energy balance methods which allow better accuracy in quantifying snowmelt in hydrologic models. Improved parameter estimation methods for snowmelt model calibration could be developed using radiative flux estimates and remote surveillance techniques, such as NORHSC's estimated daily snow cover data and SNODAS SWE product. Other opportunities to relate snowmelt parameters to satellite observations include NASA's blended global snow products. For example, Advanced Microwave Scanning Radiometer (AMSR-E) and QuikSCAT (Quick Scatterometer) (QSCAT) data are already validated to groundbased observations, to the extent possible, for the Great Lakes basin (Foster et al. 2011). 


\subsubsection{Sensitivity of hydrologic processes to climate change in temperate and tropic regions}

This research has shown hydrologic projections are highly sensitive to choices of climate models, hydrologic models and PET estimation methods. Relationships between temperature, snowmelt rate and evapotranspiration depend on different components of the surface energy balance. To better understand and distinguish the dynamics of hydrologic implications of climate change in these regions, a future direction is to further investigate evaporation models which adhere to the conservation of energy. In Chapter 4, hydrologic projections using the Thornthwaite (1948) method in LBRM were evaluated, and a future direction is to evaluate the sensitivity of evaporative responses using other PET estimation methods which use temperature proxy (e.g. Jensen and Haise, Hamon) or hybrids of temperature and energy methods (e.g. Priestly and Taylor, Penman-Monteith), as defined in Bae et al. (2011). In addition to streamflow responses presented in Chapter 4, snow water equivalent (SWE) and other moisture storages of the selected 14 watersheds have also been simulated using both TA and EA methods. An immediate future direction of this research includes quantifying differences in annual snowmelt budget from TA and EA methods.

It should also be noted that energy balance variables, e.g. shortwave and longwave radiation, wind speed, atmospheric vapor pressure, and drought and moisture indices, have often been expressed in terms of temperature-based relationships (Maurer et al. 2002; Dai et al. 2004). The validity of these approaches needs to be further scrutinized by comparing with climate model-derived variables, which are expected to constitute more fully coupled interactions of energy balance components within the integrated land surface-atmospheric components of GCMs. An important outcome of this research is more informed insights to challenges that remain in appropriately coupling climate and hydrologic models.

\subsubsection{Integrated uncertainty assessment of hydro-climate change impact projections}

In the research presented in Chapter 3, it was found that the development and application of regional regression models in conjunction with physically based hydrologic models can contribute to more robust multi-model approaches for climate change impact assessment. It is recommended that the limitations and strengths of these models be carefully evaluated in future climate risk assessments and decision applications, such as the one presented in Section 5.2.1. A future direction of this work is to investigate how the use of different models for impact assessment could affect water resources management decision making. For example, water resources decision making may be addressed using the "decision scaling" (Brown 2011) concept, as an alternate to the downscaling concept used in this research. Decision scaling is a 
bottom-up, resource-based, vulnerability approach to assess climate, societal and environmental threats to critical assets such as water resources infrastructure (Brown 2011, Wilby and Dessai 2010). However, it still relies on coupled climate-hydrologic models for evaluation of impacts, and how uncertainty in models translates into risk in decision making is not clear.

Many other studies (e.g., Hickox and Nichols 2003, Murphy et al. 2004) have argued that quantifying uncertainties and providing more accuracy and precision in assessment of future climate is crucial to formulate effective adaptation strategies. On the other hand, some studies question whether accurate or precise information relevant for climate change impact assessment can be delivered (Dessai and Hulme 2007, Wilby and Dessai 2010). Section 5.2.1 presents a conceptual application of adaptive decision making to inform water withdrawal permitting policy in the Great Lakes basin. It should also be noted that climate is only one of the processes which may influence outcomes while considering an adaptation decision (Nicholls et al. 2008). Population growth, land use change and economic growth scenarios are also expected to have profound influence on adaptive decisions. An extension of this research would be to integrate climate with other uncertainties to inform adaptive decision making, such as devising staged ground water abstraction policies for contingencies of climate change, population growth, and land use change. 


\section{References}

Aeschbach-Hertig, W. and T. Gleeson (2012). "Regional strategies for the accelerating global problem of groundwater depletion." Nature Geosciences 5(12): 853-861.

Ahearn, E. A. (2010). Regional Regresion Equations to Estimate Flow-duration Statistics at Ungaged Stream Sites in Connecticut. US Department of the Interior, US Geological Survey.

Anderson, T. L., R. J. Charlson, et al. (2003). "Climate Forcing by Aerosols--a Hazy Picture." Science 300(5622): 1103-1104.

Angel, J. R., and Kunkel, K. E. (2010). "The response of Great Lakes water levels to future climate scenarios with an emphasis on Lake Michigan-Huron." Journal of Great Lakes Research, 36(Supp. 2), 51-58.

Antic, S., R. Laprise, et al. (2004). "Testing the downscaling ability of a one-way nested regional climate model in regions of complex topography." Climate Dynamics 23(5): 473-493.

Archfield, S., R. Vogel, P. Steeves, S. Brandt, P. Weiskel, and S. Garabedian(2010), The Massachusetts Sustainable-Yield Estimator: A decision-support tool to assess water availability at ungaged sites in Massachusetts [CD-ROM], U.S. Geol. Surv. Sci. Invest. Rep., 2009-5227, 41 pp

Archfield, S. A. and R. M. Vogel (2010). "Map correlation method: Selection of a reference streamgage to estimate daily streamflow at ungaged catchments." Water Resources Research 46(10): W10513.

Bae, D.-H., I.-W. Jung, et al. (2011). "Hydrologic uncertainties in climate change from IPCC AR4 GCM simulations of the Chungju Basin, Korea." Journal of Hydrology 401(1-2): 90-105.

Barnett, T. P., J. C. Adam, et al. (2005). "Potential impacts of a warming climate on water availability in snow-dominated regions." Nature 438(7066): 303-309.

Bastola, S., C. Murphy, et al. (2011). "The role of hydrological modelling uncertainties in climate change impact assessments of Irish river catchments." Advances in Water Resources 34(5): 562-576.

Beven, K. (2006). "A manifesto for the equifinality thesis." Journal of Hydrology 320(12): $18-36$.

Beven, K., and J. Freer (2001). "Equifinality, data assimilation, and uncertainty estimation in mechanistic modelling of complex environmental systems using the GLUE methodology." Journal of Hydrology, 249(1-4), 11-29.

Bottcher, A.B., T. Tremwell, K.L. Campbell (1995). "Best management practices for water quality improvement in the Lake Okeechobee watershed." Ecol. Eng. 5, 341-356. 
Brekke, L., M. Dettinger, et al. (2008). "Significance of model credibility in estimating climate projection distributions for regional hydroclimatological risk assessments." Climatic Change 89(3): 371-394.

Brown, C., W. Werick, et al. (2011). "A Decision-Analytic Approach to Managing Climate Risks: Application to the Upper Great Lakes1." Journal of the American Water Resources Association 47(3): 524-534.

Brutsaert, W. and M. Parlange (1998). "Hydrologic cycle explains the evaporation paradox." Nature 396: 30.

Chao, P. (1999). "Great Lakes water resources: Climate change impact analysis with transient GCM scenarios." Journal of the American Water Resources Association, 35(6), 1499-1507.

Chiew, F. H. S., D. G. C. Kirono, et al. (2010). "Comparison of runoff modelled using rainfall from different downscaling methods for historical and future climates." Journal of Hydrology 387(1-2): 10-23.

Couillard, D., D. Cluis, et al. (1988). "An extension of the grid-based hydrological model CEQUEAU to suspended sediment movement through drainage basins." Water Research 22(8): 991-999.

Croley, T. E., II (2002). Large basin runoff model. Mathematical models of large watershed hydrology, V. Singh, D. Frevert, and S. Meyer, eds., Water Resources Publications, Highlands Ranch, CO, 717-770.

Croley, T. and C. He (2005). "Distributed-Parameter Large Basin Runoff Model. I: Model Development." Journal of Hydrologic Engineering 10(3): 173-181.

Croley, T. E., II, and C. He (2006). "Watershed surface and subsurface spatial intraflows model." Journal of Hydrologic Engineering, 11(1), 12-20.

Dai, A., K. E. Trenberth, and T. Qian, (2004). "A global dataset of Palmer Drought Severity Index for 1870-2002: Relationship with soil moisture and effects of surface warming. Journal of Hydrometeorology (5) 1117-1130.

Daly, S. F., Ochs, E. S., Brooks, P. F., Pangburn, T., and Davis, E. M. (1999). "Distributed snow process model for use with Hydrologic Engineering Center's hydrologic modeling system (HEC-HMS)." Cold regions engineering: Putting research into practice, J. E. Zufelt, ed., ASCE, Reston, VA, 538-549.

DeMarchi, C., F. Xing, et al. (2010). "Application of a Distributed Large Basin Runoff Model to Lake Erie: Model Calibration and Analysis of Parameter Spatial Variation." Journal of Hydrologic Engineering 16(3): 193-202.

Déqué, M., D. Rowell, et al. (2007). "An intercomparison of regional climate simulations for Europe: assessing uncertainties in model projections." Climatic Change 81(0): 53-70.

Dessai, S. and M. Hulme (2007). "Assessing the robustness of adaptation decisions to climate change uncertainties: A case study on water resources management in the East of England." Global Environmental Change 17(1): 59-72.

Doesken, N. J., and Judson, A. (1997). A guide to the science, climatology, and measurement of snow in the United States, 2nd Ed., Dept. of Atmospheric Science, Colorado State Univ., Fort Collins, CO. 
Duan, N. (1983). "Smearing Estimate: A Nonparametric Retransformation Method." Journal of the American Statistical Association 78(383): 605-610.

Duan, Q., J. Schaake, et al. (2006). "Model Parameter Estimation Experiment (MOPEX): An overview of science strategy and major results from the second and third workshops." Journal of Hydrology 320(1-2): 3-17.

Duan, Q., S. Sorooshian, and V. Gupta (1992). "Effective and efficient global optimization for conceptual rainfall-runoff models." Water Resources Research 28(4), 1015-1031.

Eberhard, R., C. J. Robinson, et al. (2009). "Adaptive management for water quality planning - from theory to practice." Marine and Freshwater Research 60(11): 1189-1195.

Emerson, H. C., Welty, C., and Traver, R. G. (2005). "Scale evaluation of a system of storm water detention basins." Journal of Hydrologic Engineering 10(3), 237242.

Falcone, J. (2012). GAGES-II:Geospatial Attributes of Gages for Evaluating Streamflow. NSDI Node. Reston, Virginia, U.S. Geological Survey.

Fennessey, N.M. "Potential Climate Change Impacts to Streamflow in Northeast U.S." Presentation at University of Massachusetts-Dartmouth, June 29, 2011.

Fleming, M., and V.S. Neary (2004). "Continuous hydrologic modeling study with HMS." Journal of Hydrologic Engineering 9(3), 175-183.

Fortin, J., Turcotte, R., Massicotte, S., Moussa, R., Fitzback, J., and Villeneuve, J. (2001). "Distributed watershed model compatible with remote sensing and GIS data. I: Description of model." Journal of Hydrologic Engineering 6(2), 91-99.

Fry, J., et al. (2011). "Completion of the 2006 National Land Cover Database for the conterminous United States." Photogram. Eng. Remote Sens., 77(9), 858-864 $\langle$ http://viewer.nationalmap.gov〉 (Dec. 19,2012).

Fu, G., S. P. Charles, et al. (2007). "A two-parameter climate elasticity of streamflow index to assess climate change effects on annual streamflow." Water Resources Research 43(11): W11419.

Garbrecht, J., Ogden, F. L., DeBarry, P. A., and Maidment, D. R. (2001).“GIS and distributed watershed models I: Data coverages and sources." Journal of Hydrologic Engineering 6(6), 506-514.

Gleckler, P. J., K. E. Taylor, et al. (2008). "Performance metrics for climate models." Journal of Geophysical Research 113(D6): D06104.

Golubev, V. S. (2001). "Evaporation changes over the contiguous United States and the former USSR: a reassessment." Geophysical Research Letters 28(13): 2665-2668.

Gyawali, R. (2010). "Surface water availability modeling of Kalamazoo River watershed.” MS Rep., Dept. of Civil and Environmental Engineering, Michigan Technological Univ., Houghton, MI.

Gyawali, R., and D.W. Watkins (2013).“Continuous Hydrologic Modeling of SnowAffected Watersheds in the Great Lakes Basin Using HEC-HMS."Journal of Hydrologic Engineering 18(1):29-39. 
Haddeland, I., Heinke, J., Voß, F., Eisner, S., Chen, C., Hagemann, S., \& Ludwig, F. (2012). Effects of climate model radiation, humidity and wind estimates on hydrological simulations. Hydrology and Earth System Sciences 16(2), 305.

Hamilton, D.A. and P.W. Seelbach (2010). "Determining environmental limits to streamflow depletion across Michigan." The Book of the States 2010. The Council of State Governments, Lexington, Kentucky, USA.

Hamon, W. R. (1963). "Computation of direct runoff amounts from storm rainfall." Int. Assoc. Sci. Hydrol. Publ., 63, 52-62.

Han, W. S., and Burian, S. J. (2009). "Determining effective impervious area for urban hydrologic modeling." Journal of Hydrologic Engineering 14(2), 111-120.

Hanssen-Bauer, I., C. Achberger, et al. (2005). "Statistical downscaling of climate scenarios over Scandinavia." Climate Research 29(3): 255-268.

Harding, B. L., A. W. Wood, et al. (2012). "The implications of climate change scenario selection for future streamflow projection in the Upper Colorado River Basin." Hydrol. Earth Syst. Sci. Discuss. 9(1): 847-894.

Hartmann, H. C. "Climate change impacts on Laurentian Great Lakes levels." Climatic Change 17(1990): 49-67.

Haylock, M. R., G. C. Cawley, et al. (2006). "Downscaling heavy precipitation over the United Kingdom: a comparison of dynamical and statistical methods and their future scenarios." International Journal of Climatology 26(10): 1397-1415.

Haylock, M. R. and C. M. Goodess (2004). "Interannual variability of European extreme winter rainfall and links with mean large-scale circulation." International Journal of Climatology 24(6): 759-776.

He, C. and T. E. Croley Ii (2007). "Application of a distributed large basin runoff model in the Great Lakes basin." Control Engineering Practice 15(8): 1001-1011.

Helfrich, S. R., McNamara, D., Ramsay, B. H., Baldwin, T., and Kasheta, T. (2007). "Enhancements to, and forthcoming developments in the Interactive Multisensor Snow and Ice Mapping System (IMS)." Hydrologic Processes, 21(12), 15761586.

Hoblit, B. C., Liu, L., and Curtis, D. C. (2002). "Extreme rainfall estimation using radar for Tropical Storm Allison.” Proc. 2002 Water Resources Planning and Management Conf., Environmental and Water Resources Institute, Washington, DC, $1-8$.

Hickox, W.H. and Nichols M.D. (2003) Climate research. Issues in Science and Technology, 19, 6-7.

Hodgkins, G. A., Dudley, R. W., and Aichele, S. S. (2007). "Historical changes in precipitation and streamflow in the U.S. Great Lakes Basin, 1915-2004.” Rep. SIR2007-5118, U.S. Geological Survey, Rolla, MO.

Hurrell, J., G. A. Meehl, et al. (2009). "A Unified Modeling Approach to Climate System Prediction." Bulletin of the American Meteorological Society 90(12): 1819-1832. Jones, R. N. (2000). "Managing Uncertainty in Climate Change Projections Issues for Impact Assessment." Climatic Change 45(3): 403-419. 
IPCC, 2007: Climate Change 2007: The Physical Science Basis. Contribution of Working Group I to the Fourth Assessment Report of the Intergovernmental Panel on Climate Change [Solomon, S., D. Qin, M. Manning, Z. Chen, M. Marquis, K.B. Averyt, M.Tignor and H.L. Miller (eds.)]. Cambridge University Press, Cambridge, United Kingdom and New York, NY, USA.

Jones, R. N. (2000). "Managing Uncertainty in Climate Change Projections - Issues for Impact Assessment." Climatic Change 45(3): 403-419.

Kang, D. and K. Lansey (2012). "Revisiting Optimal Water-Distribution System Design: Issues and a Heuristic Hierarchical Approach.” J. Water Resour. Plann. Manage., 138(3), 208-217.

Kerr, R. A. (2011). "Vital Details of Global Warming Are Eluding Forecasters." Science 334(6053): 173-174.

Kleinman, P.J.A., A.N. Sharpley, R.W. McDowell, D.N. Flaten, A.R. Buda, L. Tao, L. Bergstrom, Q. Zhu (2012). "Managing agricultural phosphorus for water quality protection: principles for progress." Plant Soil, 349,169-182.

Konikow, L. F. (2013). "Overestimated water storage." Nature Geosci 6(1): 3-3.

Kopp, T. J., and Kiess, R. B. (1996). "The Air Force Global Weather Central snow analysis model." Preprints, 15th Conf. on Weather Analysis and Forecasting, American Meteorological Society, Boston, MA, 220-222.

Knutti, R., R. Furrer, et al. (2009). "Challenges in Combining Projections from Multiple Climate Models." Journal of Climate 23(10): 2739-2758.

Kroll, C., J. Luz, et al. (2004). "Developing a Watershed Characteristics Database to Improve Low Streamflow Prediction." Journal of Hydrologic Engineering 9(2): 116-125.

Kroll, C. and R. Vogel (2002). "Probability Distribution of Low Streamflow Series in the United States." Journal of Hydrologic Engineering 7(2): 137-146.

Kroll, C. N. and J. R. Stedinger (1999). "Development of regional regression relationships with censored data." Water Resour. Res. 35(3): 775-784.

Kroll, C. N., and P. Song (2013), "Impact of multicollinearity on small sample hydrologic regression models, Water Resources Research 49, doi:10.1002/wrcr.20315.

Kuczera, G., and Parent, E. (1998). "Monte Carlo assessment of parameter uncertainty in conceptual catchment models: the Metropolis algorithm." Journal of Hydrology 211(1-4), 69-85.

Liang, X., D. P. Lettenmaier, et al. (1994). "A simple hydrologically based model of land surface water and energy fluxes for general circulation models." J. Geophys. Res. 99(D7): 14415-14428.

Lins, H. F. and J. R. Slack (1999). "Streamflow trends in the United States." Geophys. Res. Lett. 26(2): 227-230.

Lee, G. F., W. Rast, R.A. Jones (1978). "Eutrophication of water bodies: insights for an age-old problem." Environ. Sci. Technol., 12, 900-908.

Lofgren, B. M., T. S. Hunter, et al. (2011). "Effects of using air temperature as a proxy for potential evapotranspiration in climate change scenarios of Great Lakes basin hydrology." Journal of Great Lakes Research 37(4): 744-752. 
Lofgren, B. M., F. H. Quinn, et al. (2002). "Evaluation of Potential Impacts on Great Lakes Water Resources Based on Climate Scenarios of Two GCMs." Journal of Great Lakes Research 28(4): 537-554.

Manning, L. J., J. W. Hall, et al. (2009). "Using probabilistic climate change information from a multimodel ensemble for water resources assessment." Water Resour. Res. 45(11): W11411.

Matulla, C., H. Scheifinger, et al. (2003). "Exploring two methods for statistical downscaling of Central European phenological time series." International Journal of Biometeorology 48(2): 56-64.

Maurer, E. P., A. W. Wood, et al. (2002). "A Long-Term Hydrologically Based Dataset of Land Surface Fluxes and States for the Conterminous United States*." Journal of Climate 15(22): 3237-3251.

Maurer, E. P., H. G. Hidalgo, et al. (2010). "The utility of daily large-scale climate data in the assessment of climate change impacts on daily streamflow in California." Hydrol. Earth Syst. Sci. 14(6): 1125-1138.

Mayer A., Watkins, D.W., Mirchi, A., Gyawali, R., Watson, K.A. (2012), "Determination of Water Stress Indices as a Function of Ecological Flows." Proceedings, World Environment and Water Resources Congress, Albuquerque, NM, May 20-24, 2012, ASCE (2012).

Montanari, A., Brath, A., (2004). A stochastic approach for assessing the uncertainty of rainfall-runoff simulations. Water Resour. Res., 40(1): W01106.

Montgomery, D.C., and Peck, E.A., 1982. Introduction to linear regression analysis: John Wiley, New York, $504 \mathrm{p}$.

Mearns, L.O., Hulme, M., Carter, T.R., Leemans, R., Lal, M. and Whetton, P. (2001): Climate scenario development. In: Climate Change 2001: The Scientific Basis. Contribution of Working Group I to the Third Assessment Report of the Intergovernmental Panel on Climate Change (Eds., Houghton, J.T., Ding, Y., Griggs, D.J., Noguer, M., van der Linden, P.J., Dai, X., Maskell, K. and Johnson, C.A.), Cambridge University Press, Cambridge and New York, pp. 739-768. Available for download from: http://www.ipcc.ch (Chapter 13 of the IPCC WG1 Assessment).

Meehl, G., C. Covey, et al. (2007). "The WCRP CMIP3 Multimodel Dataset: A new era in climate change research." Bulletin of the American Meteorological Society 88(9): 1383-1394.

Meier, H. (2006). "Baltic Sea climate in the late twenty-first century: a dynamical downscaling approach using two global models and two emission scenarios." Climate Dynamics 27(1): 39-68.

Melloh, A. R. (1999). "A synopsis and comparison of selected snow melt algorithms." CRREL Rep. 99-8, Cold Regions Research and Engineering Laboratory, U.S. Army Corps of Engineers, Hanover, NH. 
Midwestern Regional Climate Center [MRCC] (2010). "30-year average monthly precipitation, snow, temperature and growing season."

〈http://mrcc.isws.illinois.edu/climate_midwest/mwclimate_data_summaries .htm\#) (Mar. 15, 2010).

Milly, P. C. D., J. Betancourt, et al. (2008). "Stationarity Is Dead: Whither Water Management?" Science 319(5863): 573-574.

Milly, P. C. D., R. T. Wetherald, et al. (2002). "Increasing risk of great floods in a changing climate." Nature 415(6871): 514-517.

Milly, P. C. D. and K. A. Dunne (2010). "On the Hydrologic Adjustment of ClimateModel Projections: The Potential Pitfall of Potential Evapotranspiration." Earth Interactions 15(1): 1-14.

Mirchi, A. and Watkins, D., Jr. (2012). "A Systems Approach to Holistic TMDL Policy: The Case of Lake Allegan, Michigan." J. Water Resour. Plann. Manage., 10.1061/(ASCE)WR.1943-5452.0000292

Montanari, A. and A. Brath (2004). "A stochastic approach for assessing the uncertainty of rainfall-runoff simulations." Water Resour. Res. 40(1): W01106.

Monteith, J. (1981). "Evaporation and surface temperatures." Q. J. Royal Meteorol. Soc., 107(451), 1-27.

Mote, P., L. Brekke, et al. (2011). "Guidelines for constructing climate scenarios." Eos Trans. AGU 92(31).

Mote, P. and E. Salathé (2010). "Future climate in the Pacific Northwest." Climatic Change 102(1): 29-50.

Murphy, J. M., D. M. H. Sexton, et al. (2004). "Quantification of modelling uncertainties in a large ensemble of climate change simulations." Nature 430(7001): 768-772.

Nash, J. E., and Sutcliffe, J. V. (1970). "River flow forecasting through conceptual models part I-A discussion of principles." J. Hydrol., 10(3), 282-290.

National Operational Hydrologic Remote Sensing Center (2004). Snow Data Assimilation System (SNODAS) data products at NSIDC.(National Snow and Ice Data Center).Digital media.Boulder, CO. 〈http://nsidc.org/data/g02158.html〉 (Sep. 13, 2012).

Neff, Brian P. and J. R. Nicholas, (2005), Uncertainty in the Great Lakes Water Balance, Date Posted: November 23, 2005: U.S. Geological Survey Scientific Investigations Report 2004-5100, 42 p. [http://pubs.water.usgs.gov/sir2004-5100/]

Neuman, S. P. (2003). "Maximum likelihood Bayesian averaging of uncertain model predictions." Stochastic Environmental Research and Risk Assessment 17(5): 291305.

New, M., A. Lopez, et al. (2007). "Challenges in using probabilistic climate change information for impact assessments: an example from the water sector." Philosophical Transactions of the Royal Society A: Mathematical, Physical and Engineering Sciences 365(1857): 2117-2131.

Nicholls, R., P. Wong, et al. (2008). "Climate change and coastal vulnerability assessment: scenarios for integrated assessment." Sustainability Science 3(1): 89102. 
Ogden, F. L., Garbrecht, J., Debarry, P. A., and Maidment, A. R. (2001). "GIS and distributed watershed models II: Modules, interfaces, and models.” J. Hydrol. Eng., 6(6), 515-523.

Penman, H. L. (1948). "Natural Evaporation from Open Water, Bare Soil and Grass." Proceedings of the Royal Society of London. Series A. Mathematical and Physical Sciences 193(1032): 120-145.

Peterson, T. C., V. S. Golubev, et al. (1995). "Evaporation losing its strength." Nature 377: 687-688.

Pidwirny, M. (2006). “Actual and potential evapotranspiration.” Fundamentals of physical geography, 2nd Ed., Univ. of British Columbia, Okanagan, BC, Canada.

Pielke, R. A., Sr. and R. L. Wilby (2012). "Regional climate downscaling: What's the point?" Eos Trans. AGU 93(5).

Pierce, D. W., T. P. Barnett, et al. (2009). "Selecting global climate models for regional climate change studies." Proceedings of the National Academy of Sciences 106(21): 8441-8446.

Priestley, C. H. B., \& Taylor, R. J. (1972). On the assessment of surface heat flux and evaporation using large-scale parameters. Monthly Weather Review, 100, 81-92.

Pokhrel, Y. N., N. Hanasaki, et al. (2012). "Model estimates of sea-level change due to anthropogenic impacts on terrestrial water storage." Nature Geosci advance online publication < doi:10.1038/ngeo1476>.

Prudhomme, C., N. Reynard, et al. (2002). "Downscaling of global climate models for flood frequency analysis: where are we now?" Hydrological Processes 16(6): 1137-1150.

Rasmussen, J. et al., (2012) "Climate change effects on irrigation demands and minimum stream discharge: impact of bias-correction method." Hydrol. Earth Syst. Sci. 16(12): 4675-4691.

R Development Core Team. "R: A Language and Environment for Statistical Computing."R Foundation for Statistical Computing, Vienna, Austria, 2011.(ISBN) 3-900051-07-0, http://www.R-project.org

Rawlings, J. O., Pantula, S. G., and Dickey, D. A. (1998). Applied regression analysis: A research tool, 2nd Ed., Springer, New York.

Ries III, K.G., Friesz, P.J. (2000). Methods for Estimating Low-flow Statistics for Massachusetts Streams. USGS Water-Resources Investigations Report 00-4135, $81 \mathrm{pp}$.

Risley, J., Stonewall, A. and Haluska, T. (2008), Estimating flow-duration and low-flow frequency statistics for unregulated streams in Oregon: U.S. Geological Survey Scientific Investigations Report 2008-5126, 22 p.

Robertson, D. M., \& Saad, D. A. (2011). Nutrient Inputs to the Laurentian Great Lakes by Source and Watershed Estimated Using SPARROW Watershed Models 1. Journal of the American Water Resources Association, 47(5), 1011-1033

Rojas, R., S. Kahunde, et al. (2010). "Application of a multimodel approach to account for conceptual model and scenario uncertainties in groundwater modelling." Journal of Hydrology 394(3-4): 416-435. 
Rosenthal, W. D., R. Srinivasan, and J.G. Arnold (1995). "Alternative river management using a linked GIS-hydrology model " Transactions of the ASAE 38(3): 783-790.

Sankarasubramanian, A., R. M. Vogel, et al. (2001). "Climate elasticity of streamflow in the United States." Water Resources Research 37(6): 1771-1781.

Sanford, W. E. and D. L. Selnick (2013). "Estimation of Evapotranspiration Across the Conterminous United States Using a Regression With Climate and Land-Cover Data1." JAWRA Journal of the American Water Resources Association 49(1): 217-230.

Santer, B. D., K. E. Taylor, et al. (2009). "Incorporating model quality information in climate change detection and attribution studies." Proceedings of the National Academy of Sciences 106(35): 14778-14783.

Saxton, K. E., Rawls, W. J., Romberger, S. J., and Papendick, R. I. (1986). "Estimating generalized soil-water characteristics from texture.” Soil Sci. Soc. Am. J., 50(4), 1031-1036.

Scavia, D. "Confronting Climate Change in the Great Lakes." $3{ }^{\text {rd }}$. Annual Great Lakes Conference, September 2007, Chicago IL

(http://vilaslandandwater.org/water_resources_pages/development trends/climate lecture scavia.pdf), accessed 1/17/2012

Schaake, J. C. (1981). "Summary of river forecasting raingage network density requirements." 〈http://www.nws.noaa.gov/oh/mopex/raingage \%20density\%20requirement.htm $\rangle$ (Nov. 15, 2011).

Scharffenberg, B. (2008). "Introduction to HEC-HMS." Watershed Modeling with HECHMS, California Water and Engineering Forum, Sacramento, CA, May 28, 2008 〈http://www.cwemf.org/workshops/HEC-HMSwrkshp/HEC-HMSWrkshp.pdf) (Mar. 15, 2010).

Schmidli, J., C. Frei, et al. (2006). "Downscaling from GCM precipitation: a benchmark for dynamical and statistical downscaling methods." International Journal of Climatology 26(5): 679-689.

Schmidli, J., C. M. Goodess, et al. (2007). "Statistical and dynamical downscaling of precipitation: An evaluation and comparison of scenarios for the European Alps." J. Geophys. Res. 112(D4): D04105.

Sellers, P. J., et al. (1996). "A revised land surface parameterization (SiB2) for atmospheric GCMs. Part I: Model formulation.” J. Clim., 9(4),676-705.

Senarath, S.U.,Ogden, F.L.,Downer, C.W., and Sharif, H.O. (2000). "On the calibration and verification of two-dimensional, distributed, Hortonian, continuous watershed models." Water Resour. Res., 36(6), 1495-1510.

Shapiro, M., J. Shukla, et al. (2010). "An Earth-System Prediction Initiative for the Twenty-First Century." Bulletin of the American Meteorological Society 91(10): 1377-1388.

Sharma, M., P. Coulibaly, et al. (2011). "Assessing the Need for Downscaling RCM Data for Hydrologic Impact Study." Journal of Hydrologic Engineering 16(6): 534539. 
Sharpley, A.N. (1994). "Managing agricultural phosphorus for protection of surface waters: Issues and options." J. Environ. Qual., 23, 437-451.

Shaw, S. B. and S. J. Riha (2011). "Assessing temperature-based PET equations under a changing climate in temperate, deciduous forests." Hydrological Processes 25(9): 1466-1478.

Singh, R., T. Wagener, et al. (2011). "A trading-space-for-time approach to probabilistic continuous streamflow predictions in a changing climate - accounting for changing watershed behavior." Hydrol. Earth Syst. Sci. 15(11): 3591-3603.

Slack, J. R., Lumb, A. M., and Landwehr, J. M. (1993). "Hydro-climatic data network (HCDN): A U.S. Geological Survey streamflow data set for the United States for the study of climate variations, $1874-1988$.’U.S. Geological Survey Water Resources Investigation Rep., 93-4076, U.S. Geological Survey, Reston, VA.

Smith, M. B., D.-J. Seo, et al. (2004). "The distributed model intercomparison project (DMIP): motivation and experiment design." Journal of Hydrology 298(1-4): 426.

Solomon, S., D. Qin, M. Manning, M. Marquis, K. Averyt, M. M. D. Tignor, J. Henry LerRoy MIller and Z. Chen, Eds. (2007). Climate Change 2007: The Physical Science Basis, Contribution of Working Group I to the Fourth Assessment Report of the Intergovernmental Panel on Climate Change. Cambridge, Cambridge University Press.

Stanhill, G., \& Cohen, S. (2001). Global dimming: a review of the evidence for a widespread and significant reduction in global radiation with discussion of its probable causes and possible agricultural consequences. Agricultural and Forest Meteorology, 107(4), 255-278

Stehlík, J. and A. Bárdossy (2002). "Multivariate stochastic downscaling model for generating daily precipitation series based on atmospheric circulation." Journal of Hydrology 256(1-2): 120-141.

Stephenson, D. (1979). "Direct optimization of Muskingum routing coefficients." Journal of Hydrology 41(1-2), 161-165.

Tasker, G. D. (1980). "Hydrologic regression with weighted least squares." Water Resour. Res. 16(6): 1107-1113.

Tarboton, D. G. and C. H. Luce (1996). Utah energy balance snow accumulation and melt model (UEB), Utah Water Research Laboratory.

Tebaldi, C. and R. Knutti (2007). "The use of the multi-model ensemble in probabilistic climate projections." Philosophical Transactions of the Royal Society A: Mathematical, Physical and Engineering Sciences 365(1857): 2053-2075.

Thornthwaite, C. W. (1948). "An Approach toward a Rational Classification of Climate." Geographical Review 38(1): 55-94.

U.S. Army Corps of Engineers (USACE). (2010). "Hydrologic modeling system HECHMS user's manual." Rep. CPD-74A, Hanover, NH.

USDA (2012). "Soil Survey Staff, Natural Resources Conservation Service, United States Department of Agriculture. Soil Series ClassificationDatabase." 〈http://soils.usda.gov/technical/classification/scfile/index.html〉 (Dec. 19, 2012). 
USGS (1997). "STATSGO soil characteristics for the conterminous United States." 〈http://water.usgs.gov/GIS/metadata/usgswrd/XML/muid〉 (Mar. 15, 2010).

Velázquez, J. A., F. Anctil, et al. (2011). "Can a multi-model approach improve hydrological ensemble forecasting? A study on 29 French catchments using 16 hydrological model structures." Adv. Geosci. 29: 33-42.

Vogel, R. M., and Kroll, C. N. (1992). "Regional geohydrologic-geomorphic relationships for the estimation of low-flow statistics." Water Resources Research, 28(9), 2451-2458.

Vogel, R. and N. Fennessey (1994). "Flow-Duration Curves. I: New Interpretation and Confidence Intervals." Journal of Water Resources Planning and Management 120(4): 485-504.

Vogel, R., I. Wilson, et al. (1999). "Regional Regression Models of Annual Streamflow for the United States." Journal of Irrigation and Drainage Engineering 125(3): 148-157.

Wada, Y. et al. (2010). "Global depletion of groundwater resources." Geophys. Res. Lett. 37, L20402

Wagener, T., Boyle, D., Lees, M., Wheater, H., Gupta, H., and Sorooshian, S. (2001). “A framework for development and application of hydrological models." Hydrol. Earth Syst. Sci., 5(1), 13-26.

Watkins, D. W., Li, H., and Cowden, J. (2007). "Adjustment of radarbased precipitation estimates for Great Lakes hydrologic modeling." J. Hydrol. Eng., 12(3), 298-305.

Watershed Modeling System (WMS). (1999). WMS V6.1 tutorials, Environmental Modeling Research Laboratory, Brigham Young Univ., Provo, UT.

Wilby, R. L., and Fowler, H.J. (2010). Regional climate downscaling, in Modelling the Impact of Climate Change in Water Resources, Chichester, U.K., WileyBlackwell.

Wilby, R. L., Charles, S. P., Zorita, E., Timbal, B., Whetton, P., and Mearns, L.O. (2004). Guidelines for Use of Climate Scenarios Developed from Statistical Downscaling Methods, Geneva, Switzerland, IPCC TGICA.

Wilby, R. L. and S. Dessai (2010). "Robust adaptation to climate change." Weather 65(7): 180-185.

Wilby, R. L., J. Troni, et al. (2009). "A review of climate risk information for adaptation and development planning." International Journal of Climatology 29(9): 11931215.

Wilby, R. L., T. M. L. Wigley, et al. (1998). "Statistical downscaling of general circulation model output: A comparison of methods." Water Resour. Res. 34(11): 2995-3008.

Wild, M. and B. Liepert (2010). "The Earth radiation balance as driver of the global hydrological cycle." Environmental Research Letters 5(2): 025203.

Wilks, D. S., and R. L. Wilby., "The weather generation game: A review of stochastic weather models." Prog. Phys. Geogr., 23 (1999), 329-357 
Wood, A. W., L. R. Leung, et al. (2004). "Hydrologic Implications of Dynamical and Statistical Approaches to Downscaling Climate Model Outputs." Climatic Change 62(1): 189-216.

Xu, C.-Y. (1999). "Climate Change and Hydrologic Models: A Review of Existing Gaps and Recent Research Developments." Water Resources Management 13(5): 369382.

Xu, C.-Y., and Singh, V. P. (2001). "Evaluation and generalization of temperature-based methods for calculating evaporation." Hydrol.Processes, 15(2), 305-319.

Xu, Z. U., Ito, K., Shultz, G. A., and Li, J. Y. (2001). "Integrated hydrologic modeling and GIS in water resources management." J. Comput. Civ. Eng., 15(3) 217-223.

Yilmaz, A., Imteaz, M., and Ogwuda, O. (2012). "Accuracy of HEC-HMS and LBRM models in simulating snow runoffs in Upper Euphrates Basin." J. Hydrol. Eng., 17(2), 342-347.

You, J., Tarboton, D.G., Luce, C.H. (2004).Modeling the snow surface temperature in an energy balance snowmelt model. Lincoln, Nebraska, 68583

Zorita, E. and H. von Storch (1999). "The Analog Method as a Simple Statistical Downscaling Technique: Comparison with More Complicated Methods." Journal of Climate 12(8): 2474-2489.

Zorn, T.G., P.W. Seelbach, E.S. Rutherford, T.C. Wills, S.T. Cheng, and M.J. Wiley. (2008). A regional-scale habitat suitability model to assess the effects of flow reduction on fish assemblages in Michigan streams. Ann Arbor: Michigan Department of Natural Resources, Fisheries Division. 


\section{Appendix A: Copyright permissions}

Permission has been granted by AS C E for the publication of $\mathrm{C}$ hapter 2 as per the following approval:

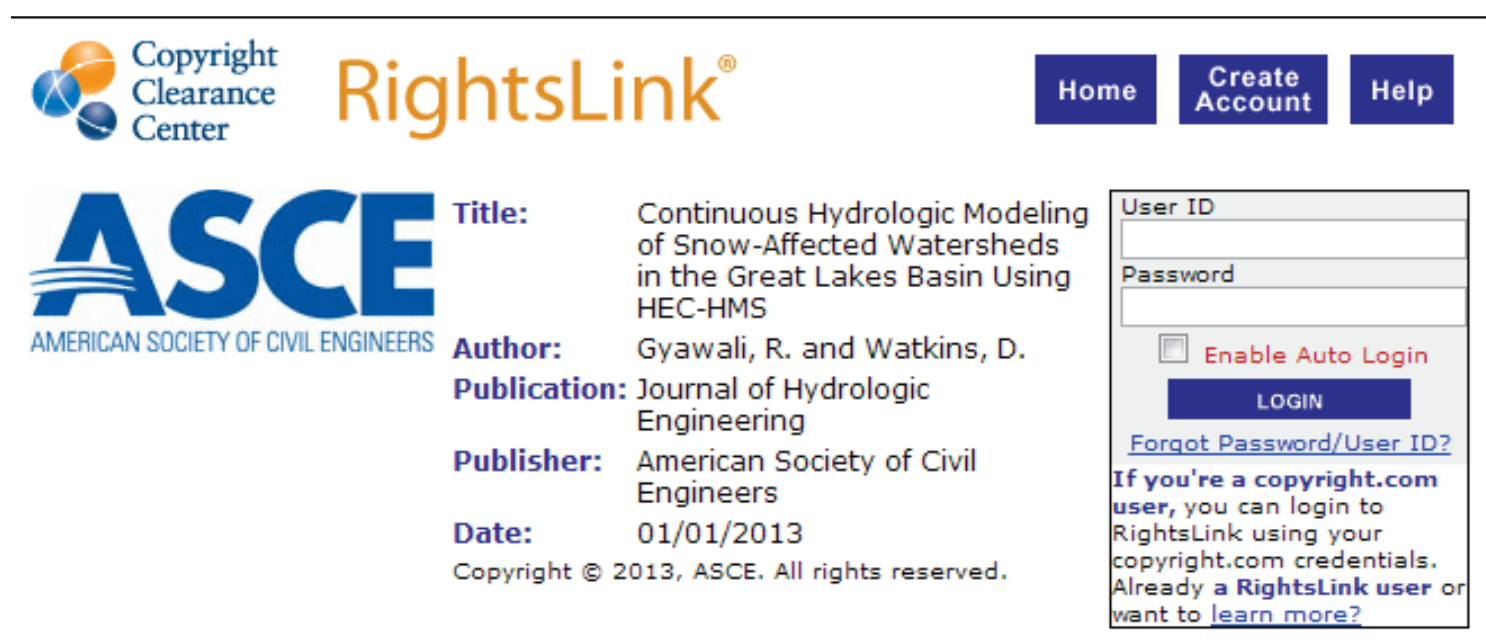

\section{Permissions Request}

As an ASCE author, you are permitted to reuse you own content for another ASCE or non-ASCE publication.

Please add the full credit line "With permission from ASCE" to your source citation. Please print this page for your records.

Type of use: Dissertation/Thesis

Portion: full article

Format: print and electronic

Use of this content will make up more than $25 \%$ of the new work: no

Author of this ASCE work or ASCE will publish the new work: yes

\section{BACK}

\section{CLOSE WINDOW}

Copyright () 2013 Copyright Clearance Center, Inc. All Rights Reserved. Privacy statement. Comments? We would like to hear from you. E-mail us at customercare@copyriqht.com 
Permission has been granted by AS $\mathrm{C}$ E for the publication of $\mathrm{F}$ igure $\mathrm{p}$ - $\mathrm{per}$ the following approval:

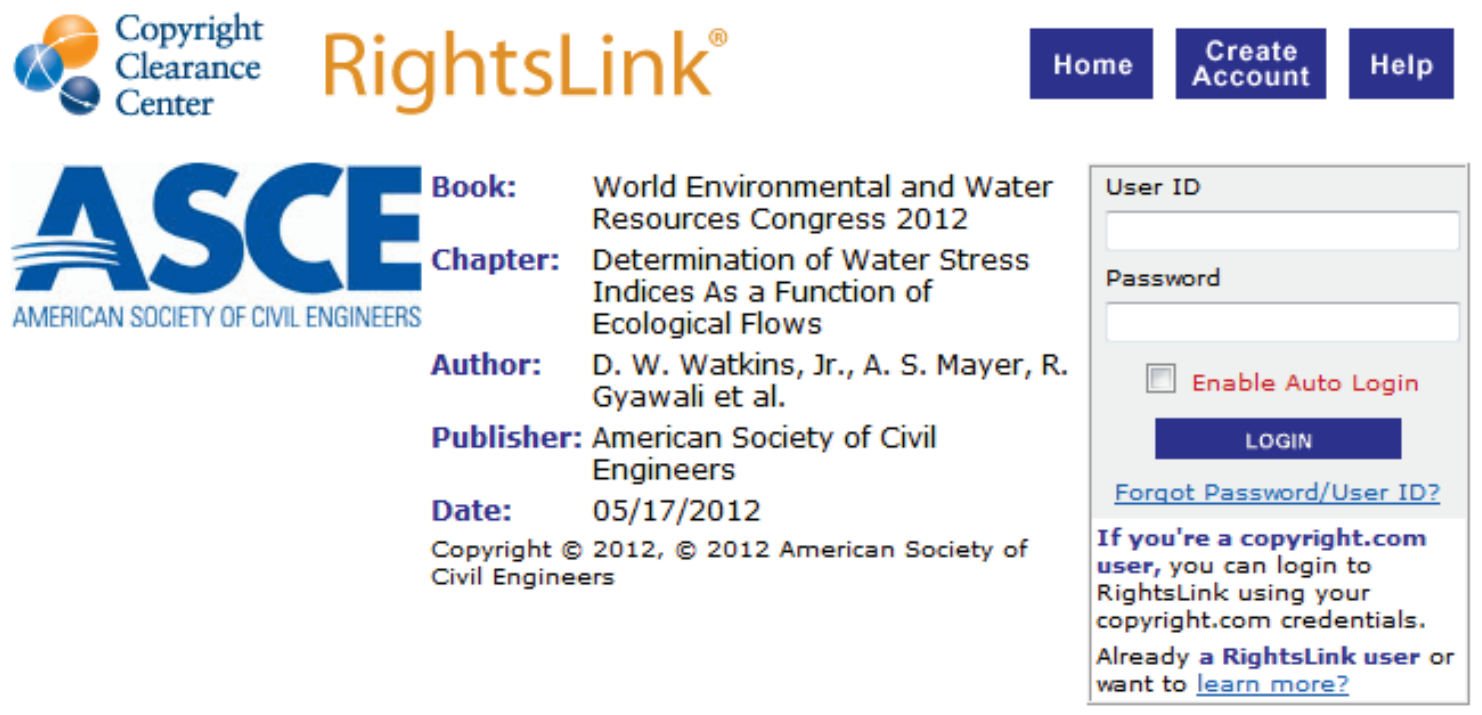

\section{Permissions Request}

As an ASCE author, you are permitted to reuse you own content for another ASCE or non-ASCE publication.

Please add the full credit line "With permission from ASCE" to your source citation. Please print this page for your records.

Type of use: Dissertation/Thesis

Portion: figures/tables/illustrations

Format: print and electronic

Use of this content will make up more than $25 \%$ of the new work: no

Author of this ASCE work or ASCE will publish the new work: yes

\section{BACK}

\section{CLOSE WINDOW}

Copyright @ 2013 Copyriqht Clearance Center, Inc. All Rights Reserved. Privacy statement. Comments? We would like to hear from you. E-mail us at customercare@copyright.com

$\mathrm{F}$ igure 2-2 is reproduced from the public domain $\mathrm{U} S$ Army $\mathrm{C}$ orps of Engineers (US AC E) and is cited accordingly as no permission is requi red to publish the material. 


\section{Appendix B: Regression iterations and diagnostics (Chapter 3)}

In this section, the development of regional regression model discussed in Chapter 3 is detailed. Regression modeling was done using the statistical software package R. The following example shows the back-ward stepwise regression iterations for the Q99 regression model. The regression method involves iteratively dropping the least significant variable from the model considered.

\section{$\underline{\text { Regression iterations }}$}

Example iterations along with $\mathrm{R}$ code are as follows:

library(car)

Qtile<-read.csv("D:/GAGES IIregression/WLSinput/WLStransinctempseas.csv")

\section{\#1st Iteration}

fullreg1 <-

Im(Q99 DRAIN_SQKM+PPTAVG_BASIN+T_AVG_BASIN+T_MAX_BASIN $+R H \_B A S I$

$N+P R E C I P \_S E \bar{A} S \_I N D+S T R E A M \bar{S} \_K M \_S Q \_K M+\bar{N} O 10 A V E+C L A \bar{Y} A V E+S I L T A \bar{V} E+S$ $A N D A V E+\overline{P E R M} \bar{A} V E+B D A V E+E L \bar{E} V \_\bar{M} E A N_{-} M_{-} B A S I N+S L O P E \_P C T$, weights $=$ Qtile\$W99, Qtile)

Call:

$\operatorname{lm}$ (formula $=$ Q99 $\sim$ DRAIN_SQKM + PPTAVG_BASIN + T_AVG_BASIN +

T_MAX BASIN + RH_BASIN + PRECIP SEAS IND + STREAMS KM SQ KM

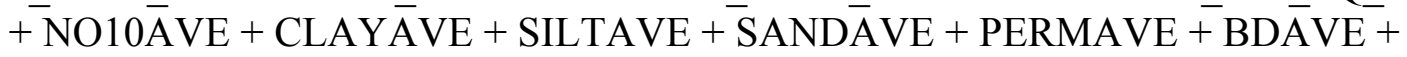

ELEV_MEAN_M_BASIN + SLOPE_PCT, data= Qtile, weights = Qtile\$W99)

Residuals:

Min 1Q Median 3Q Max

$\begin{array}{lllll}-1.19434 & -0.17207 & 0.06355 & 0.18728 & 0.67278\end{array}$

Coefficients:

$\begin{array}{lclcl} & \text { Estimate } & \text { Std. Error } & \mathrm{t} \text { value } & \operatorname{Pr}(>|\mathrm{t}|) \\ \text { (Intercept) } & -5.14486 & 12.17177 & -0.423 & 0.673717 \\ \text { DRAIN_SQKM } & 0.93654 & 0.03130 & 29.921 & <2 \mathrm{e}-16 * * * \\ \text { PPTAVG_BASIN } & 3.90746 & 0.62581 & 6.244 & 2.25 \mathrm{e}-08 * * * \\ \text { T_AVG_BASIN } & -0.99677 & 0.70380 & -1.416 & 0.160785 \\ \text { T_MAX_BASIN } & -1.75579 & 2.19139 & -0.801 & 0.425502 \\ \text { RH_BASIN } & -0.21335 & 1.97638 & -0.108 & 0.914319\end{array}$




$\begin{array}{lccll}\text { PRECIP_SEAS_IND } & -0.43070 & 0.19635 & -2.194 & 0.031324 * \\ \text { STREAMS_KM_SQ_KM } & 0.57164 & 0.15511 & 3.685 & 0.000426 * * * \\ \text { NO10AVE } & -0.47910 & 0.85373 & -0.561 & 0.576327 \\ \text { CLAYAVE } & 0.28032 & 0.15440 & 1.816 & 0.073379 \\ \text { SILTAVE } & -0.31107 & 0.26036 & -1.195 & 0.235880 \\ \text { SANDAVE } & 0.28597 & 0.14031 & 2.038 & 0.045011 * \\ \text { PERMAVE } & -0.69832 & 0.16036 & -4.355 & 4.11 \mathrm{e}-05 * * * \\ \text { BDAVE } & -0.12870 & 0.58457 & -0.220 & 0.826331 \\ \text { ELEV_MEAN_M_BASIN-0.55037 } & 0.36202 & -1.520 & 0.132592 \\ \text { SLOPE_PCT } & -0.13143 & 0.06567 & -2.001 & 0.048932 *\end{array}$

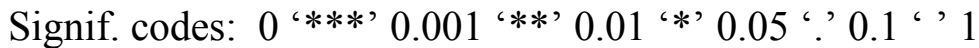

Residual standard error: 0.3259 on 76 degrees of freedom

Multiple R-squared: 0.9465, Adjusted R-squared: 0.9359

F-statistic: 89.63 on 15 and $76 \mathrm{DF}$, p-value: $<2.2 \mathrm{e}-16$

$\# 2^{\text {nd }}$ Iteration

Variable with the largest p-value, RH_Basin (Basin relative humidity), is dropped.

fullreg2 <-

Im(Q99 DRAIN_SQKM+PPTAVG_BASIN+T_AVG_BASIN+T_MAX_BASIN+PRECIP SEAS IND+STREAMS KM SQ KM + NOIOAVE $+\overline{C L A Y A V E}+\overline{S I L T A} \bar{V} E+$ SANDAVE $+\bar{P}$ $\left.E R M \bar{A} V E+B D A V E+E L E V \_\bar{M} E \bar{A} N_{-} M_{-} B A S I N+S L O P E \_P C T, w e i g h t s=Q t i l e \$ W 99, Q t i l e\right)$ summary(fullreg2)

Call:

$\operatorname{lm}($ formula $=$ Q99 $\sim$ DRAIN_SQKM + PPTAVG_BASIN + T AVG BASIN + T_MAX_BASIN + PRECIP_SEAS_IND + +STREAMS_KM_SQ_KM + NO10AVE + CLAYAVE + SILTAVE + SANDAVE + PERMAVE + BDAVE +

ELEV_MEAN_M_BASIN + SLOPE_PCT, data = Qtile, weights = Qtile\$W99)

Residuals:

Min 1Q Median 3Q Max

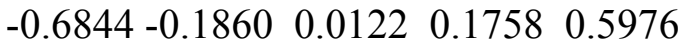

Coefficients:

(Intercept)

$\begin{array}{rlll}\text { Estimate } & \text { Std. Error } & \mathrm{t} \text { value } & \operatorname{Pr}(>|\mathrm{t}|) \\ -5.25883 & 9.22046 & -0.570 & 0.570105 \\ 0.94675 & 0.02700 & 35.069 & <2 \mathrm{e}-16 * * * \\ 4.07836 & 0.51746 & 7.881 & 1.72 \mathrm{e}-11 * * * \\ -1.11327 & 0.62037 & -1.795 & 0.076651\end{array}$




$\begin{array}{lrlll}\text { T_MAX_BASIN } & -1.87279 & 1.94034 & -0.965 & 0.337472 \\ \text { PRECIP_SEAS_IND } & -0.42634 & 0.16517 & -2.581 & 0.011747 * \\ \text { STREAMS_KM_SQ_KM } & 0.59051 & 0.13276 & 4.448 & 2.88 \mathrm{e}-05 \text { *** } \\ \text { NO10AVE } & -0.69956 & 0.79048 & -0.885 & 0.378920 \\ \text { CLAYAVE } & 0.12187 & 0.13283 & 0.917 & 0.361767 \\ \text { SILTAVE } & -0.18796 & 0.22435 & -0.838 & 0.404727 \\ \text { SANDAVE } & 0.14463 & 0.11627 & 1.244 & 0.217314 \\ \text { PERMAVE } & -0.58992 & 0.13675 & -4.314 & 4.71 \mathrm{e}-05 * * * \\ \text { BDAVE } & 0.15223 & 0.48862 & 0.312 & 0.756230 \\ \text { ELEV_MEAN_M_BASIN }-0.50987 & 0.32648 & -1.562 & 0.122461 \\ \text { SLOPE_PCT } & -0.19799 & 0.05579 & -3.549 & 0.000663 * * *\end{array}$

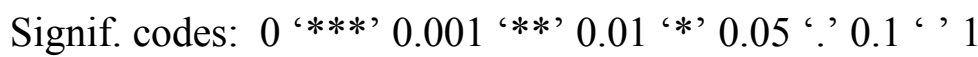

Residual standard error: 0.2768 on 77 degrees of freedom Multiple R-squared: 0.9587, Adjusted R-squared: 0.9512 F-statistic: 127.8 on 14 and 77 DF, p-value: $<2.2 \mathrm{e}-16$

$\# 3^{\text {nd }}$ Iteration

Variable with the largest p-value, BDAVE (Avg. Bulk Density), is dropped.

fullreg3 <-

Im(Q99 DRAIN_SQKM+PPTAVG_BASIN+T_AVG_BASIN+T_MAX_BASIN+PRECIP $S E A S \_I N D+S T R E A M S \_K M \_S Q \_K M+N O 10 A \bar{V} E+\overline{C L} A Y A V E+\bar{S} I L T A \bar{V} E+S A N D A V E+P$ ERMA $\bar{A} V E+E L E V \_M E \overline{A N} \_M_{-} B A S I N+S L O P E \_P C T$,weights $=$ Qtile\$W99, + Qtile) summary(fullreg $\overline{3})$

Call:

$\operatorname{lm}($ formula $=$ Q99 $\sim$ DRAIN_SQKM + PPTAVG_BASIN + T_AVG_BASIN + T_MX_BASIN + PRECIP_SEAS_IND + STREAMS_KM_SQ_KM + NO10AVE + $\overline{C L A Y A V E}+$ SILTAVE + SANDAVE + PERMAVE + ELEE_MEAN_M_BASIN + SLOPE_PCT, data = Qtile, weights = Qtile\$W99)

Residuals:

Min 1Q Median 3Q Max $\begin{array}{lllll}-0.68715 & -0.18533 & 0.00392 & 0.18525 & 0.61685\end{array}$

Coefficients:

(Intercept)

DRAIN_SQKM PPTAVG_BASIN

$\begin{array}{lccl}\text { Estimate } & \text { Std. Error } & \mathrm{t} \text { value } & \operatorname{Pr}(>|\mathrm{t}|) \\ -5.76229 & 9.02504 & -0.638 & 0.525033 \\ 0.94584 & 0.02668 & 35.451 & <2 \mathrm{e}-16 * * * \\ 4.07168 & 0.51401 & 7.921 & 1.34 \mathrm{e}-11 * * *\end{array}$




$\begin{array}{lllll} & & & \\ \text { T_AVG_BASIN } & -1.10692 & 0.61643 & -1.796 & 0.076416 \\ \text { T_MAX_BASIN } & -1.77341 & 1.90283 & -0.932 & 0.354219 \\ \text { PRECIP_SEAS_IND } & -0.42603 & 0.16421 & -2.594 & 0.011315 * \\ \text { STREAMS_KM_SQ_KM } & 0.59904 & 0.12916 & 4.638 & 1.39 \mathrm{e}-055^{* * *} \\ \text { NO10AVE } & -0.68614 & 0.78472 & -0.874 & 0.384602 \\ \text { CLAYAVE } & 0.12497 & 0.13169 & 0.949 & 0.345565 \\ \text { SILTAVE } & -0.19602 & 0.22156 & -0.885 & 0.379014 \\ \text { SANDAVE } & 0.15613 & 0.10961 & 1.424 & 0.158326 \\ \text { PERMAVE } & -0.59831 & 0.13329 & -4.489 & 2.44 \mathrm{e}-05 \text { *** } \\ \text { ELEV_MEAN_M_BASIN } & -0.48009 & 0.31037 & -1.547 & 0.125951 \\ \text { SLOPE_PCT _-0.19630 } & 0.05520 & -3.5560 .000643 * * * & \end{array}$

Signif. codes: 0 ‘***’ 0.001 '**’ 0.01 '*’ 0.05 '? 0.1 ' ’ 1

Residual standard error: 0.2752 on 78 degrees of freedom Multiple R-squared: 0.9587, Adjusted R-squared: 0.9518 F-statistic: 139.2 on 13 and 78 DF, p-value: $<2.2 \mathrm{e}-16$

Similar procedure is followed until all significant variables in the regression model are identified.

\section{\#Final iteration}

fullregFinal $<-$ lm $\left(Q 99 \sim D R A I N \_S Q K M+P P T A V G \_B A S I N+T \_A V G \_B A S I N+\right.$ + STREAMS_KM_SQ_KM+PERMAVE+SLOPE_PCT,weights $=$ Qtile\$W99,Qtile) summary(fullregFinal)

Call:

$\operatorname{lm}($ formula $=$ Q99 $\sim$ DRAIN_SQKM + PPTAVG_BASIN + T_AVG_BASIN + +STREAMS_KM_SQ_KM + PERMAVE + SLOPE_PCT, data $=\bar{Q}$ tile, weights $=$ Qtile\$W99)

Residuals:

Min 1Q Median 3Q Max $\begin{array}{lllll}-0.84847 & -0.19077 & 0.00524 & 0.20241 & 0.54784\end{array}$

Coefficients:

(Intercept)

DRAIN_SQKM PPTAVG_BASIN

T_AVG_BASIN

\begin{tabular}{|c|c|c|c|}
\hline Estimate & Std. Error & t value & $\operatorname{Pr}(>|t|)$ \\
\hline-20.39668 & 1.99347 & -10.232 & $<2 \mathrm{e}-16 * * *$ \\
\hline 0.92859 & 0.02908 & 31.932 & $<2 \mathrm{e}-16 * * *$ \\
\hline 4.84505 & 0.47058 & 10.296 & $<2 \mathrm{e}-16 * * *$ \\
\hline 1.42535 & 0.14055 & -10.141 & $2.67 \mathrm{e}-16 * * *$ \\
\hline
\end{tabular}




$\begin{array}{lllll}\text { STREAMS_KM_SQ_KM } & 0.56954 & 0.12334 & 4.618 & 1.37 \mathrm{e}-05 * * * \\ \text { PERMAVE } & -0.24754 & 0.06231 & -3.973 & 0.000148 * * * \\ \text { SLOPE_PCT } & -0.31362 & 0.04532 & -6.920 & 7.97 \mathrm{e}-10 * * *\end{array}$

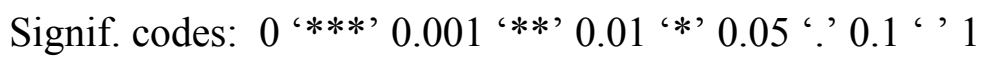

Residual standard error: 0.3167 on 85 degrees of freedom Multiple R-squared: 0.9404, Adjusted R-squared: 0.9362

F-statistic: 223.4 on 6 and 85 DF, p-value: $<2.2 \mathrm{e}-16$

\section{Variation Inflation Factor (VIF)}

VIF was checked for all variables included in the regression model. Final models considered for the regression analysis had VIF $<2.5$, indicating minimal multicollinearity. The following examples show VIFs and regression diagnostics of the $1^{\text {st }}$ iteration and the final Q99 model.

$\underline{\# 1^{\text {st }} \text { iteration }}$

\# Checking for VIF and identifying ones with the problem vif (fullregl)

\begin{tabular}{|c|c|c|c|c|}
\hline $\begin{array}{l}\text { DRAIN_SQKM } \\
1.281679\end{array}$ & $\begin{array}{l}\text { PPTAVG_BASIN } \\
3.388440\end{array}$ & $\mathrm{~T}_{-} \mathrm{AV}$ & $\begin{array}{l}\text { ASIN } \\
6828\end{array}$ & $\underset{-73.636957}{T}$ \\
\hline $\begin{array}{c}\text { RH_BASIN PRECIP } \\
1.877631\end{array}$ & $\begin{array}{c}\text { SEAS_IND } \\
4.888404\end{array}$ & $\begin{array}{r}\text { STREAMS_K } \\
3\end{array}$ & $\begin{array}{l}\text { S_KM } \\
049\end{array}$ & $\begin{array}{l}\text { NO10AVE } \\
4.187427\end{array}$ \\
\hline $\begin{array}{l}\text { CLAYAVE } \\
6.613019\end{array}$ & $\begin{array}{l}\text { SILTAVE } \\
16.168587\end{array}$ & $\begin{array}{l}\text { SANDAVE } \\
11.332575\end{array}$ & $\begin{array}{r}\text { PERM } \\
13.15\end{array}$ & $\begin{array}{l}\mathrm{AVE} \\
3602\end{array}$ \\
\hline $\begin{array}{l}\text { BDAVE } \\
2.078280\end{array}$ & $\begin{array}{c}\text { LEV_MEAN } \\
9.455174\end{array}$ & 1_BASIN & $\begin{array}{r}\text { SLOP } \\
2.473\end{array}$ & $\frac{\mathrm{PCT}}{58}$ \\
\hline
\end{tabular}

vif(fullreg1) $>2.5$ \# problem?

\# If VIF is $>2.5$ then there is a problem with the variable in the model

$\begin{array}{cccc}\text { DRAIN_SQKM } & \text { PPTAVG_BASIN } & \text { T_AVG_BASIN } & \text { T_MIN_BASIN } \\ \text { FALSE } & \text { TRUE } & \text { TRUE } & \text { TRUE }\end{array}$

$\begin{array}{cccc}\text { RH_BASIN } & \text { PRECIP_SEAS_IND } & \text { STREAMS_KM_SQ_KM } & \text { NO10AVE } \\ \text { FALSE } & \text { TRUE } & \text { TRUE } & \text { TRUE }\end{array}$ 


$\begin{array}{cccc}\text { CLAYAVE } & \text { SILTAVE } & \text { SANDAVE } & \text { PERMAVE } \\ \text { TRUE } & \text { TRUE } & \text { TRUE } & \text { TRUE } \\ & & & \\ \text { BDAVE } & \text { ELEV_MEAN_M_BASIN } & \text { SLOPE_PCT } & \\ \text { FALSE } & \text { TRUE } & \text { FALSE } & \end{array}$

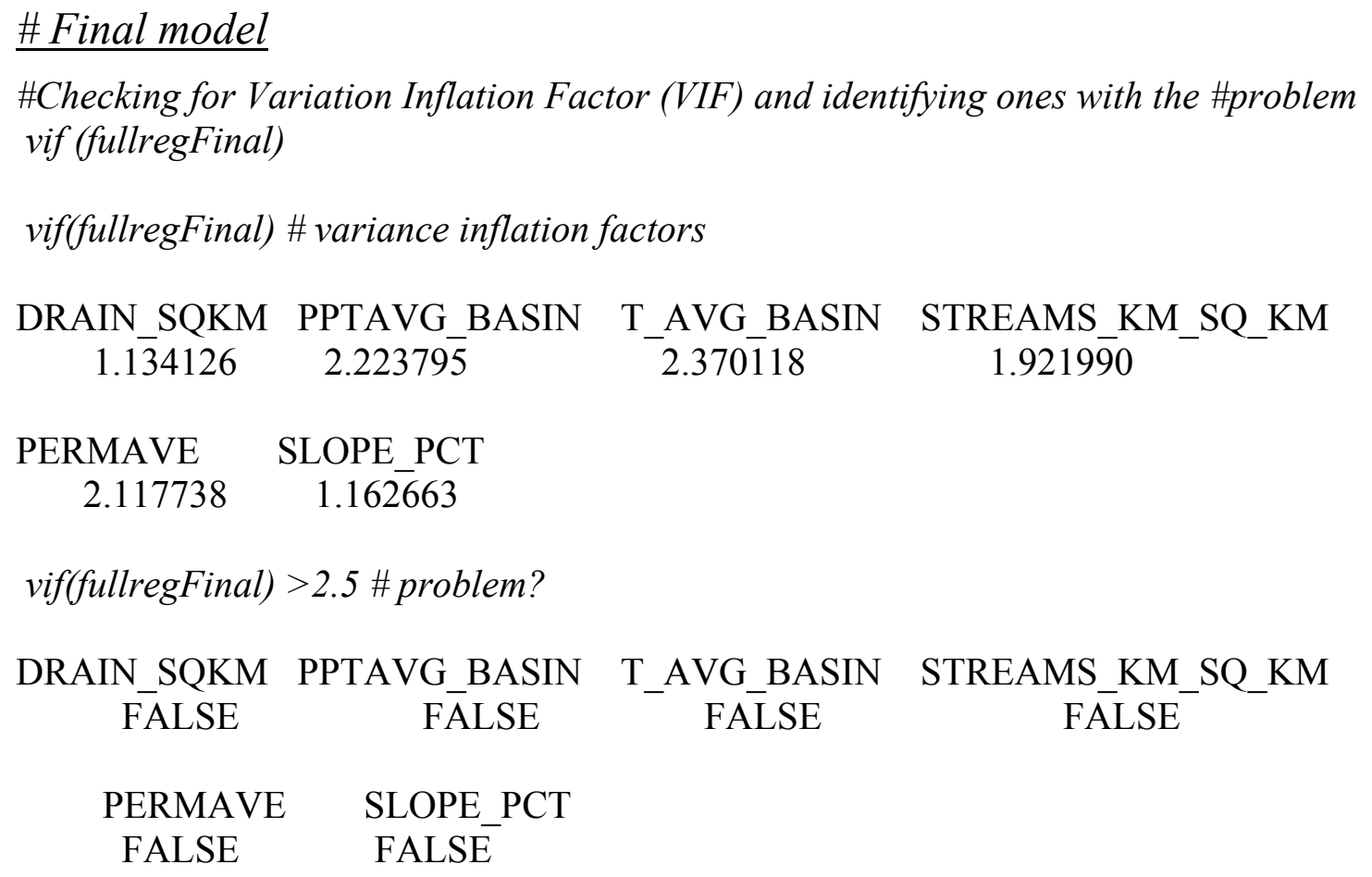

\section{\#Regression diagnostic plots}

Regression diagnostics are employed to assess homoscedasticity, influential observations and outliers

\# $1^{\text {st }}$ iteration

layout (matrix (1:4,2,2))

plot (fullreg1) 


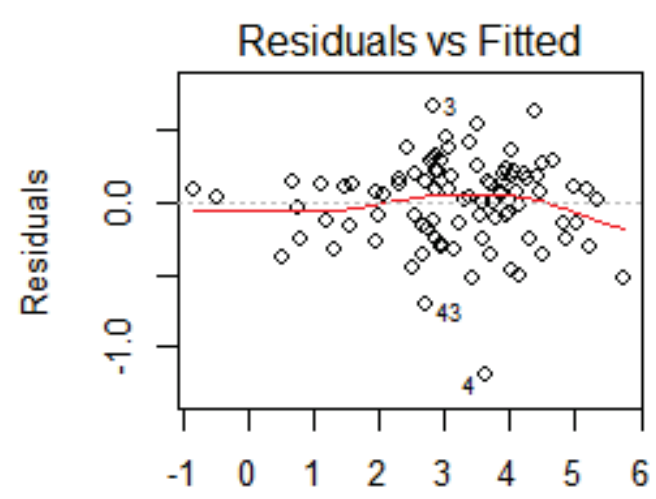

Fitted values

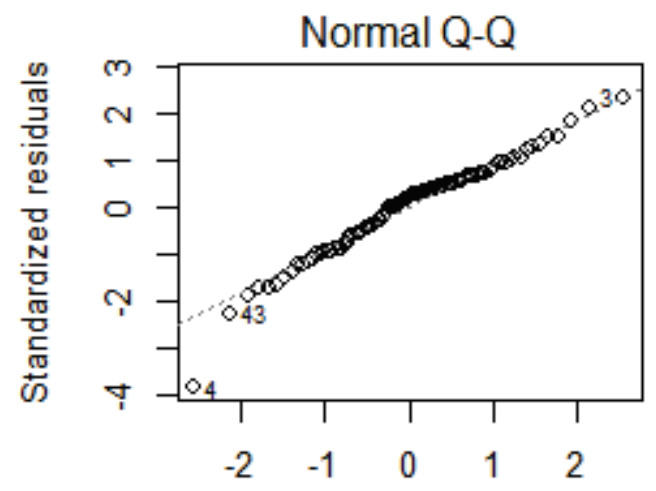

Theoretical Quantiles

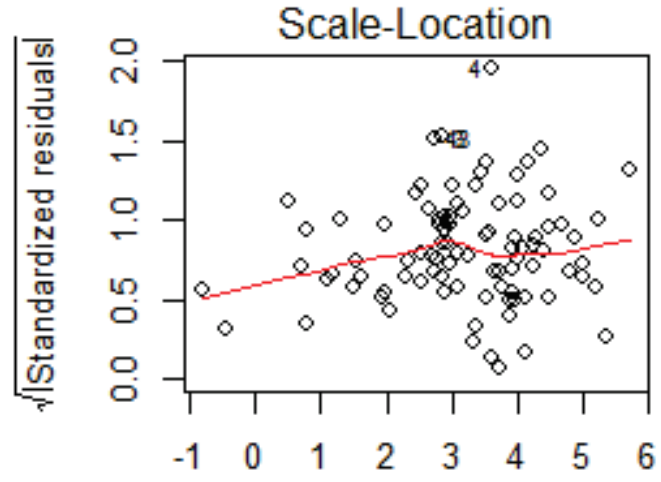

Fitted values

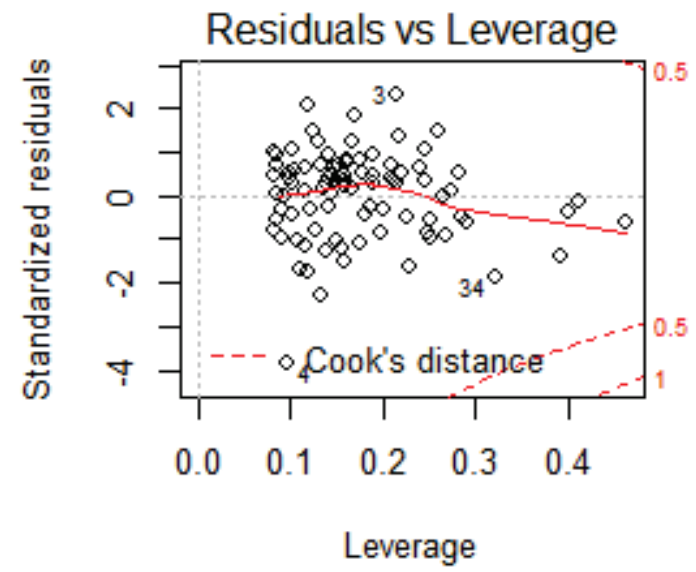

F igure A- 1 Rgression diagnostic plots to assess homoscedasticity, influential observations and outliers of the first iteration of Q 99 regression model.

\# Final model

layout(matrix $(1: 4,2,2)$ )

plot(fullregFinal) 


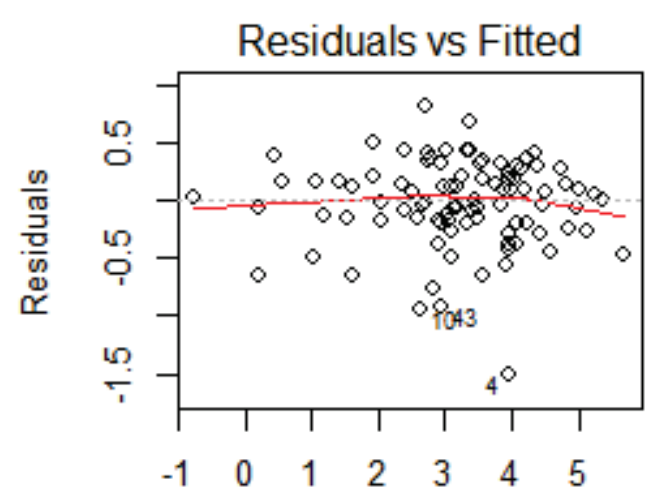

Fitted values

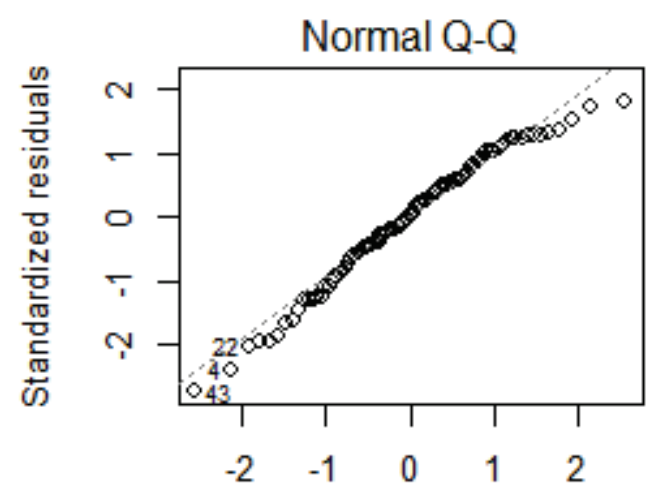

Theoretical Quantiles

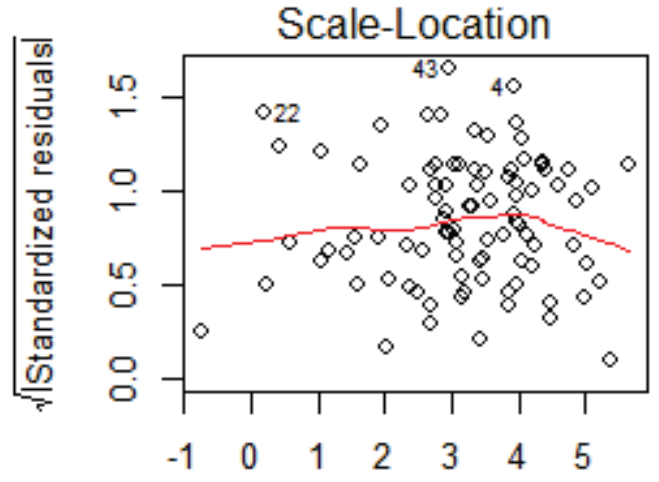

Fitted values

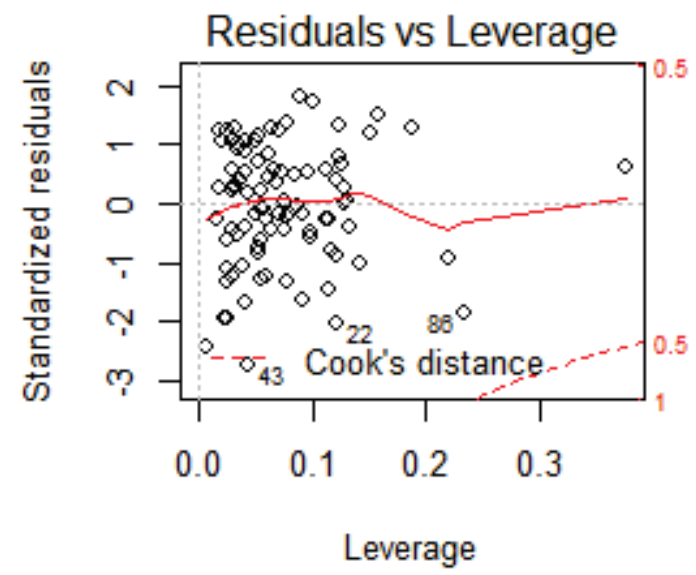

$\mathrm{F}$ igure $\mathrm{A}-\mathbb{R}$ egession diagnostics plots to assess homoscedasticity, influential observations and outliers 


\section{Appendix C: Supplementary tables (Chapter 4)}

Shown are average monthly percent changes in precipitation, PET and Runoff between the baseline (1980-1999) and near-future period (2046-2065) based on simulations using EA method in the selected watersheds 


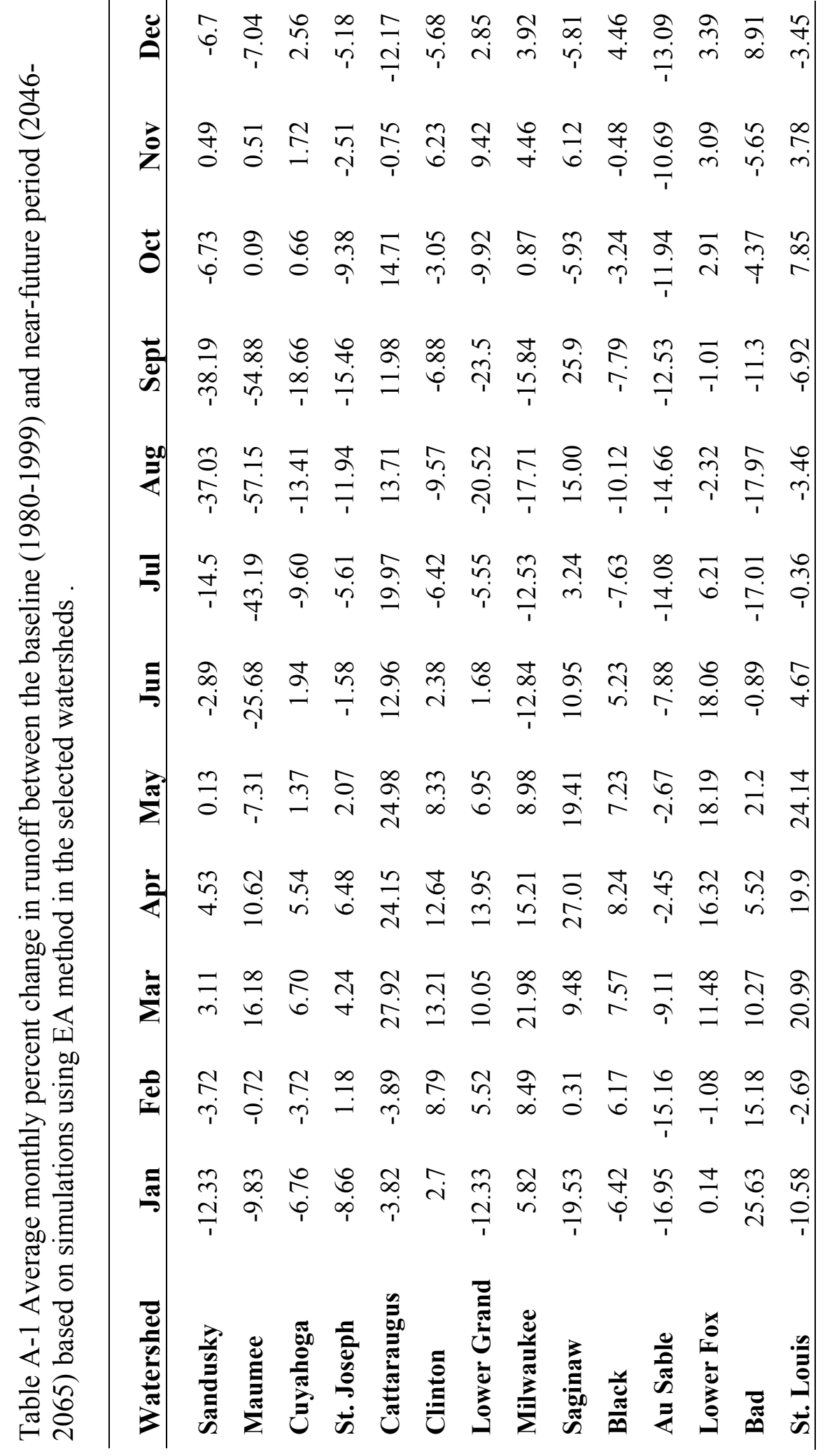




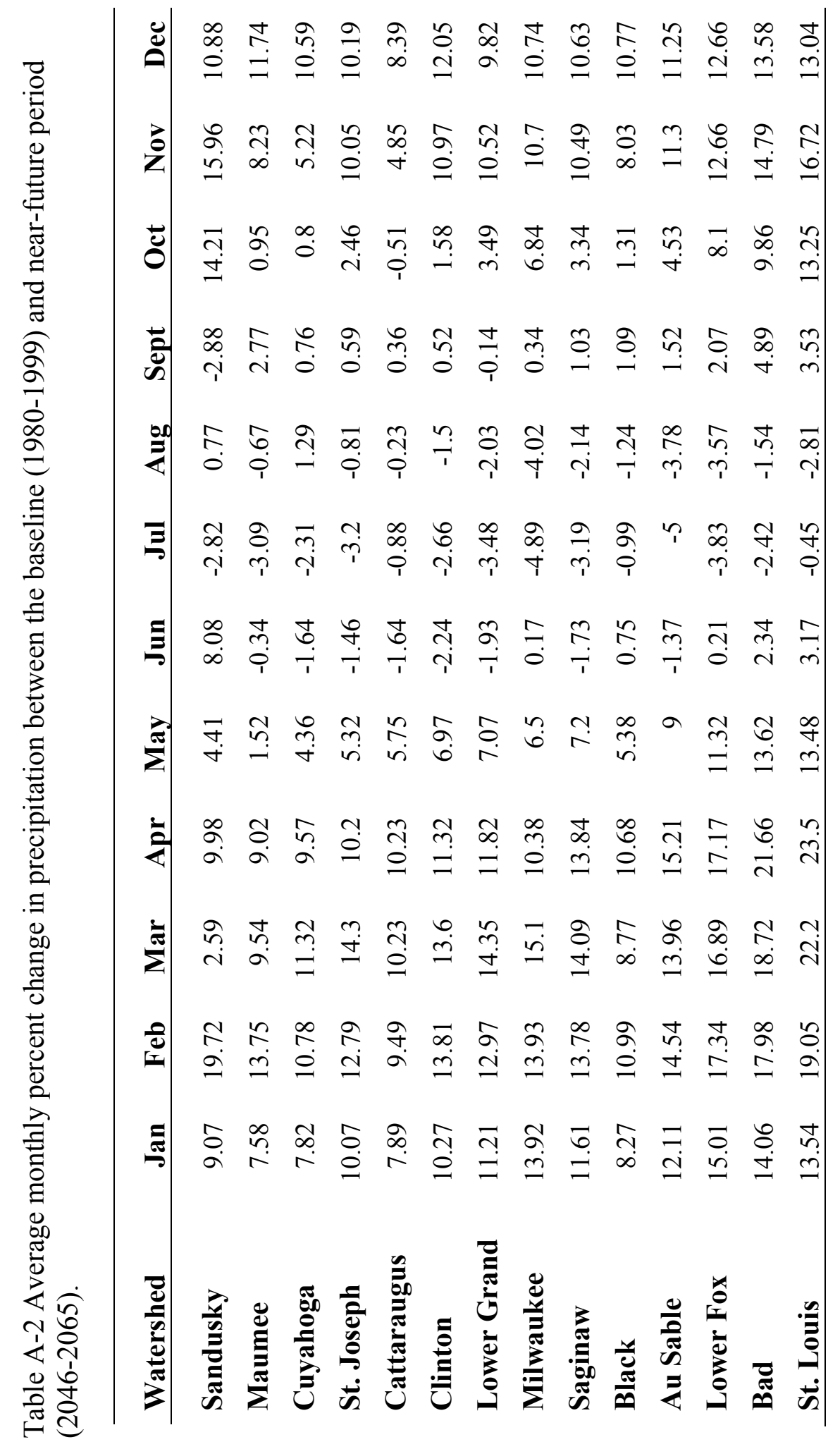




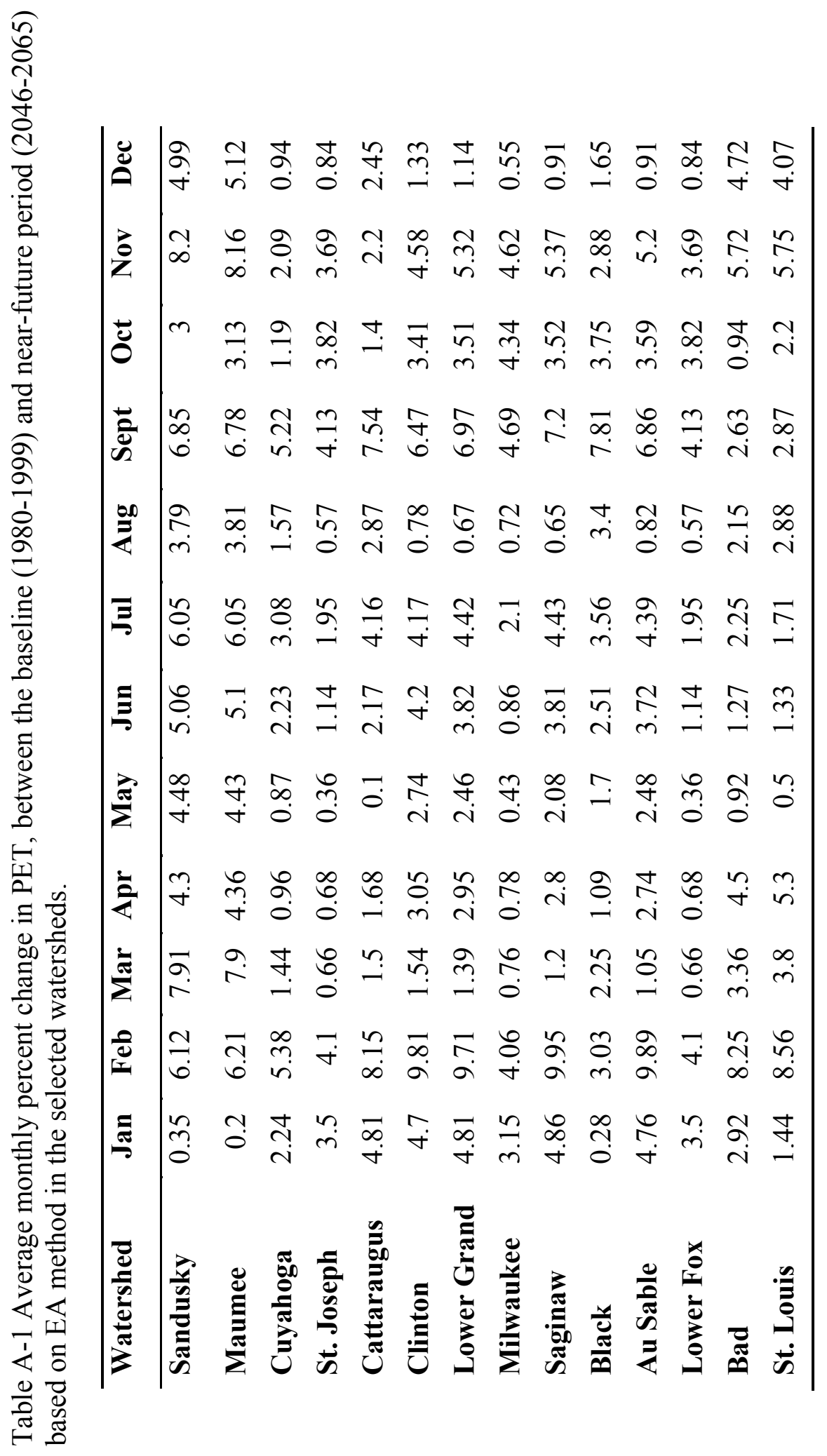




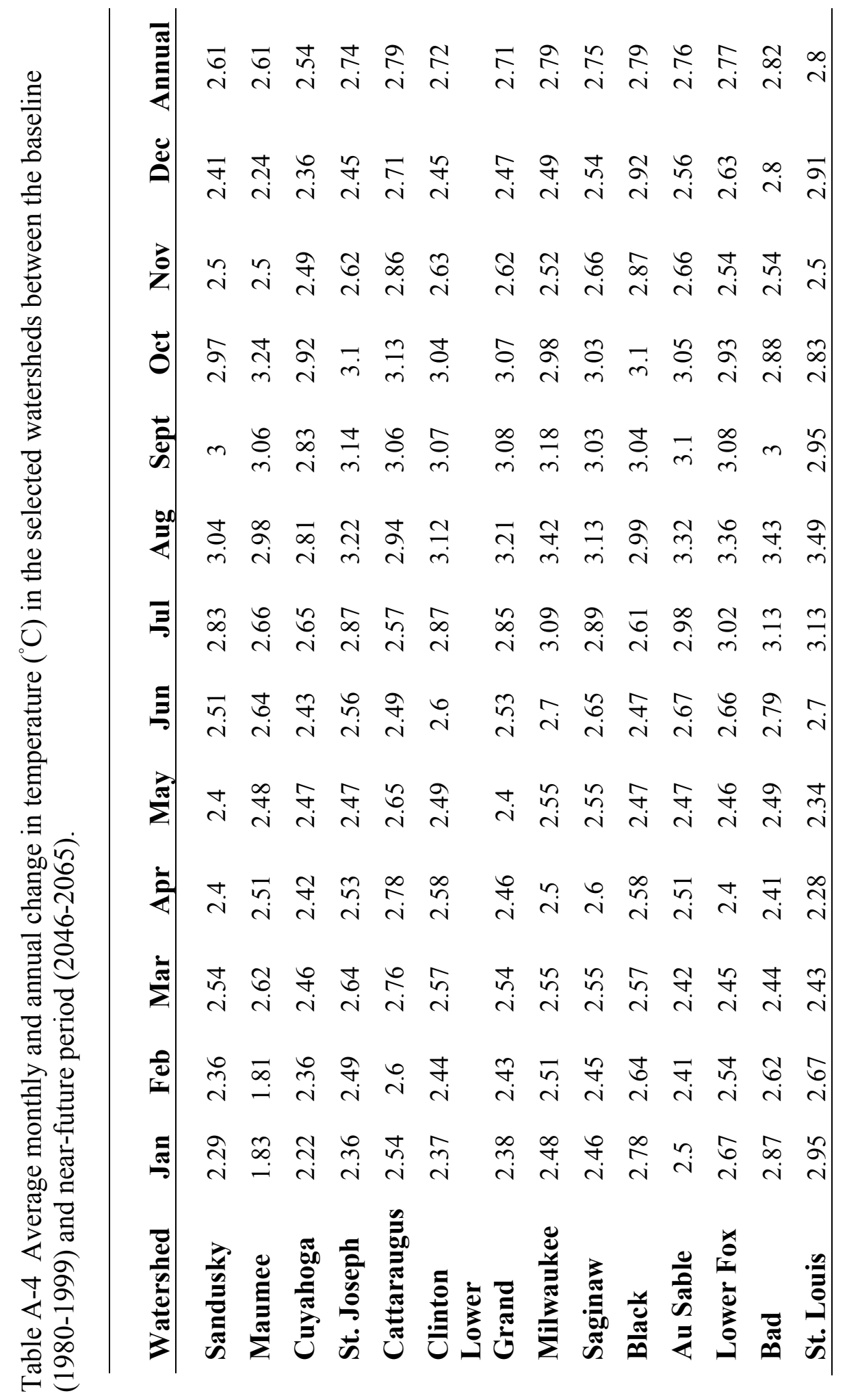




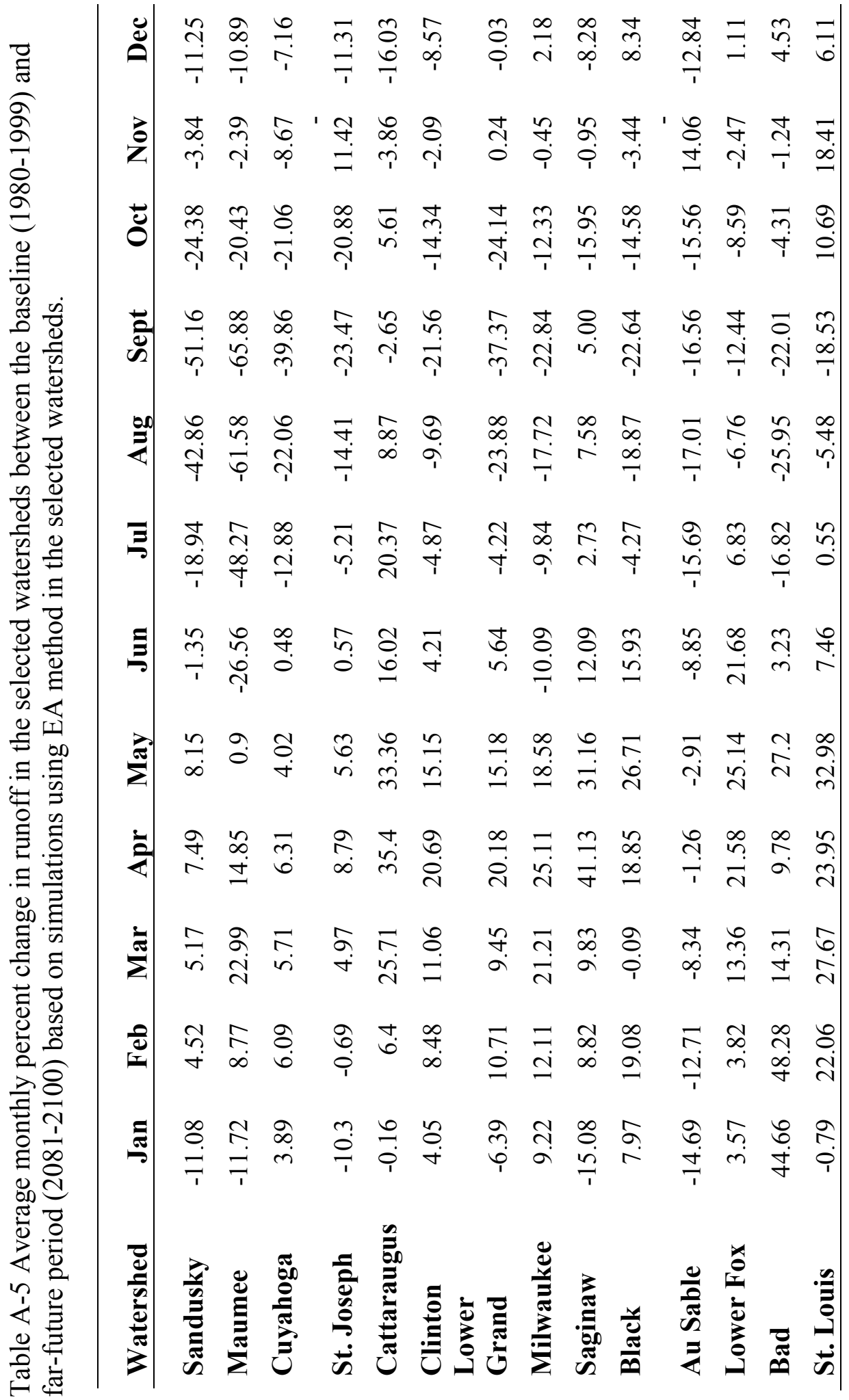




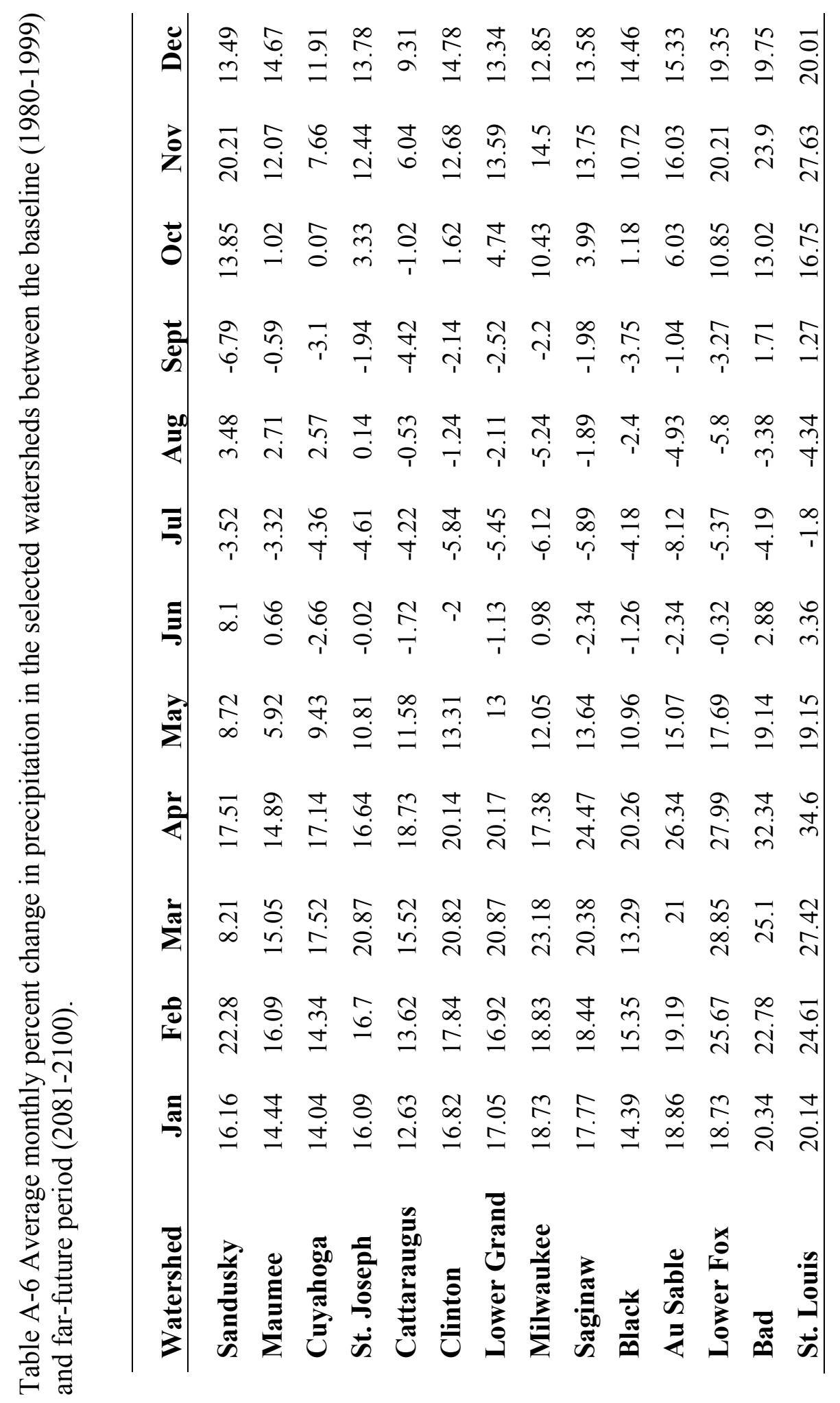




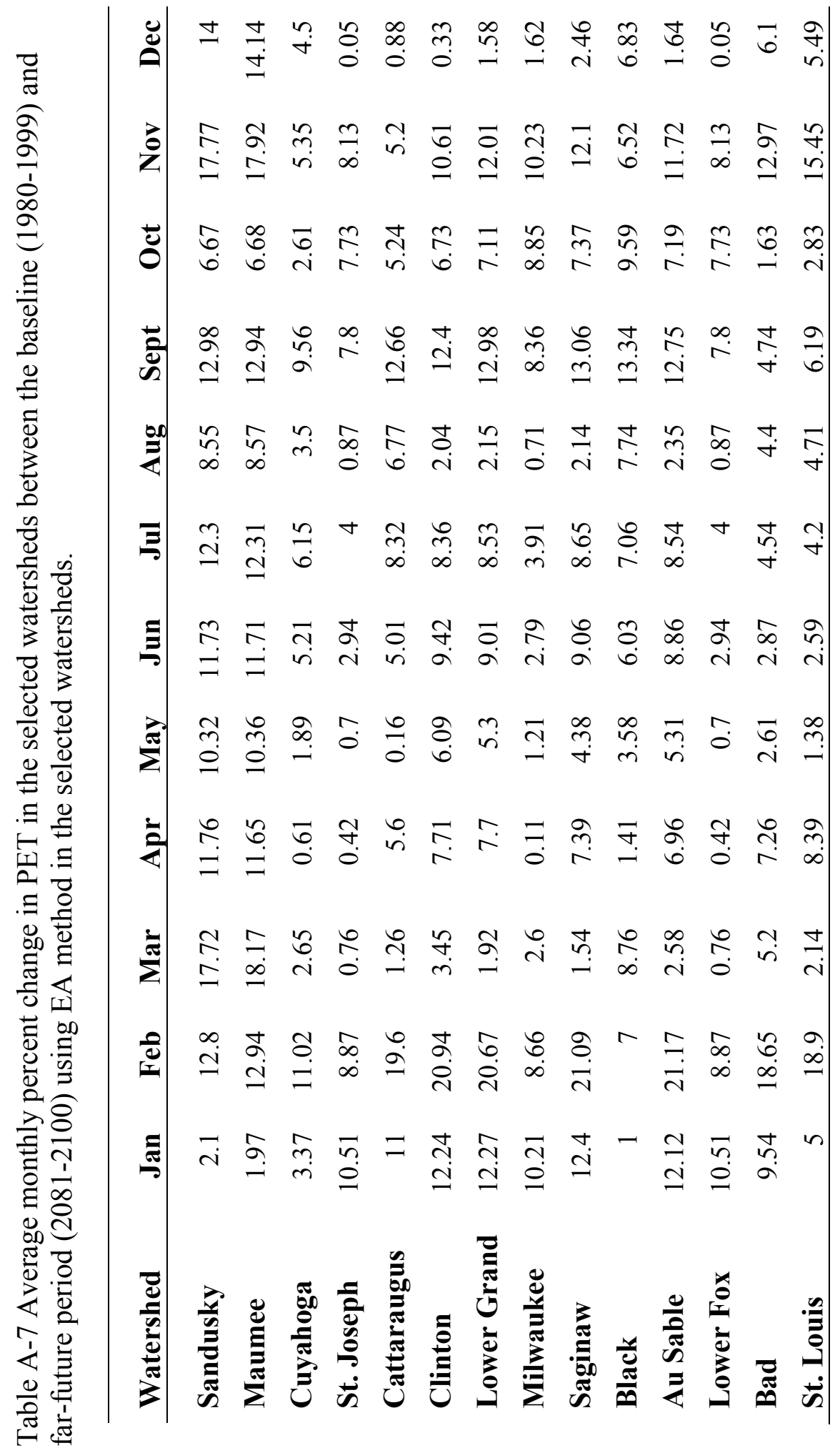




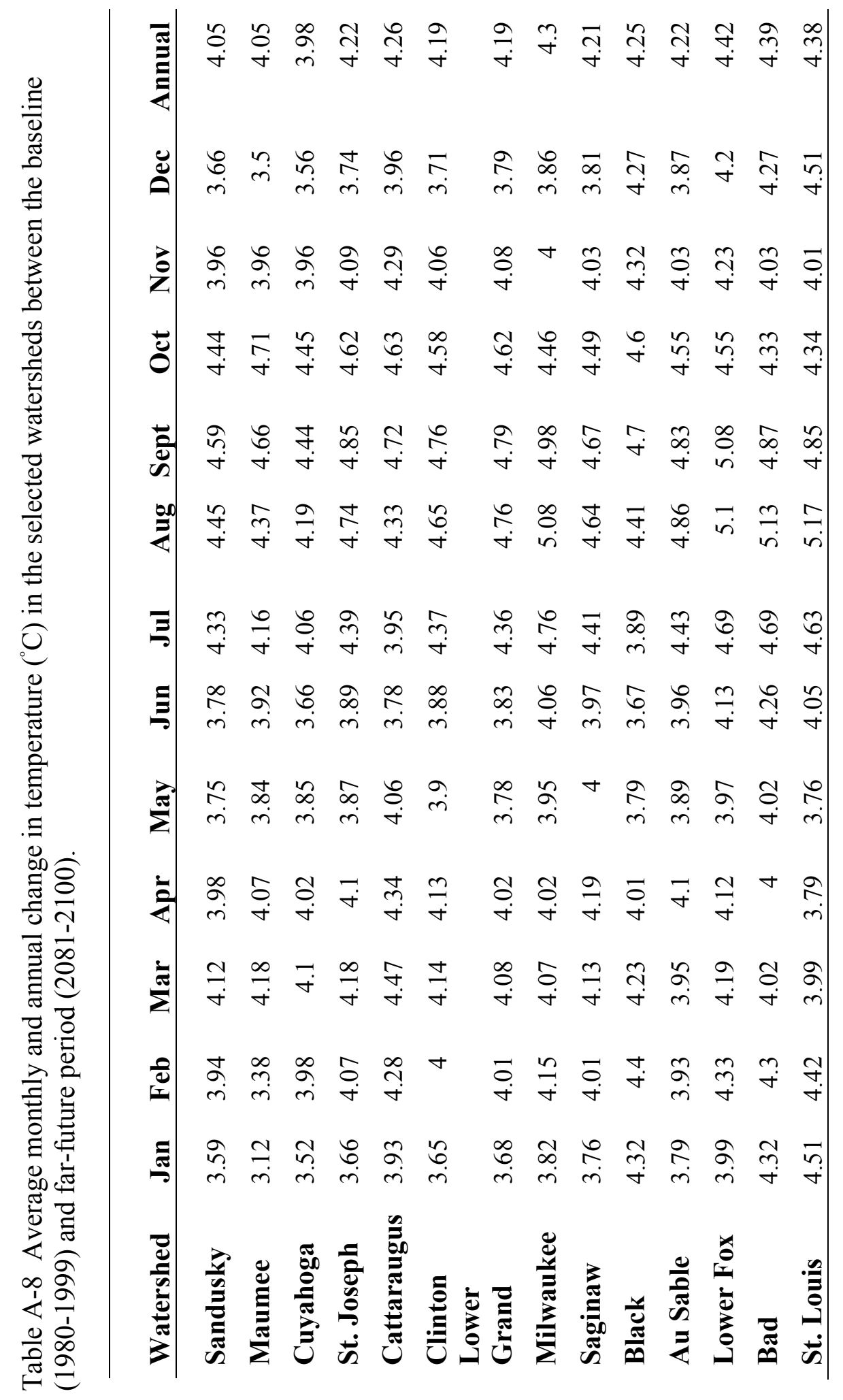

